\title{
Proceedings for a
}

Workshop on Deposit Modeling,

Mineral Resource Assessment, and

Their Role in Sustainable Development

APrepared in cooperation with the

Deposit Modeling Program,

International Union of Geological Sciences,

United Nations Educational, Scientific and Cultural Organization



T. rising



Circular 1294

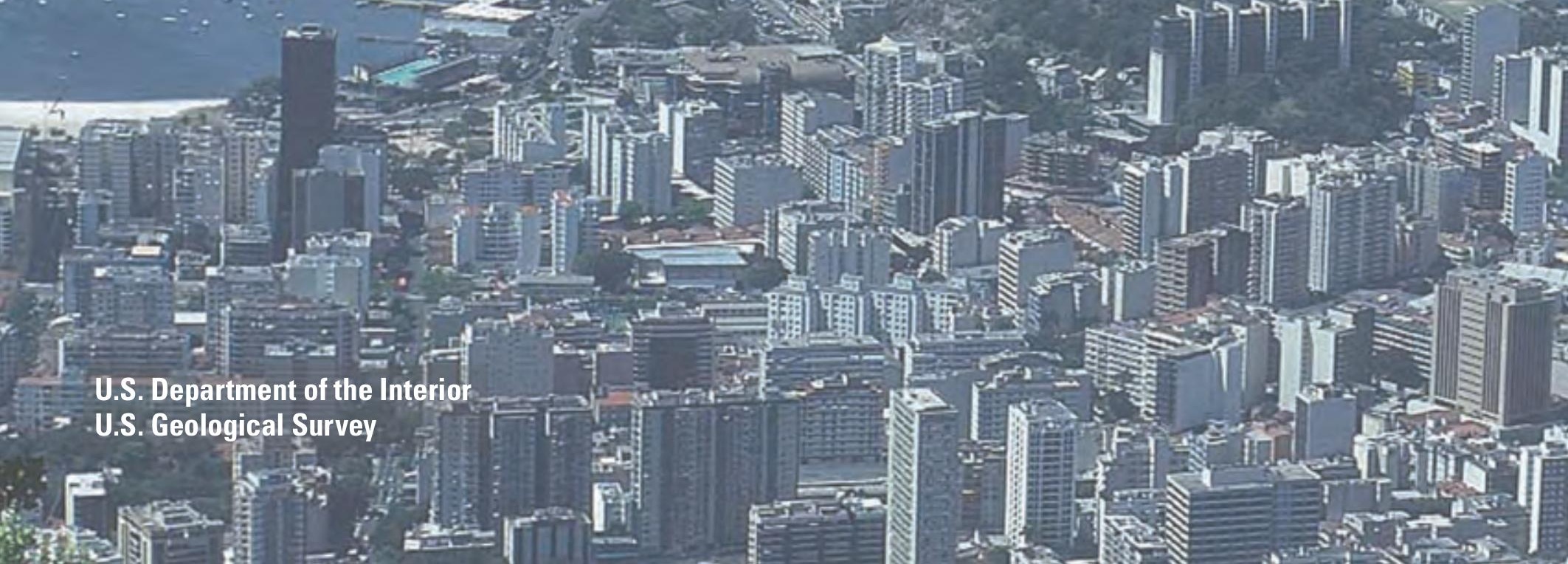


Back cover: Three photographs of Rio de Janeiro, Brazil, where the workshop was held in 2000. Top, Sugarloaf Mountain. Middle, Wooden streetcar built in 1896 and originally pulled by donkeys; the electrified streetcar still runs between downtown Rio de Janeiro and Santa Teresa. Bottom, View from Pao de Azucar showing workshop location indicated by the arrow and Copacabana beach in the background. Top and middle photographs by Markus A. Jegerlehner (available online at http://www.bigfoto.com/sites/galery/riodejan/); bottom photograph by Manfred Leiter. All photographs are copyrighted and used with permission.

Front cover: Sugarloaf Mountain at Rio de Janeiro, Brazil; same photograph as on the back cover. 


\section{Proceedings for a Workshop on Deposit Modeling, Mineral Resource Assessment, and Their Role in Sustainable Development}

Edited by Joseph A. Briskey and Klaus J. Schulz

Prepared in cooperation with the

Deposit Modeling Program, International Union of Geological Sciences,

United Nations Educational, Scientific and Cultural Organization

Proceedings of a workshop that followed the 31 st International Geological Congress,

Rio de Janeiro, Brazil,

August 18-19, 2000

Circular 1294 


\section{U.S. Department of the Interior DIRK KEMPTHORNE, Secretary}

\section{U.S. Geological Survey Mark D. Myers, Director}

\section{U.S. Geological Survey, Reston, Virginia: 2007}

For product and ordering information:

World Wide Web: http://www.usgs.gov/pubprod

Telephone: 1-888-ASK-USGS

For more information on the USGS - the Federal source for science about the Earth, its natural and living resources, natural hazards, and the environment:

World Wide Web: http://www.usgs.gov

Telephone: 1-888-ASK-USGS

Any use of trade, product, or firm names is for descriptive purposes only and does not imply endorsement by the U.S. Government.

Although this report is in the public domain, permission must be secured from the individual copyright owners to reproduce any copyrighted materials contained within this report.

Suggested citation:

Briskey, J.A., and Schulz, K.J., eds., 2007, Proceedings for a Workshop on Deposit Modeling, Mineral Resource Assessment, and Their Role in Sustainable Development: U.S. Geological Survey Circular 1294, 143 p. (Also available on CD-ROM and online.)

\section{Library of Congress Cataloging-in-Publication Data}

Workshop on Deposit Modeling, Mineral Resource Assessment, and Their Role in Sustainable Development (2000: Rio de Janeiro, Brazil)

Proceedings for a Workshop on Deposit Modeling, Mineral Resource Assessment, and Their Role in Sustainable Development : proceedings of a workshop that followed the 31st International Geological Congress, Rio de Janeiro, Brazil, August 18-19, 2000 / edited by Joseph A. Briskey and Klaus J. Schulz; prepared in cooperation with the Deposit Modeling Program, International Union of Geological Sciences, United Nations Educational, Scientific and Cultural Organization.

p. $\quad$ cm. - (U.S. Geological Survey circular ; 1294)

Includes bibliographical references.

ISBN 978-1-4113-1127-5 (book) — ISBN 978-1-4113-1128-2 (CD-ROM)

1. Ore deposits - Congresses. 2. Mines and mineral resources-Congresses. 3. Sustainable developmentCongresses. 4. Geology—Congresses. I. Briskey, Joseph A. II. Schulz, K. J. III. United Nations Educational, Scientific, and Cultural Organization-Deposit Modeling Program. IV. International Geological Congress (31st : 2000 : Rio de Janeiro, Brazil) V. Title.

TN263.W665 2000

$333.8^{\prime} 5-\mathrm{dc} 22$

ISBN 978-1-411-31127-5 (Book) 


\section{Preface}

The world's use of nonfuel mineral resources continues to increase to support a growing population and increasing standards of living. The ability to meet this increasing demand is affected especially by concerns about possible environmental degradation associated with minerals production and by competing land uses. What information does the world need to support global minerals development in a sustainable way?

Informed planning and decisions concerning sustainability and future mineral resource supply require a long-term perspective and an integrated approach to resource, land use, economic, and environmental management worldwide. Such perspective and approach require unbiased information on the global distribution of identified and especially undiscovered resources, the economic and political factors influencing their development, and the potential environmental consequences of their exploitation.

The U.S. Geological Survey and the former Deposit Modeling Program of the International Union of Geological Sciences (IUGS) of the United Nations Educational, Scientific and Cultural Organization (UNESCO) sponsored a workshop on "Deposit Modeling, Mineral Resource Assessment, and Their Role in Sustainable Development" at the 31st International Geological Congress (IGC) in Rio de Janeiro, Brazil, on August 18-19, 2000. The purpose of the workshop was to review the state-of-the-art in mineral deposit modeling and resource assessment and to examine the role of global assessments of nonfuel mineral resources in sustainable development.

The workshop addressed questions such as the following: Which of the available mineral deposit models and assessment methods are best suited for predicting the locations, deposit types, and amounts of undiscovered nonfuel mineral resources remaining in the world? What is the availability of global geologic, mineral deposit, and mineral exploration information? How can mineral resource assessments be used to address economic and environmental issues? Presentations included overviews of assessment methods applied in previous national and other small-scale assessments of large regions and of the resulting assessment products and their uses.

Twenty-seven people from Canada, China, Finland, Germany, Japan, Peru, Slovenia, South Africa, United States, and Venezuela participated in the 2-day post-Congress workshop. The attendees represented academia, government, environmental organizations, and the mining industry.

The workshop agenda, extended abstracts, and participant biographies were published previously in the following report:

Briskey, J.A., and Schulz, K.J, eds., 2002, Agenda, extended abstracts, and bibliographies for a Workshop on Deposit Modeling, Mineral Resource Assessment, and Their Role in Sustainable Development-31st International Geological Congress [Rio de Janeiro, Brazil, August 18-19, 2000]: U.S. Geological Survey Open-File Report 02-423, 85 p. on one CD-ROM. (Available online at http://pubs.usgs.gov/of/2002/of02-423).)

Joseph A. Briskey and Klaus J. Schulz

U.S. Geological Survey 954 National Center 12201 Sunrise Valley Drive Reston, VA 20192-0002, U.S.A. 


\section{Conversion Factors and Notes}

[Papers in this Circular use a variety of units according to the preferences of the authors. Conversion factors are provided below]

\begin{tabular}{|c|c|c|}
\hline Multiply & By & To obtain \\
\hline \multicolumn{3}{|c|}{ Length } \\
\hline millimeter (mm) & 0.03937 & inch (in.) \\
\hline meter $(\mathrm{m})$ & 3.281 & foot $(\mathrm{ft})$ \\
\hline kilometer $(\mathrm{km})$ & 0.6214 & mile (mi) \\
\hline foot $(\mathrm{ft})$ & 0.3048 & meter $(\mathrm{m})$ \\
\hline mile (mi) & 1.609 & kilometer $(\mathrm{km})$ \\
\hline \multicolumn{3}{|c|}{ Area } \\
\hline hectare (ha) & 2.471 & acre \\
\hline hectare (ha) & 0.003861 & square mile $\left(\mathrm{mi}^{2}\right)$ \\
\hline square kilometer $\left(\mathrm{km}^{2}\right)$ & 247.1 & acre \\
\hline square kilometer $\left(\mathrm{km}^{2}\right)$ & 0.3861 & square mile $\left(\mathrm{mi}^{2}\right)$ \\
\hline acre & 0.4047 & hectare (ha) \\
\hline acre & 0.004047 & square kilometer $\left(\mathrm{km}^{2}\right)$ \\
\hline square mile $\left(\mathrm{mi}^{2}\right)$ & 259.0 & hectare (ha) \\
\hline square mile $\left(\mathrm{mi}^{2}\right)$ & 2.590 & square kilometer $\left(\mathrm{km}^{2}\right)$ \\
\hline \multicolumn{3}{|c|}{ Volume } \\
\hline cubic meter $\left(\mathrm{m}^{3}\right)$ & 35.31 & cubic foot $\left(\mathrm{ft}^{3}\right)$ \\
\hline \multicolumn{3}{|c|}{ Mass } \\
\hline milligram (mg) & 0.00003527 & ounce, avoirdupois (oz) \\
\hline $\operatorname{gram}(\mathrm{g})$ & 0.03527 & ounce, avoirdupois (oz) \\
\hline kilogram (kg) & 2.205 & pound avoirdupois (lb) \\
\hline megagram $(\mathrm{Mg})=$ metric ton $(\mathrm{t})$ & 1.102 & ton, short $(2,000 \mathrm{lb})$ \\
\hline megagram $(\mathrm{Mg})=$ metric ton $(\mathrm{t})$ & 0.9842 & ton, long $(2,240 \mathrm{lb})$ \\
\hline metric ton per annum (t/a) & 1.102 & ton per year (ton/yr) \\
\hline ounce, avoirdupois (oz) & 28.35 & $\operatorname{gram}(\mathrm{g})$ \\
\hline pound, avoirdupois (lb) & 0.4536 & kilogram $(\mathrm{kg})$ \\
\hline ton, short $(2,000 \mathrm{lb})$ & 0.9072 & metric ton $(\mathrm{t})$ \\
\hline ton, long $(2,240 \mathrm{lb})$ & 1.016 & metric ton $(\mathrm{t})$ \\
\hline \multicolumn{3}{|c|}{ Energy } \\
\hline joule (J) & $2.778 \times 10^{-7}$ & kilowatthour $(\mathrm{kWh})$ \\
\hline gigajoule (GJ) & $2.778 \times 10^{2}$ & kilowatthour $(\mathrm{kWh})$ \\
\hline petajoule $(\mathrm{PJ})$ & $2.778 \times 10^{8}$ & kilowatthour $(\mathrm{kWh})$ \\
\hline kilowatthour (kWh) & $3.600 \times 10^{6}$ & joule $(\mathrm{J})$ \\
\hline \multicolumn{3}{|c|}{ Ore grade } \\
\hline gram per metric ton $(\mathrm{g} / \mathrm{t})$ & 0.032 & ounce, avoirdupois, per ton (oz/ton) \\
\hline
\end{tabular}

The time of a geologic event is expressed as Ma (mega-annum, $10^{6}$ years ago, meaning before A.D. 1950) or Ga (giga-annum, $10^{9}$ years ago).

In this Circular, "million" is used for $10^{6}$, "billion" is used for $10^{9}$, and "trillion" is used for $10^{12}$. 


\section{Volume Contents}

\section{Preface}

By Joseph A. Briskey and Klaus J. Schulz iiii

Conversion Factors and Notes.

Keynote Address

Global Nonfuel Mineral Resources and Sustainability

By Friedrich-Wilhelm Wellmer and Jens Dieter Becker-Platen 1

Uses of a Global Mineral Resource Assessment

The Contributions of Geologic Information to

Economic, Social, and Environmental Sustainability

By Deborah J. Shields.

Environmental Planning Issues and a Conceptual Global Assessment of

Undiscovered Nonfuel Mineral Resources

By Joseph A. Briskey, Klaus J. Schulz, John P. Mosesso,

Lief R. Horwitz, and Charles G. Cunningham

Who Will Use a Global Mineral Resource Assessment?

An Environmental Perspective

By Penny Flick Langhammer..

Minerals, Biodiversity, and Choices

By Charles G. Cunningham, Walter J. Bawiec, Klaus J. Schulz, Joseph A. Briskey, James F. Carlin, Jr., and David M. Sutphin

Sustainable Development and Nonrenewable Resources-A Multilateral Perspective

By George A. Nooten...

Mineral Resources Information and Socioeconomic Development

By Gotthard Walser

Economics and Environment as Factors of Sustainable Development of

Siberian Mineral Resources

By N.L. Dobretsov, A.V. Kanygin, and A.E. Kontorovich

Mineral Supply and Demand into the 21st Century

By Stephen E. Kesler

Global Mineral Exploration and Production-The Impact of Technology

By Michael D. Doggett 
Who Will Use a Global Mineral Resource Assessment?

An Industry Perspective

By G.E. McKelvey..

Mineral Resource Assessment Methodologies

Deposit Models and Their Application in

Mineral Resource Assessments

By Donald A. Singer and Vladimir I. Berger

Estimating Amounts of Undiscovered Mineral Resources

By Donald A. Singer..

Overview of Methodology of Combined Regional

Metallogenic and Tectonic Analysis

By Warren J. Nokleberg, Thomas K. Bundtzen, Kenneth M. Dawson,

Roman A. Eremin, Nikolai A. Goryachev, Alexander I. Khanchuk,

James W.H. Monger, Alexander A. Obolenskiy, Leonid M. Parfenov,

Vladimir V. Ratkin, Sergey M. Rodionov, and Vladimir I. Shpikerman....

Data Needs and Availability

Digital Inventory of Bedrock and Mineral Deposit Geology

By Lesley Chorlton, Robert Laramée, David Sinclair, and Elizabeth Hillary

Status of Metallogenic Mapping in the World Today-

With Special Reference to the Digital Metallogenic Map of Africa

By Erik Hammerbeck and Milica Veselinovic-Williams

The Use of Mineral Occurrence and Geologic Databases in

Quantitative Mineral Resource Assessment

By Bruce R. Lipin and Walter J. Bawiec.

Example of Continental-Scale Mineral Resource Assessments

U.S. Geological Survey National Mineral Resource Assessment-

An Estimate of Undiscovered Deposits of

Gold, Silver, Copper, Lead, and Zinc in the United States

By Klaus J. Schulz and Joseph A. Briskey....

Author Biographies. 


\title{
Keynote Address
}

\section{Global Nonfuel Mineral Resources and Sustainability}

\author{
By Friedrich-Wilhelm Wellmer ${ }^{1}$ and Jens Dieter Becker-Platen ${ }^{1}$
}

\section{Introduction}

All countries are responsible for safeguarding the environment and for maintaining a relatively intact world for future generations. This is true not only for the mining and mineral exporting countries but also for the industrialized ones that buy and import most of their raw materials, especially the high-value metals and energy supplies. Together, all countries are responsible for working out a global strategy for exploiting mineral resources that fulfills the requirements of sustainable development.

Highly industrialized countries such as those of Western Europe, which import all of their metallic mineral resources and most of their energy supplies, still produce a large proportion of their required nonmetallic mineral resources (that is, raw

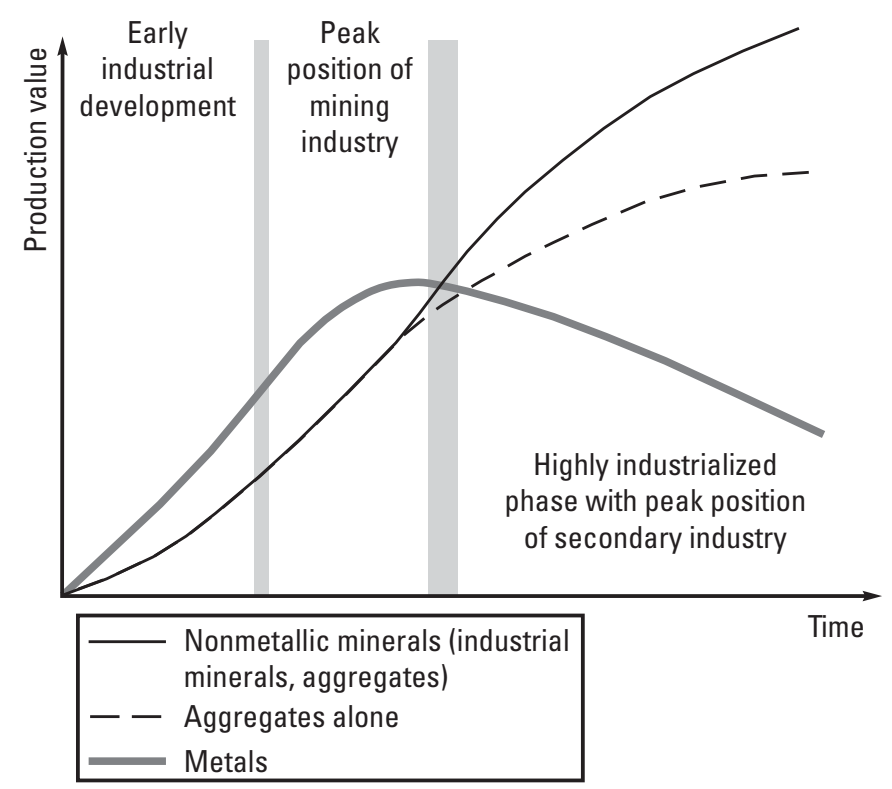

Figure 1. Comparison of the production trends of metallic ores, industrial minerals, and aggregates in industrialized countries (Wellmer and Lorenz, 1999; modified from Bristow, 1987).

\footnotetext{
'Bundesanstalt für Geowissenschaften und Rohstoffe (BGR) [Federal Institute for Geosciences and Natural Resources] and the Lower Saxony Geological Survey (NLfB), Stilleweg 2, D-30655, Hannover, Germany.
}

materials for construction and many of the industrial minerals). In Germany, for example, nonmetallic mineral resources total about 80 percent of mineral commodities consumed. The lifetime curve of nonmetallic resource production in a country shows a positive time offset relative to the curve for production of metallic resources and attains a maximum when almost all of the metal mines in that country have been abandoned (fig. 1). It follows that the industrial countries, which are the major importers of mineral resources and thus are customers of the rest of the world, must have a vested interest in the sustainable development of mineral resources, not only from a global point of view but also in a local context (Wellmer and Becker-Platen, 2001).

\section{Sustainable Development}

\section{The Concept of Sustainable Development}

Sustainable development is a normative term like liberty or equality according to German philosopher Immanuel Kant. In the United Nations (U.N.) Report, "Our Common Future," commonly called the "Brundtland Report," sustainable development is defined as development that meets the needs of the present without compromising the ability of future generations to meet their own needs (Brundtland, 1987, p. 8). This has become the most accepted definition internationally. It has been expanded by the U.N. Environment Programme, which added that the concept also requires the maintenance, rational use, and enhancement of the natural resources base that underpins ecological resilience and economic growth and that it implies progress toward international equity (United Nations Environment Programme, 1989).

The next steps were the Rio Declaration at the U.N. Conference on Environment and Development in Rio de Janeiro in 1992 and Agenda 21, which stress three objectives of sustainable development-(1) to conserve the basic needs of life, (2) to enable all people to achieve economic prosperity, and (3) to strive toward social justice. All three objectives initially should be considered to have the same priority. Whereas the Brundtland definition deals with "intergeneration fairness," Agenda 21 adds the element of "intrageneration fairness." 


\section{Guidelines for Sustainable Development}

The first practical guidelines for sustainable development came from the German forestry administration. The man credited with inventing sustainable development is von Carlowitz, who published the book "Sylvicultura oeconomica" (von Carlowitz, 1713). He was the head of the mining administration of the famous silver mining district around Freiberg, Saxony. In this position, he was responsible not only for the mining and smelting operations in his district but also for the forestry because wood was needed for timbers in the underground mines and vast amounts of wood were needed to produce the charcoal required to smelt the silver ores. He realized that the uncontrolled cutting of the forest for these purposes would lead to the collapse of forestry production. He was the first to spell out what sustainable development meant in forestry (that is, that the amount of wood cut should not exceed the growth rate).

Although his rule for renewable resources is quite logical, at the beginning of the 18th century, it was difficult for it to become broadly accepted. Even today, there is international resistance to similar sustainable development initiatives; for example, the use of quotas on fish catches to avoid overfishing. The reason for such resistance was and always is that, when sustainable development is introduced for a natural resource, structural changes must occur in the economy and in society. People and interest groups directly affected frequently resist these changes.

In contrast to guidelines for the use of renewable resources, guidelines for nonrenewable resources are more difficult to develop. In 1993, the Enquete Commission on Protection of Man and the Environment, set up by the German Federal Parliament, formulated four general rules for the sustainable development of natural resources (Enquete-Kommission Schutz des Menschen und der Umwelt, 1993); these rules can be applied worldwide. Rules 1 and 2 concern resources, and rules 3 and 4 concern the resilience of the environment.

- Rule 1. Use of renewable resources.-The rate of consumption of renewable resources should not exceed the rate at which they can be regenerated. This rule is the same in essence as that already formulated by von Carlowitz (1713).

- Rule 2. Use of nonrenewable resources.-The consumption of nonrenewable resources should not exceed the amount that can be substituted by functionally equivalent renewable resources or by attaining a higher efficiency in the use of renewable or nonrenewable resources.

- Rule 3. Material and energy input.-Material and energy input into the environment should not exceed the capacity of the environment to absorb them with minimal detrimental effects.

- Rule 4. Rate of anthropogenic input and environmental interference.-The rate of anthropogenic input and environmental interference should be measured against the time required for natural processes to react to and cope with the environmental damage.

If one critically examines the various elements of the concept of sustainable development as described above, together with these four rules for the sustainable development of natural resources, there is an apparent contradiction.

The creation of wealth to achieve economic prosperity, as outlined above, is one of the three cornerstones of sustainable development in the Rio Declaration of 1992. However, there is no creation of wealth without the direct or indirect use of nonrenewable resources. Even today, mineral resources are needed in our highly industrialized society, wherein creation of wealth is based to an ever-increasing degree on information technology. For example, 31 metals are needed to construct a personal computer (PC) (Jeffery, 1998). A PC requires electricity to function. Electricity is generated and delivered as a part of the vast infrastructure required to build and maintain modern societies. An infrastructure in turn requires construction materials such as steel and bricks, energy for heating and transport, and food produced in abundance by using mineral fertilizers.

Later, we will examine in detail how rule 2 can be fulfilled for nonrenewable resources. We interpret rule 2 as follows: "The consumption of nonrenewable resources should not exceed the amount that can be substituted by functionally equivalent resources or replaced in other ways" (Wellmer and Becker-Platen, 2002).

Let us consider why we need natural resources. With a few notable exceptions, exemplified here by potassium and phosphate used as fertilizers in agriculture, it is not the metal or raw material as such that is important, but a function that can be fulfilled by the material properties of the commodity (for example, the electrical conductivity of copper). Other commodities, sometimes using a totally different technology, also can perform these functions. For example, copper telephone wires are used for transmitting information. These have been extensively replaced by fiberglass cable made of silica, whose availability on Earth is limitless. Another solution to the problem of transmitting information is wireless transmission using directional radio antennae or satellites. Each solution requires different materials.

\section{Mineral Resources as Renewable Resources}

Metallic and nonmetallic resources normally are considered to be nonrenewable. However, in a few exceptional cases, they can be viewed as renewable. An example is diatomite. One of the uses of diatomite is as a filter medium for beverages, and one of the places this mineral is exploited is in Lake Myvatn, Iceland. Diatoms in the lake metabolize siliceous exhalations percolating through the lake and regenerate the deposit as they die and settle to the lake bottom. Another example is gravel in rivers that are eroding mountains. If 
gravel can be extracted from a riverbed without increasing the erosive power of the river, and thus damaging embankments or bridges, its extraction meets the sustainable development guideline of rule 1 for renewable resources. In this way, about 5 million metric tons of gravel are produced annually from rivers flowing from the Alps into Germany. Nevertheless, demand for gravel in southern Germany is substantially higher.

Substances dissolved in seawater also can be considered renewable resources. The prices of sodium, potassium, bromine, and magnesium salts, for example, will determine when technologies will be developed for commercial extraction of these salts from the ocean. Already, about 16 percent of sodium chloride is produced directly from seawater (Wellmer and Becker-Platen, 2001).

\section{Mineral Resources as Nonrenewable Resources}

Most of the mineral resources we consume, of course, are nonrenewable. Nonetheless, ways must be found to fulfill the Brundtland Report requirement that future generations be able "to meet their own needs." Current annual world consumption of mineral and energy resources is about $32 \times 10^{9}$ metric tons (32 billion metric tons), worth about 952 billion euros. Figure 2 is a bar diagram showing the annual world production of all mineral and energy resources by quantity in 1998. Figure 3 is the equivalent diagram based on value. In both diagrams, the base of the pyramid is formed by sand and gravel, aggregates, and energy resources, all of which are required to meet our basic needs for housing, heating, and transportation. Most of the nonmetallic resources are in the lower half of the quantity pyramid, whereas most of the metals are in the upper part of the quantity pyramid. Only the following nine metals are produced at a rate of more than 1 million metric tons annually: iron $(\mathrm{Fe})$, by far the largest, aluminum $(\mathrm{Al})$, copper $(\mathrm{Cu})$, manganese $(\mathrm{Mn})$, zinc $(\mathrm{Zn})$, chromium $(\mathrm{Cr})$, lead $(\mathrm{Pb})$, titanium (Ti), and nickel (Ni).

The very top of the quantity pyramid, of course, is made up of the precious metals and semiprecious and precious stones that together are represented by the most important precious stone, diamond. The special and "electronic" metals, like gallium, indium, or germanium, also are at the top of the quantity pyramid (fig. 4). These metals are the most important commodities in our information technology society. They are essential for electronic components in measuring and control-engineering technology, which are key technologies for increasing the efficiency with which we utilize our resources, especially our energy resources. These metals are used annually in tens or hundreds of metric tons and are critical components for the efficient utilization of resources that are used and consumed on the order of millions and billions of metric tons.

One can ask whether we can maintain this level of consumption and still fulfill the requirements of sustainable development, particularly in view of the fact that we have consumed more resources since World War II than during the whole of our long history before that. Figure 5 shows the relative cumulative consumption trends of the "old" metals—gold ( $\mathrm{Au})$, tin $(\mathrm{Sn})$, copper $(\mathrm{Cu})$, and iron $(\mathrm{Fe})$ - using total consumption as of today as 100 percent. Of these four metals, iron is the "youngest." The beginning of its use in the Middle East marks the birth of the Iron Age about 3,400 years ago; gold, tin, and copper have been used even longer. Figure 5 clearly shows that in 1945, at the end of World War II, cumulative consumption of these metals was less than 50 percent of the cumulative consumption of 1995, only 50 years later.

Few people realize how much the production and consumption of natural resources have accelerated. The following two examples are given to illustrate this trend.

1. The most intensively researched historical statistics probably are those for gold production table 1). During the nearly 1,000 years from the end of the Roman Empire at about A.D. 500 to the discovery of the Americas by Columbus in 1492, the estimated total world gold production was about 2,500 metric tons, approximately the same as a single year's production today.

2. The famous Rammelsberg mine in the Paleozoic Harz Mountains in Germany is a polymetallic sedimentaryexhalative-type deposit that was in production for more than 1,000 years, from 968 to 1988 . For long periods of time in the Middle Ages, the mine produced 10,000 metric tons per annum (t/a). It rarely produced more than $30,000 \mathrm{t} / \mathrm{a}$, which was equivalent to only 6 weeks' production at the end of its lifetime. The deposit contained 32 million metric tons of ore. By using a formula for the optimal lifetime of a deposit today (Taylor, 1978), we can calculate that the deposit would be exhausted in only 15 years.

It is tempting to correlate the increase in mineral resource production and consumption with the increase in world population, which grew from about 1.6 billion people in 1900 to the following milestones: about 2.4 billion in 1950, about 3.2 billion in 1965, and more than 6 billion $\left(6 \times 10^{9}\right)$ in October 1999 . However, the bulk of mineral resource consumption takes place in industrialized countries, which have had only a very moderate population increase. The large increase in population has occurred mainly in the developing nations (fig. 6). This uneven consumption pattern, however, offers an opportunity to find a solution to the problem of sustaining the future supply of mineral resources.

The efficiency of production and utilization of mineral raw materials will have to be increased. This improvement requires investments in research and development, which can be much more easily undertaken in the relatively rich industrialized nations than in the relatively poor developing nations. Moreover, industrialized nations start much higher on the learning curve for efficient use of natural resources than do the developing nations. After development by industrial nations, more efficient technologies then can be adopted by 


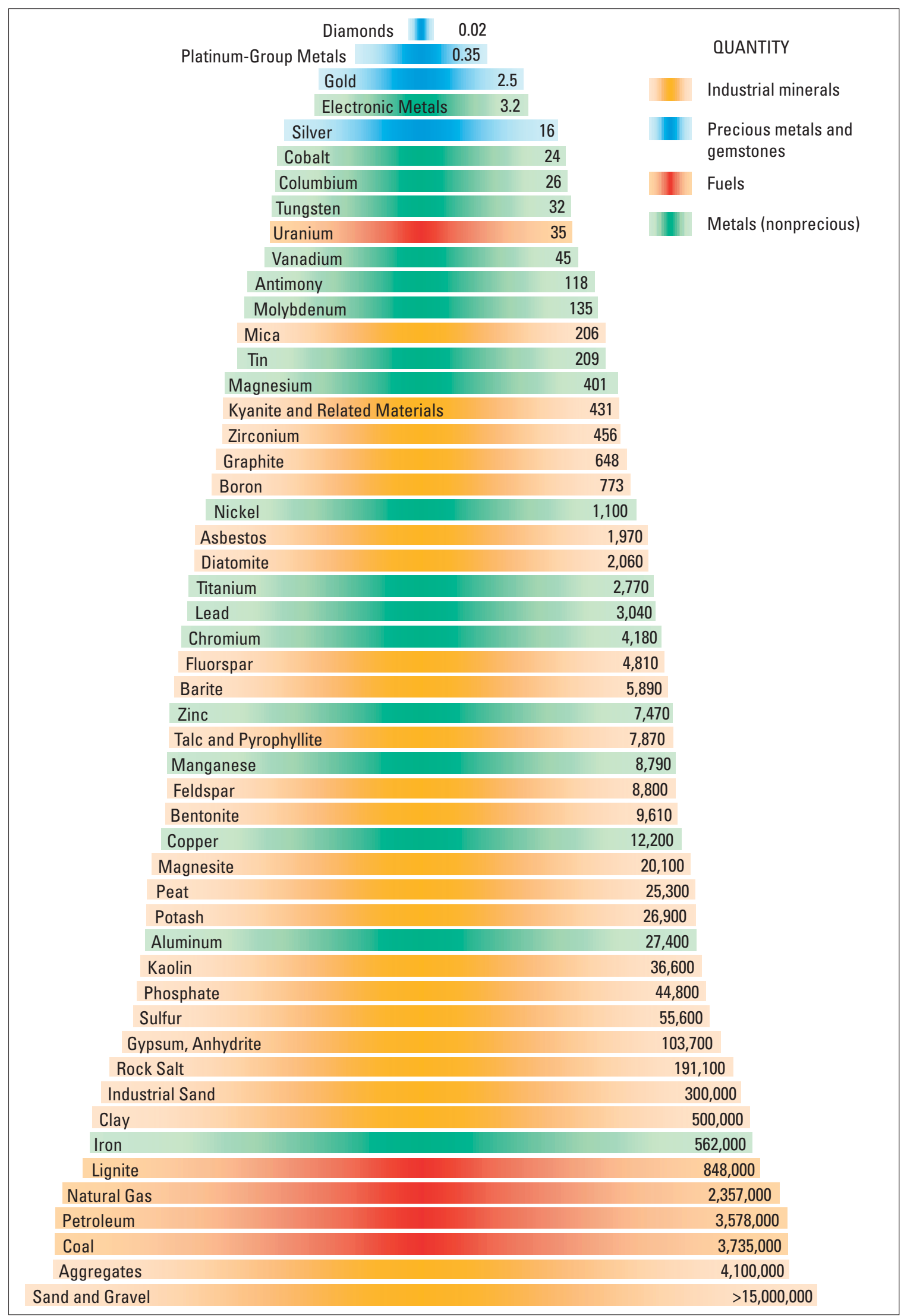

Figure 2. World primary production of mineral and energy resources in 1998 by quantity (Kippenberger, 2001). Ores are given as metal equivalent in thousands of metric tons; natural gas, in millions of cubic meters. The label "Diamonds" represents all precious and semiprecious gemstones. Electronic metals include gallium, indium, and germanium. Details about the top of the pyramid are in figure 4. 


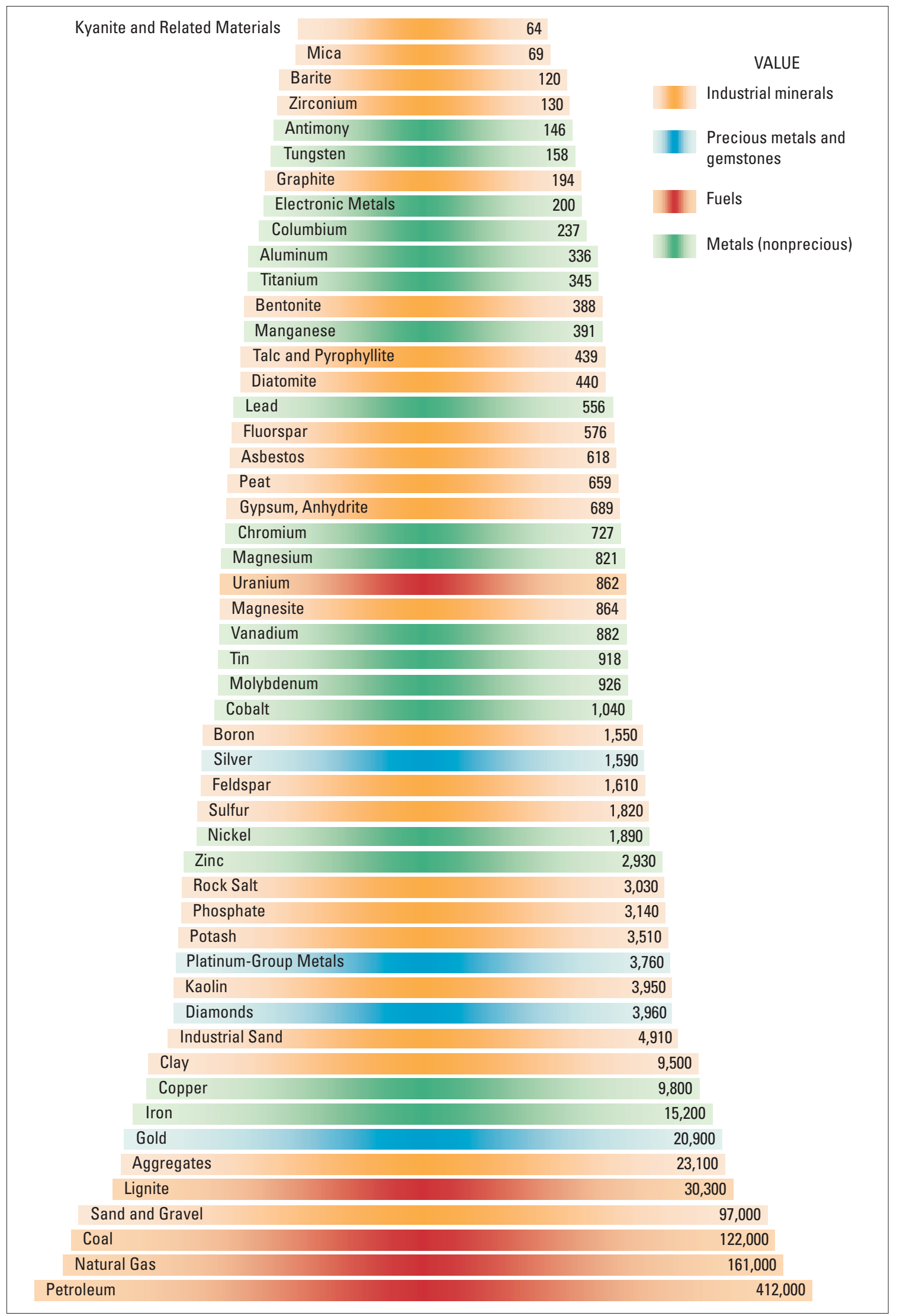

Figure 3. World primary production of mineral and energy resources in 1998 by value (Kippenberger, 2001). Values are given in millions of euros. Commodities are the same as in figure 2. 


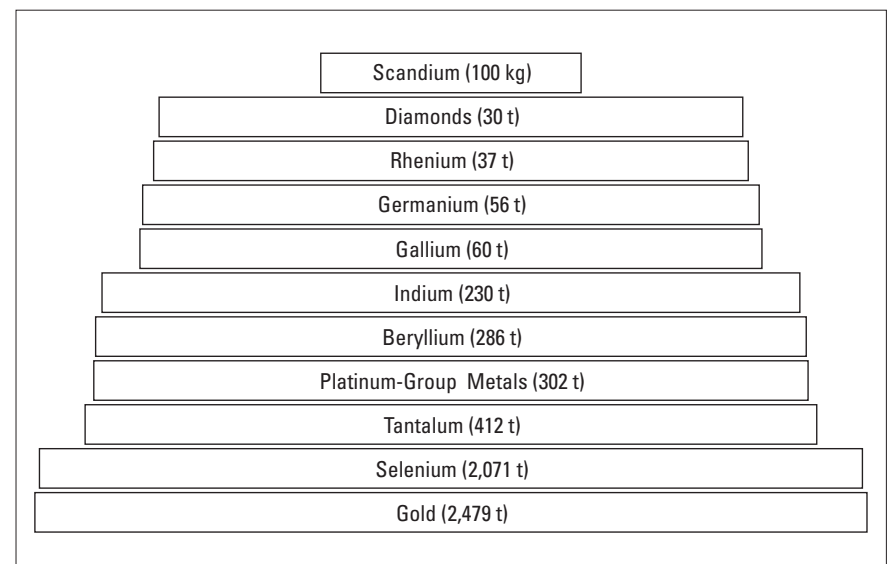

Figure 4. A modified expansion of the top of the quantity pyramid from figure 2, showing the precious metals, precious and semiprecious stones (designated by "Diamonds"), and electronic metals (including gallium, indium, and germanium) (Kippenberger, 2001). Quantities are in metric tons (t) and kilograms (kg).

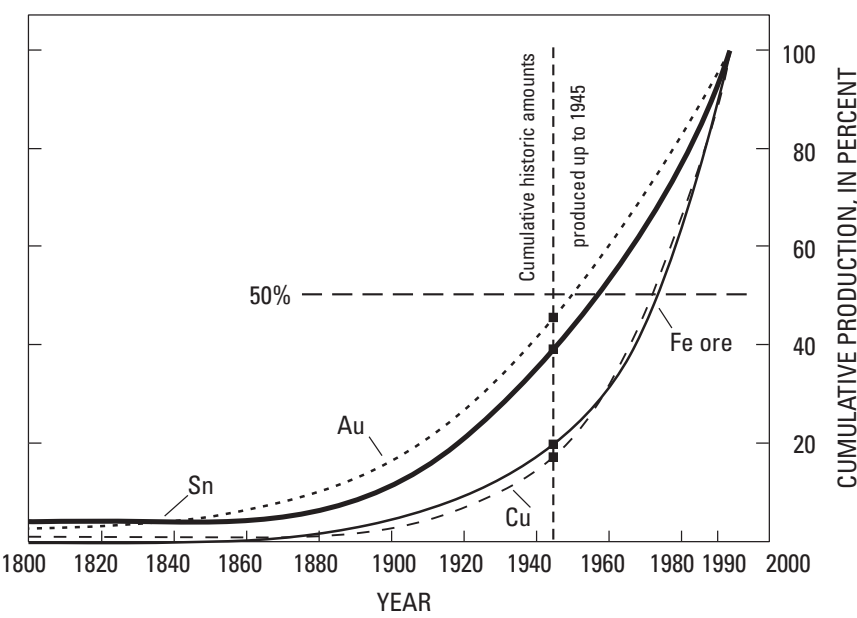

Figure 5. Cumulative world production of iron (Fe) ore, gold (Au), copper (Cu), and tin (Sn) (Wellmer and Becker-Platen, 2001; courtesy of Encyclopedia of Life Support Systems Publishers, Oxford, United Kingdom).

Table 1. World gold production.

[From Wellmer and Becker-Platen, 2001; courtesy of Encyclopedia of Life Support Systems Publishers, Oxford, United Kingdom]

\begin{tabular}{|l|c|}
\hline \multicolumn{1}{|c|}{ Period } & $\begin{array}{c}\text { Production, } \\
\text { in metric } \\
\text { tons }\end{array}$ \\
\hline $\begin{array}{c}\text { 3900 B.C. - A.D. 500 (end of Roman Empire), } \\
\text { 4,400 years }\end{array}$ & 10,257 \\
\hline $500-1492$ (discovery of America), 992 years & 2,472 \\
\hline $1493-1999,507$ years & 125,059 \\
\hline Total: 5,899 years & $\mathbf{1 3 7 , 7 7 8}$ \\
\hline 1999,1 year & 2,514 \\
\hline
\end{tabular}

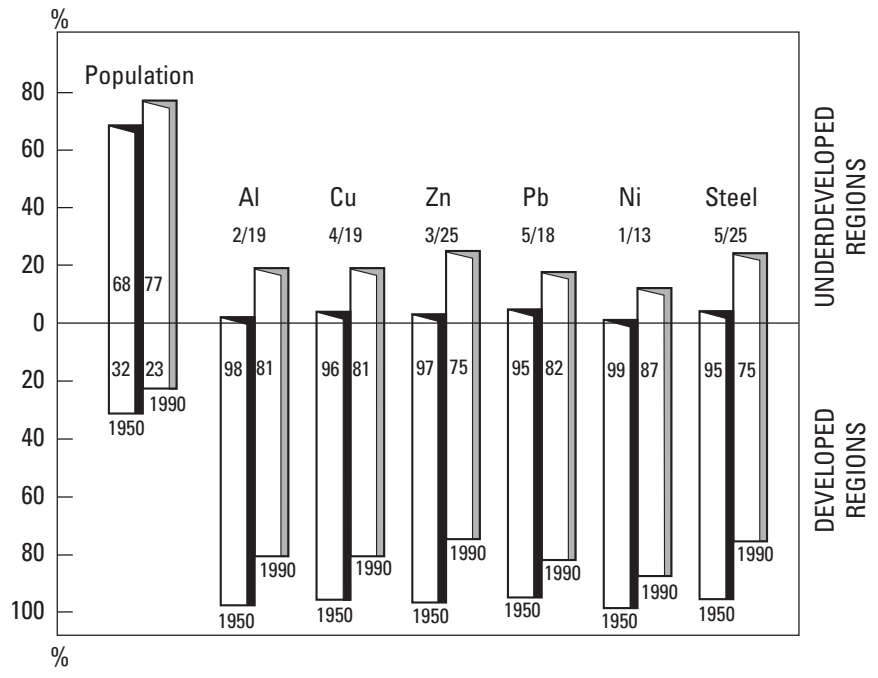

Figure 6. Distribution in percent of world population and metal consumption between the underdeveloped and developed regions in 1950 and 1990. Data for developed regions from Wellmer and Becker-Platen, 2001; courtesy of Encyclopedia of Life Support Systems Publishers, Oxford, United Kingdom. Al, aluminum; $\mathrm{Cu}$, copper; $\mathrm{Zn}$, zinc; $\mathrm{Pb}$, lead; $\mathrm{Ni}$, nickel.

the developing nations to meet the natural resources needs of their growing populations. Such development and application of technology allow us to extend the three-cornerstone concept in the Rio Declaration of 1992 to a four-cornerstone concept by adding the need for research and technology to achieve a higher efficiency in the use of natural resources fig. 7). In the long run, including research and technology is the only possibility for achieving sustainable development globally.

\section{The Future Availability of Resources}

\section{Lifetime of Reserves}

The future availability of resources commonly is estimated by using the concept of "reserves lifetime," which is defined as the known reserves divided by current annual consumption. In practice, however, reserves lifetime is a completely inappropriate measure of future availability. This estimate is influenced by many factors, such as type of deposit, distribution of reserves according to deposit size, costs, price level, intensity of exploration, and development of technology. The reserves lifetime is nothing more than a statistical snapshot of a dynamic system that says much more about the need for innovation than about true future availability. Commodities that occur in extensive seams, such as potash or coal, and that cover considerable areas in some deposits typically have lifetimes of more than 150 years because it is much easier to calculate and extrapolate reserves for such commodities than for those occurring in more local discontinuous concentrations. Typical representatives of the commodities having localized concentrations are lead and zinc, which have 


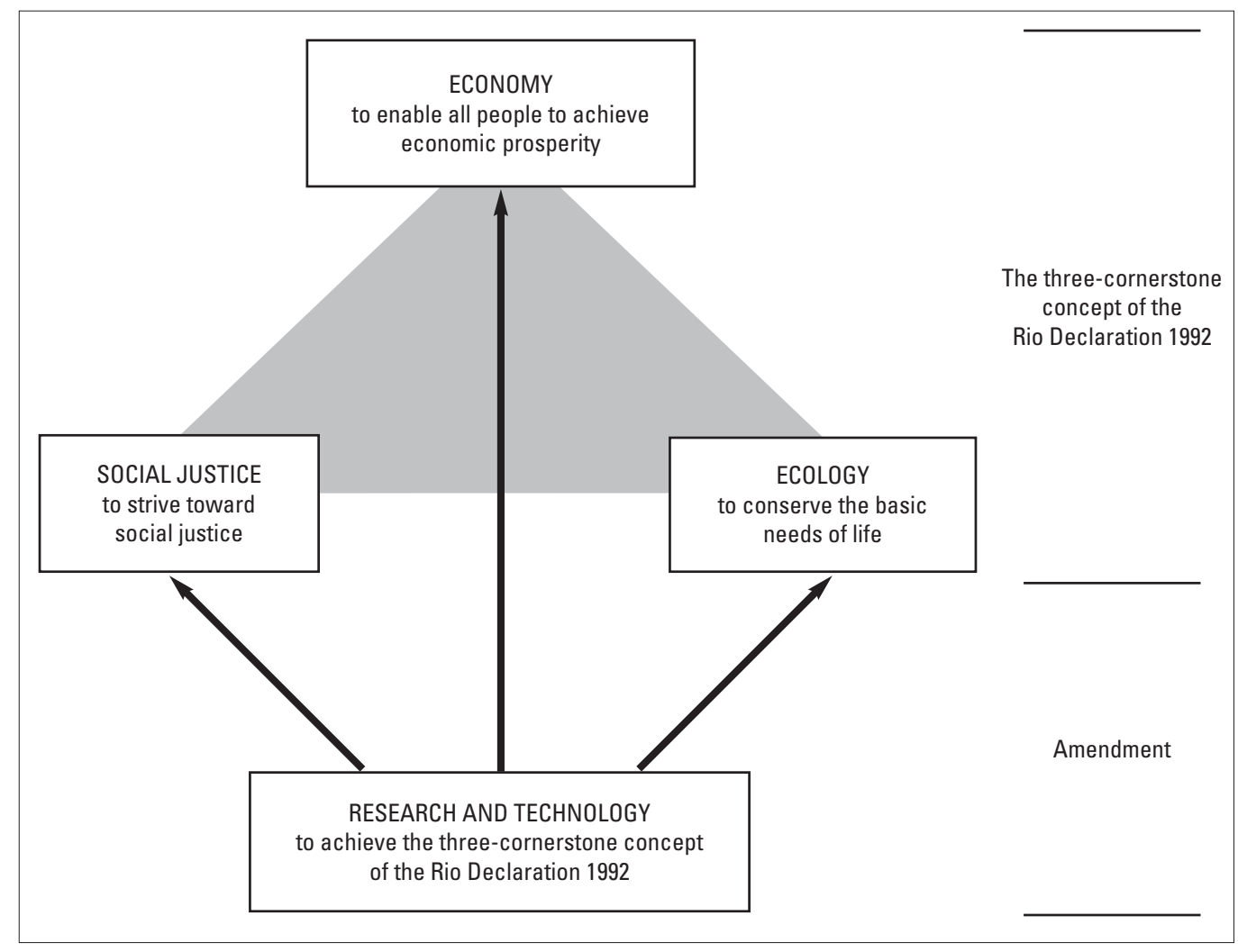

Figure 7. The three-cornerstone concept of the 1992 Rio Declaration (economy, ecology, and social justice) extended to a fourcornerstone concept that includes research and technology to achieve sustainable development globally.

lifetimes of only 20 to 25 years. The lifetimes for lead and zinc, however, have remained the same since 1950 , despite an increase in production from 1.7 million metric tons of lead and 2.2 million metric tons of zinc in 1950 to 3.0 million metric tons of lead and 8.0 million metric tons of zinc in 1999. The stability of these lifetimes means that a dynamic balance between consumption and the discovery of new reserves of these two metals has been maintained for the last 50 years. Obviously, a far larger and more constant effort is needed to keep a dynamic balance for commodities with short lifetimes than for those with very long lifetimes (Wellmer and Becker-Platen, 2001). Thus, reserves lifetime figures can be interpreted as indicators of the need for innovation and of the available time buffer during which functionally equivalent substitutes for scarce resources must be found in accordance with rule 2 of the Enquete Commission.

With this understanding of the reserves lifetime concept, let us take a look at mineral fertilizers. Generally, we need only the functions of natural resources, not the natural resources as such. Among the exceptions to this statement are potassium (potash) and phosphorus (phosphate). Both are essential plant nutrients. Like water, they have no substitutes. In this respect, potassium and phosphorus must be considered among the most critical commodities. Fortunately, their reserves lifetimes are quite high-81 years for phosphorus and 329 years for potassium - giving humanity a substantial time buffer to find sustainable solutions. Moreover, the ultimate source of potassium is seawater, which is practically a renewable resource. Although it is more difficult to develop a comparable concept for sustainability of phosphorus, future options to do so are likely to include improved fertilizing technology, precision farming, and improved recycling of wastes such as manure.

\section{Supply and Demand Cycle of Mineral Resources}

If one wants to understand the future supply of mineral resources, one must consider their supply and demand cycle. This cycle is driven primarily by the price of the commodity, although it should be noted that other aspects, such as increased environmental awareness and concern, are playing an increasingly important role. It also is essential to consider these cycles in connection with one further resource-human creativity. Discovery of new reserves may be viewed as only a temporary possible solution to mineral resource sustainability. Under rule 2 of the Enquete Commission, a number of other potential solutions to sustainability of nonrenewable resources are emphasized and rely on human creativity. Examples for mineral resources include (1) enhancing recovery from the mineral deposit, (2) finding new substitutes, (3) improving recycling, (4) reducing consumption by more efficient utilization, and (5) finding totally new solutions (such as the new technologies that allow transmitting information over fiberglass cables instead of copper wire or by wireless transmission 
Table 2. Recovery rates during mining, beneficiation, smelting, and refining of aluminum, chromium, iron, copper, manganese, nickel, phosphate, and hard coal.

[Modified from Kippenberger, 2001]

\begin{tabular}{|c|c|c|c|}
\hline Commodity & $\begin{array}{l}\text { Percent of world production } \\
\text { included in this survey }\end{array}$ & $\begin{array}{c}\text { Total recovery, } \\
\text { in percent }\end{array}$ & $\begin{array}{l}\text { Share of underground } \\
\text { mines, in percent }\end{array}$ \\
\hline Aluminum & $\begin{array}{ll}\text { Mines } & 79 \\
\text { Smelters/refineries } & 90 \\
\end{array}$ & 87 & 0 \\
\hline Chromium & $\begin{array}{l}\text { Mines } \\
\text { Smelters/refineries }\end{array}$ & 65 & 70 \\
\hline Iron & $\begin{array}{l}\text { Mines } \\
\text { Smelters/refineries }\end{array}$ & 77 & 4 \\
\hline Copper & $\begin{array}{l}\text { Mines } \\
\text { (Relative to capacity) } \\
\text { Smelters/refineries }\end{array}$ & 71 & $\begin{array}{c}35 \\
\text { (estimated) }\end{array}$ \\
\hline Manganese & $\begin{array}{l}\text { Mines } \\
\text { Smelters/refineries }\end{array}$ & 47 & 30 \\
\hline Nickel & $\begin{array}{l}\text { Mines } \\
\text { Smelters/refineries }\end{array}$ & 76 & 53 \\
\hline Phosphate & Mines & 64 & 3 \\
\hline Hard coal & Mines & 77 & 75 \\
\hline
\end{tabular}

using satellites). Some of these examples are described in more detail below.

Enhancing recovery.-In a worldwide materials-flow study, Kippenberger (2001) examined the recovery rates for mining, beneficiating, and smelting eight mineral and energy commodities: iron, aluminum, copper, nickel, chromium, manganese, phosphate, and coal. His results (summarized in table 2) show that total recoveries of these commodities from mining to smelting are well below 100 percent, indicating that significant improvements in utilization efficiency are possible in the future.

Finding new substitutes.-The effect of rising prices as a driving force on finding new solutions to mineral resource sustainability is well demonstrated by the cobalt supply shortage resulting from the political Shaba crisis in Zaire in 1978. This crisis caused the price of cobalt to skyrocket. Zaire, now the Democratic Republic of Congo, is the world's largest cobalt producer. In 1976, the German Government commissioned a study to analyze what effect a shortfall of 30 percent of a commodity would have on industry. For chromium and cobalt, which were considered very difficult to replace with substitutes, it was found that about 6 million jobs would be affected. However, this study totally underestimated the flexibility of industry to react to drastic price rises. Shortly after the price rise, new substitutes (ferrites) were invented, replacing cobalt in permanent magnets and thereby totally changing the consumption pattern for cobalt (Wellmer and Becker-Platen, 2001).

Improving recycling.-What is the aim of recycling? Is it to make maximum use of the secondary material per se, or is it to minimize environmental impact (for example, by reducing energy input and thus $\mathrm{CO}_{2}$ emissions)? Most people would agree that it should be the latter. Consequently, the optimum solution may not be to recycle 100 percent of the secondary raw material (Wellmer and Becker-Platen, 2001). Take alumi- num as an example. The results of an investigation by Alkan and others (1999) to find the optimum rate for recycling aluminum used in packaging are shown in figure 8. The optimum in this case is 90 percent, definitely not 100 percent.

A potential material for metal recycling can be classified according to whether the metal it contains is concentrated or is dilute and highly disseminated. Recycling of relatively concentrated secondary metals requires less energy than does the smelting of their primary ores or concentrates. Recycled aluminum, for example, requires only 5 percent of the energy needed to produce primary aluminum; for copper, the figure is 20 percent; for lead, 50 percent. Lead in car batteries is an example of a concentrated metal that is easily recyclable. The high concentration of lead in these batteries, combined with their relatively short lifetime, is the

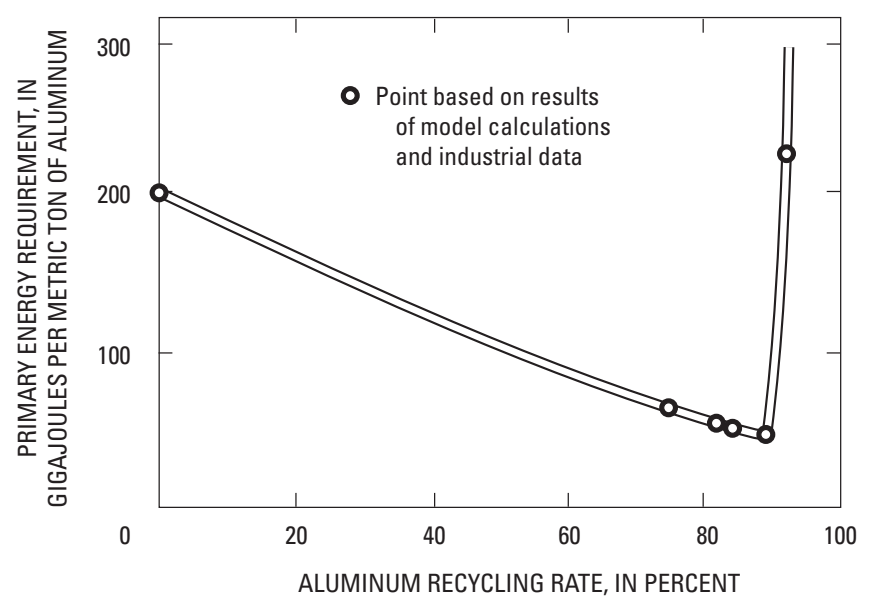

Figure 8. Primary energy requirement for producing aluminum as a function of the recycling rate for aluminum in packaging material (modified from Alkan and others, 1999; courtesy of Encyclopedia of Life Support Systems Publishers, Oxford, United Kingdom). 
reason why lead in car batteries has a recycling rate of more than 50 percent. In contrast, zinc in skin cream and titanium in paint are at the other end of the concentration scale. No one would ever think of trying to recover metals from these products. The more disseminated a metal is in the secondary raw material, the more energy required to purify it.

\section{Applying a Natural Resources Hierarchy to Sustainable Development}

Substitution of one raw material for another, such as plastics or concrete for metals, occurs constantly in industry and is driven by economics. However, substitution also can be driven by efforts to promote sustainable development. One way to do this is through consideration of a hierarchy of relative mineral resource values like that illustrated in figure 9 . The top of the hierarchy is occupied by the most valuable resources (that is, the energy resources represented in fig. 9 by fossil fuels). The next lower value category consists of those mineral resources whose deposits are created by natural enrichment (for example, metalliferous deposits and some nonmetallic deposits like phosphate and barite). The next lower level consists of bulk raw materials such as those used in construction and those whose availability from the geological point of view is unlimited in the Earth's crust. Also included are materials such as magnesium and potassium, which are present in practically unlimited quantities in the oceans and may be considered essentially as renewable resources. At the base of the hierarchy are the waste products and residues from beneficiation or burning of higher value resources. An example is ash from coal-fired powerplants, which can be used for making cement, thereby replacing primary cement raw materials. Lower value resources should always substitute for higher value ones.

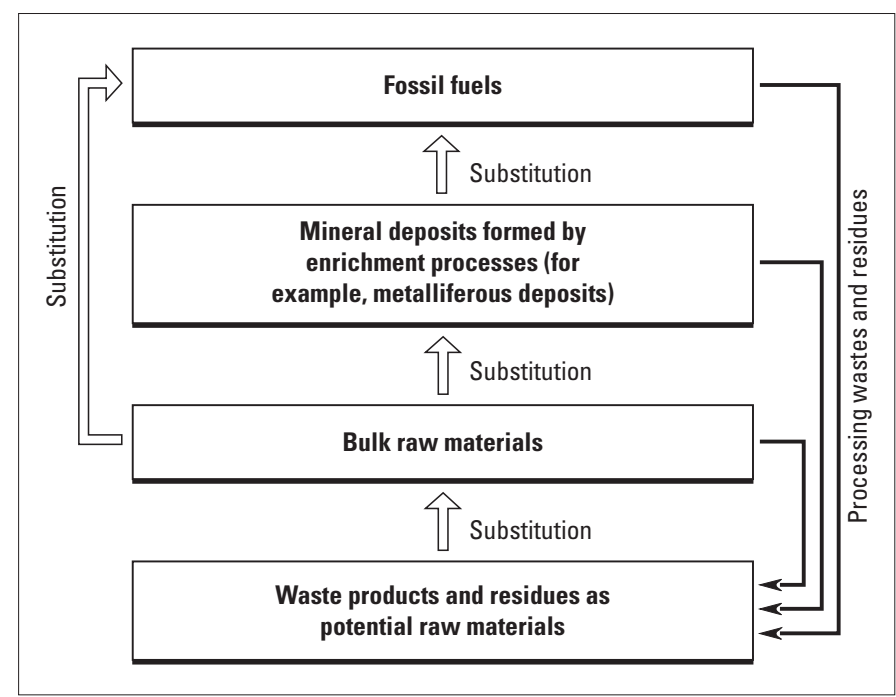

Figure 9. Hierarchy of mineral resources for managing sustainable development (Wellmer and Becker-Platen, 1999; courtesy of Encyclopedia of Life Support Systems Publishers, Oxford, United Kingdom). Resource values increase upward.
Whenever possible, the aim of mineral policy in the sense of sustainable development must be to utilize low-value resources at the base of the mineral resources hierarchy in order to conserve high-value resources at the top. An example of how this may be achieved is through a materials-flow law like Germany's Waste Avoidance, Recovery and Disposal Act, which penalizes waste disposal. This law promotes maximum utilization of waste products and minimum disposal of waste. Other measures include regional planning that permits unimpeded access to bulk mineral resources, in combination with laws encouraging environmentally compatible mineral extraction. The application of the mineral resources hierarchy to sustainable development is illustrated by the following two examples.

1. Triple-pane window glass is mandatory in Sweden. When the resulting energy savings for heating a house exceeds the amount of energy required to manufacture the triple-pane glass for the windows, then the energy balance is positive. Thus, raw materials that are lower in the resources hierarchy (sand, limestone, dolomite, and soda ash) replace energy resources at the top (fig. 9).

2. A new high-speed railway system under construction in Europe is required to follow the most direct routes possible between cities. Consequently, many tunnels and bridges are being built. Tunnels make up 34 percent and bridges make up 12 percent of the northern half of the new railway line between Hannover in northern Germany and Munich in southern Germany (Geissler and others, 1982). Primarily, the new railway system improves traveltime, but it also represents a massive investment in bulk construction materials and steel to improve energy efficiency.

Indicators of efficiency in the utilization of natural resources have been developed in various countries because, as the consideration of the mineral resources hierarchy above illustrates, it is not helpful to consider natural resources as equivalent entities (for example, making 1 metric ton of an energy resource equivalent to 1 metric ton of a metal or 1 metric ton of a bulk material). Rather, it is more helpful to measure the efficiency of utilization of the resources at the top of the hierarchy by measuring the intensity of their use. For the energy resources, the intensity of use is measured by the ratio of a unit of energy consumed to a unit of gross national product, or vice versa. Figure 10 shows how energy efficiency in Germany improved from 1990 to 1996 in the context of the nation's goal to double energy production by 2020 (Bundesministerium für Umwelt, Naturschutz und Reaktorsicherheit, 1998).

\section{The Importance of Learning}

Learning is a process that normally follows a sigmoidal curve. At the beginning, the learning curve is almost flat; that is, the start is difficult; then the curve steepens, and finally 


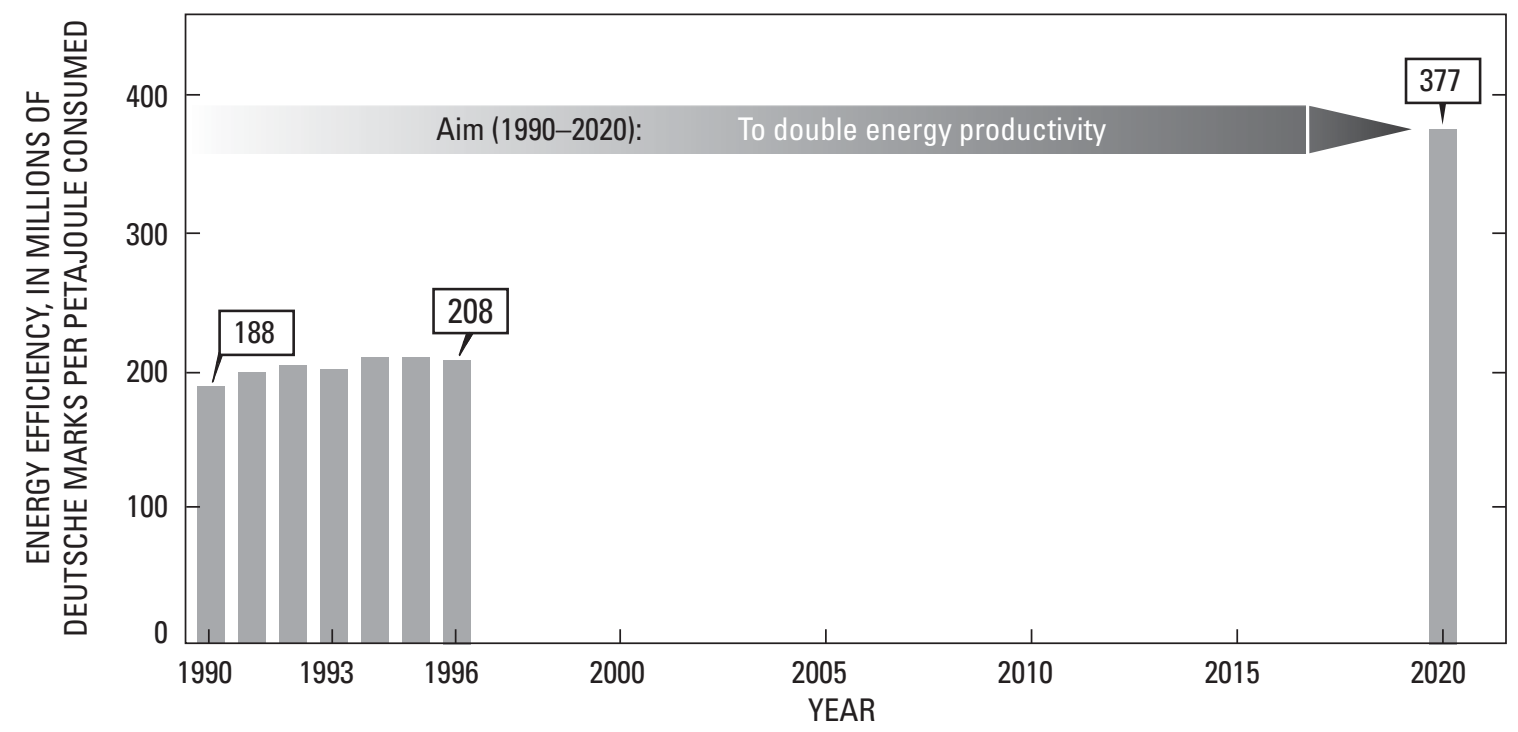

Figure 10. Development of energy efficiency in Germany (modified from Bundesministerium für Umwelt, Naturschutz und Reaktorsicherheit, 1998). Measured in millions of Deutsche Marks (DM) gross national product per petajoule (PJ) consumed.

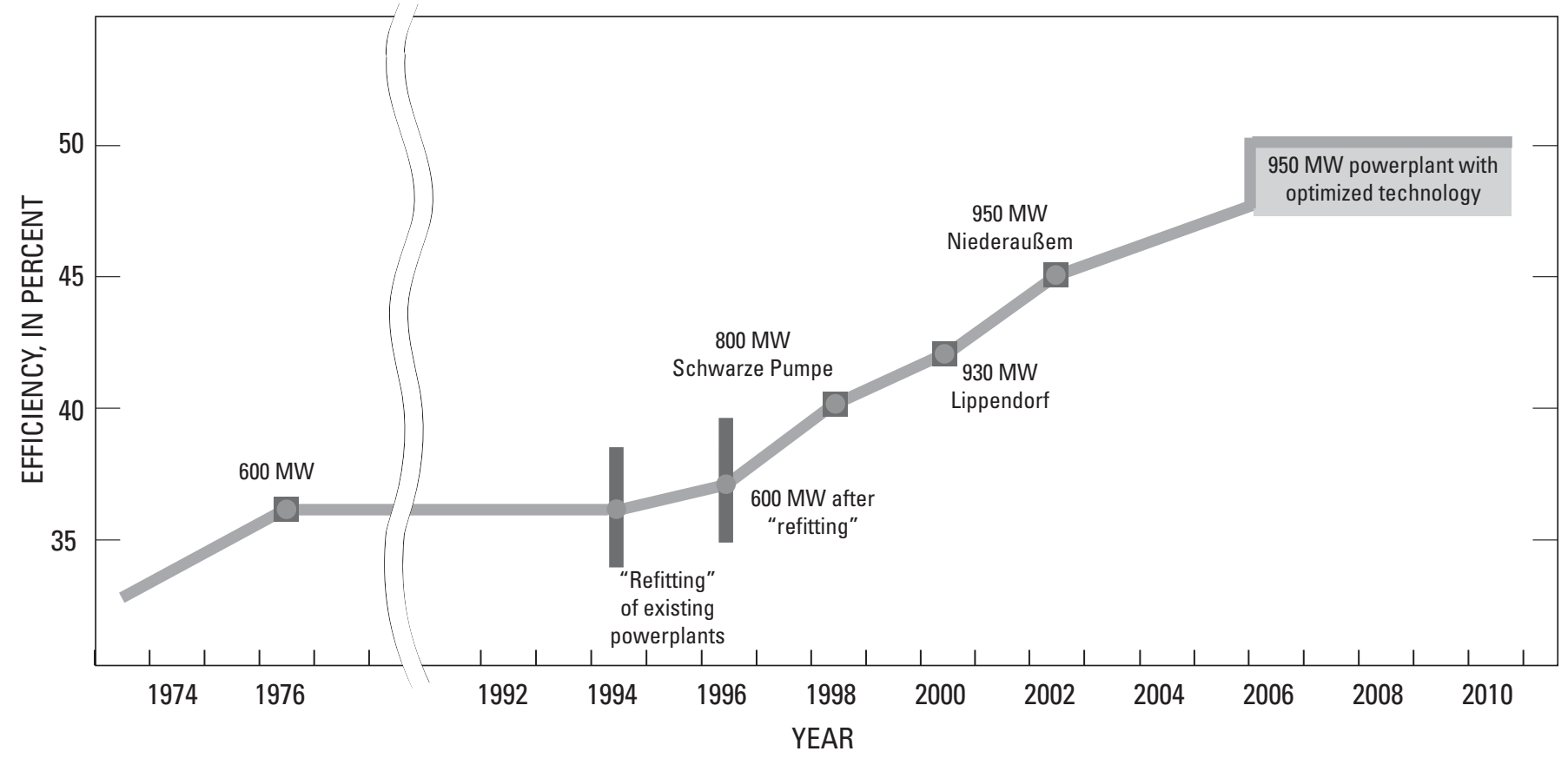

Figure 11. Increase in the efficiency of generating electricity in German lignite-fired powerplants; information from DEBRIV (Deutscher Braunkohlen-Industrie-Verein e.V.; German Association for the Lignite Industry). MW, megawatt.

it flattens again when a saturation stage is reached and the rate of learning declines. All of the examples cited above of methods for replacing nonrenewable resources by functionally equivalent resources or achieving higher efficiencies in using mineral resources as required by rule 2 of the Enquete Commission can be shown to follow such a learning curve. On the other hand, experience shows that learning curves may start anew with a technological breakthrough or radical innovation. This circumstance is exemplified by a learning curve based on the efficiency of generating electricity with lignite as fuel in German powerplants (fig. 11).

Learning is critical for improving the efficiency of production and utilization of our natural resources. In figure 6. it was shown that the bulk of natural resource consumption is occurring in the industrialized nations. This group of countries has gone through a learning curve, becoming more and more efficient in using natural resources. This occurrence is illustrated for copper consumption in figure 12. The growth 
rate shown in figure $12 B$ generally decreased from the end of World War I to the middle of the 1980s. Since that time, the growth rate for copper consumption has flattened out in the industrialized nations. However, the growth rates in world consumption are increasing again because of high growth rates in takeoff and developing nations like China (Wellmer and Wagner, 2000). The consequence is that we shall see the development of a new learning curve in the countries with high growth rates today.

It has been argued that takeoff and developing nations take over more efficient technologies immediately and skip less efficient intermediate steps. This certainly is true for selected technologies; for national economies as a whole, however, this development has not been observed so far (for example, steel consumption, as shown in fig. 13).

Figure 13A shows the intensity-of-use (IOU) factors for steel for a selected group of developing, takeoff (newly industrialized), and industrialized nations. A bell-shaped curve can be clearly seen in the plot of kilograms of iron consumption per $\$ 1,000$ gross national product versus gross national product per capita. The intensity-of-use factors rise within the group of developing nations, reach a peak in the group of takeoff nations, and decline toward the group of industrialized nations. This curve results mainly because of the increasing importance of the tertiary service sector but also because of learning effects. If the theory that takeoff and developing nations skip stages in favor of more efficient natural resource utilization were true for entire national economies, a flattening of this bell-shaped curve as shown in figure 13B would be expected. What we observe, however, is the opposite trend. Figure 13C shows the intensity-of-use factors for two time slices-1985 and 1995. It can be clearly seen that the bellshaped curve has a more pronounced peak in 1995 than in 1985. This difference obviously means that the growth of the developing nations and takeoff nations is based on more rather than fewer natural resources.

The three-cornerstone concept for sustainable development in the 1992 Rio Declaration was extended herein to a four-cornerstone concept by adding research and technology (fig. 7) to improve efficiency in the use of natural resources. Figure 13 illustrates overall the need for increased efforts in this field in order to reverse the trend shown in figure 13C.

To increase the efficiency of entire national economies with respect to the utilization of natural resources, one must take into account that each economic system has to advance through its own stages of learning. In the metallurgical field, industrialized nations have advanced to a relatively efficient stage that optimizes energy input (Wellmer and Becker-Platen, 2001). The present situation in industrialized countries, however, is the result of many learning steps, which proceeded through stages that were inefficient and certainly not sustainable by today's standards. A good example is the use of charcoal for smelting, which led to excessive cutting of timber and the formulation of the first rule for sustainable development by von Carlowitz (1713).
Developing nations, of course, will not go through these same stages again but, for a variety of reasons, will have to start on a lower part of the learning curve before reaching a high degree of resource efficiency. As an example, many smelters produce not only metals but also residues like slag and sulfuric acid. In industrialized nations today, all residues can be used in most cases in other industrial sectors (for example, slag in the construction industry; sulfuric acid in many chemical processes). The result is that residues at the base of the natural resources hierarchy of figure 9 are used again, thereby replacing primary higher value resources. However, such reuse of residues requires a developed chemical industry, which a developing nation generally does not have when it starts to industrialize by using its own natural resources.

\section{The Sink Problem of Natural Resources and the Resilience of the Environment}

So far we have dealt only with rules 1 and 2 of the Enquete Commission. We also have to consider rules 3 and 4, which address the resilience of the environment.

Per the maxim, "He who mines must dig," digging is unavoidable, even though it has an environmental impact. In a recent study by Neumann-Mahlkau (1997), it was shown that anthropogenic mass movements have reached the same order of magnitude as geogenic mass movements: about 35 billion cubic meters per annum $\left(\mathrm{m}^{3} / \mathrm{a}\right)$ compared to about 37 billion $\mathrm{m}^{3} / \mathrm{a}$. Fortunately, humanity has learned much over the past 30 years about reducing the environmental effects of mining. Good mining practices always use the best available technology that also takes into account inescapable economic considerations. Such practices sometimes are labeled "BATNEEC"; that is, best available technology not entailing excessive costs. Implementing BATNEEC means increasing limits on the quantity of water and reagents reaching the environment from the beneficiation of ores and implementing strict regulations about restoring mine sites. It also involves minimizing the land area used for mining. For example, it has been calculated that only about 0.01 percent per year of the land area of Germany is used for exploiting natural resources (Gwosdz and Lorenz, 2000). Moreover, this percentage must have a bias toward higher land usage than in other equivalent industrialized countries because Germany is the world's largest lignite producer, having very large open pits. Germany also is a significant peat producer, for which relatively large production areas are required, as well. Nonetheless, all land used for mining and quarrying today is used only intermittently in most industrialized nations; such land areas are "borrowed." In Germany, for example, all such land must be restored for industrial, agricultural, forestry, or recreational purposes or as a nature reserve (renaturation).

Accidents, especially those involving tailings dam failures, have caused considerable damage to the environment and, in the past, led to widespread public criticism of the mining industry. Although environmental damage should not be 
$A$

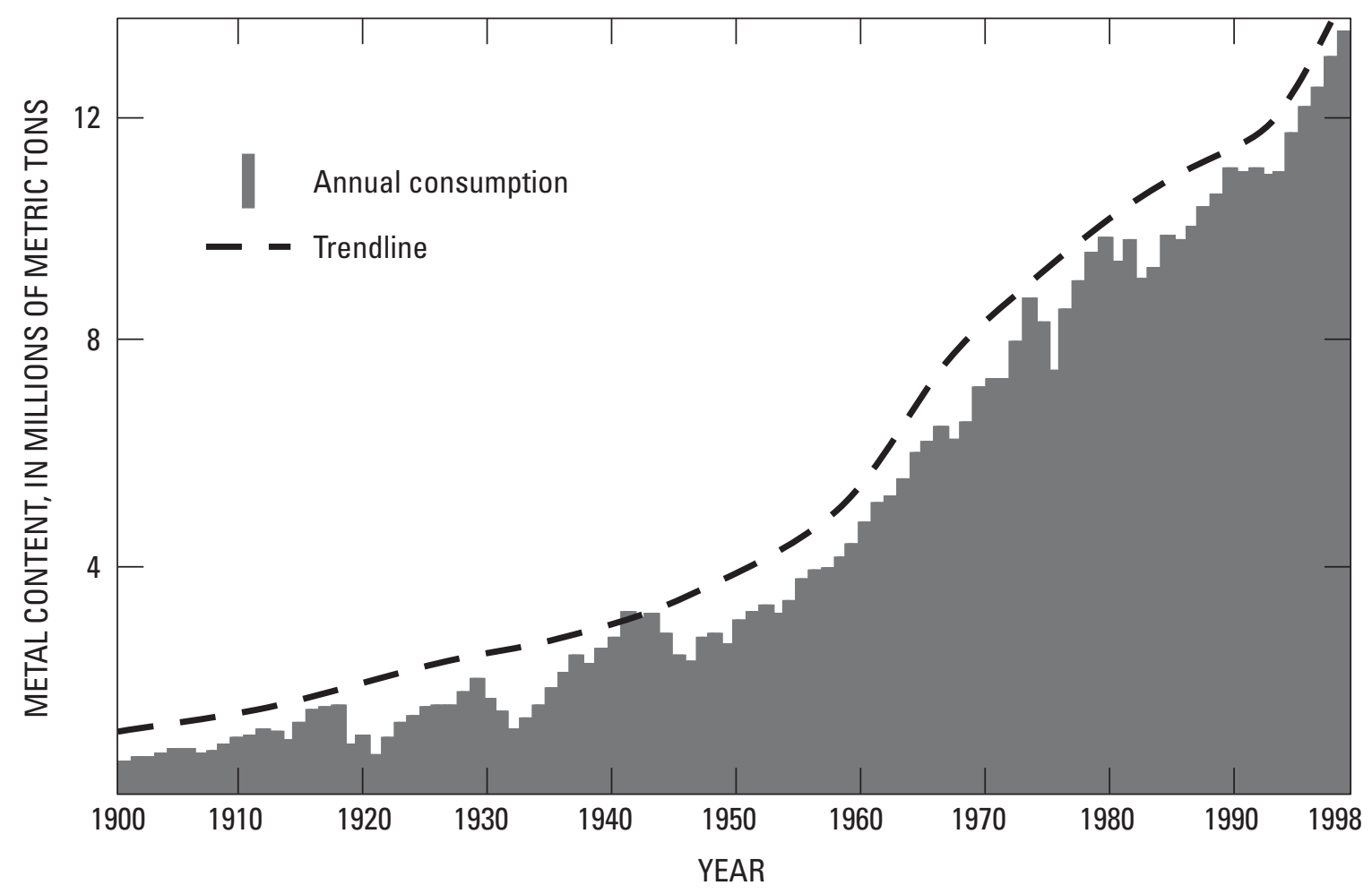

$B$

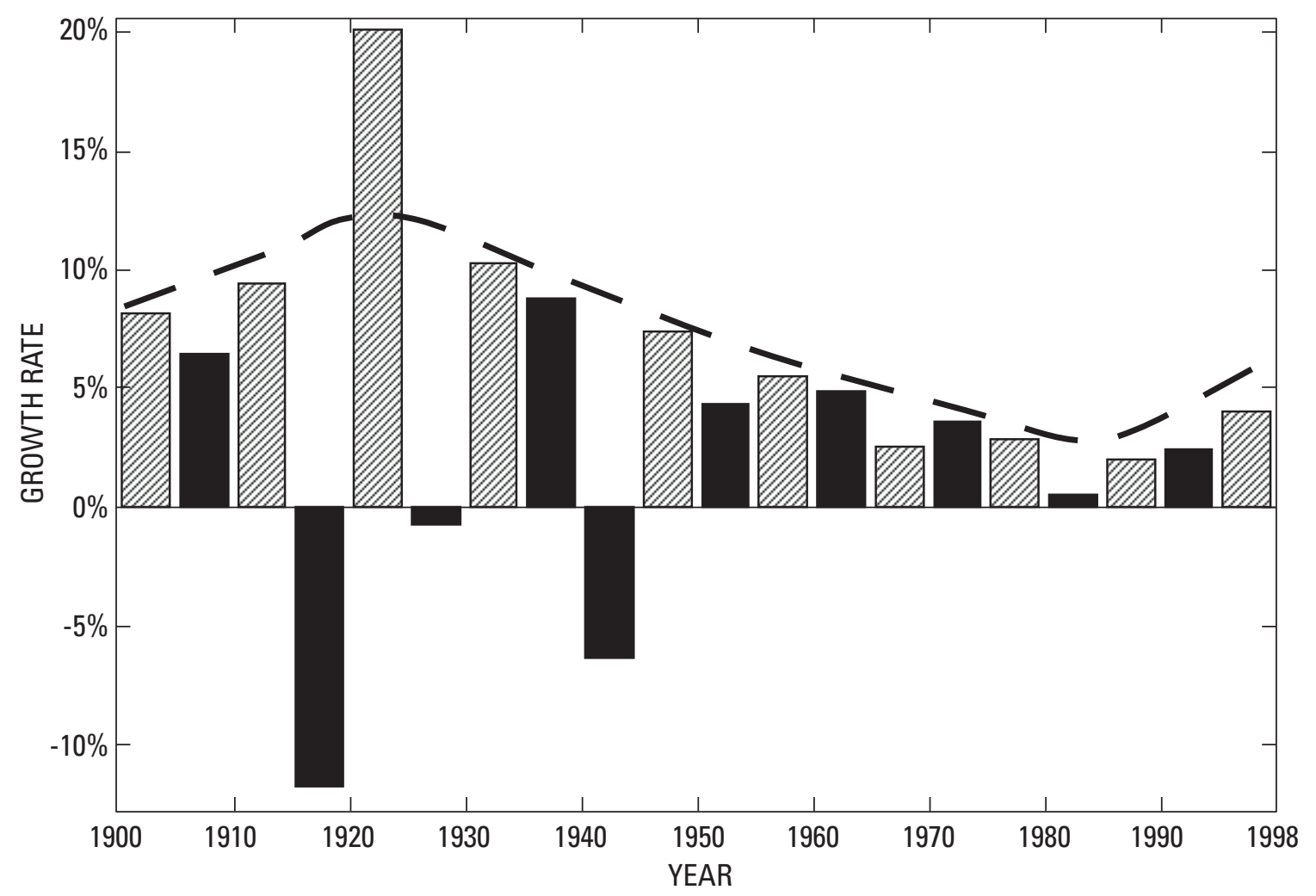

Figure 12. Worldwide copper consumption and growth rates from 1900 to 1998 (Wellmer and Wagner, 2000). $A$, Annual worldwide copper consumption. $B$, Growth rates of worldwide copper consumption where 5-year mean values are calculated relative to the previous 5 -year period. 



Figure 13. Intensity-of-use (IOU) factors for steel (in 1990 U.S. dollars) for three situations for selected countries (Wellmer and Wagner, 2000). $A$, IOU factors for steel in 1985. Dashed lines enclose groups of countries as labeled. $B$, Possible development of IOU curve for steel after successful transfer of technology (dashed line); this hypothetical curve is not observed as shown in figure 13C. C, Comparison of IOU factors for steel in 1985 and 1995. $\mathrm{Fe}$, iron; GNP, gross national product. played down, it must be pointed out that geotechnical methods are available for proper construction and safe management of tailings dams. It is a matter of good management and mining practices to enforce strict quality control down the chain of command of mining companies. Many companies increasingly are developing and applying rigorous standardized codes of conduct to their operations worldwide. Examples of national and international codes of conduct are those of the (1) Mineral Council of Australia, (2) International Council on Metals and the Environment (ICME), and (3) World Bank Guidelines for Health, Safety and Environment. ICME is based in Ottawa, Canada. Its members are major international metal mining and smelting companies.

Rules 3 and 4 of the Enquete Commission state that the amount and rate of material and energy input into the environment should not exceed the capacity for their absorption with minimum detrimental effects. In the context of these rules, the problem of soils acting as a sink for anthropogenic substances must be examined. We have to realize that man's activities have considerably increased anthropogenic heavy-metal concentrations in the soil in and around urban and industrial areas. An example from the Berlin area in Germany is shown in figure 14. Another example is the correlation between the increase of lead in human bones and the increased historical use of lead by humans shown in table 3 (Friege and others, 1985).

Continued and increased efforts must be made to devise improved methods for reducing emissions, thereby protecting our soil so that its capacity to function as a sink

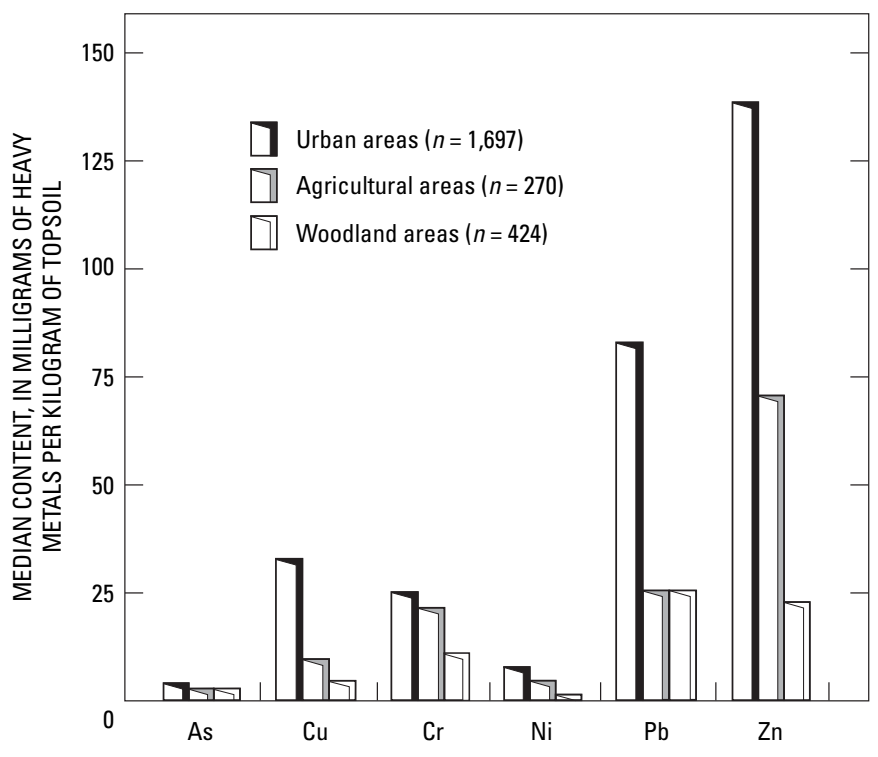

Figure 14. Contents (median values) of selected heavy metals in topsoil in urban Berlin and surrounding rural areas (modified from Birke and Rauch, 1997; courtesy of Encyclopedia of Life Support Systems Publishers, Oxford, United Kingdom). n, number of samples; As, arsenic; $\mathrm{Cu}$, copper; $\mathrm{Cr}$, chromium; Ni, nickel; $\mathrm{Pb}$, lead; $\mathrm{Zn}$, zinc. 
Table 3. Lead content in human bones.

[From Friege and others, 1985]

\begin{tabular}{|c|c|c|c|}
\hline Origin of the bones & Date & $\begin{array}{c}\text { Lead } \\
\text { content }^{1}\end{array}$ & $\begin{array}{l}\text { Reason for lead } \\
\text { content }\end{array}$ \\
\hline Inca in Peru & $\begin{array}{c}\text { A.D. 500- } \\
1000\end{array}$ & 0.55 & No lead used. \\
\hline Teutones in Bavaria & $\begin{array}{c}700-400 \\
\text { B.C. }\end{array}$ & 2.0 & Early use of lead? \\
\hline $\begin{array}{l}\text { Augsburg from late } \\
\text { Roman times }\end{array}$ & $\begin{array}{l}\text { A.D. } \\
200-400\end{array}$ & 4.7 & $\begin{array}{l}\text { Water pipes, ceramics, } \\
\text { lead food containers. }\end{array}$ \\
\hline $\begin{array}{l}\text { Augsburg, rich person } \\
\text { from the post- } \\
\text { Roman period } \\
\end{array}$ & A.D. 600 & 4.5 & $\begin{array}{l}\text { Luxurious Roman } \\
\text { lifestyle. }\end{array}$ \\
\hline $\begin{array}{l}\text { Regensburg, poor } \\
\text { person from the } \\
\text { post-Roman period } \\
\end{array}$ & A.D. 600 & 1.4 & No Roman luxury. \\
\hline $\begin{array}{l}\text { Regensburg, nuns } \\
\text { from the Middle } \\
\text { Ages } \\
\end{array}$ & \begin{tabular}{|l|} 
A.D. \\
$800-900$
\end{tabular} & 2.4 & $\begin{array}{l}\text { Increasing prosperity } \\
\text { of the cloister. }\end{array}$ \\
\hline Regensburg, nuns & A.D. 1100 & 5.1 & $\begin{array}{l}\text { Use of lead-bearing } \\
\text { tin. }\end{array}$ \\
\hline $\begin{array}{l}\text { Augsburg, monks } \\
\text { from the Middle } \\
\text { Ages }\end{array}$ & \begin{tabular}{|c} 
A.D. \\
$1000-$ \\
1200
\end{tabular} & 5.0 & $\begin{array}{l}\text { Printing presses and } \\
\text { so on. }\end{array}$ \\
\hline Modern person & A.D. 1983 & $11-12$ & $\begin{array}{l}\text { Lead in gasoline and } \\
\text { so on. }\end{array}$ \\
\hline
\end{tabular}

${ }^{1}$ Milligrams of lead per kilogram of bone. for pollutants is not diminished. Significant advances have been made in industrialized countries in the last decade. For example, a recent study by Thomas and others (1999) demonstrated that the phasing out of lead in petrol (gasoline) has led to a considerable reduction of lead concentrations in the environment. In addition, a recent study by the U.S. Geological Survey has shown that lead concentrations in sediments declined as much as 70 percent since the 1970 s and 1980s (U.S. Geological Survey, 1998; Callender and Rice, 2000).

\section{Concluding Remarks}

The process of continually finding new solutions for the replacement of our nonrenewable resources is governed by the prices of these commodities and, for mineral resources, is affected by the cycle of supply and demand and the effects of learning. In the opinion of the authors, this process so far has worked in our market economy to provide a dynamic balance between resources supply and demand. There is no reason to believe that the process will not continue to function in the future. Concerning the environmental aspects and the sink issue, one can be optimistic that improved technologies will find the necessary solutions.

A more pressing problem for humanity lies in another area-food for an ever-increasing population. Freshwater and soil are needed for growing food. In many arid and semiarid

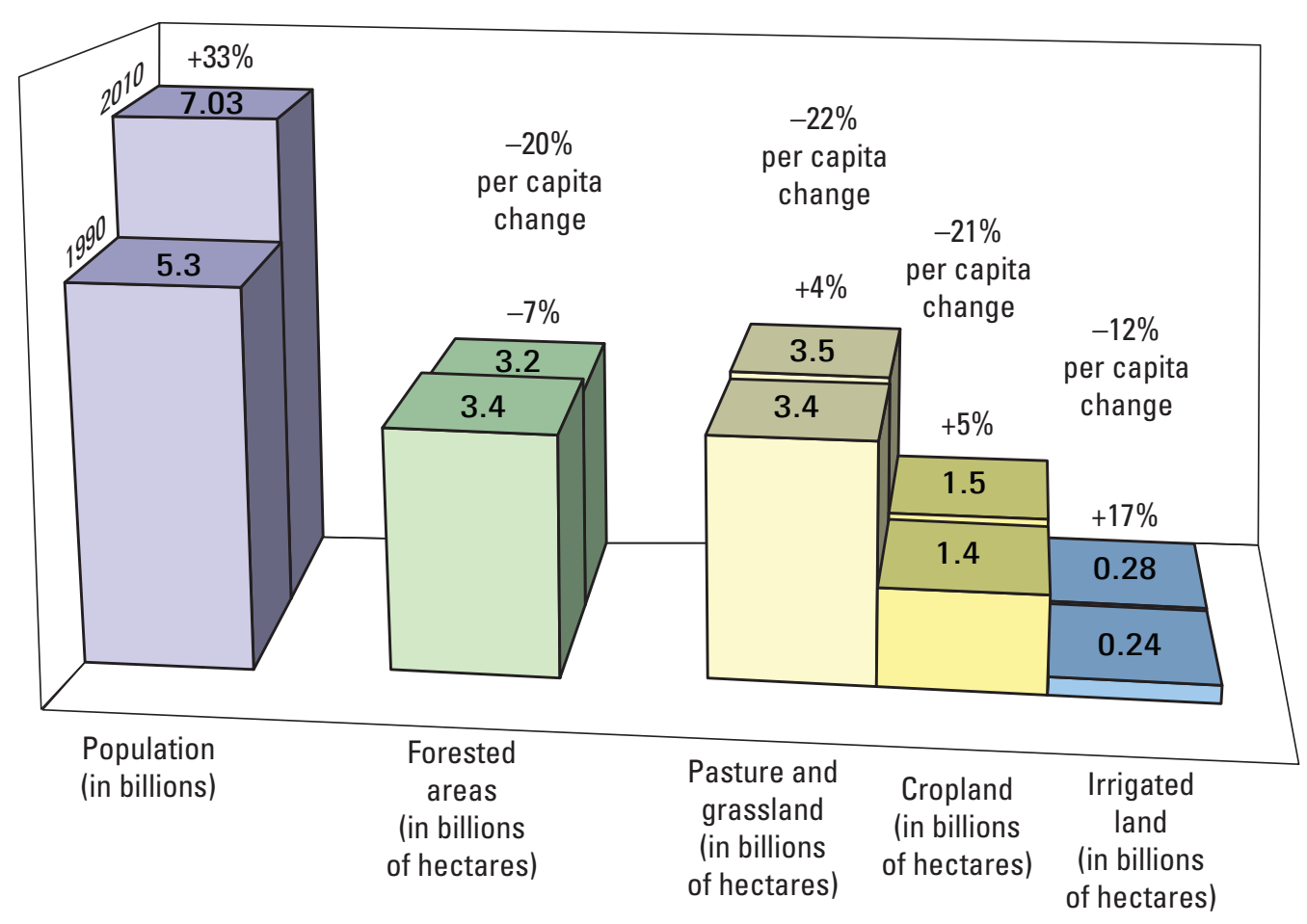

Figure 15. Comparison of population and worldwide land resources in 1990 and 2010 (Wellmer and Becker-Platen, 1999). 
areas today, fossil water is being used. Such water must be considered a nonrenewable resource when its slow recharge is measured against its rapid depletion. Huge quantities of soil, which likewise must be considered a nonrenewable resource, are lost every year to erosion by water and wind, thus reducing the amount of arable land. These growing resource constraints, in combination with an increasing population, are significantly reducing the amount of arable land per capita worldwide (fig. 15). This is an historic paradox, where humanity must be more concerned in the future with the availability of nonrenewable resources than with renewable ones.

\section{References Cited}

Alkan, Z., Briem, S., Dienhart, M., Kugeler, K., and Quinkertz, R., 1999, Methodik und Anwendung eines Energiemodells zur Analyse energetischer Aspekte von Prozessen der Metallherstellung [Methodology and application of an energy model for the analysis of the energy aspects of metal production]: Berichtskolloquium SFB 525, Ressourcenorientierte Gesamtbetrachtung von Stoffströmen metallischer Rohstoffe - Entwicklung von Methoden und ihre Anwendung, RWTH Aachen 20.10.99.

Birke, Manfred, and Rauch, Uwe, 1997, Geochemical investigations in the Berlin Metropolitan Area: Zeitschrift für angewandte Geologie, v. 43, no. 1, p. 58-65.

Bristow, C.M., 1987, Society's changing requirements for primary raw materials: Industrial Minerals, v. 233, p. 59-65.

Brundtland, G.H., 1987, Our common future-Report of the World Commission on Environment and Development: Oxford, U.K., Oxford University Press, 400 p.

Bundesministerium für Umwelt, Naturschutz und Reaktorsicherheit (German Federal Ministry for the Environment, Nature Conservation and Nuclear Safety), 1998, Nachhaltige Entwicklung in Deutschland-Entwurf eines umweltpolitischen Schwerpunktprogramms [Sustainable development in Germany_Draft environmental program]: Bonn, Bundesministerium für Umwelt, Naturschutz und Reaktorsicherheit, 147 p.

Callender, Edward, and Rice, K.C., 2000, The urban environmental gradient-Anthropogenic influences on the spatial and temporal distributions of lead and zinc in sediments: Environmental Science and Technology, v. 34, no. 2, p. 232-237.

Enquete-Kommission Schutz des Menschen und der Umwelt [Enquete Commission on Protection of Man and the Environment], 1993, Verantwortung für die Zukunft-Wege zum nachhaltigen Umgang mit Stoff- und Materialströmen [Responsibility for the future-Sustainable materials and materials flow]: Bonn, Economica-Verlag, 332 p.
Friege, Henning, Kost, Ulrich, and Claus, Frank, eds., 1985, Die tückische Hypothek-Chemiepolitik für Schwermetalle [The malicious mortgage-Chemistry politics for heavy metals]: Karlsruhe, Verlag C.F. Müller, 219 p.

Geissler, H., Moeker, H., Sauer, G., and Schrewe, F., 1982, Tunnelplanung der Deutschen Bundesbahn in erdfallgefährdetem Gebiet-NBS Hannover-Würzburg, Leinebusch-Tunnel [Tunnel planning in a region of subsidence-New high-speed railway line from Hanover to Wuerzberg, Leinbusch Tunnel]: Rock Mechanics, Supplementum 12, p. 63-73.

Gwosdz, W., and Lorenz, W., 2000, Flächenbedarf für den Abbau von oberflächennahen Rohstoffen (Steine und Erden, Braunkohle und Torf) im Jahr 1997 [Area requirements for the dismantling of raw materials near the surface (stones and ground connection, brown coal and peat) in the year 1997]: Hannover, Federal Institute for Geosciences and Natural Resources, Fakten, Analysen, wirtschaftliche Hintergrundinformationen, v. 9, 4 p.

Jeffery, W.G., 1998, A world of metals—Finding, making and using metals: Ottawa, The International Council on Metals and the Environment, $41 \mathrm{p}$.

Kippenberger, Christoph, 2001, Materials flow and energy required for the production of selected mineral commodities-Summary and conclusions: Geologisches Jahrbuch, Reihe H, Sonderheft 13, 55 p.

Neumann-Mahlkau, Peter, 1997, Anthropogenic material flow-A geologic factor, in Zhang, Zhonghu, de Mulder, E.F.J., Liu, Tungsheng, and Zhou, Liping, eds., Geoscience and human survival, environment, natural hazards, and global change: Proceedings of the 30th International Geological Congress, Beijing, China, August 4-14, 1996, v. 2-3, p. 61-66.

Taylor, H.K., 1978, Mine valuation and feasibility studies, in Hoskins, J.R., and Green,W.R., eds., Mineral industry costs (2d ed.): Spokane, Wash., Northwest Mining Association, p. 1-17.

Thomas, V.M., Socolow, R.H., Fanelli, J.J,. and Spiro, T.G., 1999, Effects of reducing lead in gasoline-An analysis of the international experience: Environmental Science and Technology, v. 33, no. 22, p. 3942-3948.

United Nations Environment Programme, 1989, Statement of sustainable development: 15th Session of the Governing Council, Governing Council Decision 15/2, May 23, 1989, Annex II, GOAR, 44th Session Supplement, no. 25.

U.S. Geological Survey, 1998, Getting the lead out-Positive effects of the Clean Air Act: U.S. Geological Survey Web page at http://www.nwrc.usgs.gov/world/content/water3.html. 
von Carlowitz, H.C., 1713, Sylvicultura oeconomica: Leipzig, Braun, 432 p.

Wellmer, F.-W., and Becker-Platen, J.D., eds., 1999, Mit der Erde leben-Beiträge Geologischer Dienste zur Daseinsvorsorge und nachhaltigen Entwicklung [Living with the Earth-Contributions of geological services to ensure life and sustainable development]: Berlin, Springer-Verlag, $273 \mathrm{p}$.

Wellmer, F.-W., and Becker-Platen, J.D., 2001, World natural resources policy-Focussing on mineral resources, in Our fragile world-Challenges and opportunities for sustainable development: Oxford, U.K., Encyclopedia of Life Support Systems Publishers Co. Ltd., v. 1, p. 183-207.
Wellmer, F.-W., and Becker-Platen, J.D., 2002, Sustainable development and the exploitation of mineral and energy resources-A review: International Journal of Earth Sciences, v. 91, no. 5, p. 723-745.

Wellmer, F.-W., and Lorenz, W., 1999, Von den (Edel-) Metallen zu den Nichtmetallen-Bodenschätze im Wandel ihrer volkswirtschaftlichen Bedeutung [From metals and noble metals to nonmetals - Changing economics of our land's natural resources]: Schriftenreihe der Georg-Agricola-Gesellschaft, Bochum, Georg-Agricola-Gesellschaft, v. 24, p. 97-116.

Wellmer, F.-W., and Wagner, Markus, 2000, Rohstofftrends am Beginn des 3. Jahrtausends [Raw material trends at the beginning of the third millennium]: Erzmetall, v. 53, no. 10, p. 569-582. 


\title{
Uses of a Global Mineral Resource Assessment
}

\section{The Contributions of Geologic Information to Economic, Social, and Environmental Sustainability}

\author{
By Deborah J. Shields ${ }^{1}$
}

Environmental issues received increasing attention during the last three decades of the 20th century, a situation that no doubt will continue as we move into the 21 st century. Societies all over the world began to realize that the ability of the Earth's systems to supply natural resources and services is finite, but that demands on those systems are multiplying rapidly (Arrow and others, 1995). The viability of current lifestyles and consumption patterns began to be questioned. Many different societies and professions embraced the paradigm of sustainable development as a philosophical construct within which to frame fundamental questions about the use and preservation of natural capital. The paradigm is based upon the ethical premise that current growth should not be achieved at the expense of future generations (Brundtland, 1987).

Sustainability deals with the intergenerational and intragenerational implications of finding an appropriate balance among the needs of economic, environmental, and social systems. Although no single definition of sustainable development is acceptable to all parties, the general concept of sustainability has become so widespread in recent years that politicians and decisionmakers have embraced it as an underlying way of thinking about their programs and policies. Sustainability often is described in terms of principles, criteria, and indicators, where criteria represent statements of what is meant by principles of sustainability and indicators are measures of the degree to which the criteria are being reached (Granholm and others, 1996). Because indicators require measures and measures must be supported by data, it follows that a focus on sustainable development inevitably will lead to an increase in the demand for reliable, unbiased information.

Science is "the organized systematic enterprise that gathers knowledge about the world and condenses the knowledge into testable laws and principles" (Wilson, 1998, p. 53). Given that science expands our understanding of the world, it is reasonable to expect that policymakers and the public will look to scientists for information about the status and functioning of the Earth's systems. The current interest in issues of sustainability thus will help raise the visibility of both the social and natural sciences,

${ }^{1}$ U.S. Department of Agriculture, U.S. Forest Service, Rocky Mountain Research Station, 2150 Centre Avenue, Bldg. A, Ft. Collins, CO 80526, U.S.A. (e-mail: dshields@fs.fed.us). including geology. To the degree that scientists are willing and able to address the urgent needs of society and then communicate their knowledge to the public and decisionmakers, the status of the sciences will be improved as well (Lubchenco, 1998).

In this presentation, I will discuss one facet of the complex interaction between experts and the public: how to increase the likelihood that the scientific expertise of geologists and the data that they can provide are utilized in the development and review of policies related to sustainable development.

The field of geology developed largely in response to societal needs for natural resources, particularly energy and mineral resources, and also in part because of geogenic impacts on the human-made environment. Energy and mineral resources remain integral components of economic and social systems, providing essential inputs to virtually every economic sector and acting as the driving force for some local, regional, and national economies. At the same time, resource extraction, processing, use, and disposal can have serious environmental consequences that have the potential to threaten environmental security and degrade present and future quality of life (Shields, 1998). In addition, surface and nearsurface earth (geological) processes determine both the character of the landscape and the state of the physical and built environment (Hughes, 1995; Berger and Iams, 1996). Clearly, geologic information will be relevant to many aspects of sustainable development.

Geologists traditionally have focused on the scientific and technical aspects of their field, but if they are to be perceived as relevant to the sustainability debate, they will have to demonstrate that geologic information will help societies achieve the goal of sustainable socioeconomic and biophysical systems. Being conversant with the concept of sustainability will be necessary but not sufficient. Geologists will need to understand the policymaking process and enhance their communications skills so that they are able to present geologic information (1) in a format that is understandable and (2) at a point in the policy or management cycle that is useful to decisionmakers. Another important step in getting geologic input utilized will be to reach a mutual understanding between the data user and data provider about the ultimate purpose for the data. The geologist, in the role of data provider, has to be aware of needs of the data user and vice versa. The data user has to be aware of the limitations of the data provided. These needs suggest that the range 
of information that geologists will supply should go well beyond what has traditionally been the case.

As Lubchenco (1995) pointed out, the best policy is based on the best science. Science, however, is a dynamic, ongoing process that continually is discovering new information. Thus, the interaction between science and policy must also be ongoing and dynamic. Lubchenco listed eight types of useful scientific communication: (1) what is known, (2) the certainty with which it is known, (3) what is not known, (4) what is suspected, (5) the limits of science, (6) probable outcomes of different policy options, (7) key areas where new information is needed, and (8) recommended mechanisms for obtaining high-priority information. Essentially, Lubchenco recommended a proactive role for scientists, one in which they not only provide information, but also frame the issues, set research priorities, synthesize complex information, and, perhaps most importantly, communicate how science works. This expanded role is an appropriate one for geologists.

Policymaking is a cyclical process that may be seen as progressing through a series of six stages: (1) identification of objectives and interests, (2) definition of policy, (3) codification of policy in laws and acts, (4) establishment of a regulatory framework, (5) monitoring, and (6) review and adaptation. The type of input geologists provide will depend upon where a society is in this policy cycle and also on the decision context, be it in the mineral sector, an issue related to land use and development, nature conservation, or interactions between the environment and society (that is, anthropogenic versus geogenic impacts).

Clearly there is a need for input from geology as a country's mineral policy is being defined. The consensus building process necessary to the achievement of a relevant and widely accepted mineral policy will depend in part upon information about the impacts and consequences of choosing one policy option over another. Decisionmakers will need information about the depletion of mineral resources and the environmental effects of mining. For earth scientists, the challenge will be to develop (1) a better scientific basis for discussion of adequacy of mineral resources; (2) better data on factors involved in mineral supply that should be in public policy analysis and decisionmaking; (3) better ways to communicate to policymakers and the public the dynamic nature of mineral supply, thus putting the prospect of "running out" in the proper context; and (4) methods to incorporate recycling and reuse into the concept of sustainability (National Research Council, Committee on Earth Resources, 1996).

There also is an enormous need for science input in the development of laws and regulations regarding the environmental impacts of mining. There is a high cost to society when the government enforces laws and subsequent regulations that make no sense to people (Wilson and Anderson, 1997). Here, geologists can provide information to policymakers and the public about (1) the environmental consequences of mining, including the costs of environmental compliance and the effects of using best practices in the environmental management of mining; (2) improved environmental management and restoration ecology associated with mining and mineral processing; and (3) how mining affects the environment and how environmental degradation can be minimized (National Research Council, Committee on Earth Resources, 1996).
Finally, the input of science in the review and adaptation phase cannot be underestimated. Environmental regulation will not adapt quickly to scientific advances unless scientists themselves remain involved in the policy cycle. However, given the engagement of scientists and a societal willingness to respond to new information and changing preferences, adaptive management is possible (Lee, 1993).

\section{References Cited}

Arrow, Kenneth, Bolin, Bert, Costanza, Robert, Dasgupta, Partha, Folke, Carl, Hollins, C.S., Jansson, Bengt-Owe, Levin, Simon, Maler, Karl-Goran, Perrings, Charles, and Pimentel, David, 1995, Economic growth, carrying capacity, and the environment: Science, v. 268, no. 5210, p. 520-521.

Berger, A.R., and Iams, W.J., 1996, Geoindicators-Assessing rapid environmental changes in earth systems: Rotterdam, A.A. Balkema, 466 p.

Brundtland, G.H., 1987, Our common future-Report of the World Commission on Environment and Development: Oxford, U.K., Oxford University Press, 400 p.

Granholm, Heikki, Vähänen, Tiina, and Sahlberg, Sari, 1996, Background document-Intergovernmental Seminar on Criteria and Indicators for Sustainable Forest Management: Helsinki, Finland Ministry of Agriculture and Forestry, $131 \mathrm{p}$.

Hughes, S.P., 1995, Two tools for integrating geology into ecosystem studies: Environmental Geology, v. 26, p. 246-251.

Lee, Kai N., 1993, Compass and gyroscope; Integrating science and politics for the environment: Washington, D.C., Island Press, 243 p.

Lubchenco, Jane, 1995, The role of science in formulating a biodiversity strategy, in Science and Biodiversity Policy, a supplement to BioScience: Washington, D.C., American Institute of Biological Sciences, p. S7-S9.

Lubchenco, Jane, 1998, Entering the century of the environment-A new social contract for science: Science, v. 279, no. 5350 , p. 491-497.

National Research Council, Committee on Earth Resources, 1996, Mineral resources and sustainability-Challenges for earth scientists: Washington, D.C., National Academy Press, 26 p.

Shields, D.J., 1998, Nonrenewable resources in economic, social, and environmental sustainability: Nonrenewable Resources, v. 7, no. 4, p. 251-262.

Wilson, E.O., 1998, Consilience-The unity of knowledge: New York, Alfred A. Knopf, 332 p.

Wilson, J.D., and Anderson, J.W., 1997, What the science says-How we use it and abuse it to make health and environmental policy: Resources, v. 128, p. 5-8. 


\title{
Environmental Planning Issues and a Conceptual Global Assessment of Undiscovered Nonfuel Mineral Resources
}

\author{
By Joseph A. Briskey, ${ }^{1}$ Klaus J. Schulz, ${ }^{1}$ John P. Mosesso, ${ }^{1}$ Lief R. Horwitz, ${ }^{2}$ and Charles G. Cunningham ${ }^{1}$
}

\section{Introduction}

Global demand for materials, including nonfuel mineral resources, will continue to increase fig. 1) for the foreseeable future because of the continuing growth of global population and efforts to improve living standards worldwide. About 89 percent of these materials, as reported by Matos and Wagner (1998), consist of nonfuel mineral resources. Copper consumption in China exemplifies the growing global consumption of nonfuel mineral resources (fig. 2). If China grows and develops over the next 25 years at a rate like that of South Korea in the past 25 years, then China could consume more copper in 2025 than was produced in the world in 1995 (Men-

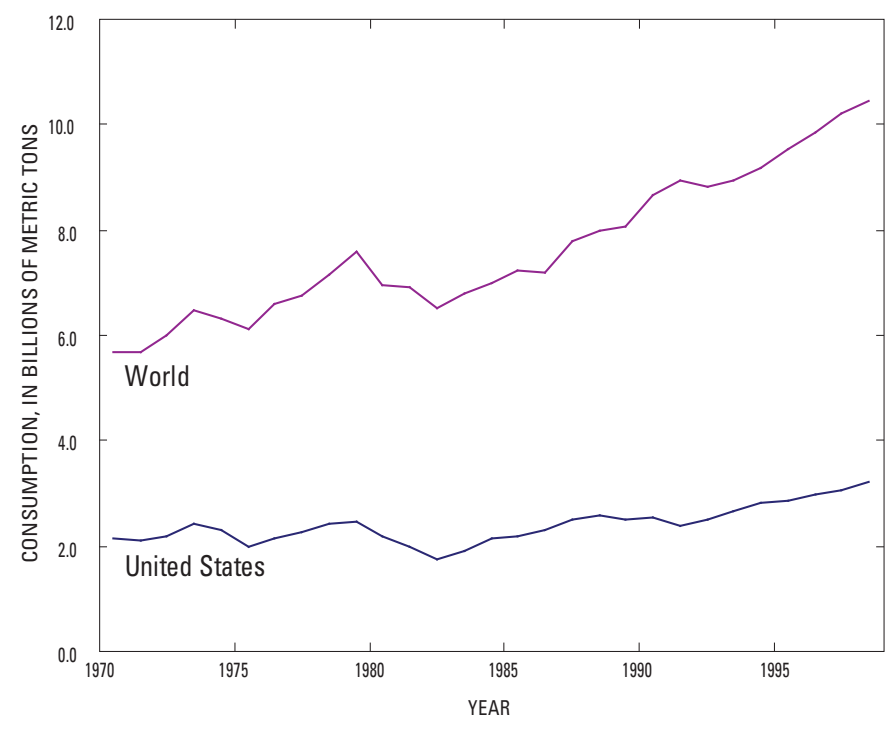

Figure 1. Graph of world and U.S. consumption (use) of nonfood, nonfuel, and nonrenewable materials, including construction materials, industrial minerals, primary and recycled metals, nonrenewable organic materials, primary and recycled paper, wood products, and material derived from agriculture (Matos and Wagner, 1998; Brown and others, 2000, p. 28; Grecia Matos, U.S. Geological Survey, written commun., 2002).

${ }^{1}$ U.S. Geological Survey, 954 National Center, 12201 Sunrise Valley Drive, Reston, VA 20192-0002, U.S.A. (e-mail: jbriskey@usgs.gov).

${ }^{2}$ U.S. Geological Survey, 909 1st Avenue, Seattle, WA 98104-1055, U.S.A. zie and others, 2003, 2005). Moreover, "industrialization is central to economic development and improved prospects for human well-being ... . A substantial share of industrial growth in developing countries revolves around the transformation of raw materials into industrial materials" (World Resources Institute and others, 1998, p. 51).

No global shortages of nonfuel mineral resources are expected in the near future. However, society's ability to meet the continuing and growing demand for minerals requires sustained exploration for, and development of, new mineral deposits. At the same time, mineral exploration and development increasingly are constrained by a variety of real and perceived factors that have begun limiting the availability of mineral resources. Among these factors are (1) other competing land uses; (2) limited local economic and social benefits of mining, especially to populations in developing countries; (3) wasteful or inefficient use of mineral materials; and (4) adverse environmental effects of mining, together with distrust of those who promise that such effects can be prevented or



Figure 2. Graph of copper consumption in China (in millions of metric tons per year). If China grows and develops in the next 25 years as South Korea has in the past 25 years, then China could consume more copper in 2025 than the whole world used in 1995 (Menzie and others, 2003, 2005). 
effectively and permanently mitigated. In particular, mineral development is affected especially by growing concerns about possible environmental degradation associated with mineral exploration and production.

Unanticipated, and therefore unplanned, mineral exploration and development, especially in sensitive ecosystems and other environments, can add to the ongoing fragmentation and destruction of habitats required for the long-term maintenance of key plant and animal communities and to an overall reduction in ecosystem health. Increasingly, human populations and their activities "are disturbing species and their habitats, disrupting natural ecological processes, and even changing climate patterns on a global scale" (President's Committee of Advisors on Science and Technology, 1998). "We are modifying physical, chemical, and biological systems in new ways, at faster rates, and over larger spatial scales than ever recorded on earth" (Lubchenco, 1998, p. 492). "If current trends continue, humanity will dramatically alter virtually all of Earth's remaining natural ecosystems within a few decades" (Daily and others, 1997, p. 3). One measure of these concerns is shown by the extent to which domesticated land has replaced much of the Earth's original land cover, as illustrated in figure 3. Another measure is the decline of Earth's forests, as shown in figures 4 and 5 .

What is the one thing the average person is most likely to believe about mining?
- Is it that we are running out of nonfuel minerals with some dire consequence? Probably not. There is no global shortage of nonfuel minerals at present.

- Is it that mining is an important part of the global economy? Probably not. By some measures, the mining sector appears to be a small player. Pierre Lassonde, Chief Executive Officer (CEO) of Franco-Nevada Mining, recently pointed out (Kral, 2000, p. 46) that "adding together all of the global gold, copper, aluminum, nickel, zinc, and diamond producers represents a business with a total market capitalization of about US $\$ 200$ billion. Some individual companies like Microsoft and Cisco Systems are valued at more than US $\$ 400$ billion. Rio Tinto, the biggest mining company in the world, has a market capitalization of about US\$25 billion."

- Is it that a number of mining companies are making major new advances in mitigating, remediating, and preventing much of the environmental impact of mining? No, probably not.

- Is it that mining causes environmental and sometimes social disasters? Probably yes.

The negative image of mining has reached the point where leaders of some major mining companies are beginning to recognize and promote the necessity and benefits to

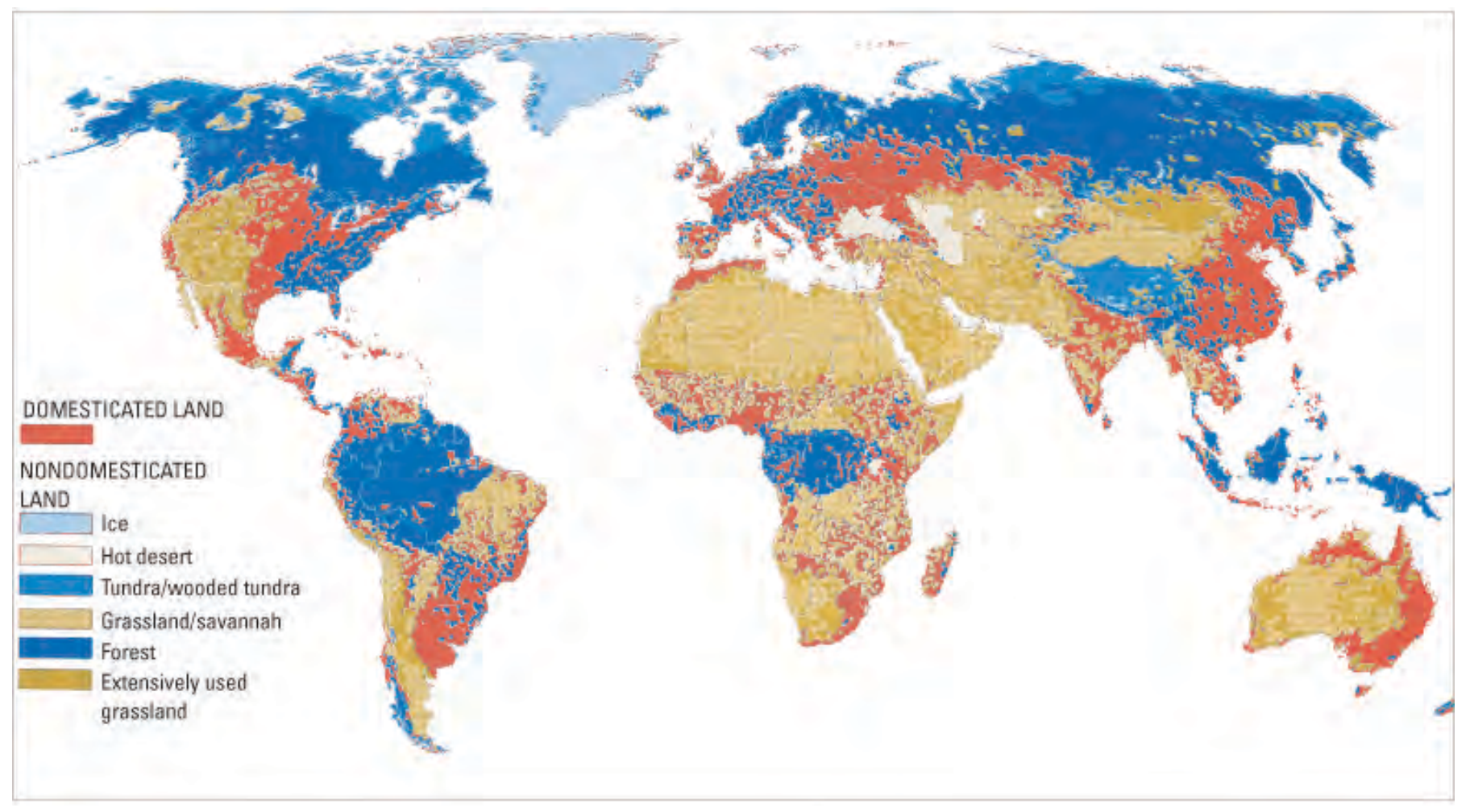

Figure 3. Map showing global distribution of domesticated and nondomesticated land areas. "Domesticated land has replaced much of Earth's original land cover. Over time, humans have converted forests and natural grasslands to croplands, pasture, urban and suburban areas, and industrial zones" (World Resources Institute and others, 1998, p. 222). Map from World Resources Institute and others (1998); reproduced by permission of the World Resources Institute. Red stippling along some continental margins, mainly in the Northern Hemisphere, is an artifact of computer colorization. 


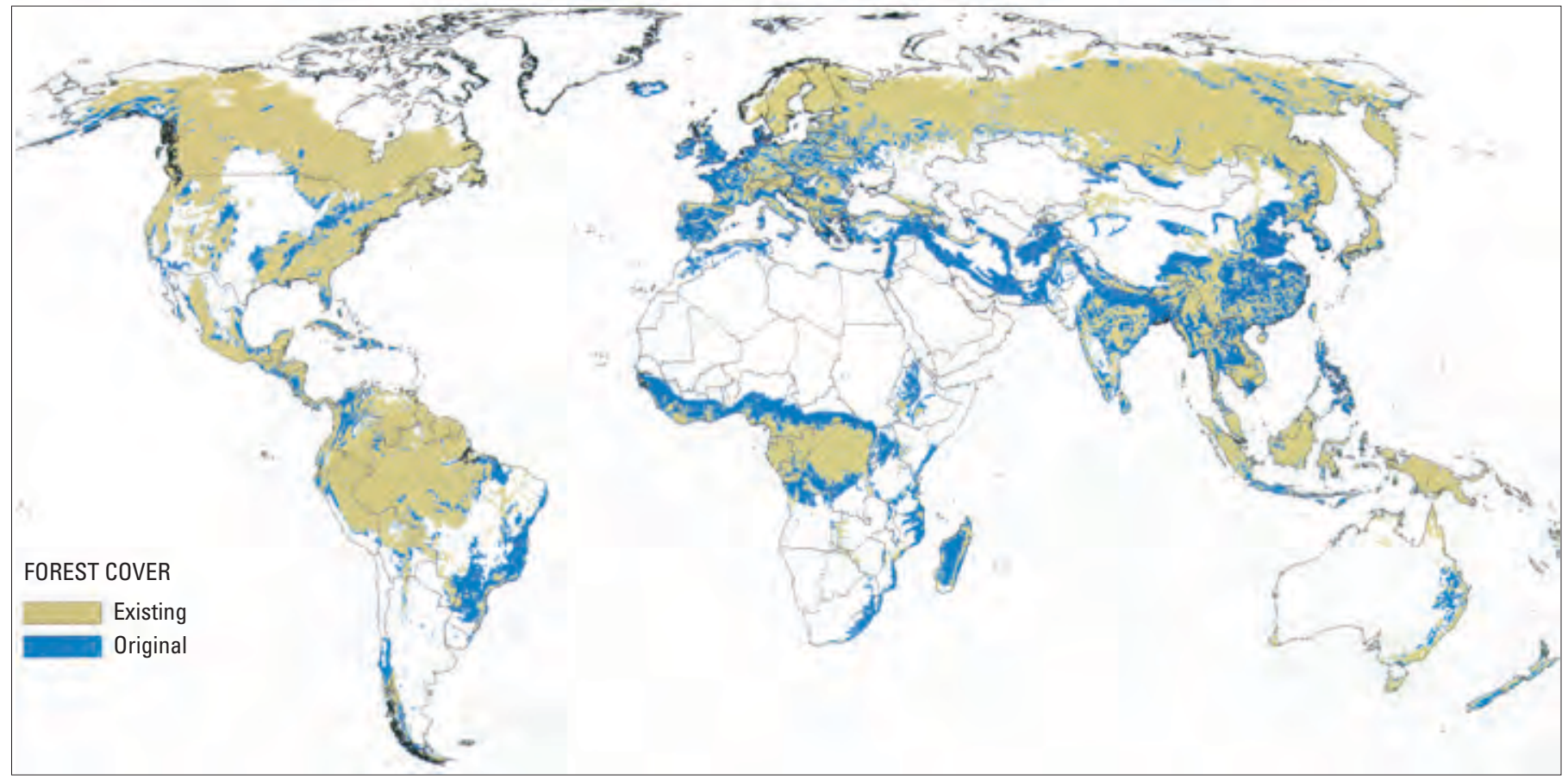

Figure 4. Map showing decline in forest cover around the world. Over the last 8,000 years, the world's forests have shrunk by nearly half with the clearing of boreal and temperate forests in the early centuries, followed today by high deforestation rates in the tropical forests. Map from World Resources Institute and others (1998); reproduced by permission of the World Resources Institute.

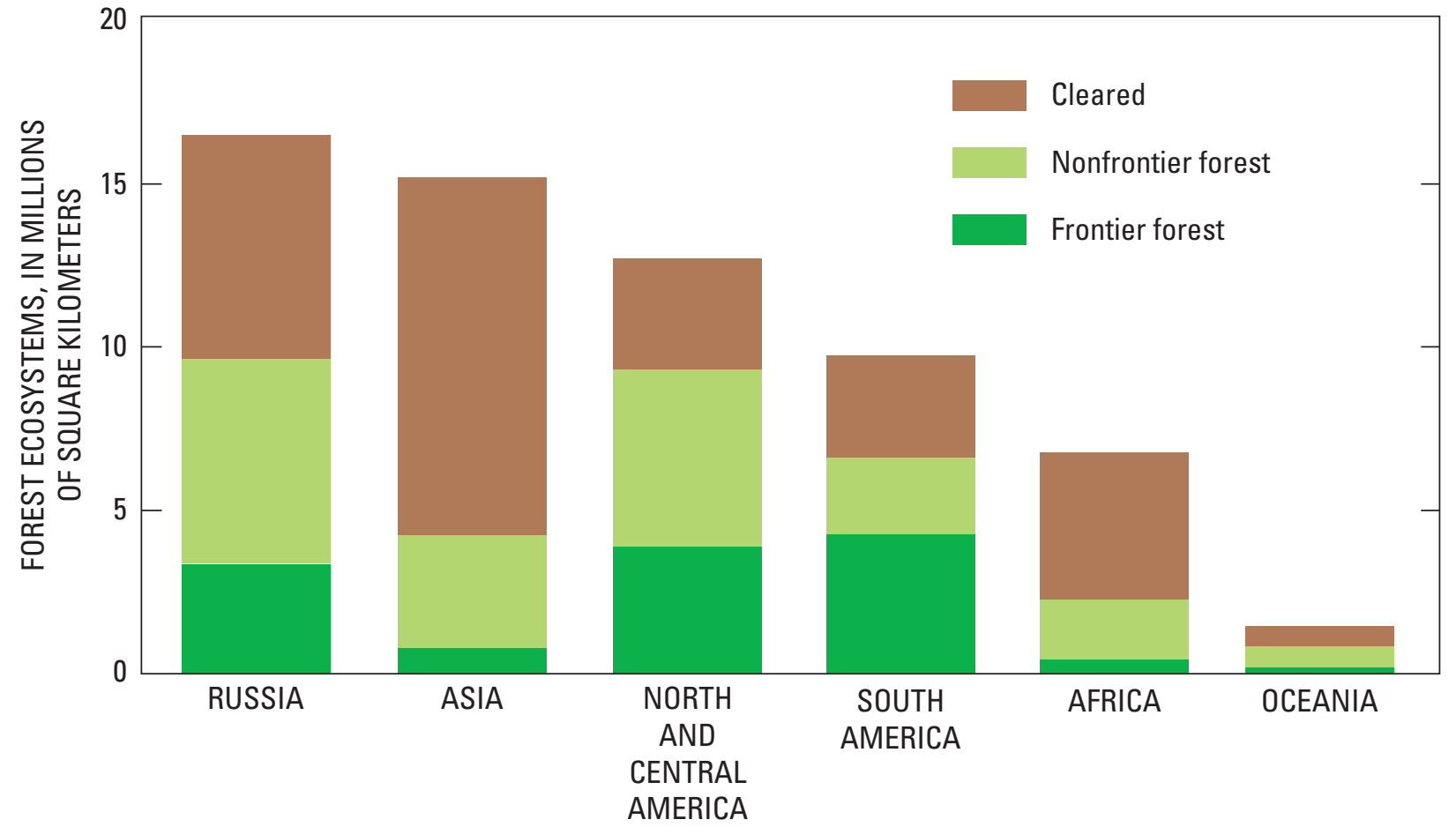

Figure 5. Graph showing the decline of global forest ecosystems. "Just one fifth of the Earth's original forest remains in large, relatively natural ecosystems — what are known as frontier forests” (World Resources Institute and others, 1998, p. 187). Graph from World Resources Institute and others (1998); reproduced by permission of the World Resources Institute. 
the mining industry of admitting to past shortcomings and embracing environmental and social values and responsibilities in the cause of sustainable development. Patrick James, CEO of Rio Algom Ltd, was among the first voices (James, 1999) to urge that mining, like other forms of development, must contribute not only economic value to stakeholders but also environmental and social value. He emphasized that, "as an industry, we will gradually find ourselves unable to operate anywhere if we are incapable, or reluctant to effectively combine economic, environmental, and social goals everywhere we do business" (James, 1999, p. 90).

Sir Robert Wilson, Executive Chairman of Rio Tinto, in summarizing the major challenges facing the mining industry (O'Neil and others, 2000), asserted that mining finds itself in increasing disfavor in the United States, Canada, Europe, and many other parts of the world. Industry's traditional responses-to say that criticisms are ill founded, to remind critics that they depend on mineral products, and to engage in education, advertising, and public relations campaigns - have all been to little or no avail. Mining's reputation continues to deteriorate. Sir Robert urged the mining industry to change the nature of its dialog with stakeholders, especially with nongovernmental organizations. He supported a new global mining initiative to seek independent analysis of issues that will determine the future of mining, and he recognized that these issues are social and environmental as well as economic (O'Neil and others, 2000). The global mineral resource assessment discussed herein is an important component of such an analysis.

\section{Global Land and Resource Planning}

Informed planning and decisions concerning biological sustainability and resource development require a long-term perspective and an integrated approach to land use, resource, and environmental management worldwide. This approach, in turn, requires unbiased information on the global distribution of identified resources and, especially, of undiscovered resources; the economic, social, and political factors influencing their development; and the environmental consequences of, and requirements for, their use.

The world's current approach to land and mineral resource planning appears to be piecemeal and haphazard rather than comprehensive and integrated. In separate actions by diverse governmental and nongovernmental organizations over the years, mineral development has been prohibited or has been proposed to become prohibited, in large parts of the world, including Antarctica; the Arctic Islands; numerous national and international parks, wildlife preserves, and wilderness areas; tropical rainforests; temperate old-growth forests; a variety of alpine and desert regions; and many other sensitive or endangered habitats, ecosystems, scenic vistas, and roadless areas. Concomitantly, and ironically, as countries grow, develop, and use more mineral products, mining can become increasingly unwelcome at home. Sources of future mineral supply rapidly are becoming more restricted, while national and international governmental and nongovernmental organizations appear to be devoting little effort to identifying and assuring access to areas of future mineral supply that might best sustain the environmental effects of mining.

The economies of highly industrialized societies use tremendous amounts of materials per capita -45 to 85 metric tons per person per year in one study cited by the World Resources Institute and others (1998). Further, the use of these materials requires moving or processing huge amounts of natural resources not actually used in the final product. As much as 50 to 75 percent of this hidden materials flow, and associated environmental effects, often takes place in other countries (World Resources Institute and others, 1998). Highly industrialized societies can help plan global mineral development and ecosystem sustainability by helping initiate and conduct an international assessment of the probable regional locations, amounts, and types of the world's remaining undiscovered nonfuel mineral resources in relation to sensitive ecosystems and habitats. With such information, mineral development could be encouraged in those areas most able to sustain the environmental effects of mining and mineral processing and discouraged or carefully managed in especially sensitive areas. If the choices for future supplies of some minerals prove to be limited mostly to areas where maintaining ecosystem health and sustainability may be difficult, then international cooperation could be justified and accelerated to (1) optimize materials flows and recycling of materials derived from these minerals, (2) promote research into alternative materials and technology to replace these minerals or minimize their use, and (3) develop advanced new mitigation techniques for exploration, mining, and processing for these minerals. "An electorate that does not understand the natural world or the nature of the tradeoffs that must be made in managing it wisely and sustainably cannot make informed decisions" (President's Committee of Advisors on Science and Technology, 1998, p. xviii).

\section{A Global Mineral Resource Assessment}

In response to growing concern about the global sustainability of nonfuel mineral production and environmental quality, and the concomitant increase in demand for global mineral resource information, the U.S. Geological Survey (USGS) is joining with international collaborators to identify the regional locations and estimate the probable amounts of the world's undiscovered nonfuel mineral resources at a scale of 1:1 million on land in conventional deposit types to a depth of 1 kilometer. The assessment will begin with copper, platinum-group metals, and potash. Potash will be assessed to a depth of 2 kilometers.

Teams of experts following the USGS three-part protocol for mineral resource assessment (Singer, this volume) will delineate areas where geology permits the occurrence of a given type of undiscovered mineral deposit. The teams then will make subjective, probabilistic estimates of the numbers 


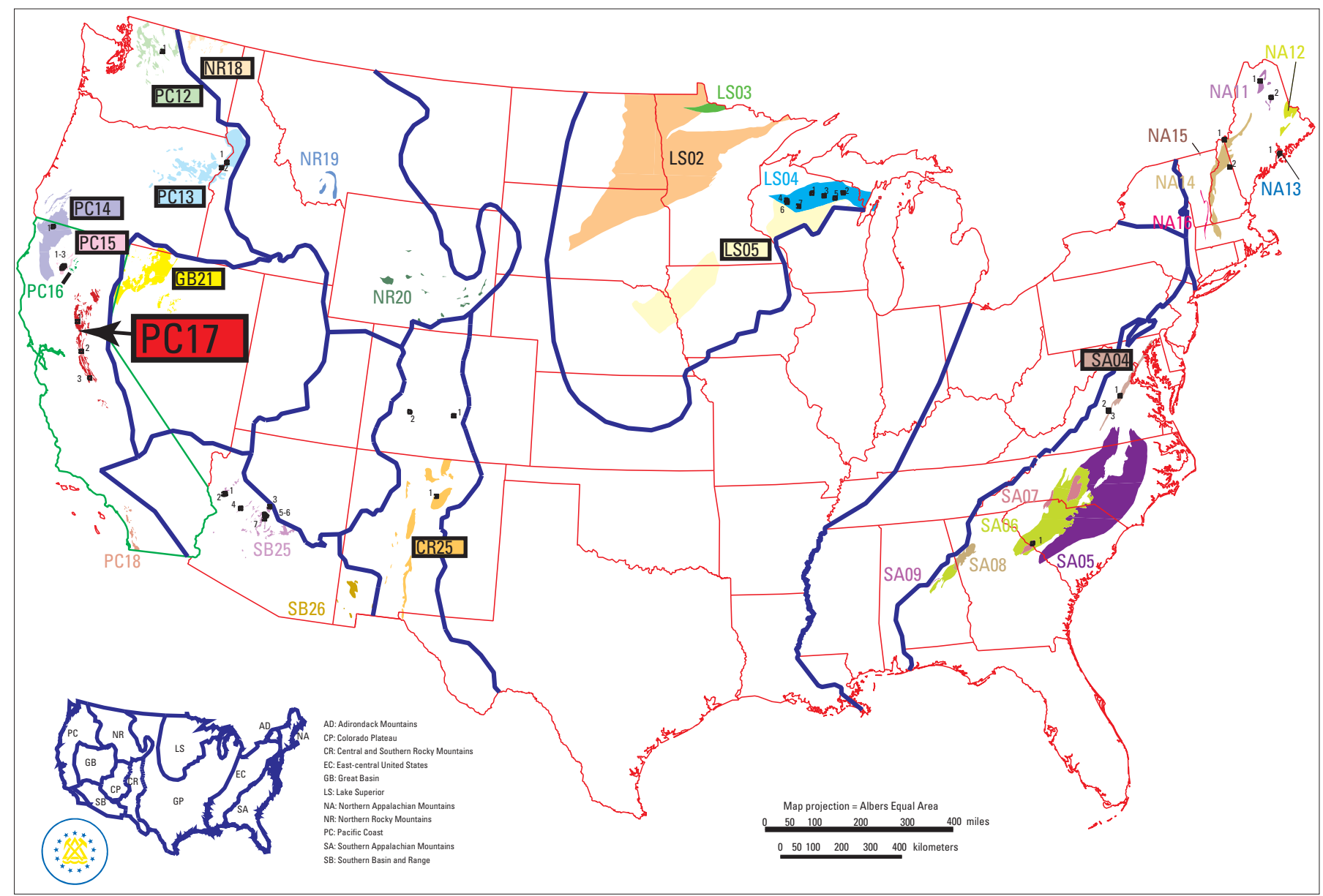

Figure 6. Tract map for kuroko massive sulfide deposits in the conterminous United States showing areas where the geology is permissive for the occurrence of this type of deposit. Favorable areas are shown by different colors and labels. From Luddington and others (1996). Estimates of undiscovered deposits and metal resources in tract PC-17 are shown in figures 7 and 8.

of undiscovered deposits they believe to exist in each area. To help interpret results such as these, a computer program called MARK3 (Root and others, 1992; Duval, 2001) was developed. The program uses Monte Carlo simulation to combine the estimated numbers of deposits with appropriate grade and tonnage models to produce a probability distribution of the quantities of contained metals or other mineral commodities. The net present value of the undiscovered resources will be analyzed by using new economic filters under development for addition to MARK3 (J.S. Duval, USGS, oral commun., 2000).

The three-part assessment protocol was used by the USGS to produce the first assessment of conventional undiscovered deposits of gold, silver, copper, lead, and zinc in the United States (Ludington and others, 1996). Illustrative examples of products from this national assessment are shown in figures 6, 7, and 8 for undiscovered kuroko massive sulfide deposits. At a minimum, three types of data are needed for an assessment of undiscovered mineral resources: (1) maps showing the locations, sizes, and geologic types of significant known mineral deposits and occurrences; (2) geologic maps compiled to show rocks permissive for the occurrence of undiscovered mineral deposits by type; and (3) as much information as possible about mineral exploration history.

\section{Conceptual Assessment Products and Some Potential Environmental Planning Issues}

Assessments of undiscovered mineral resources can be of great importance in helping society recognize, discuss, manage, and minimize or prevent environmental impacts associated with mineral exploration and mining, while maintaining or expanding mineral supplies. This section briefly describes a few of the potential environmental planning issues that might be identified and addressed in part by a global mineral resource assessment. A hypothetical example of such an assessment is illustrated conceptually in figure 9 and is intended only as a starting point for discussion of such issues.

\section{Biodiversity and Sensitive Habitats}

With reference to figure 9, what are some examples of the potential consequences of mineral development that might be considered with respect to biodiversity and sensitive habitats? 


\section{Estimated Undiscovered Deposits}

There is a $90 \%$ or greater chance of 2 or more deposits. There is a $50 \%$ or greater chance of 13 or more deposits. There is a $10 \%$ or greater chance of 25 or more deposits. There is a $5 \%$ or greater chance of 25 or more deposits. There is a $1 \%$ or greater chance of 25 or more deposits.

\section{Estimated amounts of contained metal and mineralized rock, in metric tons}

\begin{tabular}{rrrrrrrr}
\multicolumn{1}{r}{ Quantile } & \multicolumn{1}{c}{$\mathrm{Cu}$} & $\mathrm{Au}$ & $\mathrm{Zn}$ & $\mathrm{Ag}$ & $\mathrm{Pb}$ & \multicolumn{1}{c}{ Rock } \\
\cline { 2 - 7 } & 700 & 0 & 0 & 0 & 0 & 97,000 \\
0.95 & 12,000 & 0 & 12,000 & 18 & 0 & 690,000 \\
0.50 & 140,000 & 16 & 260,000 & 710 & 46,000 & $8,500,000$ \\
0.10 & 310,000 & 45 & 815,000 & 2,700 & 200,000 & $19,000,000$ \\
0.05 & 360,000 & 55 & 990,000 & 3,400 & 250,000 & $22,000,000$ \\
Mean & 160,000 & 20 & 340,000 & 1,100 & 76,000 & $9,200,000$ \\
Probability of mean & 0.46 & 0.43 & 0.40 & 0.38 & 0.38 & 0.46 \\
Probability of zero & 0.04 & 0.06 & 0.06 & 0.05 & 0.10 & 0.04 \\
\cline { 3 - 7 } & & & & & &
\end{tabular}

Figure 7. Chart summarizing probabilistic subjective estimates by experts of numbers of undiscovered kuroko massive sulfide deposits in tract PC-17, California (see fig. 6). From Ludington and others (1996). Corresponding amounts of contained metal and mineralized rock were estimated by Monte Carlo simulation.

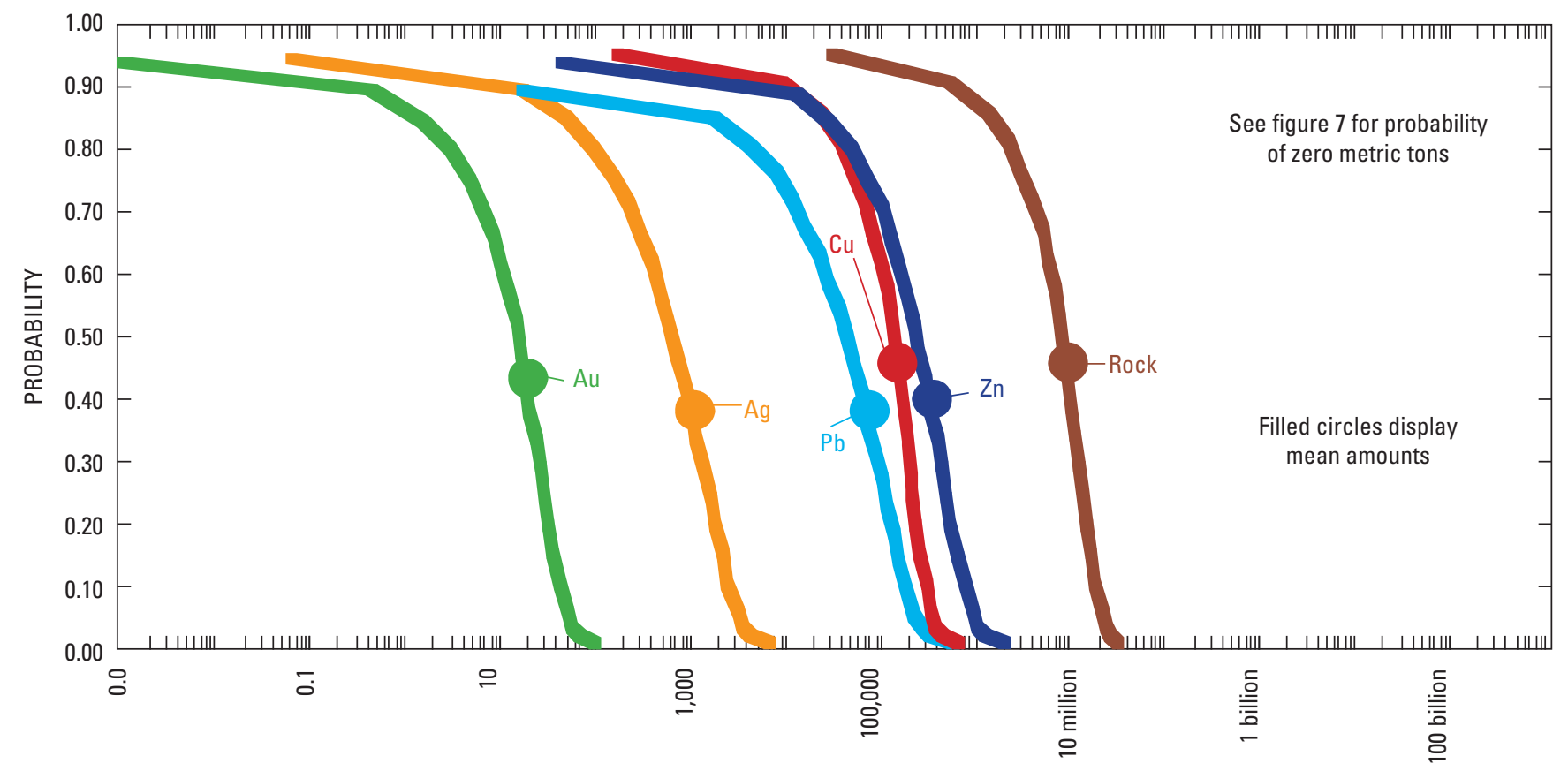

Figure 8. Graph showing cumulative distributions of contained metal and mineralized rock (in metric tons) in undiscovered kuroko massive sulfide deposits estimated in tract PC-17, California (see figs. 6 and 7). From Ludington and others (1996). 


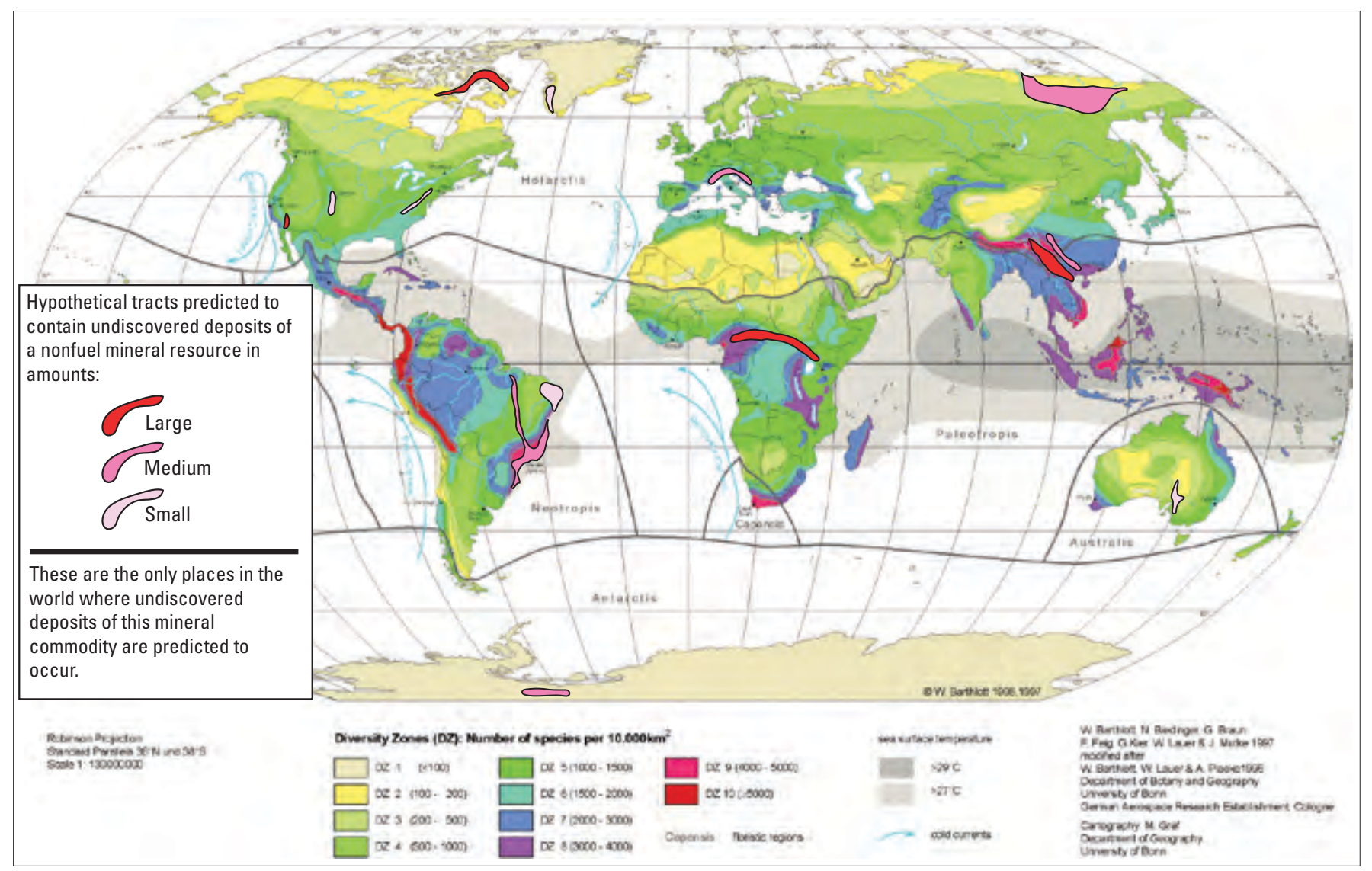

Figure 9. A conceptual global assessment in which tracts predicted to contain deposits of a generic undiscovered nonfuel mineral resource are plotted on a base map showing global biodiversity of vascular plant species represented by the numbers of vascular plants per 10,000 square kilometers. The base map is available online at http://www.biologie.uni-hamburg.de/b-online/e56/56b.htm (accessed June 15, 2005) and is modified from Barthlott and others (1999); reproduced by permission of the Finnish Zoological and Botanical Publishing Board.

- In the severe climates of high latitudes, fragile ecosystems disturbed by mining and associated infrastructure development are slow to recover (for example, see Forbes, 1997; Oksanen and Virtanen, 1997; Rapport and others, 1997). However, biodiversity is relatively low (fig. 9), and impacts on biodiversity potentially would be correspondingly low. Moreover, people whose livelihoods depend on mining are less likely to continue living in many of these harsh, isolated areas after mining and mining-related jobs end.

- Hypothetical undiscovered mineral resources that might occur as shown in Southeast Asia (fig. 9) would be in what presently is habitat for endangered tigers.

- Discovery and development of estimated undiscovered kuroko massive sulfide deposits in the foothills of central California (fig. 6) have the potential to adversely affect endangered species habitat and vulnerable plant communities that have been delineated by the USGS GAP Analysis Program (figs. 10 and 11).

- World tin resources in differing geologic settings have a high spatial correlation (Cunningham and others, this volume) with the distribution of biodiversity "hotspots" as defined by Conservation International (Mittermeier and others, 1999).

\section{Land Use}

Habitat disturbance, fragmentation, and destruction resulting from infrastructure development are principal causes of species extinction. Ideally, mineral exploration programs would limit land disturbance globally by focusing mainly on areas assessed to have a high probability of containing an economic deposit (Sweeting and Clark, 2000).

Mineral exploration and development also might be encouraged where areas having a high probability of containing an economic deposit coincide with areas of existing infrastructure. Consequently, maps and other information showing the types and density of infrastructure development and associated land uses would be important ancillary databases, in combination with a global mineral resource assessment.

Large parts of the world are restricted or closed to mineral discovery and development. An example for the State of Idaho in the United States is shown in figure 12. All of the colored areas in figure 12 once were open to mineral exploration and development. By 1988, only the green areas were open. Similar maps for other parts of the world, together with a global assessment of undiscovered mineral resources, are critical for identification and analysis of remaining sources of future mineral supply, as additional areas are considered for closure. 


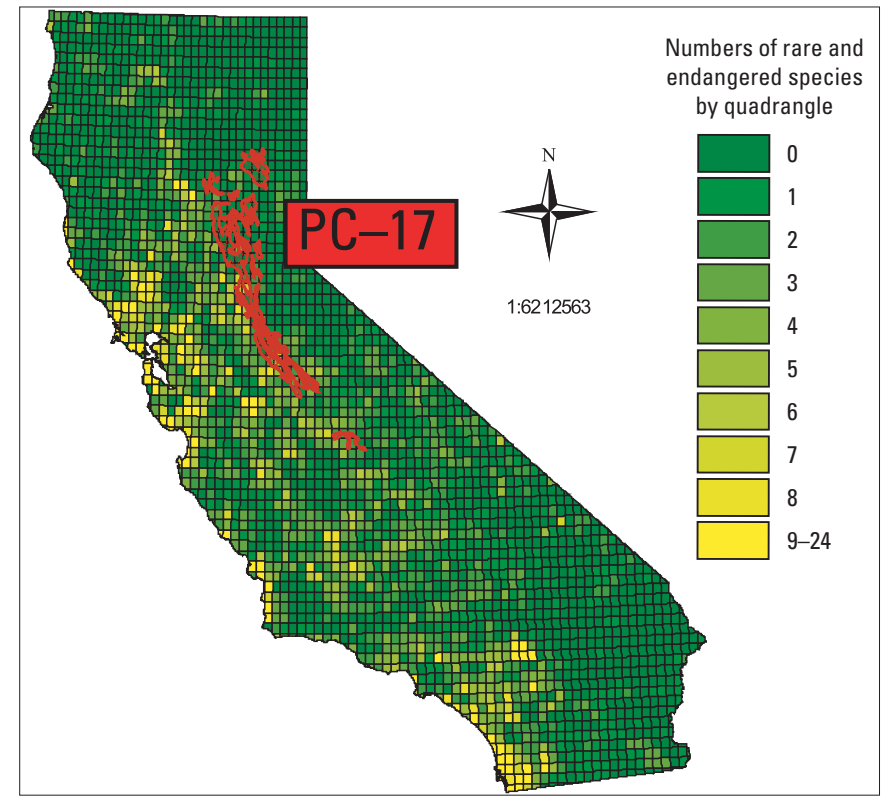

Figure 10. Map showing mineral resource tract PC-17 (fig. 6) in relation to numbers of rare and endangered species in California, U.S.A. (Davis and others, 1998).



Figure 11. Map showing mineral resource tract PC-17 (fig. 6 ) in relation to vulnerable plant communities by quadrangle in California, U.S.A. (Davis and others, 1998).

\section{Water Resources and Quality}

The boundaries of major drainage basins commonly are international, as illustrated in figure 13. A global mineral resource assessment can help identify future mineral resources in regions having adequate water supplies and hydrologic and geologic characteristics best able to maintain water quantity and quality during and (or) after mineral development. Such an assessment also has the potential to identify types of undiscovered mineral resources and climates least likely in combination to cause serious environmental challenges.

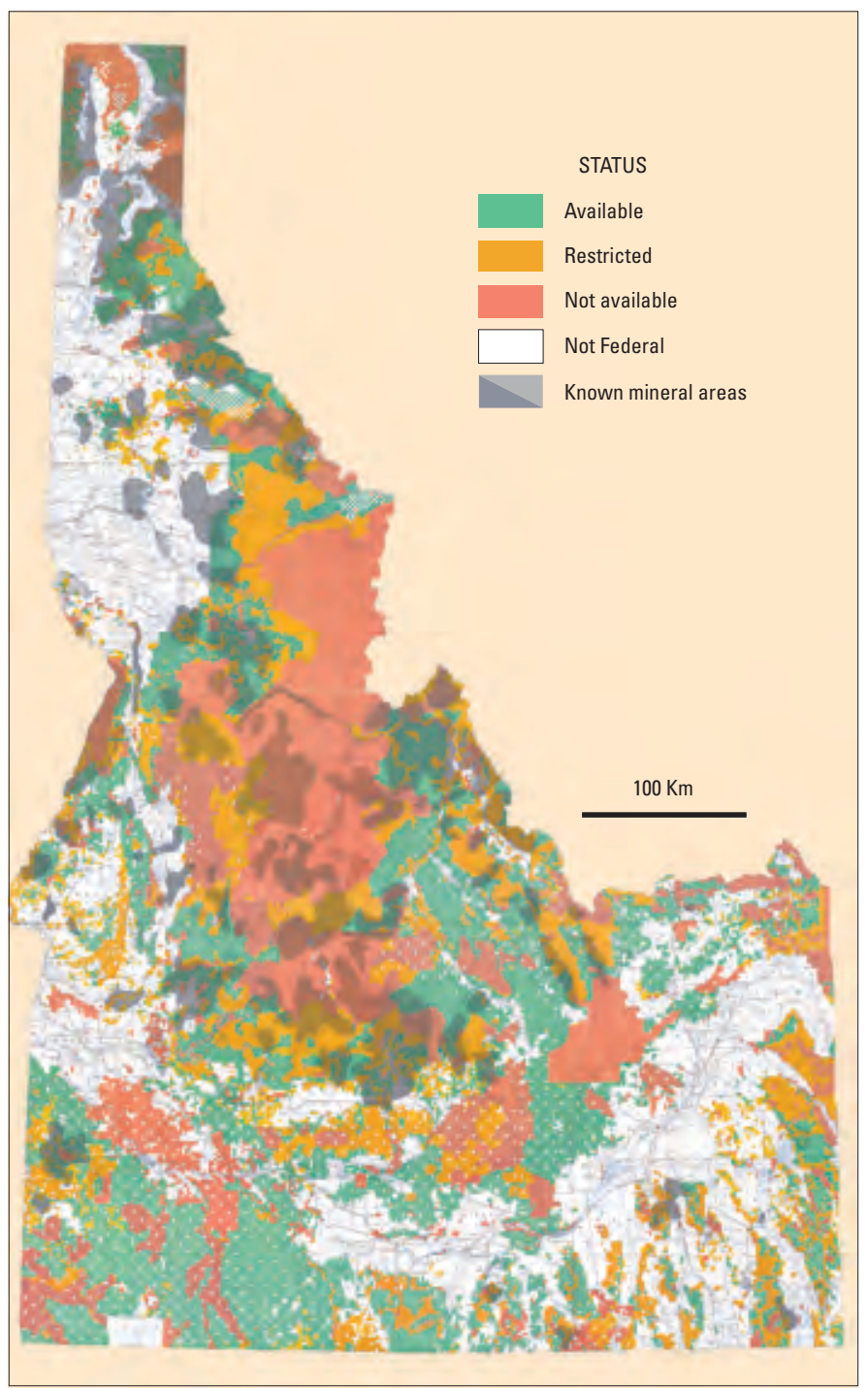

Figure 12. Map showing 1988 status of availability of Federal land for some locatable minerals (includes most metallic and nonmetallic minerals) in Idaho, U.S.A. (Hyndman and others, 1990).

\section{In the Final Analysis}

Individual countries are becoming less free to develop their natural resources at the expense, real or perceived, of social and, especially, environmental quality; environmental concerns include clean air and water, protection of endangered species, biodiversity, global climate, and the ozone layer. National decisions about trade, including those made in the United States, often must follow laws requiring that associated environmental consequences be considered. Global environmental and trade agreements can be linked in ways restricting natural resource development. International funding agencies like the World Bank and the United Nations may withhold funding from projects seen as potential threats to environmental quality. Boycotts by consumers and national governments have been used effectively to influence, restrict, and even stop natural resource development. The charter for the World Trade 


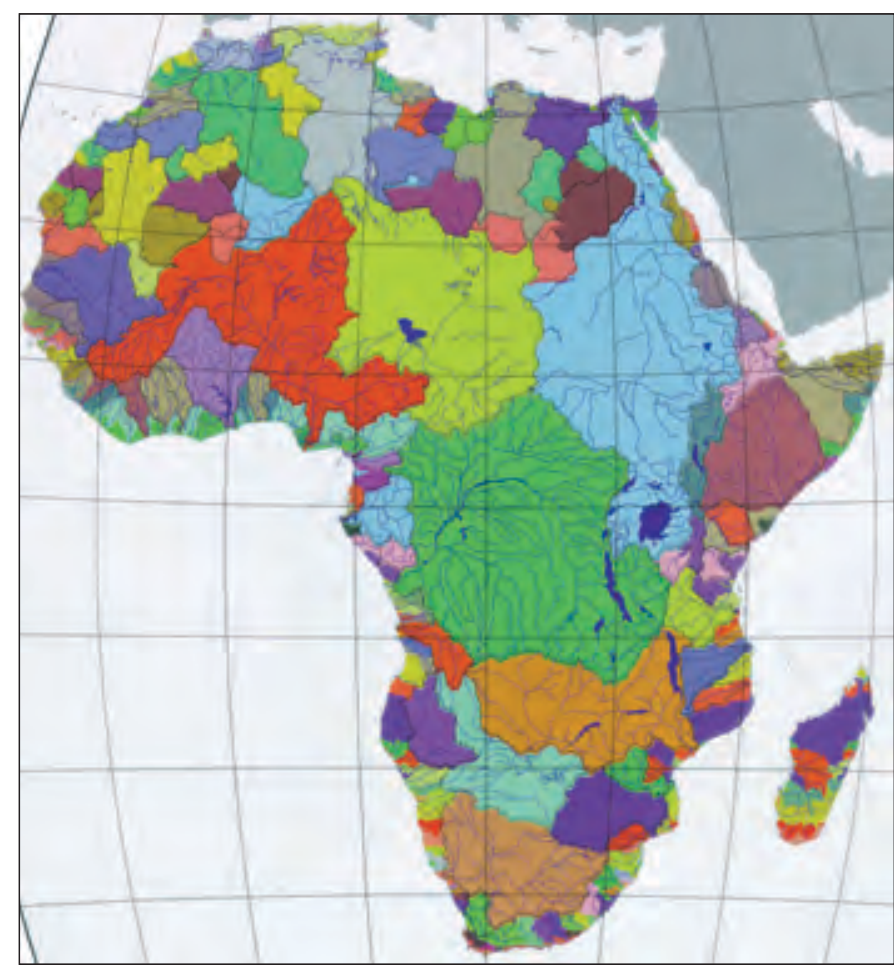

Figure 13. Map showing major drainage basins of Africa (Singh and others, 1997). The boundaries of drainage basins are not related to country borders (not shown).

Organization allows environmentalist import bans so long as the reason for them is not disguised protectionism.

Free trade no longer includes a number of resources such as whales, ivory, seals, furs, eagle feathers, and other parts of endangered species, to name only a few. It has become difficult to market tuna and shrimp unless they are caught in ways that protect dolphins and turtles, respectively. International pressure to protect the environment in all its aspects will only grow with time. Concomitantly, without the kinds of information that could be provided by a global mineral resource assessment, the world could unknowingly foreclose future mineral supply options that might otherwise have resulted in reduced environmental degradation, improved economic benefits, and enhanced social values.

\section{Acknowledgments}

The authors are grateful for improvements to the manuscript suggested by their USGS colleagues Jane M. Hammarstrom and David M. Sutphin.

\section{References Cited}

Barthlott, W., Biedinger, N., Braun, G., Feig, F., Kier, G., and Mutke, J., 1999, Terminological and methodological aspects of the mapping and analysis of the global biodiversity: Acta Botanica Fennica, v. 162, p. 103-110.
Brown, W.M., III, Matos, G.R., and Sullivan, D.E., comps., 2000, Materials and energy flows in the earth science century-A summary of a workshop held by the USGS in November 1998: U.S. Geological Survey Circular 1194, 71 p. (Also available online at http://pubs.usgs.gov/circ/2000/ c1194/.)

Daily, G.C., Alexander, Susan, Ehrlich, P.R., Goulder, Larry, Lubchenco, Jane, Matson P.A., Mooney, H.A., Postel, Sandra, Schneider, S.H., Tilman, David, and Woodwell, G.M., 1997, Ecosystem services-Benefits supplied to human societies by natural ecosystems: Issues in Ecology, no. 2, 16 p. (Also available online at http://www.esa.org/science/ Issues/FileEnglish/issue2.pdf.)

Davis, F.W., Stoms, D.M., Hollander, A.D., Thomas, K.A., Stine, P.A., Odion, Dennis, Borchert, M.I., Thorne, J.H., Gray, M.V., Walker, R.E., Warner, Katherine, and Graae, Josh, 1998, The California GAP analysis project reportAn interactive atlas of terrestrial biodiversity and land management: Santa Barbara, Calif., University of California, one CD-ROM. (Also available online at http://www. biogeog.ucsb.edu/projects/gap/gap_rep.html.)

Duval, J.S., 2001, A Microsoft Windows version of the MARK3 Monte Carlo resource simulator: U.S. Geological Survey Open-File Report 00-415, one CD-ROM. (Also available online at http://pubs.usgs.gov/of/2000/of00-415/.)

Forbes, B.C., 1997, Anthropogenic tundra disturbance in Canada and Russia-Patterns of response within and among different ecosystems, in Crawford, R.M.M., ed., Disturbance and recovery in Arctic lands-An ecological perspective: Dordrecht, The Netherlands, Kluwer Academic Publishers, p. 365-379.

Hyndman, P.C., Ridenour, James, Crandell, W.D., and Rumsey, C.M., 1990, Availability of federally owned minerals for exploration and development in Western States-Idaho, 1988: Washington, D.C., U.S. Bureau of Mines Special Publication, $56 \mathrm{p}$.

James, P.M., 1999, The miner and sustainable development: Mining Engineering, v. 51, no. 6, p. 89-92.

Kral, Steve, 2000, CIM and PDAC—-South African goldMining in a dot.com world: Mining Engineering, v. 52, no. 7, p. 43-49.

Lubchenco, Jane, 1998, Entering the century of the environment-A new social contract for science: Science, v. 279, no. 5350, p. 491-497.

Ludington, Steve, Cox, Dennis, and McCammon, Richard, eds., 1996, Data base for a national mineral-resource assessment of undiscovered deposits of gold, silver, copper, lead, and zinc in the conterminous United States: U.S. Geological Survey Open-File Report 96-96, one CD-ROM. (Also available online at http://pubs.usgs.gov/of/1996/of96-096/.) 
Matos, Grecia, and Wagner, Lorie, 1998, Consumption of materials in the United States, 1900-1995: Annual Review of Energy and the Environment, v. 23, p. 107-122.

Menzie, W.D., DeYoung, J.H., Jr., and Steblez, W.G., 2003, Some implications of changing patterns of mineral consumption: U.S. Geological Survey Open-File Report 03-382, 35 p. (Also available online at http://pubs.usgs. gov/of/2003/of03-382/.)

Menzie, W.D., Singer, D.A., and DeYoung, J.H., Jr., 2005, Mineral resources and consumption in the 21 st century, chap. 2 of Simpson, R.D., Toman, M.A., and Ayres, R.U., eds., Scarcity and growth revisited-Natural resources and the environment in the new millennium: Washington, D.C., Resources for the Future Press, p. 33-53.

Mittermeier, R.A., Myers, Norman, Robles Gil, Patricio, and Mittermeier, C.G., 1999, Hotspots_-Earth's biologically richest and most endangered terrestrial ecoregions: Mexico City, Agrupacíon Sierra Madre, S.C., and Conservation International, $430 \mathrm{p}$.

Oksanen, Lauri, and Virtanen, Risto, 1997, Adaptation to disturbance as a part of the strategy of Arctic and alpine plants-Perspectives for management and restoration, in Crawford, R.M.M., ed., Disturbance and recovery in Arctic lands-An ecological perspective: Dordrecht, The Netherlands, Kluwer Academic Publishers, p. 91-113.

O’Neil, Tim, Kral, Steve, and Yernberg, W.R., 2000, New frontiers in mining-Meeting 21st century challenges: Mining Engineering, v. 52, no. 6, p. 70-78.
President's Committee of Advisors on Science and Technology, 1998, Teaming with life-Investing in science to understand and use America's living capital: Washington, D.C., U.S. Government Printing Office, Report to the President dated March 6, 1998, 86 p. (Available online at http://www.ostp.gov/Environment/html/teamingcover.html.)

Rapport, D.J., Hildén, Mikael, and Roots, E.F., 1997, Transformation of northern ecosystems under stress-Arctic ecological changes from the perspective of ecosystem health, in Crawford, R.M.M., ed., Disturbance and recovery in Arctic lands-An ecological perspective: Dordrecht, The Netherlands, Kluwer Academic Publishers, p. 73-89.

Root, D.H., Menzie, W.D., and Scott, W.A., 1992, Computer Monte Carlo simulation in quantitative resource estimation: Nonrenewable Resources, v. 1, no. 2, p. 125-138.

Singh, Ashbindu, Fosnight, E.A., and Rykhus, Russell, 1997, Spatial data sets for environmental assessment-Towards bridging the data gap: United Nations Environment Programme, Division of Environment Information and Assessment, Environment Information and Assessment Technical Report 4 (UNEP/DEIA/TR.97-4), 66 p.

Sweeting, A.R., and Clark, A.P., 2000, Lightening the lodeA guide to responsible large-scale mining: Washington, D.C., Conservation International, 112 p.

World Resources Institute, United Nations Environment Programme and Development Programme, and The World Bank, 1998, World resources 1998-99: New York, Oxford University Press, 369 p. 


\title{
Who Will Use a Global Mineral Resource Assessment? An Environmental Perspective ${ }^{1}$
}

\author{
By Penny Flick Langhammer ${ }^{2}$
}

The loss of biological diversity is one of the most serious environmental problems facing our planet. Species, genetic diversity within species, and biological communities are disappearing at a rate faster than at any time in history. Environmental degradation, extinction, and the subsequent loss of biological diversity, or biodiversity, has wide-ranging implications for humans. The fact that we will leave our children with a biologically impoverished planet may be the lesser of our concerns. Environmental degradation has been linked to poverty, malnutrition, and disease. While the root of this degradation often lies in the consumptive behavior of developed countries, the consequences are felt most strongly

${ }^{1}$ Reprinted from "Geotimes," March 2001, v. 46, no. 3, p. 18-19, with permission. Copyright 2001, the American Geological Institute.

${ }^{2}$ Conservation International, 1919 M Street, N.W., Suite 600, Washington, D.C. 20036, U.S.A. (e-mail: p.langhammer@conservation.org). in developing countries, which may not have the technology or capacity to cope with the problems.

Effective conservation depends on identifying potential threats to biodiversity before they have irreversible impacts. An early warning system that helps conservationists identify threats, and react quickly to address them, requires accurate, up-to-date information from many different sources. Scientific data from the fields of biology, taxonomy, behavioral ecology, geology, economics, and sociology are critically important to devising conservation strategies that work. Identifying areas of potential resource development is an important component of this early warning system.

Past mineral exploration and development have resulted in direct and indirect damage to biodiversity, and current exploration and development pose increasing threats in the world's biodiversity hotspots and major tropical wilderness areas (fig. 11). There is some concern that a global mineral resource assess-

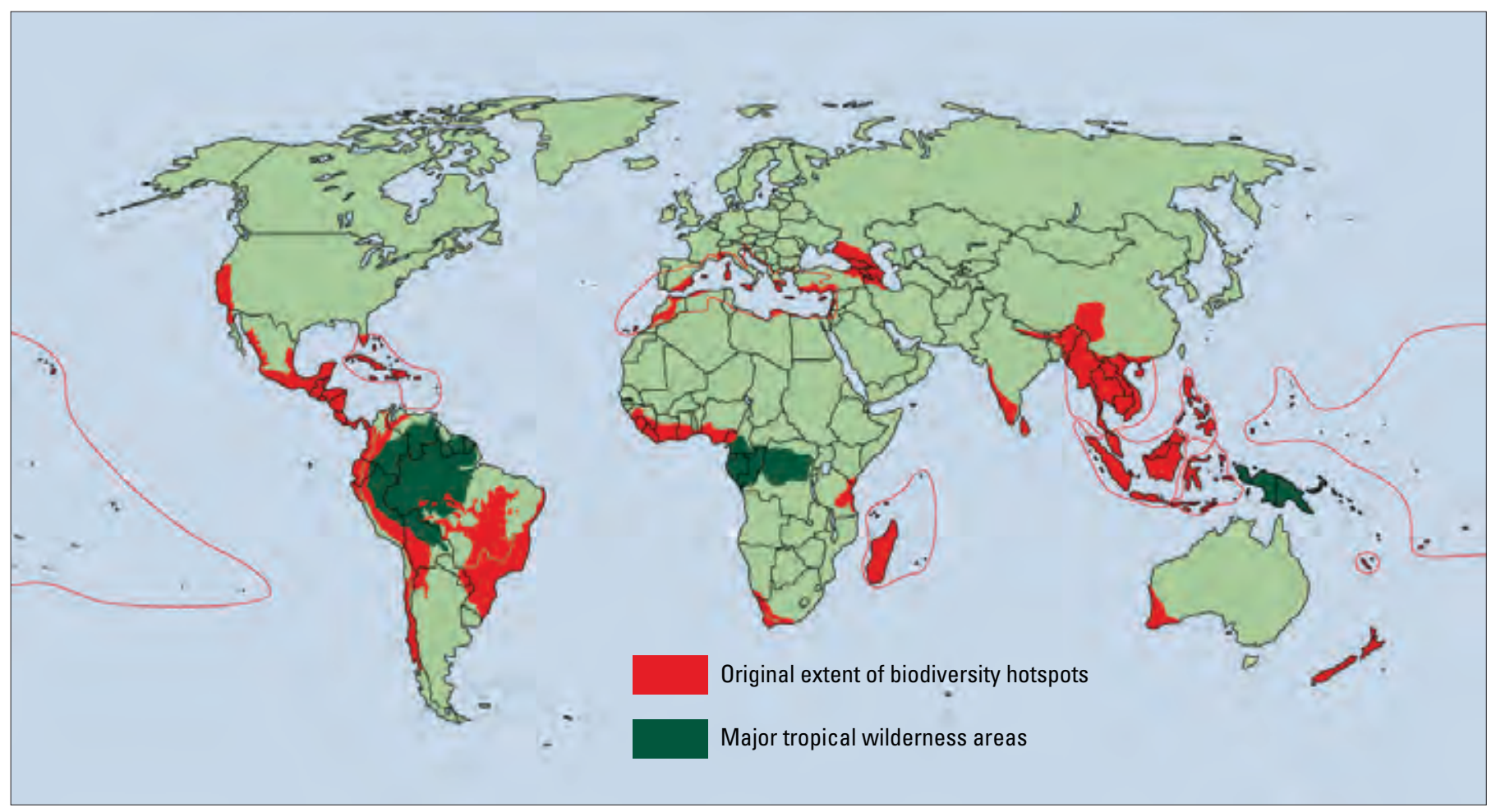

Figure 1. Map of biodiversity hotspots-Earth's biologically richest and most endangered terrestrial ecoregions (modified from Conservation International, 2000). 
ment might highlight, and consequently target, biologically sensitive areas for mineral exploration. The reality is that mining companies probably have this information already, whereas most conservation organizations do not. It is important to know which areas are suitable for mineral development so that, when faced with such development, conservation groups can propose areas of lesser biological value or devise strategies to mitigate this development. Information resources from the geosciences, such as the global mineral resource assessment initiated by the U.S. Geological Survey, can level the playing field.

As conservation efforts increasingly aim to protect entire ecosystems, biologists need earth science information to understand the habitat requirements of organisms, including abiotic components such as water, soil, substrate, and nutrient cycles. The distribution of biodiversity is defined largely by the physical structure of Earth-elevation, soils, river meander, even continental drift over time.

Biologists need geological and topographical data to model species distributions when expensive field survey data are not available. Information on the distribution of species, especially those that are threatened and endangered, is important for designing systems of protected areas and for monitoring. In turn, biologists can help geoscientists to define a research agenda that would enhance conservation efforts. They can also work together to understand the effects of mineral exploration and development on biodiversity and human cultures. Science underpins effective conservation, and biologists and physical scientists need to collaborate.

\section{Reference Cited}

Conservation International, 2000, Map of biodiversity hotspots-Earth's biologically richest and most endangered terrestrial ecoregions: Washington, D.C., Conservation International, 1 sheet, scale 1:38,485,000. 


\title{
Minerals, Biodiversity, and Choices
}

\author{
By Charles G. Cunningham, 'Walter J. Bawiec, ${ }^{1}$ Klaus J. Schulz, Joseph A. Briskey, James F. Carlin, Jr., and \\ David M. Sutphin'
}

Do you remember 1960? In the United States, John F. Kennedy was elected President, the song "Cathy's Clown" by the Everly Brothers headed the top-ten list, and a gallon of gasoline cost 25 cents. The population of the Earth was 3 billion people. Now, 40 years later, the world population is 6 billion people. As the population increases, so does the consumption of most metals, a trend that has continued since the Industrial Revolution. The year 1960 also was the height of the Cold War, a time of concern about shortages of strategic mineral resources, and the early days of the environmental movement. Today, there is no cold war, we have a steady global supply of resources, there is no concern about shortages (at least in the near term), and there are heightened concerns about the environment and sustainable development. Growing materials use, increasing population, and rising living standards are renewing discussions of global priorities and confronting us with difficult choices. How do we assure that we can obtain necessary nonrenewable resources, while minimizing the impact on the environment?

In the current global economy, there generally is an adequate supply of most metals. Nevertheless, we need to maintain a balance that will sustain both the global economy and the global environment. Sometimes, the choice of where to develop comes with the negative consequences of infrastructure development and habitat fragmentation and the subsequent impacts on population, fauna, and flora. A global mineral resource assessment that provides a measure of the distribution and amount of both known and undiscovered mineral resources can assist in making livable choices regarding minerals development and environmental protection. For example, comparison of the distribution of specific mineral resources, both known and undiscovered, with measures of biodiversity can help identify areas where minerals exploitation could most affect ecosystem health. The Washington, D.C.-based nonprofit organization Conservation International (CI) has identified biodiversity hotspots. These areas contain an inordinately large concentration of endemic species and are at the greatest risk for habitat loss. CI recently identified the 25 highest priority hotspots that together contain as endemics 44 percent of the total plant species and 35 percent of all known species of birds, mammals, reptiles, and amphibians. Importantly, the undisturbed

${ }^{1}$ U.S. Geological Survey, 954 National Center, 12201 Sunrise Valley Drive, Reston, VA 20192-0002, U.S.A. (e-mail: cunningham@usgs.gov). part of the hotspot habitat is only 1.4 percent of the Earth's land surface. These hotspots are defined and documented in the book "Hotspots-Earth's Biologically Richest and Most Endangered Terrestrial Ecoregions" (Mittermeier and others, 1999) and in a cover article in "Nature" (Myers and others, 2000). A simplified version of the hotspot-areas map (Conservation International, 2000) is shown in figure 1.

A challenge for society is to recognize and deal with overlaps that will occur between the distribution of ecological hotspots and needed mineral resources. To illustrate both sides of this issue, we consider two elements important to the global economy, but with contrasting sources: tin and chromium. Much of the commodity information used in this paper is from a series of reports by the International Strategic Minerals Inventory group published in U.S. Geological Survey (USGS) Circular 930 (DeYoung and others, 1984; Sutphin and others, 1990) and from annual USGS mineral summaries such as "Mineral Commodity Summaries 2000" (U.S. Geological Survey, 2000).

\section{Chromium}

The principal use of chromium is for the production of stainless steel and superalloys. There is no adequate substitute for it. Chromite is the only mineral mined for chromium, and it occurs in a variety of geologic settings. In 1999, the United States net import reliance on chromium was 80 percent (Papp, 2000), with the remainder of U.S. consumption supplied by recycling. India, Kazakhstan, South Africa, and Turkey produce 80 percent of the world production of chromite ore. South Africa provides over 40 percent of the world production. Brazil and Cuba currently are the only producers in the Western Hemisphere (Papp, 2000). Figure 2 shows the global distribution and relative sizes of known chromium sources. Comparing these data to the locations of biodiversity hotspots in the same figure indicates that there is little spatial overlap. Deposits that are present in Madagascar, the Philippines, Cuba, Greece, and Turkey are small and not likely to see major development. No large chromium deposits are known in the 25 biodiversity hotspots, and thus decisions as to where to mine chromite may be based primarily on other factors, such as economics, politics, and local infrastructure issues. 


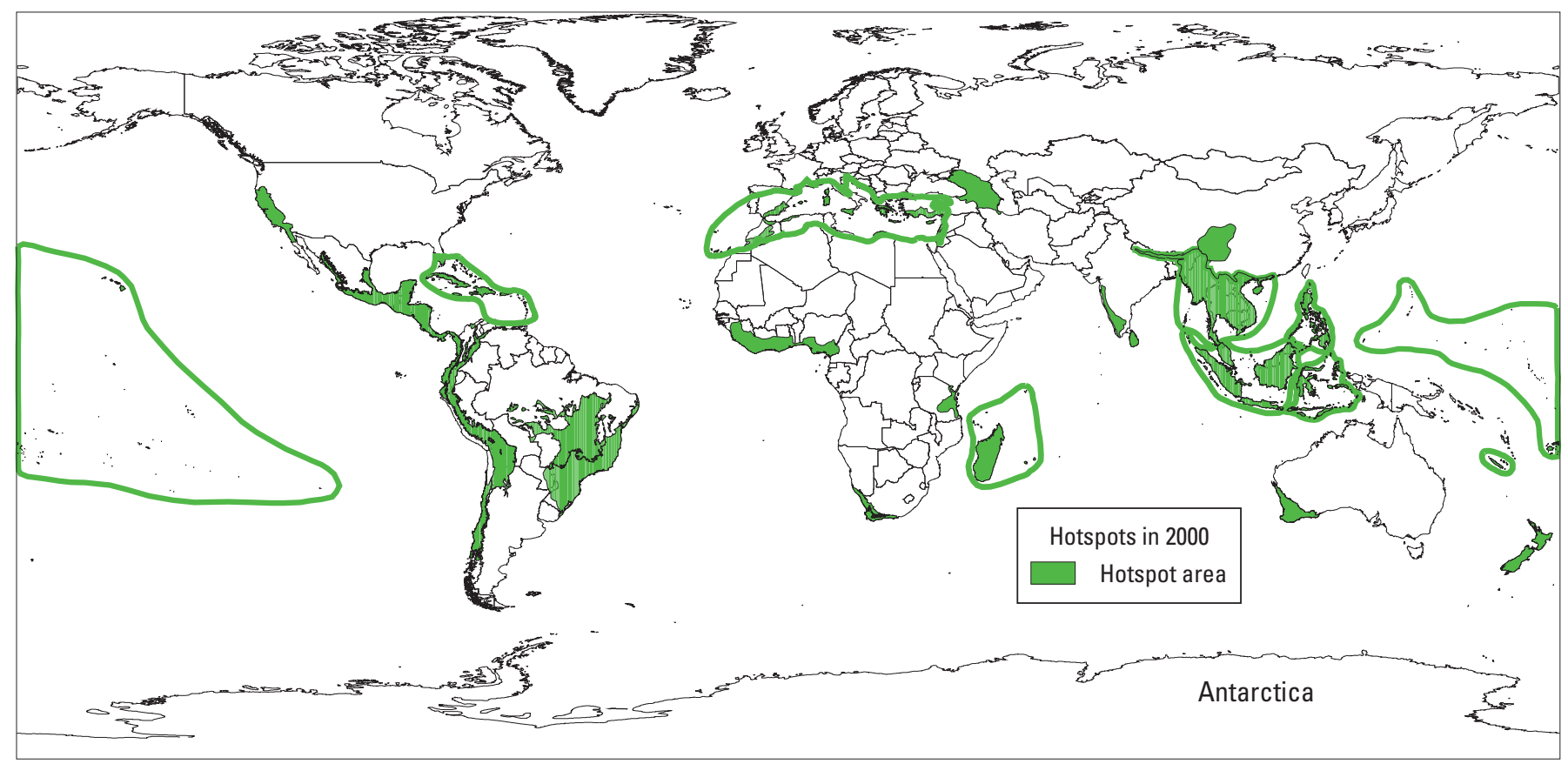

Figure 1. Map of biodiversity hotspots. Modified from Conservation International (2000); used with permission.

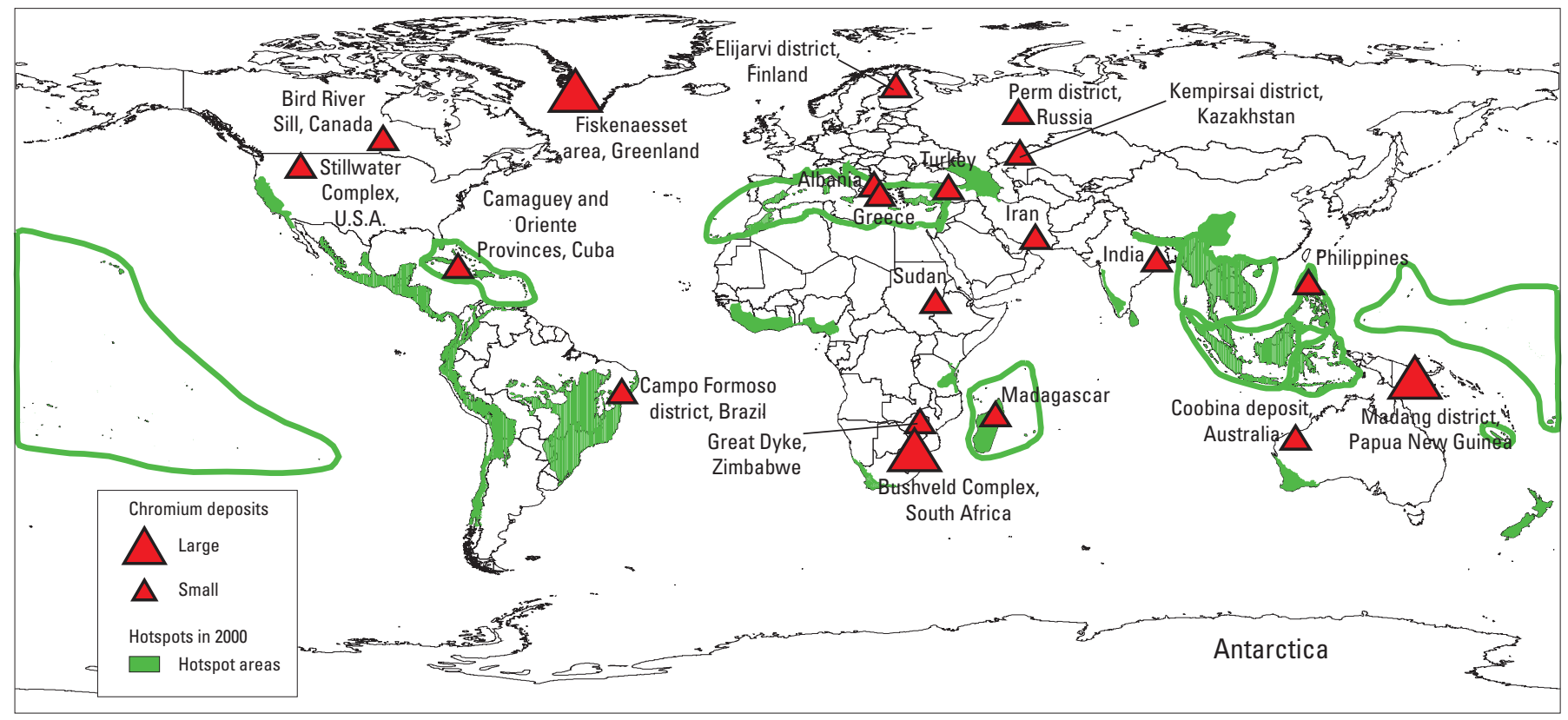

Figure 2. Chromium sources plotted on a map of biodiversity hotspots. Base map modified from Conservation International (2000); used with permission. Chromium deposits primarily modified from DeYoung and others (1984).

\section{Tin}

Tin is used extensively for solder in the modern electronics industry, for plumbing in the building trades, and for chemical products. It also is used for cans and containers because of its compatibility with human physiology. Tin is generally nontoxic, is corrosion resistant, and eventually is biodegradable. Although the beverage industry dominates the container market and uses aluminum cans, about a quarter of all cans are tin-plated steel. World consumption of tin is about 250,000 metric tons per annum. The United States uses 40,000 metric tons per annum of tin, more than any other country, with about a quarter of it from recycling.

Tin resources are abundant. The world mines over 200,000 metric tons per annum and makes up the difference between this and total consumption from recycling and stockpiles. Major tin 


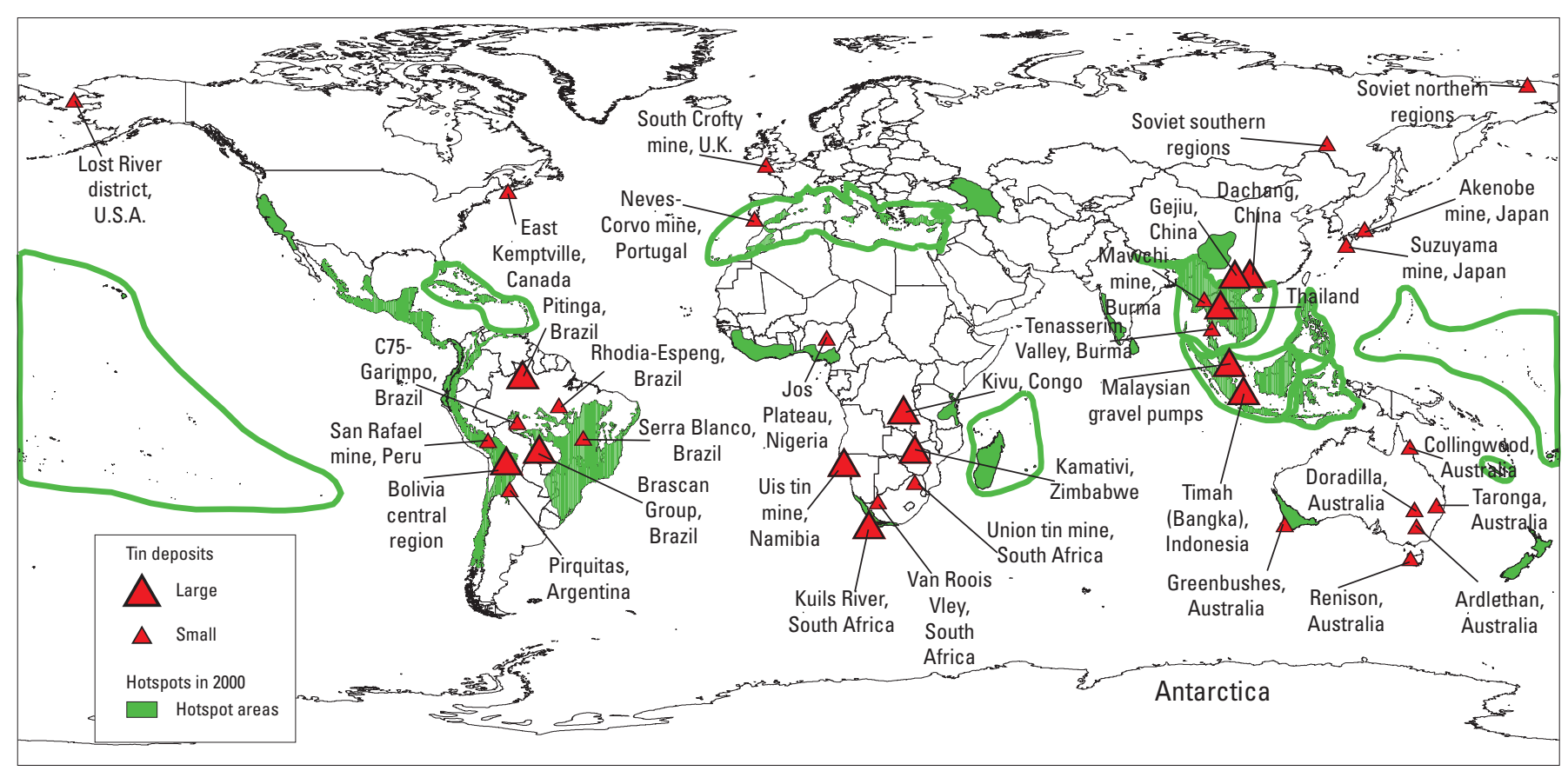

Figure 3. Tin sources plotted on a map of biodiversity hotspots. Base map modified from Conservation International (2000); used with permission. Tin deposits primarily modified from Sutphin and others (1990).

producers are China, Indonesia, Peru, Brazil, and Bolivia ffig. 3; Carlin, 2000). The United States has a Government stockpile of 80,000 metric tons, from which it sells 12,000 metric tons per annum. The United States currently has no need to mine the metal. In fact, industrial market economy countries consume about three-quarters of the world's tin produced each year, while low- and middle-income economy countries account for 90 percent of the world's tin production.

Mineral deposits occur nonuniformly across the Earth's surface, where for geologic reasons, they tend to form in clusters. Almost all tin production has been from similar mineral deposits within specific areas (fig. 3). Therefore, it is reasonable to expect that more production in the future, and many of the new discoveries, will be from these same areas. The juxtaposition of tin sources with the biodiversity hotspots is shown in figure 3. Many of the world's largest tin deposits and known resources occur within the biodiversity hotspots. There is no a priori geologic or biologic reason that there should be such a correspondence in space between known tin deposits and biodiversity hotspots, but the coincidence is striking.

A smaller number of tin deposits, such as those in eastern Australia, Zimbabwe, and Japan, are well away from designated hotspots. Other tin deposits, such as those in Cornwall, U.K., and Alaska, U.S.A., presently are not economic. However, the tin deposits of Indonesia, Thailand, and China are the largest in the world and are within or adjacent to the second richest hotspot for endemic plants. This hotspot also is well known for its mammal diversity and includes the habitat of two recently discovered species - the saola, one of the world's rarest mammals, and the giant muntjac. Some major tin sources in Brazil, such as Pitinga in the western Amazon region, are in the largest tropical rain forest in the world. Smaller deposits to the east are within the hotspot where several unique mammal species occur, including the giant anteater and the maned wolf. The Greenbushes tin deposit in southwestern Australia is within a hotspot rich in endemic plants, reptiles, and marsupial mammals. The large tin deposits of South Africa are in a hotspot noted for having the greatest concentration of nontropical plant species in the world.

Some of the greatest impacts of mining can come from the ancillary effects of infrastructure development, and the effects have both positive and negative aspects. Habitat fragmentation, such as new roads associated with development, farms developed as a result of improved access, or denuded forests that supply fuel and lumber to the developing mining industry, has a major negative effect on biodiversity. On the other hand, mining can also bring jobs to a region, which increases the standard of living and improves medical care, sanitation, transportation, and communication.

\section{Conclusion}

In a global economy, environmental concerns will exert a growing influence on the complex choices that must be made with regard to exploration and exploitation of metallic, and nonmetallic, nonrenewable resources. Wise stewardship of our global resources should rely upon informed decisions related to alternative sources, recycling, and alternative substitutions. The bottom line is that a global assessment of mineral resources will help all countries better understand the regional and global implications of decisions they make regarding minerals development and other land uses. 


\section{Acknowledgments}

Data on biodiversity hotspots were provided by Conservation International. The U.S. Geological Survey gratefully acknowledges the participation of Conservation International in the 2000 IUGS/UNESCO Workshop on Deposit Modeling, Mineral Resource Assessment, and Their Role in Sustainable Development. Paul Barton, Lief Horwitz, and Art Schultz of the U.S. Geological Survey and Penny Flick Langhammer of Conservation International contributed helpful reviews.

\section{References Cited}

Carlin, J.F., Jr., 2000, Tin, in Mineral commodity summaries 2000: Reston, Va., U.S. Geological Survey, p. 176-177.

(Also available online at http://minerals.usgs.gov/minerals/ pubs/commodity/tin/660300.pdf.)

Conservation International, 2000, Map of biodiversity hotspots-Earth's biologically richest and most endangered terrestrial ecoregions: Washington, D.C., Conservation International, 1 sheet, scale 1:38,485,000.
DeYoung, J.H., Jr., Lee, M.P., and Lipin, B.R., 1984, International strategic minerals inventory summary reportChromium: U.S. Geological Survey Circular 930-B, 41 p.

Mittermeier, R.A., Myers, Norman, Robles Gil, Patricio, and Mittermeier, C.G., 1999, Hotspots—Earth's biologically richest and most endangered terrestrial ecoregions: Mexico City, Agrupacíon Sierra Madre, S.C., and Conservation International, $430 \mathrm{p}$.

Myers, Norman, Mittermeier, R.A., Mittermeier, C.G., da Fonseca, G.A.B., and Kent, Jennifer, 2000, Biodiversity hotspots for conservation priorities: Nature, v. 403, February 24,2000, p. $853-858$.

Papp, J.F., 2000, Chromium, in Mineral commodity summaries 2000: Reston, Va., U.S. Geological Survey, p. 48-49. (Also available online at http://minerals.usgs.gov/minerals/ pubs/commodity/chromium/180300.pdf.)

Sutphin, D.M., Sabin, A.E., and Reed, B.L., 1990, International strategic minerals inventory summary report-Tin: U.S. Geological Survey Circular 930-J, 52 p.

U.S. Geological Survey, 2000, Mineral commodity summaries 2000: Reston, Va., U.S. Geological Survey, 197 p. (Also available online at http://minerals.usgs.gov/minerals/pubs/ mcs/2000/mcs2000.pdf.) 


\title{
Sustainable Development and Nonrenewable Resources- A Multilateral Perspective
}

\author{
By George A. Nooten ${ }^{1}$
}

\section{Introduction}

The link between sustainable development and nonrenewable resources appears at first glance to be inconsistent, because nonrenewable resources are finite. The concept of sustainable development has generated a great deal of debate and spawned a multitude of definitions since it was put forward by Malthus (1798) about 200 years ago. He argued that the fixed land base could not sustain the continuing growth in human population and, if people did not restrain their reproduction, the population would be controlled by war, pestilence, and starvation. This early thinking evolved to what we now accept as the fundamental premise of sustainable development as stated by the World Commission on Environment and Development (Brundtland, 1987, p. 8)—“development that meets the needs of the present without compromising the ability of future generations to meet their own needs." The United Nations Development Programme (UNDP) believes that development must have a human face and coined the term "sustainable human development." Its mission, therefore, is to help countries in their efforts to achieve sustainable human development by assisting them to build their capacity to design and carry out development programs in poverty eradication, employment creation and sustainable livelihoods, the empowerment of women, and the protection and regeneration of the environment, giving first priority to poverty eradication.

The idea of sustainable development in the context of nonrenewable resources, in particular mineral resources, may seem a contradiction if a one-dimensional view is taken. Mineral resource development is unsustainable only if we ignore the complex interaction of economic growth, social development, and the environment. It is not always self-evident that our present modern technological society requires an ongoing supply of minerals. Mineral production, although having environmental impacts, is and will continue to be an essential part of ensuring the economic well-being of our society. To satisfy the present global mineral needs without compromising the mineral resource needs of future generations, it is imperative that we approach mineral resource development

${ }^{1}$ Former Officer-in-Charge, United Nations Revolving Fund for Natural Resources Exploration, New York, N.Y., U.S.A. (e-mail: vanooten@msn.com). within a holistic framework comprising all components of the complex interaction between humans and the ecosystem on which they depend. By using nonrenewable resources for capital formation that will be reinvested in social, economic, and environmental activities, the concept of sustainability and mineral resource development would no longer seem to be a contradiction.

Since the establishment of the UNDP in 1965, the organization has supported mineral resources development activities, including exploration, feasibility studies, capacity building, and institutional strengthening of mining departments in developing countries. As a result of these activities, several important mineral deposits were discovered, including one of its earliest and largest discoveries, the Baja la Alumbrera copper deposit in Argentina. Today, UNDP's direct involvement in the mineral sector is minimal, mainly because it is felt that this activity should be left to the private sector. However, the wealth of information that resides within UNDP archives could contribute to the global assessment of future sources of mineral supplies. A global mineral resource assessment is seen as a prerequisite to adequate planning for the sustainable use of these nonrenewable resources and as a contribution to the achievement of UNDP's overarching goal of poverty eradication.

This paper discusses the evolution of the concept of sustainable development and the need to treat mineral resource development as one component in a complex interaction between humans and their environment. UNDP's approach and contribution to fostering an enabling environment for global mineral resource development within the framework of sustainable human development are presented.

\section{Sustainable Development}

\section{Evolution of the Concept}

The concept of sustainable development can be traced back to the 18th century, when there was concern that the limited amount of land and resources would retard economic growth. Tahvonen (2000) traced the development of economic thought on sustainability and scarcity of natural resources by citing four main periods, as follows. 
The 1st period

1798

1862

Thomas Malthus (1798) believed that the fixed land base could not sustain the continuing growth of human population. He predicted that, if humankind did not make the moral decision to control the increasing number of people on the planet, populations would be held in check by war, pestilence, or starvation.

John Stuart Mill (1862) emphasized that, while the limited amount of natural resources could in principle constrain increases in production, this limit would not be reached in any country over any meaningful timeframe.

The $2 \mathrm{~d}$ period

1890-1920 The U.S. conservation movement in its doctrine stated that economic growth has clear physical boundaries that cannot be avoided by technological development. Too rapid use of nonrenewable resources was considered a major threat to future generations. It was argued that, the lower the use of nonrenewable resources, the better.

1931

Studies by Hotelling (1931) proposed a theoretical model in which social well-being from nonrenewable resources was maximized over an infinitely long time period.

1963

Barnett and Morse (1963) questioned the pessimistic Malthusian view and the basic premises of the conservation movement. They found that, on the basis of price and cost time series data on minerals, agriculture, and renewable resources, (1) the price and production costs had fallen or remained constant during the period 1870-1957 and (2) only the price level of forestry had shown an upward trend. These findings were explained by technological development, which produced substitutes for scarce resources, decreased extraction costs of minerals, and expanded the size of economic reserves.

The $3 \mathrm{~d}$ period

The "Limits to Growth" report for the Club of Rome by Meadows and others (1972), using the modeling method called "systems analysis," predicted that the future world population level, food production, and industrialization would first grow exponentially but then collapse during the next century. The collapse would occur because the world economy would reach its physical limits in terms of nonrenewable resources, agricultural production, and excessive pollution. The study predicted that 11 vital minerals could be exhausted before the end of 2000.
1977
Wassily Leontief and others (1977), on request by the United Nations, applied equally pessimistic assumptions as the "Limits to Growth" report, except that they took into account that demand may respond to higher prices. Their results showed that only two minerals were in danger of being exhausted.

The 4th period

After 1974 Presustainability from 1974 onward.-Two economists, Partha Dasgupta and Geoffrey Heal (1974), asked whether an economy can maintain a positive consumption level forever, given that there is no technical development and that the production of commodities is possible only by using limited nonrenewable resources like oil. Their analysis revealed that it is possible to maintain a positive consumption level only if capital can be substituted for nonrenewable resources without technical difficulties.

The concept of sustainable development has evolved and gained global recognition since the report by the World Commission on Environment and Development (Brundtland, 1987) and the United Nations Conference on Environment and Development in 1992. The concept is complex, requiring a delicate balance among economic growth, environmental protection, and social development to secure the well-being of the increasing population on a sustainable basis.

\section{Defining Sustainable Development}

The complexity of sustainable development has spawned a myriad of definitions. The most quoted definition is by the World Commission on Environment and Development (Brundtland, 1987, p. 8), which says that sustainable development is "development that meets the needs of the present without compromising the ability of future generations to meet their own needs." The concept is further elaborated therein by the statement, "In essence, sustainable development is a process of change in which the exploitation of resources, the direction of investments, the orientation of technological development, and institutional change are all in harmony and enhance both current and future potential to meet human needs and aspirations."

In 1991, "Caring for the Earth-A Strategy for Sustainable Living," published by the International Union for Conservation of Nature and Natural Resources, United Nations Environment Programme, and World Wide Fund for Nature (Munro and Holdgate, 1991), defined sustainable development as, "improving the quality of human life while living within the carrying capacity of supporting ecosystems." The Australia Ecologically Sustainable Development Working Group on Mining (1991) defined sustainable development as, "ensuring that the mineral raw materials needs of society are met, with- 
out compromising the ability either of future societies to meet their needs, or of the natural environment to sustain indefinitely the quality of environmental services (such as climate systems), biological diversity, and ecological integrity."

UNDP advocates sustainable human development, which is an approach that seeks to expand choices for all peoplewomen, men and children, current and future generationswhile protecting the natural systems on which all life depends. Moving away from a narrow, economy-centered approach to development, sustainable human development places people at the core and views humans as both a means and an end of development. Thus, sustainable human development aims to eliminate poverty, promote human dignity and rights, and provide equitable opportunities for all.

In addition to the several definitions of sustainable development, the concept is elaborated in principles $1,4,5$, and 8 of the Rio Declaration (United Nations, 1992), as follows:

Principle 1. Human beings are at the center of concerns for sustainable development. They are entitled to a healthy and productive life in harmony with nature.

Principle 4. In order to achieve sustainable development, environmental protection shall constitute an integral part of the development process and cannot be considered in isolation from it.

Principle 5. All States and all people shall cooperate in the essential task of eradicating poverty as an indispensable requirement for sustainable development, in order to decrease the disparities in standards of living and better meet the needs of the majority of the people of the world.

Principle 8. To achieve sustainable development and a higher quality of life for all people, States should reduce and eliminate unsustainable patterns of production and consumption and promote appropriate demographic policies.

Although several definitions exist, the three main elements-economic growth, social responsibility, and environment and natural resource conservation-are persistent in the definitions of sustainable development. There is an unquestionable global acceptance of the need for all nations to embrace the concept of sustainable development, which upholds the universal values of fulfilling basic needs and access to good health, wealth, dignity, knowledge, justice, equity, and peace.

\section{Nonrenewable Resources}

At first glance, a nonrenewable resource seems to be incompatible with sustainable development. This is true because the concept of a nonrenewable resource implies that, once a resource is used, since it cannot reproduce itself, sustainability is not possible. This one-dimensional view of nonrenewable resources seems to support the widely held view that the extractive industries cannot be supportive of the concept of sustainable development. A closer examination of the issue, however, reveals a different perspective.

Nonrenewable resources, in particular mineral resources, are necessary for the economic well-being of our societies. It is not always self-evident that without a supply of mineral products our living standards will be drastically reduced and the impact on the global economy will be disastrous. The modern conveniences, such as automobiles, building and transportation infrastructure, fertilizers for increased food production, television sets, computers, solar panels, aircraft, medical diagnostic and treatment methods and instruments, farming equipment, and cooking utensils, require mineral products. It is a truism that what is not grown must be mined. To have access to mineral resources, their extraction from the Earth and the environmental impacts associated with this activity are unavoidable.

In limiting the concept of nonrenewability to exhaustion and depletion in the case of mineral resources, we are ignoring the impact of technology. Advances in technology, new mineral discoveries, and limits on the material riches desired by our societies can minimize the possibility for exhaustion and depletion of the Earth's recoverable mineral supply. Technology provides the possibility of finding ways to renew the supply of minerals through advances in exploration techniques, extraction processes, recycling, and substitution. In the case of some resources we think of as renewable, such as biological resources, the reality is that some bird and fish species have become extinct and, therefore, also can be considered nonrenewable. In viewing mineral resource depletion at the scale of individual mine sites, the limited perspective of nonrenewability can apply; on a global scale, however, given the untapped resources of the oceans and deeper parts of the Earth's crust, we should consider a broader view of nonrenewability.

Given the important role that minerals play in our societies, it is necessary to view mineral development as one of the important components of continuing economic growth without impairing the capacity of future generations to enjoy the same or a better standard of living. Sustainability requires economic growth, environmental protection of our ecosystem, and social responsibility. The dynamic interplay of these three components is a prerequisite for achieving the goals of sustainability. Mineral development can be viewed as supporting the concept of sustainable development if the extraction of minerals takes place in a manner that minimizes the environmental impacts; equitably shares the benefits from the new wealth created; utilizes the capital obtained to provide adequate healthcare, education, and other social services; and reduces the level of waste through recycling and improved technologies to optimize recoveries.

In considering national and international mineral supplies, it is necessary to recognize the dynamic characteristics 
of the minerals industry and to take into account the other factors apart from the economic and geologic ones. It is well accepted that the environmental and sociocultural aspects must be an integral part of the way the minerals industry operates.

\section{Sustainability of Mineral Supply}

Although some authors predicted that the world would run out of some minerals, thus contributing to constrained economic growth, this pessimistic prediction has failed to materialize despite increasing consumption and population growth. The main reason for this failure was that projections of supply and demand models failed to take into account the dynamic nature of the minerals industry. Some minerals in use today were not in use 50 years ago, while others have been substituted for by plastics, composites, and other materials. For example, we are seeing an increased use of optical fiber replacing copper in the communications industry. It is possible that with new technologies the future uses of some minerals will require reduced quantities of the mineral raw material to be mined.

Dzioubinski and Chipman (1999) presented an overview of the trends in production and consumption of copper, lead, and aluminum. They found that there will be no shortage of copper due to depletion of ore in the foreseeable future. The reserve base of copper will last for more than 40 years, and copper resources for more than 105 years. For lead, the reserve base is sufficient for 40 years, and identified resources for 500 years. For aluminum production, the primary raw material is bauxite. Reserves of bauxite will last for about 100 years, and estimated resources between 170 and 200 years. As can be seen, there is no evidence that these or other nonrenewable resources will be scarce due to extraction and depletion in the medium to long term. As technologies emerge for the development of resource substitutes, recycling methods, and improved exploration and mining methodologies, together with the potential for discovery of minerals not yet known, global mineral supply is in no danger of becoming scarce due to depletion of mineral resources.

\section{UNDP's Contribution and Role}

Mineral exploration activities in the developing world have been supported by the United Nations (U.N.) and in particular by the UNDP for more than 40 years. This support was in recognition that the mineral wealth of a country was an engine of economic growth. The U.N. programs covered many aspects of mineral resource development in the developing countries, including the following:

1. Institutional strengthening of geological surveys and mineral resource departments and ministries.

2. Training of nationals in all fields of mineral resources.
3. Mineral exploration using geochemical prospecting, airborne and ground geophysics, analytical chemistry, and assaying.

4. Drilling.

5. Economic feasibility studies.

6. Mining and mineral processing — establishing mining and metallurgical institutes.

7. Mining legislation.

Exploration results have been positive in many of the exploration programs undertaken by UNDP. The discovery of the Cerro Petaquilla porphyry copper deposit in Panama (1965-71) attracted international mining companies that began exploration in Panama and neighboring countries for similar deposits in the circumpacific orogenic belt in the Americas. In Mexico, UNDP projects led to the discovery of La Caridad porphyry copper deposit and the Las Truchas iron ore deposit. In Asia, discoveries include the Mamut porphyry copper deposit in Sabah, Malaysia; offshore tin in Indonesia; and the Sar Chesmeh copper deposit in Iran. In Africa, several deposits were found by UNDP mineral exploration programs; notably, lateritic nickel in Burundi and Tanzania, iron ore in Guinea, and gold in Burkina Faso.

Rapidly changing external and internal factors have necessitated a change in focus of the activities of the UNDP. Externally, there have been major global political changes such as the breakup of the Soviet Union. Several armed conflicts in the developing world have created a major refugee crisis requiring the intervention of U.N. peacekeeping teams. There have been important social changes, such as the emergence of global movements regarding women and indigenous people and regarding environmental and human rights. Internally, major reforms of the organization have taken place, resulting in the reorientation of programs to respond to the demands of these dramatic changes. The current development approach embodies all the elements of sustainable development, with a major focus on poverty elimination.

In response to the many changes, mineral exploration activities by UNDP declined and were replaced by an emphasis on processing and manufacturing activities. Examples of this new direction are (1) providing advice to governments in reforming their mining codes and their fiscal regimes, (2) providing policy advice in environmental matters, (3) promoting women's issues, and (4) providing assistance in the transformation of informal small-scale mining to a formal sector.

The stated mission of UNDP is to contribute to halving world poverty by 2015 . To achieve this goal, the emphasis is on pro-poor and sustainable growth. It is recognized that sustained poverty reduction requires socially, politically, and environmentally sustained economic growth in all countries. The present activities in the natural resource sector focus on poverty reduction strategies, and because the private sector is better positioned to play a key role in the mineral sector, UNDP now concentrates on issues pertaining to good governance, capacity building, and the strengthening of institutions. 
In the natural resources management cluster, emphasis is placed on water, sustainable agriculture and food security, and renewable energy and energy policy.

Although UNDP no longer is directly involved in mineral exploration activities, it continues to contribute to the mineral sector through implementation of the sustainable livelihoods (SL) approach to artisanal mining. As one of UNDP's five corporate mandates, SL offers both a conceptual and a programming framework for poverty reduction in a sustainable manner. Conceptually, livelihoods connote the means, activities, entitlements, and assets by which people make a living. Assets, in this particular context, are defined as not only natural or biological (that is, land, water, minerals, common-property resources, flora, fauna) but also social (that is, community, family, social networks, participation, empowerment), human (that is, knowledge creation by skills), and physical (that is, roads, markets, clinics, schools, bridges). The sustainable livelihood approach could be instrumental in tapping the vitality of mining to improve community livelihoods and contribute to poverty eradication.

\section{UNRFNRE's Role in Sustainable Development}

In 1973, the U.N. Revolving Fund for Natural Resources Exploration (UNRFNRE) was established to respond to fears expressed about the future scarcity of mineral supply. The revolving fund acted as a catalyst in mineral resource development through its executing and financing mechanism, which promoted self-reliance and cooperation among developing countries. The creation of the fund was a cooperative attempt by the world community to expand the inventory of mineral resources at mankind's disposal for the future. Voluntary contributions made by donors both from developing and developed countries provided the high-risk capital for mineral exploration at no cost to the recipient governments. The only requirement was that, in the event that the fund was successful in discovering an economic mineral deposit that went into production, the government was obligated to make replenishment payments to the fund. The replenishment rate was 2 percent ( 1 percent for least developed countries) of the gross value of annual production for a period of 15 years, with a ceiling of 10 times the amount of the cost of exploration incurred by the fund. It was estimated that, after 25 years, the fund would be self-sustaining and not dependent on contributions from donors. The replenishment payments would be the pool of high-risk capital for developing countries to utilize for their mineral exploration activities. In this way, countries would share the risk and be self-reliant in financing their mineral exploration activities.

During its 26 years of existence, UNRFNRE has assisted developing countries to locate and define the economic mineral deposits within their borders. With a total expenditure of nearly US\$100 million, the fund has evaluated over 100 mineral prospects, carried out 34 mineral exploration projects, and discovered 10 economic mineral deposits with an in-place value of approximately US\$3.4 billion. To date, deposits of gold in Peru and Ecuador and chromite in the Philippines have been mined. On August 3, 2000, one of the fund's projects, the Geita, Tanzania, gold mine, was officially opened; it will be producing 500,000 ounces of gold annually from a reserve of 5 million ounces and a resource of 12 million ounces.

The changed focus of UNDP to concentrate on processing and manufacturing activities, and the decision to phase out the activities of the fund by the end of 2000, brings an end to the mineral exploration activities within the UNDP. It is hoped that the new wealth created by the fund's discoveries will be reinvested in social, economic, and environmental activities in line with sustainable development objectives.

\section{Conclusions}

Nonrenewable resource development and sustainable human development are inextricably linked, complementary, and multidimensional. Development is unsustainable if equity does not exist or where large numbers of people live in abject and degrading poverty. As a development organization, UNDP supports the development of national capacity in the participating countries through sustainable human development activities. The approach is holistic and multidimensional, recognizing the mutual dependency and complementary nature of the social, economic, environmental, cultural, civil, and political dimensions of development.

Although UNDP and UNRFNRE will no longer engage directly in mineral exploration activities, contributions to the mineral sector will continue through UNDP's four main areas of sustainable human development programming - (1) eliminating poverty and implementing sustainable livelihoods, (2) promoting the advancement of women, (3) protecting and regenerating the environment, and (4) developing capacity for good governance. All of these areas have dimensions pivotal to the development of nonrenewable resources in a sustainable manner.

\section{References Cited}

[Australia] Ecologically Sustainable Development Working Group on Mining, 1991, Draft report-Mining: Canberra, Australian Government Publishing Service. [Also see United Nations Conference on Trade and Development Mineral Resources Forum, General Forum, Sustainable Development, Defining Sustainable Development; Sustainable Development and Mineral Resources, Australia, Web site at http://www.natural-resources.org/minerals/ generalforum/minag21.htm. (Accessed January 15, 2003.)]

Barnett, H.J., and Morse, Chandler, 1963, Scarcity and growth-The economics of natural resource availability: Baltimore, Md., Johns Hopkins Press, 288 p. 
Brundtland, G.H., 1987, Our common future-Report of the World Commission on Environment and Development:

Oxford, U.K., Oxford University Press, 400 p.

Dasgupta, P.S., and Heal, G.M., 1974, The optimal depletion of exhaustible resources: Review of Economic Studies, v. 41, p. $3-28$.

Dzioubinski, Oleg, and Chipman, Ralph, 1999, Trends in consumption and production-Selected minerals: United Nations Department of Economic and Social Affairs Discussion Paper 5, ST/ESA/1999/DP.5, 14 p., available online at http://www.un.org/esa/esa99dp5.pdf. (Accessed January 16, 2003.)

Hotelling, Harold, 1931, The economics of exhaustible resources: Journal of Political Economy, v. 39, no. 2, p. 137-175.

Leontief, W.W., Carter, A.P., and Petri, P., 1977, The future of the world economy-A United Nations study: New York, Oxford University Press, 110 p.

Malthus, Thomas, 1798, An essay on the principle of population, as it affects the future improvement of society with remarks on the speculations of Mr. Godwin, M. Condorcet, and other writers: London, printed for J. Johnson, in St. Paul's Church-Yard, 396 p.
Meadows, D.H., Meadows, D.L., Randers, Jorgen, and Behrens, W.W., III, 1972, The limits to growth-A report for the Club of Rome's project on the predicament of mankind: New York, Universe Books, 205 p.

Mill, John Stuart, 1862, The principles of political economy, with some of their applications to social philosophy (5th ed.): London, Parker, 2 v.

Munro, D.A., and Holdgate, M.W., eds., 1991, Caring for the Earth-A strategy for sustainable living: Gland, Switzerland, International Union for Conservation of Nature and Natural Resources, United Nations Environment Programme, and World Wide Fund for Nature, 227 p. (Also available online at http://coombs.anu.edu.au/ vern/caring/ caring.html; accessed January 16, 2003.)

Tahvonen, Olli, 2000, Economic sustainability and scarcity of natural resources-A brief historical review: Washington, D.C., Resources for the Future, 13 p., available online at] http://www.rff.org/Documents/RFF-IB-00-tahvonen.pdf.

United Nations, 1992, Report of the United Nations Conference on Environment and Development-Annex I, Rio Declaration on Environment and Development, Rio de Janeiro: New York, United Nations, 5 p., available online at http://www.un.org/documents/ga/conf151/ aconf15126-1annex1.htm. (Accessed January 16, 2003.) 


\title{
Mineral Resources Information and Socioeconomic Development
}

\author{
By Gotthard Walser ${ }^{1}$
}

The contribution of mining to sustainable development needs to be considered in terms of economic and technical viability, ecological sustainability, and social equity. Governments, mining companies, and local communities, as well, must work and cooperate on these issues through the different stages of a mining project and over a considerable time span, extending from exploration to mine operation and to postmine closure. As shown by World Bank's experience in mining sector development in recent years, such principles have to be taken into account even at the very early stages of regional mineral resources assessment.

Sustainable resource use planning requires that areas of mineral potential be evaluated in the context of existing and alternative land use options, integrating social, environmental, cultural, and economic factors. Civil society and governments are increasingly aware that minerals form only one component of a country's resources. An integrated approach that calls for a strategic and participatory process of analysis, debate, capacity strengthening, planning, and action, involving all stakeholders, including local communities, is the only way to optimize mineral resources exploitation from a sustainable development point of view and to identify and avoid potential conflicts in land use. To develop such a process in a rational

${ }^{1}$ World Bank Group, Mining Department, Washington, D.C. and fair manner inevitably requires accurate data depicting the available resource base, as well as the transparent and open sharing and coordination of multiuser information.

Ensuring the availability of strategic information with respect to mineral resources constitutes one of the main mandates of most national geological survey organizations. The World Bank long has recognized the importance of geological surveys as "enablers" to provide the required data to make well-informed decisions regarding sustainable land and resource use and, within the framework of mining sector reforms, has provided loans to development projects that include the strengthening of these institutions, the collation and dissemination of regional multidisciplinary geoscientific data, and the development of information and management systems. The availability of modern and reliable geoscientific data not only enhances the capacity to assess and manage mineral resources but also is applicable to agriculture, forestry, environmental and health risk analysis, conservation, and land use planning.

A recent and particularly illustrative case history is represented by the development in Ecuador of such an integrated geoscientific database by the National Directorate of Geology, with the assistance of the British Geological Survey. Other examples include Argentina, Bolivia, Burkina Faso, Mauritania, Mozambique, and Papua New Guinea. 


\title{
Economics and Environment as Factors of Sustainable Development of Siberian Mineral Resources
}

\author{
By N.L. Dobretsov, ${ }^{1}$ A.V. Kanygin, ${ }^{1}$ and A.E. Kontorovich ${ }^{1}$
}

\section{Introduction}

Siberia is one of the major regions of the world whose energy and mineral resources will be important during the 21 st century for industrial development not only of Russia but also of many other countries, particularly in Europe and the Asia-Pacific region. Siberia has some of the largest explored and potential reserves of energy raw materials in the world (gas, oil, coal, gas hydrates), as well as major concentrations of nickel, cobalt, platinum-group metals, diamonds, rare earth elements, helium, agricultural minerals, and many other types of mineral raw materials. These resources are mainly concentrated in Siberia's northern and eastern regions, commonly in very remote areas. Many of these deposits were discovered only in recent decades and have yet to be developed. It is predicted that further significant resources will be discovered in Siberia given the generally low levels of exploration that have been conducted in regions that have good geologic potential for undiscovered resources. Also, discoveries have been made of new, previously unknown genetic types of deposits with unique combinations of useful mineral commodities figs. 1 and 2). In addition, the increasing deficiency of freshwater globally makes the large reserves in Siberian rivers and lakes of great importance for the future progress of mankind. Lake Baikal alone contains 20 percent of the world's reserves of fresh surface water (excluding water in glaciers in Antarctica and Greenland).

Although Siberia contains significant concentrations of natural resources, economic development in the region faces many challenges related to natural climatic, social-demographic, infrastructure, and industrial factors. Siberia's critical environmental, economic, social, and political problems were put on the agenda of the Earth Summit in Rio de Janeiro in 1992. The severity of natural climatic problems in Siberia is highlighted by the fact that most of the region (about 10 million square kilometers) experiences extreme climatic conditions, under which ecosystems are highly sensitive to anthropogenic loading, particularly in the areas of permafrost where most of the major extractable and promising resources are concentrated.

${ }^{1}$ United Institute of Geology, Geophysics and Mineralogy, Siberian Branch of the Russian Academy of Sciences, Novosibirsk, Russia.
The economic problems of Siberia derive from the fact that, although the region has rich natural resources of great importance to the mining and petroleum industries, development is hampered by the unfavorable natural and climatic conditions of their locations and the poorly developed transportation systems and other infrastructure. In addition, the region has an imbalance between the mining and processing branches of the raw materials industry. This imbalance in general significantly decreases the resources' profitability and requires large initial capital investments to bring new deposits into production.

Social problems in Siberia are to a large extent the result of the former two factors (natural climatic and economic) and the historical social disparity between Siberia and the European parts of Russia. This disparity has been responsible for unfavorable demographic trends in the region. The social and economic problems of the northern and eastern regions of Siberia are further complicated by the fact that these regions require expensive measures for protection and preservation of natural environments and for protection of aboriginal populations, with their specific cultural adaptation to extreme natural conditions.

Politically, effective use of the strategically important natural resources of Siberia, particularly its energy resources, is one of the most important factors for addressing the current economic crisis for Russia, stabilizing its economy, and integrating with the world-market-based economic system. We place particular emphasis on the development of energy resources because of their importance to basic macroeconomic indices. As early as the beginning of the 1970s, Dennis L. Meadows and a group from the Club of Rome, while examining possible scenarios of world development at the close of the 20 th and beginning of the 21 st century, found through analysis of statistical data that there is a linear relation between the per capita gross domestic product (GDP) and energy consumption in industrialized countries (Meadows and others, 1972; see fig. 3 of this paper). Deviations from this linear relation can result from differences in climate, local prices of energy resources, and the level of contribution of heavy industry to the economy of countries.

Recently, in considering the development of Russia's energy strategy for the 21st century, Kontorovich and others (1999a) analyzed world economic data from the last three 


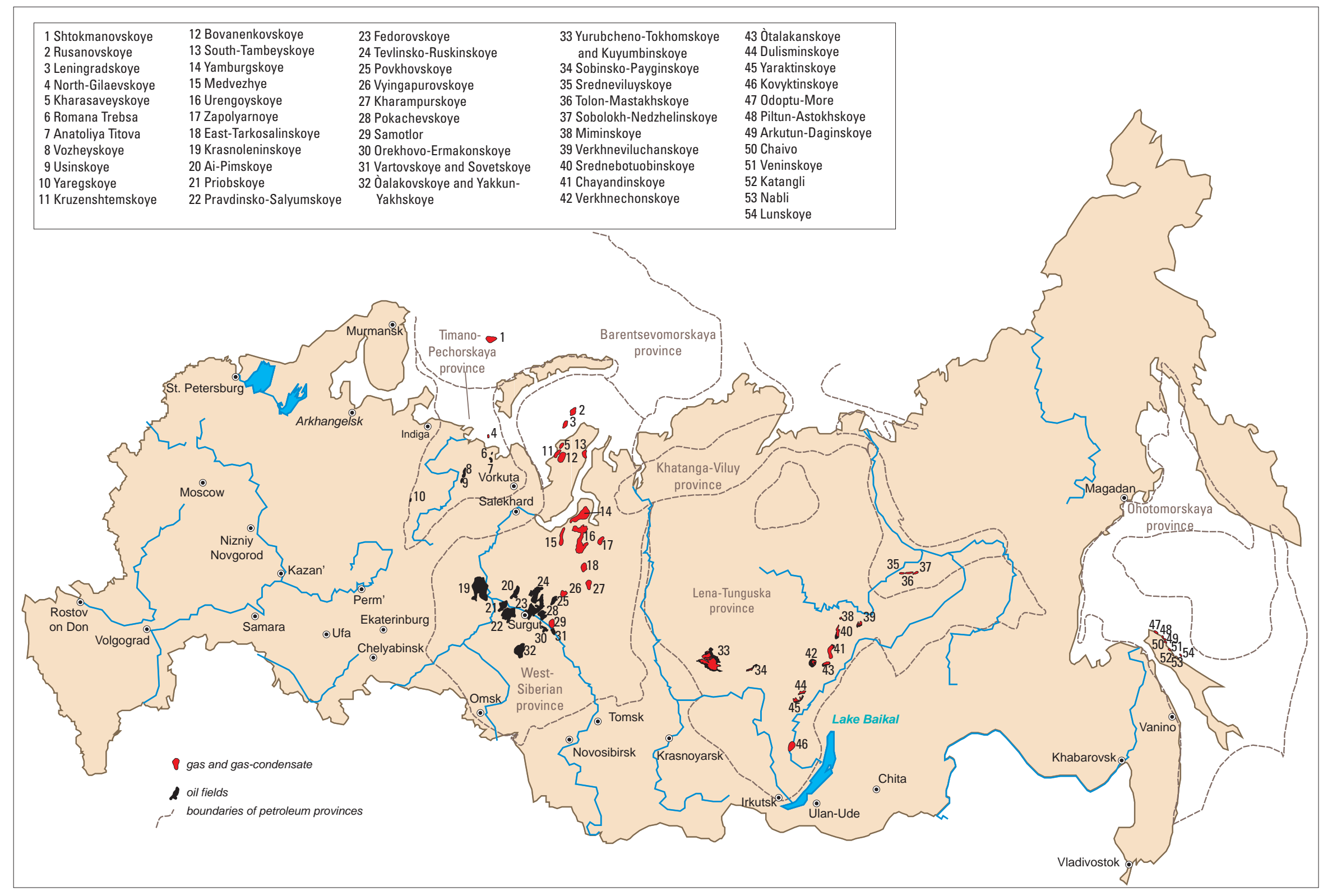

Figure 1. Map showing location of major oil and gas fields of the Russian Arctic, Siberia, and Far East. 


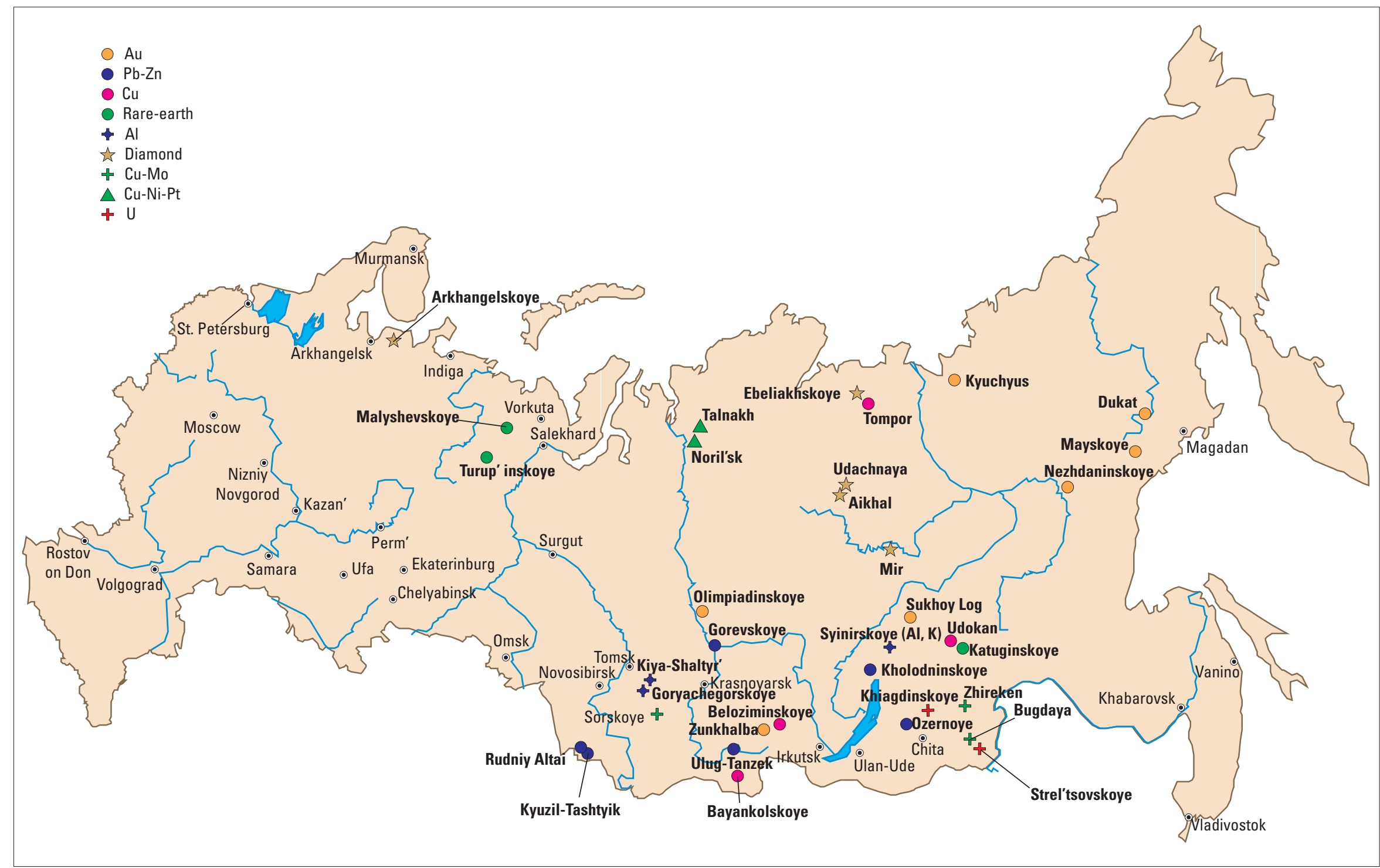

Figure 2. Map showing location of major diamond, uranium (U), noble metal ( $\mathrm{Au}, \mathrm{Pt})$, nonferrous metal ( $\mathrm{Pb}-\mathrm{Zn}, \mathrm{Al}, \mathrm{Cu}, \mathrm{Cu}-\mathrm{Mo}$, Cu-Ni-Pt), and rare earth metal deposits of the Russian Arctic, Siberia, and Far East. 


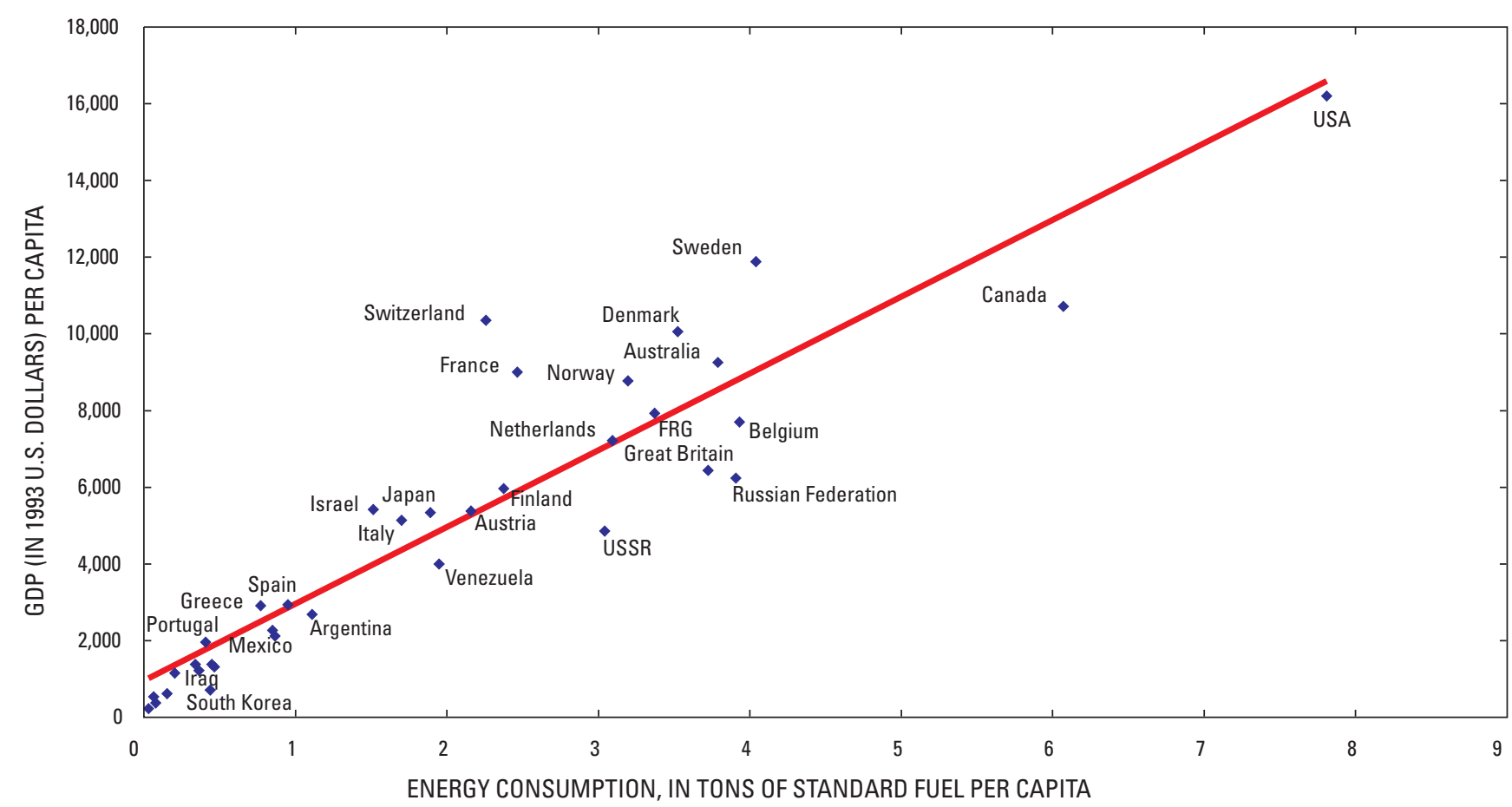

Figure 3. Graph showing the relation between gross domestic product (GDP) per capita and the consumption of energy resources by countries of the world in 1968 (modified from P.L. Kapitsa). FRG, Federal Republic of Germany.

decades and confirmed that the production and effective consumption of energy are the most important general indicators of a country's economic state. In addition, Kontorovich and others (1999a) found that an increase in the use of energy-saving technologies during recent decades accompanied a general increase in world per capita energy consumption and a growing disparity between countries in their level of energy efficiency (fig. 4).

GDP and levels of energy consumption and production were taken as basic factors in outlining a strategy for the longterm development of Russia's economy and energy industry in a global context. Factors restricting resources were also considered, including the availability of measured and indicated reserves, the profitability of present-day production and future production technologies, areal distribution of resource fields, availability of transportation, and return on investment. In addition, restrictions on the rate of GDP growth, efficiency of energy consumption, balance of energy sources (the ratio of oil, gas, coal, nuclear, and hydropower energy resources), and estimated exports of energy resources to the countries of Europe and the Asia-Pacific region were considered.

On the basis of accepted scenarios of Russia's economic development, energy consumption in the country is expected to grow from 850 million- 870 million tons of standard fuel (tsf) in 2000 to 900 million-1,000 million tsf by 2010, 1,050 million-1,130 million tsf by 2020 , and 1,175 million- 1,450 million tsf by 2030. It is very important that the increase in energy consumption is expected to be accompanied by accelerated growth in per capita GDP of 2.4 to 2.7 times during this period, with an accompanying 3.3 to 4.2 times increase in the efficiency of energy consumption. Oil and gas are expected to remain the dominant energy sources (greater than 70 percent of all energy production) until 2030, with some decrease in the percentage of oil and, correspondingly, growth in the percentage of gas. Comparative data on production of primary energy resources for Russia and other countries of the world are given in figures 5 and $\mathrm{G}$ (based on studies conducted under the direction of academician A.E. Kontorovich at the Institute of Petroleum Geology, Siberian Branch, Russian Academy of Sciences). Estimates of production levels of the main energy sources for Russia for the period 2000 to 2020 are presented in figure 7 .

\section{Siberian Energy Resources}

The distribution of oil and gas resources in different regions of Russia (figs. 8 and 9) shows that Siberian energy resources will play a determining role in any scenario of Russia's economic development in the 21 st century and will markedly affect the energy supply of countries in Europe and the Asia-Pacific region, where these resources are limited. Presently, the main base of Russia's oil and gas industry is in northern West Siberia, where 90 percent of the gas and 60 percent of the oil are produced ( 25 percent and 10 percent of worldwide production, respectively). However, future development in this region is complicated because of a significant decline in identified reserves in the giant fields, resulting in increased well depths, decreased density of reserves, and declines in production rates. As a result of Russia's economic turmoil, exploration activities in northern West Siberia have sharply decreased, and the rate of addition of new reserves has dropped behind the rate of production. 


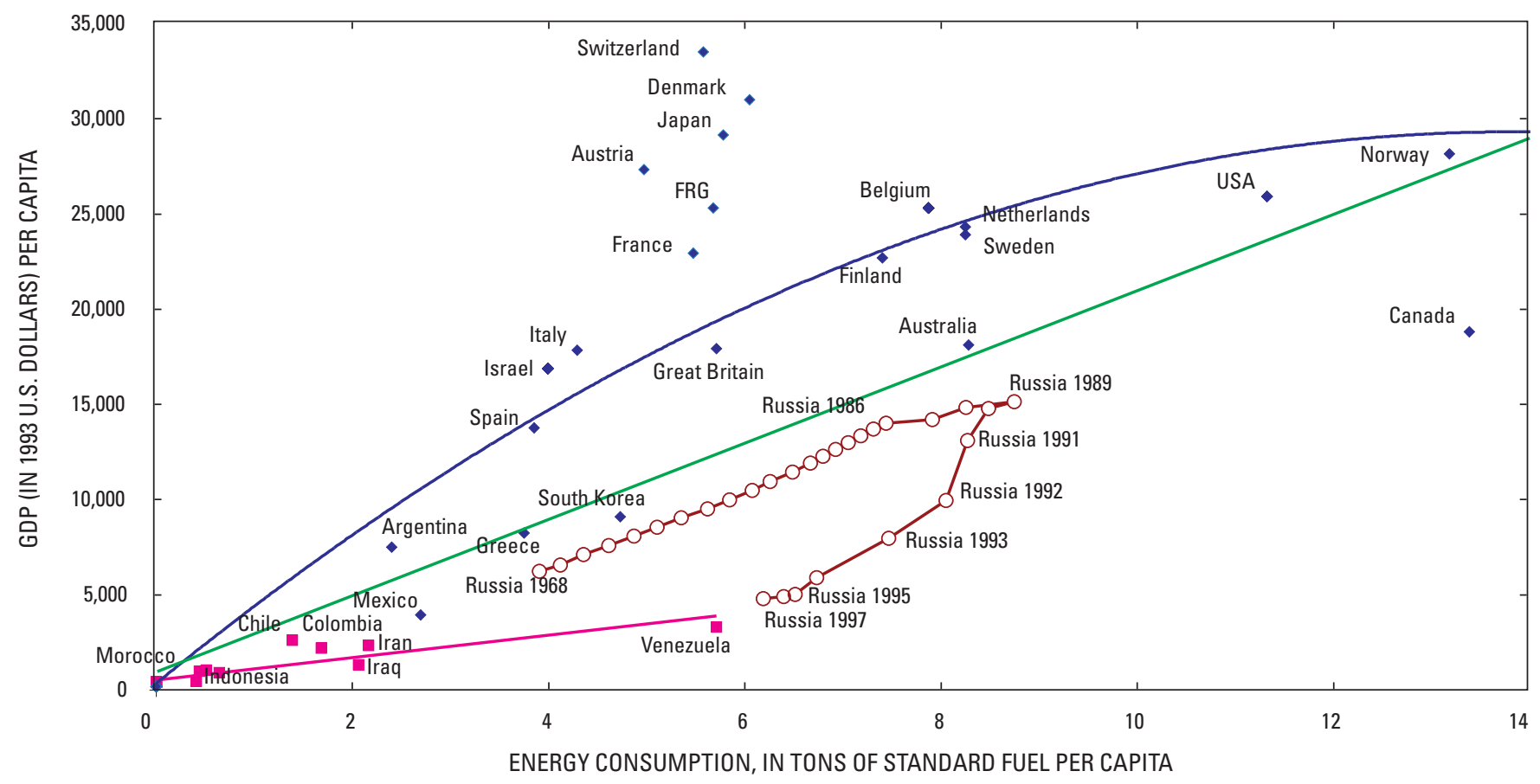

Figure 4. Graph showing the evolution of gross domestic product (GDP) per capita versus the consumption of energy resources in Russia during the period 1968-97 (hysteresis loop (red) for the Russian economy) relative to worldwide trends. Green line, average global energy consumption vs. GDP trend; blue line, fit to relatively developed countries, most of which have a GDP above the global average; pink line, fit to developing countries, most of which have a GDP below the global average. FRG, Federal Republic of Germany. From Kontorovich and others (1999a).

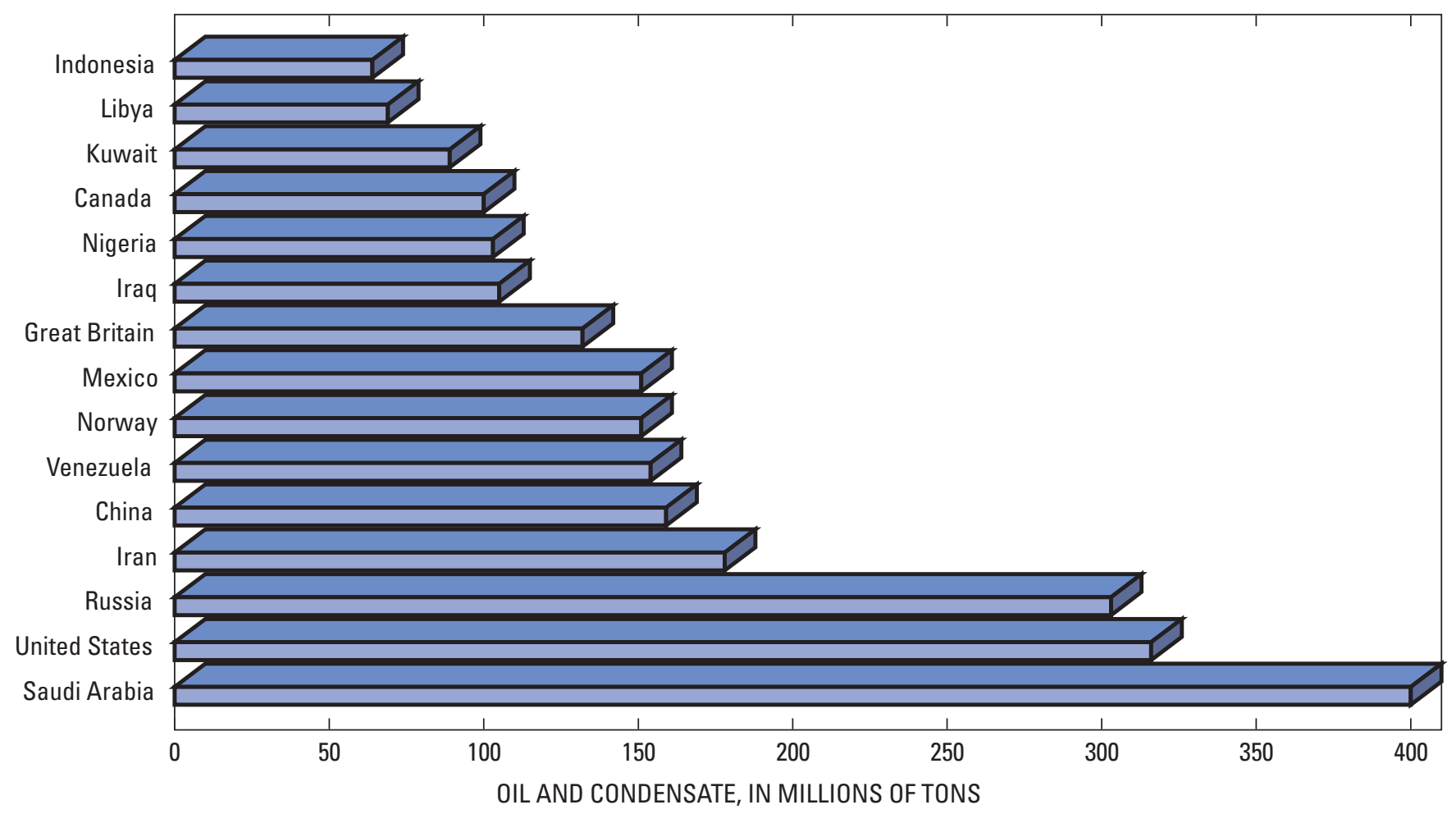

Figure 5. Graph showing oil and condensate production in 2000 by the major world producers. 


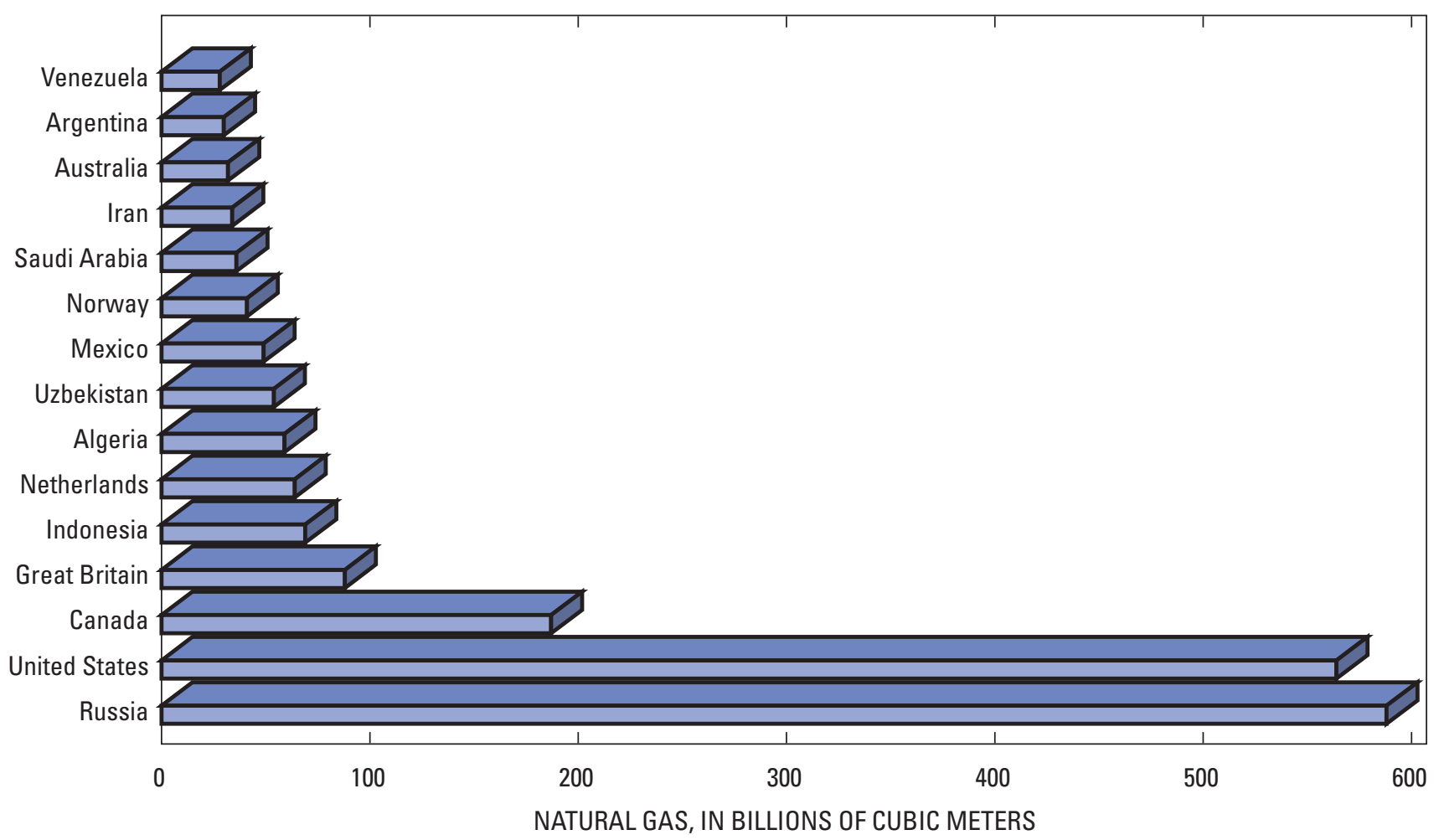

Figure 6. Graph showing production of natural gas in 2000 by the major world producers.

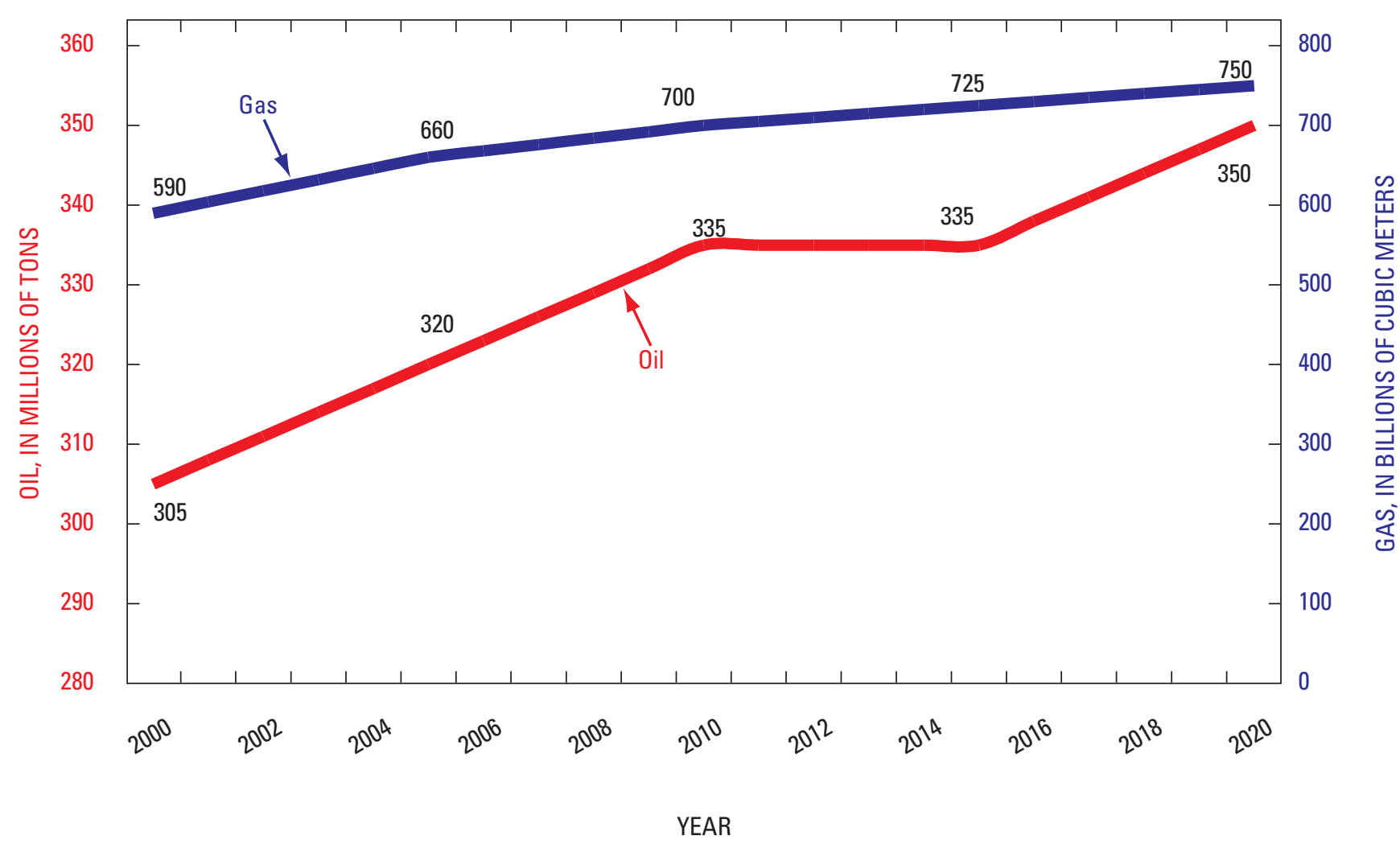

Figure 7. Graph showing forecast of oil and gas production in Russia from 2000 to 2020 (data from The Project of Energy Strategy in Russia until 2020). 


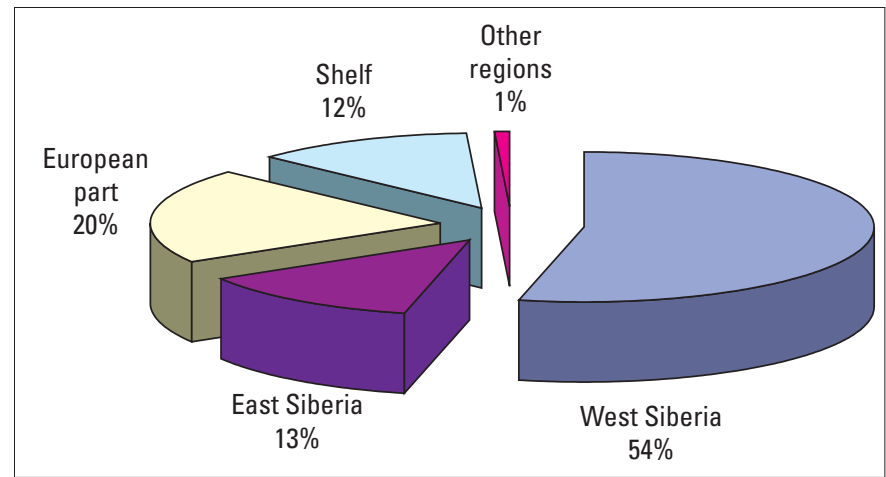

Figure 8. Pie diagram showing the distribution of in-place oil resources in Russia.

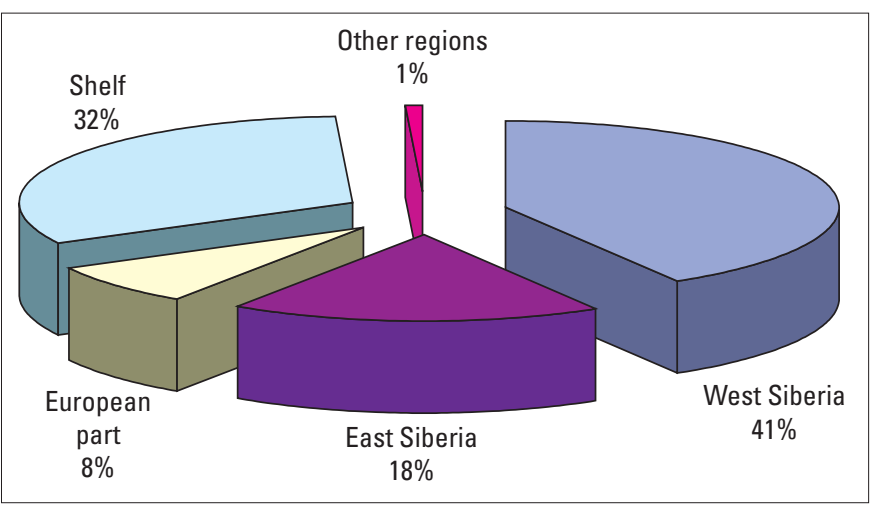

Figure 9. Pie diagram showing the distribution of in-place gas resources in Russia.

\section{Oil and Gas Resources}

In the near term, stable development and export of Russia's energy resources require continued exploration for additional reserves and improvements in development technology, particularly in the mature fields in northern West Siberia. In the middle term, the gas fields in the Yamal Peninsula (northern West Siberia), with identified reserves exceeding 10 trillion cubic meters, will need to be brought into production, and new centers of oil and gas production established in East Siberia (area of the Siberian Platform). Resource estimates made at the Institute of Petroleum Geology of the Siberian Branch of the Russian Academy of Sciences (Kontorovich and others, 1999b,c) suggest that, if the proposed scenarios of development of the oil, gas, and coal resources are realized, cumulative production in Russia will be 8.1 billion-10.9 billion tons of oil, 20 trillion-21.5 trillion cubic meters of gas, and 9.8 billion-11 billion tons of coal for 2001 to 2030. During this period, major additions to Russia's reserve base from Siberia should be at least 400 million tons per year of oil, 900 billion cubic meters per year of gas, and 350 million tons per year of coal.

For growth of Russia's energy reserve base to occur, it is necessary that exploration activity be significantly increased over current levels and that state-of-the-art drilling methods and new geophysical and research techniques be applied.
In addition, increased exploration should be supported by national economic incentives for major investments in resource development. We believe these objectives will be addressed given the significance of the predicted hydrocarbon resources in Siberia.

Scientists of the Siberian Branch of the Russian Academy of Sciences have prepared proposals on the development of some Siberian petroleum provinces and area-administrative units for the Government of Russia within the context of the new energy strategy of Russia (figs. 10 and 11). In the near term, because of current regional, national, and geopolitical conditions, emphasis should be placed on development of an oil and gas industry in East Siberia, including the Sakha Republic (Yakutia). This region has very large hydrocarbon reserves, but they remain largely undeveloped. Only the Sakha Republic (Yakutia) is a current producer of oil and gas, with a production of more than 1 billion cubic meters per year. In the remainder of East Siberia and the Russian Far East, coal, mainly in low-rank deposits, accounts for more than 70 percent of the energy base. In this region, high-energy-consuming and environmentally harmful industries also are widely

\begin{tabular}{lrrrr}
\hline \multirow{2}{*}{\multicolumn{1}{c}{ Subjects of Federation }} & \multicolumn{4}{c}{ Years } \\
\cline { 2 - 5 } & \multicolumn{1}{c}{2000} & \multicolumn{2}{c}{010} & \multicolumn{2}{c}{2020} & \multicolumn{1}{c}{2030} \\
\hline Khanty-Mansy autonomous okrug & 154,250 & 210,139 & 329,562 & 330,000 \\
\hline Yamal-Nenets autonomous okrug & 26,364 & 43,755 & 69,992 & 70,000 \\
\hline Tomsk region & 6,300 & 7,000 & 3,600 & 2,600 \\
\hline South of Tyumen region & 190 & 2,040 & 3,000 & 3,000 \\
\hline Novosibirsk region & 52 & 1,206 & 1,280 & 1,280 \\
\hline Sakha Republic (Yakutia) & 390 & 3,000 & 5,150 & 6,624 \\
Irkutsk region & & 5,379 & 6,743 & 7,341 \\
\hline Krasnoyarsk kray & 80 & 2,500 & 34,990 & 36,035 \\
\hline Total & $\mathbf{1 8 7 , 6 2 6}$ & $\mathbf{2 7 5 , 0 1 9}$ & $\mathbf{4 5 4 , 3 1 7}$ & $\mathbf{4 5 6 , 8 8 0}$ \\
\hline
\end{tabular}

Figure 10. Chart showing forecast of maximum oil production of oil fields of the West Siberian Plate and Siberian Platform under current technologies and resource base in 2000 to 2030 (values in thousands of tons).

\begin{tabular}{lcccc}
\hline \multirow{2}{*}{ Subjects of Federation } & \multicolumn{4}{c}{ Years } \\
\cline { 2 - 5 } & 2000 & 2010 & 2020 & 2030 \\
\hline Khanty-Mansy autonomous okrug & 12,989 & 14,000 & 11,621 & 5,606 \\
Yamal-Nenets autonomous okrug & 527,030 & 603,160 & 610,000 & 615,570 \\
Tomsk region & & 8,151 & 10,200 & 10,200 \\
Sakha Republic (Yakutia) & 1,868 & 11,610 & 44,530 & 77,649 \\
Irkutsk region & & 25,677 & 26,764 & 18,520 \\
Krasnoyarsk kray & & 9,771 & 27,753 & 15,841 \\
\hline Total & $\mathbf{5 4 1 , 8 8 7}$ & $\mathbf{6 7 2 , 3 6 9}$ & $\mathbf{7 3 0 , 8 6 8}$ & $\mathbf{7 4 3 , 3 8 6}$
\end{tabular}

Figure 11. Chart showing forecast of maximum gas production of gas fields of the West Siberian Plate and Siberian Platform under current technologies and resource base in 2000 to 2030 (values in millions of cubic meters). 
developed. In comparison to the European part of Russia, Western Europe, and North America, consumption of cleaner fuels such as natural gas is very low in East Siberia and the Russian Far East, as well as in countries of the Asia-Pacific region geographically close to Siberia. Only Japan, which does not possess significant resources of natural gas, consumes gas in significant quantities. In Japan, environmental protection legislation prohibits the use of coal in electric power stations (with the exception of Hokkaido).

Current estimates suggest that the actual demand for natural gas in southern East Siberia and the Russian Far East by 2010 is expected to be about 30 billion- 40 billion cubic meters per year. In addition, demand for natural gas in China, Japan, and Korea is estimated to be more than 50 billion cubic meters per year.

In the 1970s through the 1980s, before the current economic crisis in Russia, significant geologic exploration was conducted in East Siberia and the Sakha Republic (Yakutia). In this region, annual deep wildcat and exploratory drilling was up to $300,000-350,000$ meters, and up to 20,000 kilometers of seismic profiles were laid out by the common-depth-point (CDP) method. This work resulted in the discovery of more than 35 oil and gas fields during a short period, many of which are very large. Development of the petroleum fields in the region (for example, Lena-Vilyuy, Nepa-Botuoba, Katanga, Baikit, and Angara-Lena) will be important for creating a successful oil and gas industry in the region.

Among the most prospective targets in East Siberia are the Yurubcheno-Tokhomskoye oil-gas field (Krasnoyarsk Territory) and the Kovyktinskoye gas field (Irkutsk region). In the Yurubcheno-Tokhomskoye field, which is the world's oldest recognized giant oil-gas deposit hosted in a sedimentary cover sequence ( 1 billion-1.4 billion years old), the predicted reserves are estimated at about 1 billion tons of oil and about 1 trillion cubic meters of gas. In the Kovyktinskoye field, gas reserves are estimated at about 1 trillion cubic meters. The identified and predicted resources in these fields would allow the creation of one of the world's largest oil and gas producers, which could provide energy supplies not only to Siberia and the Russian Far East but also to countries in the neighboring Asia-Pacific region.

In light of the energy resources already identified in East Siberia and those predicted to occur, annual gas production in the region could be brought to 125 billion-175 billion cubic meters. Thus, development of these large natural gas resources, along with production of associated oil, could provide a stable source of environmentally clean energy to a region having a significant portion of the world's population for a period of at least 50 to 60 years. If the last quarter of the 20th century is considered as a period of growth and development of an oil and gas industry in European Russia and West Siberia, then the first decades of the 21st century should be the period of growth and development of a similar industry in the East Siberia and AsiaPacific region. The realization of this level of development of a new energy-producing industry in East Siberia and the Asia-
Pacific region should be among the highest priorities for Russia in the first quarter of the 21 st century.

Achieving this level of development will require a rapid increase in geologic exploration in the region and the planning and construction of a large system of gas pipelines and related processing and manufacturing operations. This, in turn, will require large financial investments, particularly with regard to providing necessary environmental protection. The rate of financial return from such a program of natural gas development can be significantly increased by the simultaneous development of oil fields and creation of a large-scale petrochemical industry. Additional support could come from construction of a major helium industry based on the unique association of helium reserves with many of the oil fields. In the 1970s through 1980s, the Soviet Union succeeded in developing such an energy program in West Siberia and Europe with support of some West European countries. It is necessary now that Russia and its eastern neighbors concentrate their efforts to fulfill a similar development program in East Siberia and the Russian Far East.

For the more distant future, the undeveloped resources of Russia's continental shelf in the Arctic and Far East seas may represent the world's largest remaining reserve of hydrocarbons (Gramberg and Laverov, 2000). Although the very low level of past exploration in these areas precludes a reliable estimate of their actual hydrocarbon resources, very high potential can be inferred from exploration criteria such as the total area and thickness of the sedimentary cover; presence of local structures; optimum combination of oil source, reservoir, and sealing rocks; paleogeographic and structural-geodynamic prerequisites; high success ratio of exploratory drilling; and other factors fig. 12.

Three giant gas fields, Shtokmanovskoye, Rusanovskoye, and Leningradskoye, have been discovered on the shelves of the Barents and Kara Seas. These discoveries were made as a result of minimum drilling (with a success ratio of 31.2 percent in the Barents Sea and 66.6 percent in the Kara Sea). No wildcat drilling has been conducted in the eastern sector of the Arctic and Far East seas; however, geologic criteria indicate that the discovery of large new fields can be expected there.

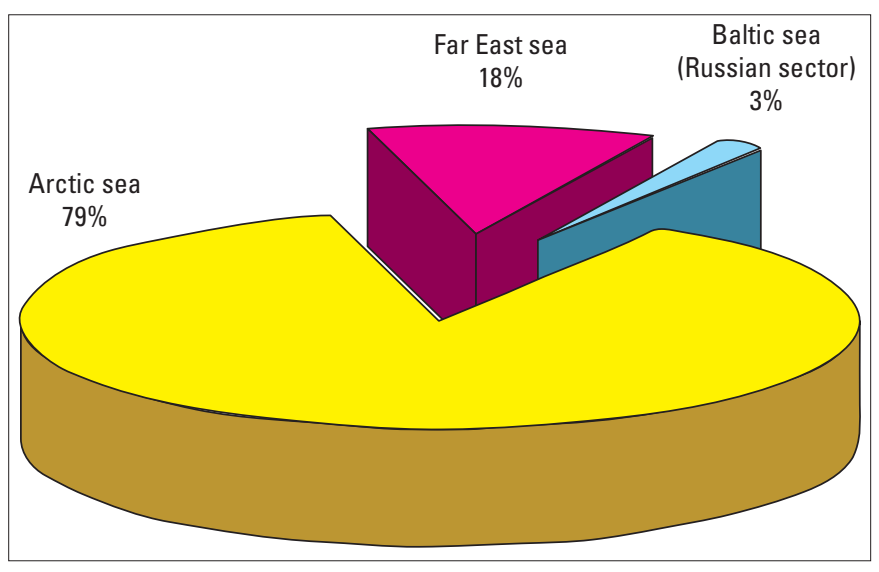

Figure 12. Pie diagram showing the distribution of initial extracted resources of hydrocarbons in the seas of Russia. 
In total, the hydrocarbon resources of the Arctic shelf are estimated at a minimum of 83 billion-110 billion tons (as converted to oil), and those of the Far East region (shelf with adjacent continental areas) at 0.4 billion tons of oil and 1.6 trillion cubic meters of gas. Although estimates of Arctic and Far East hydrocarbon resources made by different groups of specialists sometimes differ, all estimates suggest a high hydrocarbon potential in these regions. However, development of these resources will require large investments, particularly for the development of marine resources. In the future, energy also may be derived from gas hydrate reserves of the Arctic regions. The development and use of gas hydrate resources are, nonetheless, still at an early stage of scientific and technological investigations. In any scenario for the future development of world energy supplies, the resources of Siberia and its adjacent shelves will be of great significance not only for Russia but also for other countries of the world.

\section{Coal Resources}

The coal industry of Siberia is also of great importance to Russia's economy. With the change to a free-market economy, the coal industry is in drastic need of restructuring. Recently, the problems of the coal-mining industry were considered by academician K.N. Trubetskoi (2000) and those of the coal-producing industry were considered by Y.N. Malyshev (2000). The resource, economic, and environmental problems of Siberia's operating coal mines also have been analyzed by G.I. Gritsko (1999). Analysis of the situation has shown that most coal mines in the European part, Far East, and north of the country appear to be uneconomic under new economic conditions and should be shut down. Restructuring of the coal industry will necessitate reestimation of coal reserves throughout Russia. All the identified coal reserves (201.7 billion tons) have been divided into favorable and unfavorable, taking into account economic, environmental, and mining factors. This analysis suggests that about 40 percent of Russia's current coal reserves are subeconomic to uneconomic.

A great majority of the most favorable, well-explored, and especially commercial coal reserves in Russia are concentrated in the two largest coal-producing regions of West Siberia-the Kuznetsk coal basin and the Kansk-Achinsk browncoal basin. Lesser reserves also are located in deposits in East Siberia and the Russian Far East. The development potential of high-quality, economic coal deposits in Western (European) Russia and the Urals appears to be very limited. Thus, the main areas of future coal production in Russia will be concentrated in Siberia. Development of these coal resources, however, may result in increased environmental impacts.

Along with restructuring of Russia's coal industry and the economic production of coal for traditional applications (energy, coke chemistry, export), new technologies and uses for coal should be developed; for example, thermochemical processing to produce valuable fuel and nonfuel products, such as synthetic liquid fuel, adsorbents, mineral wax, and humates.
In addition, new technologies should be applied for the recovery and utilization of coal-bed methane from underground developments. Recovery of the methane would provide an important additional energy source and help address the dangerous problem resulting from gas concentrations in underground coal mines. Current estimates suggest that the major coal basins of Russia contain at least 60 trillion cubic meters of methane (Methane Emissions Mitigation, 2000). This amount is equal to almost 30 percent of the resources in conventional gas fields and represents about half of the world reserves of coal-bed methane (133 trillion cubic meters).

The main source for coal-bed methane in Russia is the Kuzbass basin, the interior of which contains up to 13 trillion cubic meters of gas to a depth of 1.8 kilometers. Most of the methane is concentrated in giant deposits, with the density of methane resources reaching 600 million-1,200 million cubic meters per square kilometer (Methane Emissions Mitigation, 2000). This density is 4 to 5 times as great as that in the developed San Juan field in the United States.

Presently, new technologies are being devised for the enrichment and thermochemical processing of coals, as well as for producing, transporting, and burning water-coal suspensions. Combustion of water-coal suspensions results in significantly lower emissions of ash, sulfur oxides, and nitrogen into the atmosphere. Currently, an experimental system is being built to transport a water-coal suspension 264 kilometers from Kuzbass to Novosibirsk. When completed, its annual production capacity is expected to be 3 million tons.

The identified coal resource base of Siberia is sufficient to meet Russia's coal needs for many more decades. In the future, the fields in the northern regions of Siberia, particularly the giant Tunguska coal basin in the Siberian Platform, will provide additional coal resources that can be brought into production.

\section{Siberian Mineral Resources}

The regions of Russia's Arctic, Siberia, and Far East also possess significant concentrations of other strategic mineral resources, such as gold, diamonds, and base and noble metals fig. 2). Presently, the value of mineral exports from these areas accounts for about 60 percent of all Russian exports, with the base metals nickel and cobalt representing more than 20 percent of world sales and platinum-group metals about 50 percent. In total, Russia exports 93 percent of its produced aluminum, 94 percent of its nickel, 77 percent of its copper, 67 percent of its zinc, 62 percent of its uranium, 60 percent of its oil and oil products, 31 percent of its tin, and 32 percent of its gas resources, all mainly from Siberia.

Major gold deposits are concentrated in Siberia. The highest priority deposits for commercial development and significant gold production are the Sukhoy Log deposit in the Irkutsk region, containing about 1,000 tons of gold and at least 500 tons of platinum-group metals; the Olimpiadinskoye deposit in the Yenisey Range, Krasnoyarsk Territory, with 
more than 600 tons of gold; the Kholbinskoye deposit in Eastern Sayan (not shown in fig. 2), with more than 500 tons of gold; the Nezhdaninskoye deposit in Yakutia, with about 500 tons of gold; and a number of deposits in the Magadan region. In the Sukhoy Log deposit, large-scale production totaling $20-30$ tons of gold is feasible. In total, by 2005 gold production could be increased by $50-60$ tons per year in the regions of East Siberia and the Far East. Along with development of the Sukhoy Log gold deposit, development should begin of the large deposits in the Udokan (copper), Katuginskoye (rare earth elements), and Northern Baikal (lead, zinc) regions along the main Baikal-Amur railroad.

The Noril'sk mining complex is the major producer of nickel, copper, and platinum-group metals in Russia. Stable development of the Noril'sk mining complex can be achieved, in spite of exhaustion of reserves of rich sulfide ores, by bringing large reserves of lower grade platinum-bearing disseminated ores into production and by improving recovery of associated mineral commodities.

Siberia may also offer a solution to the problem of providing Russia with sufficient alumina raw material. It is known that Russia does not possess significant bauxite resources. However, the predicted resources of nepheline and syenite resources that could serve as a raw material for producing aluminium are significant in southern Siberia (Kemerovsk region, Krasnoyarsk Territory, Tyva Republic, Buryat Republic). The positive results of the Achinsk alumina plant, which is using nepheline to produce aluminum without a decline in production levels, shows the feasibility of using domestic feldsparrich materials to replace imported bauxite.

Russia also has very good prospects to increase production of high-quality diamonds. Achieving increased diamond production, however, requires the active support and participation of the Government. A serious problem for the diamond-producing industry of Yakutia is the increase in depth of rich deposits, which makes inevitable the transition to underground mining. Increased diamond production also requires that development begin of the new high-grade kimberlite pipes found in recent decades in the Yakutsk and Arkhangelsk regions.

\section{Economic and Environmental Factors Affecting Development}

One of the most important economic and environmental issues related to the use of Siberian mineral resources is the application of environmentally and economically efficient technologies to deal with the materials in waste (tailings) dumps from mining operations. Many past attempts to process waste materials have had a low efficiency, with only selective recovery of a limited number of useful components from these complex deposits. This problem has led to the accumulation of large waste dumps, some of which contain dangerous environmental pollutants. At the same time, many of the waste dumps can be considered as secondary resources (manmade deposits) for many types of commodities, particularly noble (platinoids, gold, silver) and base metals, rare earth elements, and diamonds. Consideration of this problem in detail is beyond the scope of this paper, and we discuss it only conceptually here.

At the present time, mining science in Russia emphasizes the development of new methods for effectively processing complex raw materials (including waste dumps), new technologies fostering the most effective reduction or removal of various waste materials, and new methods to help prevent irreversible changes in the environment. Saving water and land areas is an important function of these technologies. Technologies that reduce the amount of waste allow for more effective use of natural resources and greater efficiency in mining operations. This effort includes obtaining additional production from and rehabilitation of quarries and mines; reducing dangerous dust and gas emissions into the atmosphere; reducing the release of quarry and mine waters into local and remote water basins; and decreasing the removal of valuable lands for locating dumps and other waste storage facilities. Because land areas and water resources have been damaged or destroyed by the wastes from mining and mineral processing operations, choosing technologies that reduce the amount and toxicity of waste materials should be a determining factor in decisions regarding future development and processing of mineral resources.

The mineral raw material base of the 21 st century will be affected by the depletion of many large near-surface deposits having relatively high concentrations of mineral commodities. This depletion will necessitate the application of new mining and processing methods to allow development of previously uneconomic mineral deposits, as well as exploration for and development of deposits of varying sizes and grades at greater depths and in remote areas. In addition, it will be necessary to develop the mineral raw materials of the continental shelves and reprocess waste materials (for example, tailings) from past mining operations.

The development and use of Siberian mineral resources will depend on the solution of a number of critical economic and environmental problems. These include the following:

1. The development and use of new economically efficient and environmentally safe technologies for the mining and processing of mineral resources and reprocessing of materials in existing waste dumps, many of which contain environmentally harmful pollutants.

2. Monitoring and scientific study of predicted environmental changes, particularly in the northern regions of Siberia, where the danger of catastrophic degradation of permafrost due to worldwide climatic warming is particularly acute and has serious consequences for the oil, gas, and mineral industries and associated social infrastructure.

3. Reduction of methane emissions into the atmosphere during the development and transport of gas, oil, and coal. Presently, methane content in the atmosphere increases by 1-2 percent annually. This problem and others were considered at the $2 \mathrm{~d}$ International Conference "Methane 
Emissions Mitigation" held in Novosibirsk, in June 2000. At the conference, particular emphasis was placed on the necessity of mitigating methane emissions from the petroleum and coal industries in Siberia; these emissions total about 30 percent of the natural methane balance.

4. Preservation of fragile ecosystems during the development of mineral resources, including in the Lake Baikal and Gornyi Alatai regions that have received special World Heritage Site status from the United Nations Educational, Scientific and Cultural Organization (UNESCO).

Lake Baikal, with its unique ecosystem (80 percent of the biological species are endemic) and the largest freshwater reserves in the world, can be considered a prime example of the need for appropriately planned and regulated development of natural resources in a unique and fragile environment. Since the 1950s to 1960 s, the scientists of the Siberian Branch of the Russian Academy of Sciences, first, under the guidance of academician A.A. Trofimuk, and then academician V.A. Koptyug, have been playing a leading role in the struggle for conservation of Lake Baikal and its adjacent landscapes.

It has taken the focused long-term efforts of scientists, as well as the heightened concern of the public and involvement of the international scientific community, to change government and industry policies in the Lake Baikal region from ones focused only on the development of natural resources to ones that include protection of the environment. This change in policies has led to stopping the development of environmentally harmful industrial plants, new environmental regulations for operating industries like pulp and paper mills, and efforts for a Federal law granting special protective status to the Baikal region. Such protective status would help assure that future development of the region's natural resources also preserves the integral ecosystems and biodiversity of the entire Baikal region (water basin and adjacent areas), as well as conserves the functional and aesthetic aspects of the natural environment. For these reasons, strict environmental regulations have been developed for licensing geologic exploration and development technologies for the unique base-metal deposits (Udokan and Kholodninskoye, fig. 2) located in the conservation zone of the Lake Baikal region.

Recognition of the unique character of the Lake Baikal region both nationally and internationally has led to its becoming the focus for the design and testing of new strategies for environmental and resource management in Russia. Further, this recognition has led to establishment of several cooperative international scientific investigations in the Baikal region, whose results have helped shape regional and global environmental policies. According to incomplete data, more than 20 international governmental and nongovernmental organizations are offering significant funding for environmental studies in the Lake Baikal region. With the support of the international community, the Lake Baikal region was designated a World Heritage Site by UNESCO. On the initiative of academician V.A. Koptyug, the Baikal region has been recommended to the consulting board on sustainable development, under the
General Secretary of the United Nations, to serve as a global model for sustainable development.

An international conference on the general problems of Russian and international foundation cooperation for investigations in the Lake Baikal region was held in Ulan-Ude, September 9-12, 1998. Considered in some detail at the conference were interdisciplinary projects supported by the International Association for Promotion of Cooperation, with scientists from the independent states of the former Soviet Union and other international foundations, as well as the projects and programs of technical assistance performed within the framework of Technical Assistance for the Commonwealth of Independent States, World Bank programs, and others. Also discussed at the conference were the prospects of further international cooperation and recommendations for regulations for economic development and environmental protection and monitoring on the local, national, and international level. Results of the conference are published in Dobretsov (1999).

Many of the conclusions and recommendations made at the Ulan-Ude conference on Lake Baikal can be applied to problems of sustainable resource management in other regions of Siberia. Many of the problems are particularly characteristic of the northern and eastern regions of Siberia that contain the major mineral resources. Along with international and state regulations, of special importance for the efficient management of natural resources (including mineral resources) in these regions is the direct involvement of local jurisdictions to incorporate the interests of native populations to preserve their cultural heritage.

\section{Conclusions}

Because of the difficult social and economic conditions currently in Russia, many of the policies required for sustainable national and regional development programs have yet to be established. Russia's transition to a free-market economy presents specific difficulties, particularly with regard to laws regulating financial return on resource production (especially mineral resources) and criteria and methods for monitoring natural resource development at the Federal, regional-administrative, and local levels. However, the general trends in current strategic development of Russia follow the principles of sustainable development stated at the world conference in Rio de Janeiro in 1992. The examples highlighting the success of addressing the most critical economic and environmental problems in Siberia convincingly illustrate the benefits of an increased role of science and international scientific cooperation in the modern world.

\section{Acknowledgments}

The authors sincerely thank and are indebted to Dr. Klaus J. Schulz of the U.S. Geological Survey (USGS) for his comprehensive review comments and editorial handling that significantly improved the structure and clarity of the manuscript. We also thank also Drs. Joseph A. Briskey and 
Warren J. Nokleberg (both of the USGS) for their assistance in publication of this paper.

\section{References Cited}

Dobretsov, N.L., ed., 1999, Baikal as an area of the World Heritage List-Results and prospects of international cooperation-Transactions of the International Conference, Ulan-Ude, Russia, September 9-12, 1998: Novosibirsk, Siberian Branch, Russian Academy of Sciences, 312 p.

Gramberg, I.S., and Laverov, N.P., eds., 2000, The Arctic on the threshold of the third millennium (resources potential and ecological problems): St. Petersburg, Nauka Press, 247 p. (In Russian with English summary and table of contents.)

Gritsko, G.I., 1999, The role of coal in Russia's fuel-energy complex and ecological problems of a coal-producing region in transition to sustainable development, in International scientific conference on the 275th Anniversary of the Russian Academy of Sciences, Ecological problems of the coal industry in a region during transition to sustainable development: Kemerovo, Kuzbassvuzizdat, v. 1, p. 23-27.

Kontorovich, A.E., Dobretsov, N.L., Laverov, N.P., Korzhubaev, A.G., and Livshits, V.R., 1999a, Energy strategy of Russia in the 21st century: Vestnik RAN, no. 9, p. 771-789. (In Russian.)

Kontorovich, A.E., Korzhubaev, A.G., and Livshits, V.R., 1999b, Oil- and gas-producing complex and the future of Russia, in Science of Tyumen at the turn of the century: Novosibirsk, Science Press, p. 20-42. (In Russian.)
Kontorovich, A.E., Korzhubaev, A.G., and Livshits, V.R., 1999c, The prospects of development of Russia's economy and fuel-energy complex in the first decades of the XXIst century, in Collection of reports at the conference "Petroleum Geology at the Boundary of Centuries-Forecast, Prospecting, Exploration and Development of Fields," v. 3, The raw material base of Russia's oil industry, its structure and prospects of development: St. Petersburg, VNIGRI, p. 232-250. (In Russian.)

Malyshev, Y.N., 2000, Technology of development of coal deposits at the boundary of centuries, in Evolution of new scientific trends and technologies of development of the Earth's underground resources: Moscow, p. 132-144. (In Russian.)

Meadows, D.H., Meadows, D.L., Randers, Jorgen, and Behrens, W.W., III, 1972, The limits to growth-A report for the Club of Rome's project on the predicament of mankind: New York, Universe Books, 205 p.

Methane Emissions Mitigation, 2000, Reports of the 2nd International Conference, Novosibirsk, June 18-23, 2000: Novosibirsk, Institute of Coal and Coal Chemistry of the Siberian Branch of the Russian Academy of Sciences, $711 \mathrm{p}$.

Trubetskoi, K.N., 2000, The problems of mining sciences in relation to scientific-technological evolution in development of the Earth's underground resources, in Evolution of new scientific trends and technologies of development of the Earth's underground resources: Moscow, p. 4-22. (In Russian.) 


\title{
Mineral Supply and Demand into the 21st Century
}

\author{
By Stephen E. Kesler ${ }^{1}$
}

\section{Introduction}

World population is growing faster than at any time in history, and mineral consumption is growing faster than population as more consumers enter the market for minerals and as the global standard of living increases fig. 1). Does this mean that we will face a mineral supply crisis in the 21 st century? If so, can we solve this mineral supply crisis by increased mineral exploration, and will this exploration require more geological information and better land access? Answers to these questions must be based on predictions of world demand for minerals into the 21 st century, along with a better understanding of the relation between global mineral reserves and those in individual deposits. Where, exactly, are our future mineral reserves and what do we know about them?

\section{World Demand for Minerals}

World demand for minerals will be affected by three general factors - uses for mineral commodities, the level of population that will consume these mineral commodities, and the standard of living that will determine just how much each person consumes. As new materials and applications are found, markets for mineral commodities can expand considerably. An example is seen in strontium, which was not widely used until the 1960s, when it was found to be the most cost-effective means of preventing radiation from escaping from color television picture tubes. This new market stimulated extensive exploration and the discovery of many new strontium deposits.

Although it is impossible to foresee all of the new products that will be developed for use by society in the future, they certainly will be composed of chemical elements and minerals from Earth because there is no other source from which they can be obtained. Furthermore, energy constraints will require that most of these products consist largely of elements and minerals that can be obtained from Earth with a minimal investment of energy. Thus, minerals will retain their dominant role as the basis for products used by society and, therefore, as the basis for world manufacturing and agriculture. Until new and significantly cheaper energy sources

${ }^{1}$ Department of Geological Sciences, University of Michigan, Ann Arbor, MI 48109, U.S.A. (e-mail: skesler@umich.edu). become available, global mineral demand probably will focus on the same metals and minerals that are of interest today.

Population will have a bigger effect on future mineral demand than the creation of new products and markets. Projections of future population range widely, depending on estimated fertility rates. For low fertility rates of 1.5 to 1.6 children per female, which are below the "replacement rate" of 2.1, world population is projected to increase from about 6 billion to about 7 billion people and then to decline after that, reaching the 1950s level of 2.5 billion in about 2150. If, on the other hand, global fertility rates remain at 2.5 to 2.6 , world population will reach about 25 billion in 2150 . For 2050, these two extremes would yield world populations of 7 billion or 11

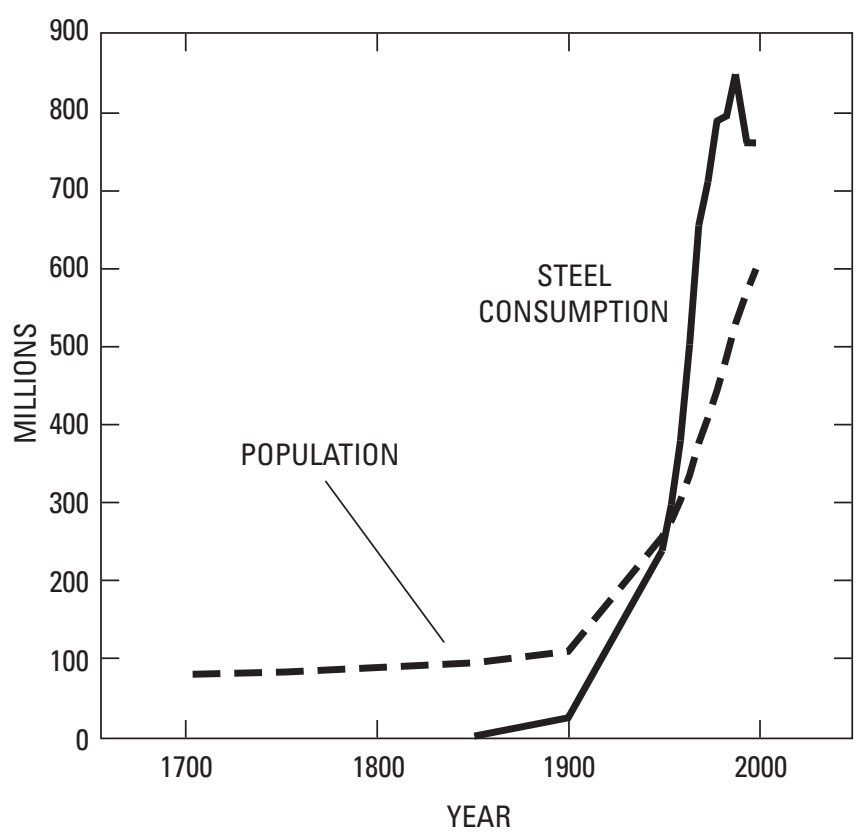

Figure 1. Schematic illustration of the change in world steel consumption and population since 1700. Dashed line shows world population (millions of people divided by 10), and solid line shows steel consumption (millions of metric tons). As for all mineral commodities, the growth of steel consumption has greatly outpaced the growth of population, reflecting increasing per capita demand for minerals. Data for this plot are from United Nations $(1966,1973,1995)$ population reports and the U.S. Bureau of Mines (1953-93) and U.S. Geological Survey (1997 and 2002) "Minerals Yearbooks" for 1950, 1955, 1960, 1965, 1970, 1975, 1980, 1985, 1990, 1995, and 2000. 
billion, largely because population changes related to low fertility rates will not yet have begun to decline and those related to high fertility will not have begun to accelerate.

Although these two estimates of world population in 2050 differ greatly, they are not likely to result in mineral demand that differs by the same amount. This is likely because there generally is a negative relation between per capita mineral demand and population for most countries (fig. 2). For instance, China and India had per capita copper consumption in 1998 of 0.6 and 2.7 pounds, respectively, whereas South Korea and Taiwan, with significantly smaller populations, had per capita copper consumption of 29.2 and 66.7 pounds, respectively. This relation reflects the greater difficulty of raising the standard of living of large populations compared to small populations, a point that is well illustrated by Singapore, which has a higher per capita income than many western countries, in part because it has a very small population. Because most future population growth will result from increases in developing countries where the standard of living is low, the effect of higher populations on total mineral consumption will not be great, at least within the range of present estimates through 2050. Taking a middle estimate of about 9 billion for global population in 2050 and assuming that each additional person will demand slightly less than the one before him or her suggest that increasing population could increase mineral demand by about 25 percent between 2000 and 2050.

Variations in the standard of living could affect future mineral demand more than population increases will. Per capita consumption of almost all minerals has increased in most areas during the last century, and the biggest differences and changes were related to increased standards of living. Asian countries have shown particularly impressive growth over the last few decades fig. 3). The increase in per capita copper consumption in Asia ranged from a low of about 40 percent in India to a high

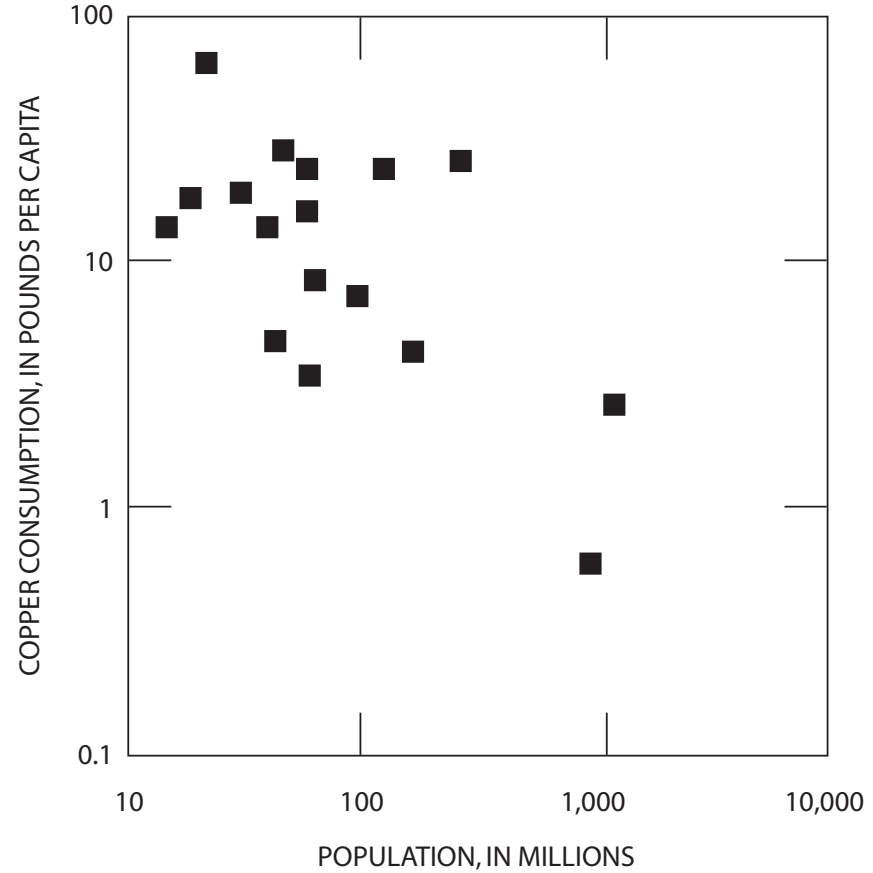

Figure 2. Graph showing per capita copper consumption vs. population in 1998 for the United States, Canada, Mexico, Brazil, Chile, France, Spain, United Kingdom, China, Korea, Thailand, Taiwan, India, Japan, Turkey, South Africa, and Australia. Data from American Bureau of Metal Statistics (various years) and the U.S. Census Bureau Web site at http://www.census.gov/ipc/www/ idbrank.htm.

of about 82 percent in Taiwan between 1985 and 1998. Changes in per capita copper consumption in developing countries in other parts of the world have been smaller, but still positive, although only barely so for Brazil and South Africa (fig. 4).

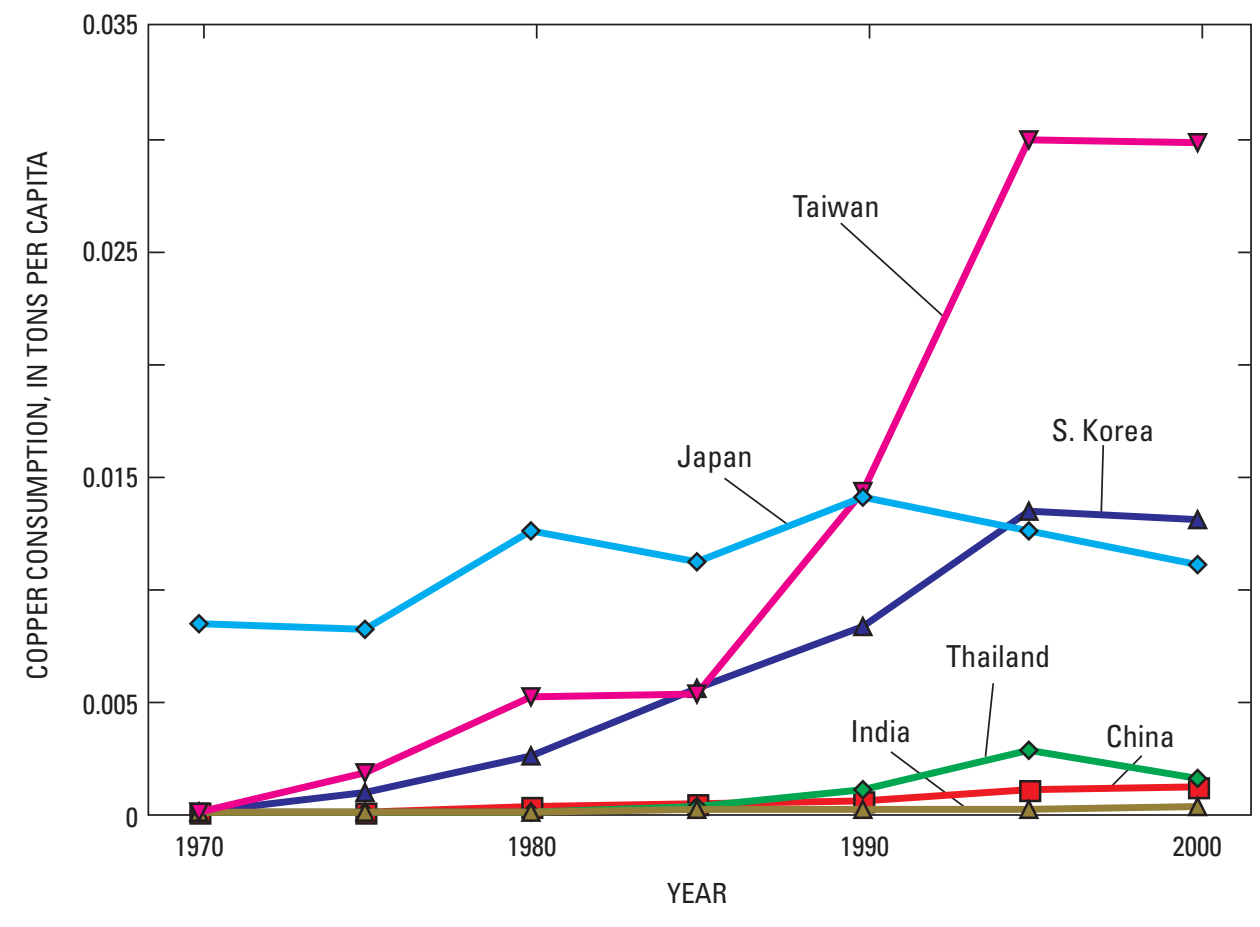

Figure 3. Graph showing changes in per capita copper consumption in China, Thailand, South Korea, Taiwan, India, and Japan during the period 1970-2000. Data from American Bureau of Metal Statistics (various years) and the U.S. Census Bureau Web site at http://www.census. gov/ipc/www/idbrank.html. 
Changes in per capita copper consumption in most developed countries also have been small and over the period 1970-2000 have ranged from positive for the United States, France, and Spain to negative for the United Kingdom, Canada, and Australia (fig. 5). Despite these regional differences, there have been overall increases in per capita copper consumption for the entire world of about 11 percent between 1985 and 1998 and 13 percent over the period 1971 to 1998 (fig. 6).

These rough comparisons suggest that the increases in population and standards of living will have relatively similar effects on global mineral demand. With each of these amount- ing to about 0.5 percent annually, the combined total increase in global mineral demand should be approximately 1 percent per year. Economic cycles, recycling, and other factors are likely to be second-order controls on overall demand for new minerals over this time span, although they will be important locally and for shorter periods. Although per capita mineral consumption does vary with economic cycles, the trend toward gradually increasing global demand has been clear for many decades and is likely to remain in place. Thus, regardless of exact demand, it is almost certain to be higher than it is today, even if population does not increase. Some of the increased demand caused
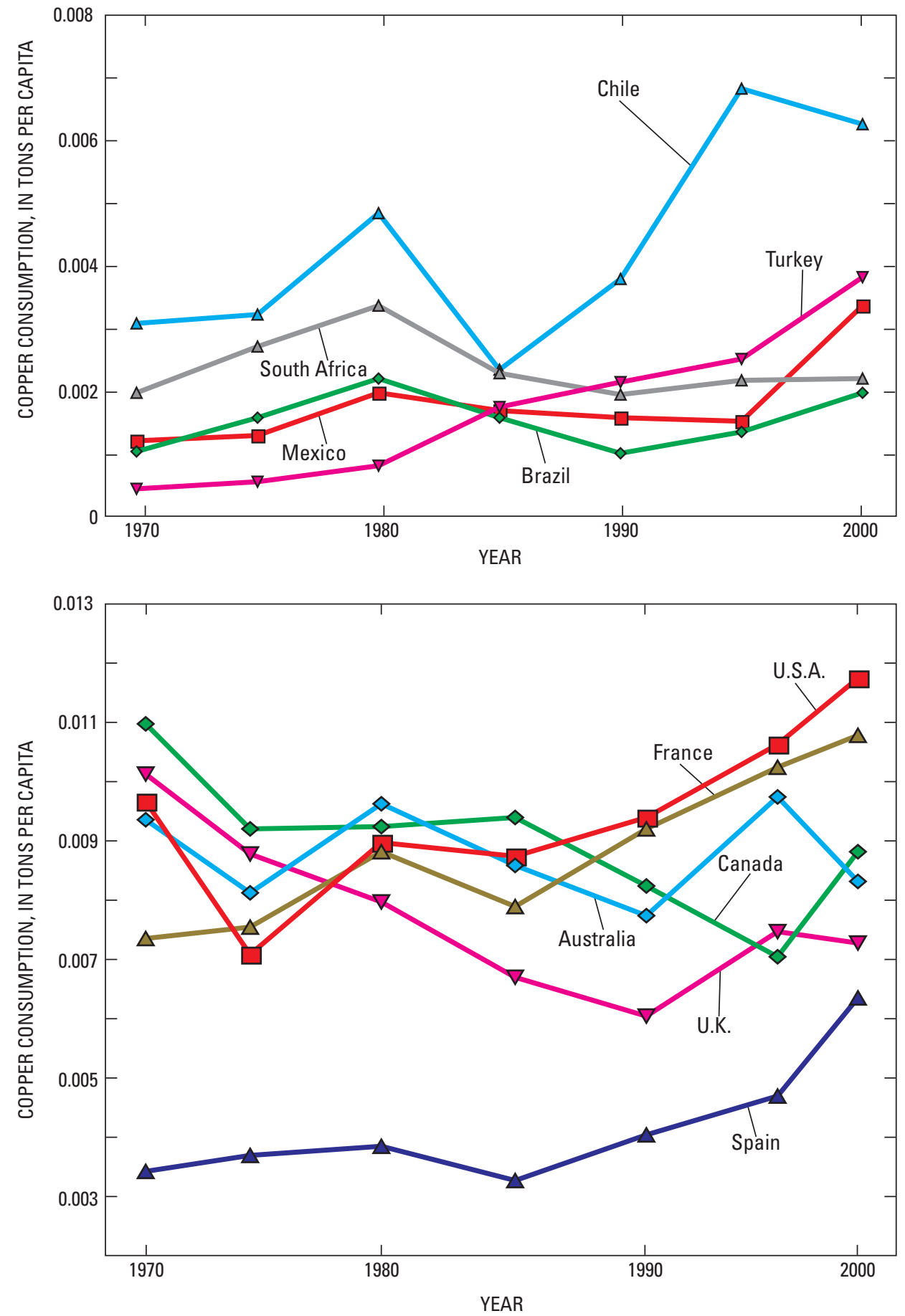

Figure 4. Graph showing changes in per capita copper consumption in Mexico, Brazil, Chile, South Africa, and Turkey during the period 1970 2000. Data from American Bureau of Metal Statistics (various years) and the U.S. Census Bureau Web site at http://www.census.gov/ipc/www/ dbrank.html.

Figure 5. Graph showing changes in per capita copper consumption in major developed countries during the period 1970-2000. Countries are the United States, Canada, Spain, France, Australia, and the United Kingdom. Data from American Bureau of Metal Statistics (various years) and the U.S. Census Bureau Web site at http://www.census. gov/ipc/www/idbrank.html. 


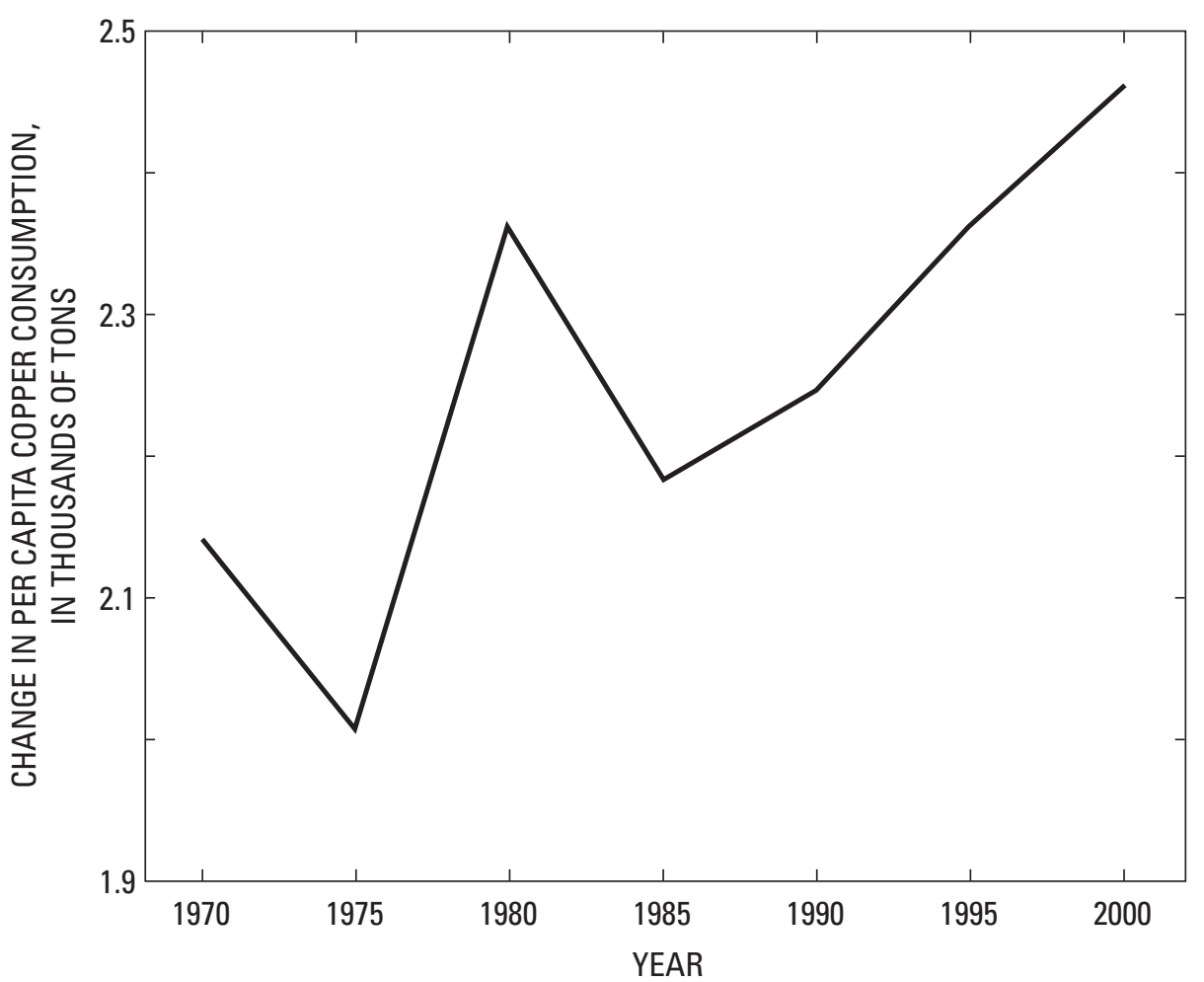

Figure 6. Graph showing change in world per capita copper consumption during the period 1970-2000. Data from American Bureau of Metal Statistics (various years) and the U.S. Census Bureau Web site at http://www.census.gov/ipc/www/ idbrank.htm|. by population increase will be met by more effective recycling, but this can be applied only to some commodities and cannot meet overall demand as long as both population and standards of living increase. These comparisons indicate that increases in demand for minerals are almost inevitable for the next 50 years or so unless there is a major breakdown in global economic activity or a catastrophic decrease in world population.

\section{Global Mineral Reserves}

Global mineral reserves are adequate to supply world mineral demand for the next 50 years, at least in theory. Presently estimated global mineral reserves are 20 to almost 1,000 times larger than present annual production, depending on the commodity of interest (fig. 7). Commodities having the lowest ratio of reserves to annual production in 1992 include diamonds and gold, which have been the object of very successful global exploration programs since that time.

If mineral demand increases at a 1 percent annual rate, as estimated above, it will be about 60 percent higher than today by 2050 , which is not enough to change the general conclusion that Earth has adequate minerals to supply its population through 2050. Thus, demand is likely to remain the dominant factor in world mineral supplies for the next few decades. Exactly when supply will become the dominant factor is difficult to predict and will undoubtedly vary from commodity to commodity and be heavily dependent on the form and cost of industrial energy. In fact, the failure of earlier predictions of mineral supply and demand relations, many of which foresaw mineral shortages by the year 2000 , has led to a dangerous complacency about future world mineral supplies and might lead us to misinterpret these reassuring reserve figures.

Although mineral reserves are large and seem adequate for the next 50 years or so when considered as a single global number, it is important to remember that these reserves are made up of many separate deposits, all of which have to be considered in the local context of which they are a part. Each of these deposits is subject to geologic, engineering, economic, environmental, and political constraints that undergo continuous change.

Geologic factors are of first-order importance and can range from new discoveries to changes in mining, beneficiation, smelting, or other treatment processes. Discoveries are the most important stimulus to exploration because they provide a reason to explore areas or geologic environments that were considered previously to be without potential. Discoveries range from recognition of a new, completely unfamiliar type of deposit, through realization that a familiar deposit type might be found in a new area, to recognition of possible lateral or depth extensions of known deposits or districts. For instance, discovery of the Olympic Dam deposit in Australia and recognition of its similarity to deposits in other parts of the world led to recognition of a new class of iron oxide-copper-gold deposits in other parts of the world and encouraged widespread exploration of terranes that previously were of little interest to copper geologists (Hitzman and others, 1992).

Discoveries of diamond-bearing kimberlites in northern Canada expanded the geologic terrane thought to be favorable for diamonds and considerably increased global diamond reserves (Levinson and others, 1992). On a smaller scale, deep drilling during the last 20 years in the Carlin area of Nevada in the United States has shown that gold ores originally considered to have formed in shallow, near-surface environments 


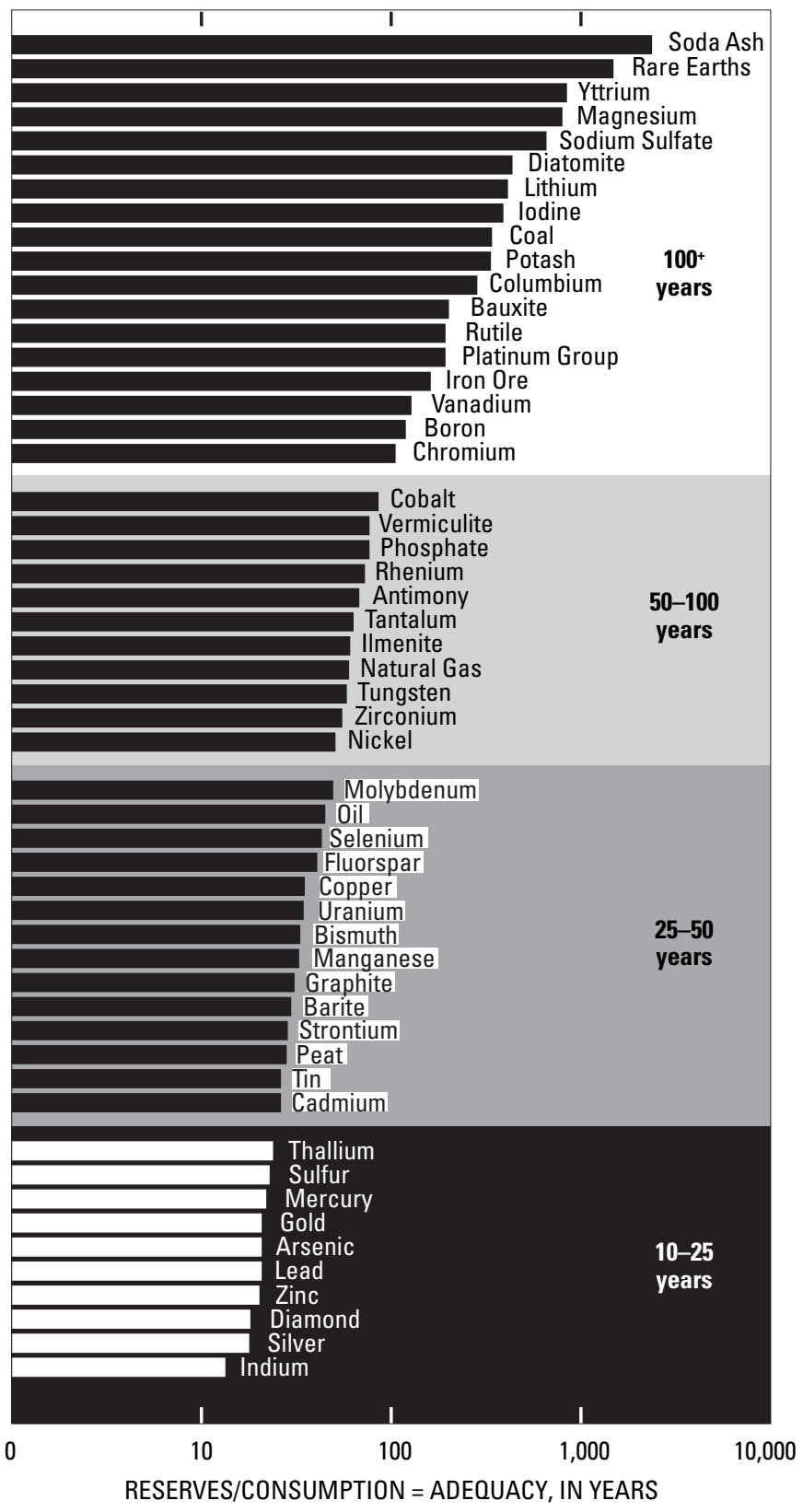

Figure 7. Graph showing ratios of global reserves to annual global production (consumption) for most mineral and energy commodities for 1992; the ratios provide a rough indication of the adequacy (in years) of currently known global reserves (from Kesler, 1994).

actually extend to significant depth. This new information opened completely new areas at depth to exploration and produced large new reserves (Teal and Jackson, 1997).

Related engineering factors can also have a big impact on mineral reserves. Introduction of heap-leaching methods during the 1970s and early 1980s permitted mining of much lower grade gold ores and considerably expanded global gold reserves. Similar changes affected the copper and zinc industries during the 1990s, making oxide deposits economically attractive and adding smaller amounts to global reserves.

It is important to understand that all these discoveries and developments resulted from increased exploration that took place in response to favorable economic frameworks. Without this encouragement, the large expenditures necessary to make these discoveries would not have taken place. Thus, political, economic, and environmental factors also are important to exploration. The importance of these factors cannot be overemphasized. As shown in figure 8, there generally is a good correlation between land area and the number of mineral commodities produced for most large countries having stable economies and regulatory structures. Countries having less stable systems do not show a similar correlation between area and mineral production, although they probably contain geologically favorable areas. Although mineral explorationists are accustomed to risk and commonly enter areas or countries earlier than most other investors, they expect an economic environment that will allow them to profit from large discoveries. Recent changes in the political and economic landscape in many Latin American countries have led to increased mineral investment and large increases in mineral exploration and production. Other countries, notably Cuba, which opened briefly for exploration in the 1990s, have found it more difficult to move exploration projects to production at least partly because of excessive revenue expectations on the part of government.

Environmental and land access regulations also play an important role in encouraging or discouraging exploration. For example, initiatives to ban the use of cyanide that have been put forward in South Dakota, Montana, and Colorado in the United States could remove large volumes of gold-bearing rock from our current reserve and are definitely discouraging exploration in these areas. Such initiatives may also place an emphasis on ores that are amenable to other forms of treatment, possibly even lowgrade placer deposits. Because mining of placers causes more extensive surface disturbance, elimination of cyanide processing can lead to greater rather than less environmental damage. Initiatives to tax reserves have a similar short-term discouraging effect that has not proved to be insurmountable in most areas.

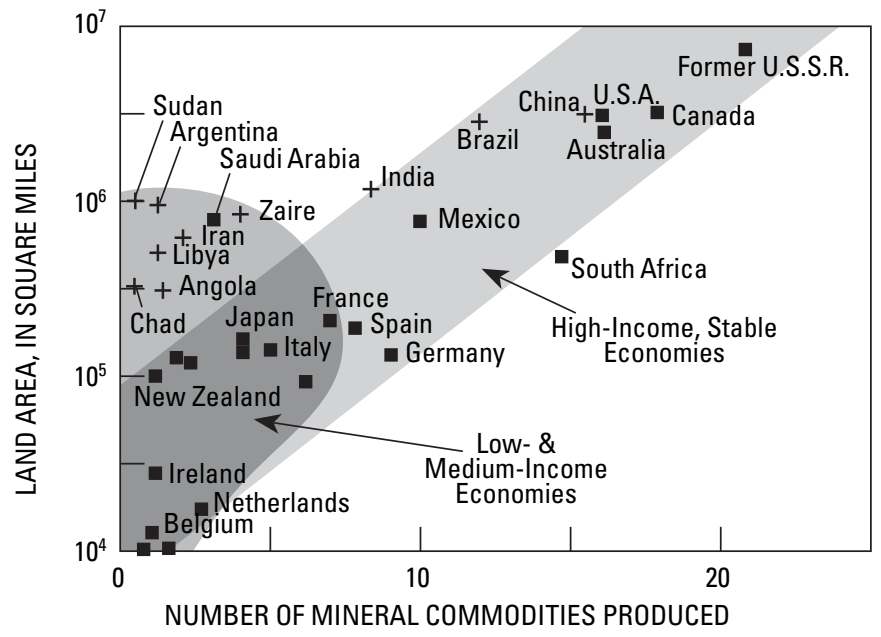

Figure 8. Graph showing the relation between land area and number of mineral commodities produced for developed and developing countries (from Kesler, 1994, based on original from Govett and Govett, 1977). +, less developed countries; $\mathbf{\square}$, more developed countries. 


\section{Future Mineral Supplies}

The factors that affect mineral exploration and reserves can change in a very short time. Discoveries and new mapping can change the geologic landscape, processing breakthroughs can make poor ore more attractive, and changes in political, economic, and regulatory environments can take place with the stroke of a pen. As a result, assessments of mineral reserves are ephemeral and must be revised continually to reflect these continuing changes.

The ultimate egalitarian goal would be for all countries to show a good correlation between mineral production and area, or, in other words, for all countries to share the burden of supplying the world's population with minerals rather than to expect others to shoulder the environmental burden. For this to happen, we need not just a leveling of the environmental and economic playing fields but also more basic geologic information. At this point, the quantity and quality of geologic information relevant to mineral exploration vary greatly across the globe. As a result, it is difficult to prioritize areas for exploration, especially in comparison to competing uses for land.

From a geologic perspective, the most important things that can be done to assure that world mineral reserves meet the challenge of the new century are the following:

1. Conduct research into the nature of processes that form mineral deposits

2. Conduct geologic mapping and related geochemical and geophysical surveys and compile data on known deposits, prospects, and favorable geologic environments

3. Conduct subsurface mapping and sampling

These three topics are discussed below.

Conduct research into the nature of processes that form mineral deposits with the goal of increasing our understanding of processes that cause ores to form and our ability to recognize far-field (distant) indicators of deposits and perhaps totally new ore-forming processes and environments. - A few far-field patterns of alteration zoning have been delineated locally, largely for porphyry copper and epithermal systems (Williams-Jones, 1986; Darce, 1990; Dilles and Einaudi, 1992). Isotopic patterns of similar size related to fluid flow have been mapped around a few hydrothermal deposits (Taylor, 1973; Cathles, 1993; Vázquez and others, 1998). Even larger scale patterns of fluid flow have been suggested by studies of organic matter maturity and illite crystallinity around Mississippi-Valley-type deposits (Bertrand and others, 1998). At least some of the measurements used to delineate these far-field patterns cost about the same as an assay, suggesting that further research might be possible to delineate fluid flow patterns and provinces over large regions.

Completely new deposits are more difficult to identify but probably are out there. For instance, water and other volatile constituents lost during prograde metamorphism are thought to move gold and possibly arsenic (Powell and others, 1991) and may form completely new deposits. Zinc may move similarly, as indicated by systematic regional depletion and enrichment patterns in metamorphic terranes (Ague, 1994). Zinc is a common trace constituent of many greenstone gold deposits and may form concentrations of its own in metamorphic terranes.

Sea-floor hydrothermal systems also offer possibilities. Only half of the heat lost from midocean ridge environments is accounted for by high-temperature hydrothermal systems along the ridges (Stein and Stein, 1994). The rest of the heat is transferred by lower temperature hydrothermal, off-ridge systems. Because of their lower temperatures, these systems must have very large water fluxes, although little is known about their capacity to transport and deposit ore elements.

Conduct geologic mapping and related geochemical and geophysical surveys and compile data on known deposits, prospects, and favorable geologic environments.-This work will provide critically important background data on the surface and near-surface part of our planet to guide future exploration. Despite the many good geologic maps that have been made over the years, there is a continuing need for new maps as the list of things that we need to describe grows. At this point, we have regional-scale geologic maps of most of Earth's surface, but we must progress from that overview to detailed maps that show not only the geology but also geochemical and geophysical patterns and features. The large volumes of data that will be produced by this activity must be put into a format that can be accessed widely and manipulated easily. Although some data will remain proprietary for various periods, most should eventually be merged into these databases and made available to the public.

Conduct subsurface mapping and sampling.-The main goal of mapping on the surface is to develop a better idea of the geologic characteristics of the subsurface. This information will lead, in time, to maps and sections that show the geologic, geochemical, and geophysical features of the subsurface and that provide much more detailed guidance for mineral exploration. Construction of these maps and sections must be based on samples that are recovered by drilling done for mineral exploration and other purposes.

Although subsurface exploration by drilling is a disruptive process, it is essential to discovery. It requires regulatory approval in most areas, which is often delayed or prevented by individuals with a poor understanding of how such exploration is carried out. This lack of understanding leads to exaggerated estimates of damage from the drilling process and reluctance to see it undertaken, just at the time in world history when we need more subsurface exploration to assure future mineral supplies. Efforts must be made to educate decisionmakers and the general public about the exploration process, what it can realistically achieve, and what type of damage it may cause to the environment.

At the same time, efforts also are needed to limit the environmental impact of subsurface exploration through directed drilling and other approaches that yield more information per unit of land area that is disturbed. Several important steps can be taken to limit the environmental impact of drilling. First, samples obtained by drilling should be characterized in as many ways as possible. Although most exploration projects do not require complete characterization, such efforts may provide 
information useful for future exploration with different objectives, thus eliminating the need for some new drill holes. Tax credits or other incentives can be offered to encourage more complete characterization of drill samples. Second, drill samples should be retained in a collection for possible later study and characterization. Maintaining collections of this type is very expensive, and new ways to do it should be sought. Finally, databases and sample libraries resulting from this drilling should be made widely available to the public or to qualified groups, thus eliminating the need for additional drill holes.

\section{Conclusions}

The actions discussed above are essential if we are to be good stewards of Earth's mineral endowment and if demand is to continue to rule the global mineral supply and demand equation. As we enter a century that will be marked by greater world trade, these actions and studies must be conducted at the scale of continents and even the entire Earth, rather than individual countries, as has been the practice up to the present.

\section{References Cited}

Ague, J.J., 1994, Mass transfer during Barrovian metamorphism of pelites, south-central Connecticut; I, Evidence for changes in composition and volume: American Journal of Science, v. 294, no. 8, p. 989-1057.

American Bureau of Metal Statistics, [various years], Nonferrous metal yearbook [issued annually]: Howell, N.J., American Bureau of Metal Statistics, Inc.

Bertrand, Rudolf, Chagnon, André, Héroux, Yvon, and Savard, M.M., 1998, Hydrothermal alteration of clay minerals and organic matter within and outside the Jubilee carbonatehosted $\mathrm{Zn}-\mathrm{Pb}$ deposit, Cape Breton Island, Nova Scotia, Canada: Economic Geology, v. 93, no. 6, p. 746-756.

Cathles, L.M., 1993, Oxygen isotope alteration in the Noranda mining district, Abitibi greenstone belt, Quebec: Economic Geology, v. 88 , no. 6, p. 1483-1511.

Darce, Mauricio, 1990, Mineralogic alteration patterns in volcanic rocks of the La Libertad gold mining district and its surroundings, Nicaragua: Economic Geology, v. 85, no. 5, p. 1059-1071.

Dilles, J.H., and Einaudi, M.T., 1992, Wall-rock alteration and hydrothermal flow paths about the Ann-Mason porphyry copper deposit, Nevada-A 6-km vertical reconstruction: Economic Geology, v. 87, no. 8, p. 1963-2001.

Govett, G.J.S., and Govett, M.H., 1977, The inequality of distribution of world mineral supplies: CIM (Canadian Institute of Mining and Metallurgy) Bulletin, v. 70, no. 784 (August 1977), p. 59-68.
Hitzman, M.W., Oreskes, Naomi, and Einaudi, M.T., 1992, Geological characteristics and tectonic setting of Proterozoic iron oxide (Cu-U-Au-REE) deposits: Precambrian Research, v. 58, no. 1-4, p. 241-287.

Kesler, S.E., 1994, Mineral resources, economics and the environment: New York, Macmillan, 396 p.

Levinson, A.A., Gurney, J.J., and Kirkley, M.B., 1992, Diamond sources and production-Past, present, and future: Gems and Gemology, v. 28, no. 4, p. 234-254.

Powell, Roger, Will, T.M., and Phillips, G.N., 1991, Metamorphism in Archaean greenstone belts-Calculated fluid compositions and implications for gold mineralization: Journal of Metamorphic Geology, v. 9, no. 2, p. 141-150.

Stein, C.A., and Stein, Seth, 1994, Constraints on hydrothermal heat flux through the oceanic lithosphere from global heat flow: Journal of Geophysical Research, B, Solid Earth and Planets, v. 99, no. 2, p. 3081-3095.

Taylor, H.P., Jr., $1973,{ }^{18} \mathrm{O} /{ }^{16} \mathrm{O}$ evidence for meteoric-hydrothermal alteration and ore deposition in the Tonopah, Comstock Lode, and Goldfield mining districts, Nevada: Economic Geology, v. 68, no. 6, p. 747-764.

Teal, Lewis, and Jackson, Mac, 1997, Geologic overview of the Carlin trend gold deposits and descriptions of recent deep discoveries, in Vikre, Peter, Thompson, T.B., Bettles, Keith, Christensen, Odin, and Parratt, Ron, eds., CarlinType Gold Deposits Field Conference: Society of Economic Geologists Guidebook Series, v. 28, p. 3-38.

United Nations, 1966, World population prospects as assessed in 1963: New York, United Nations, Department of Economic and Social Affairs, Population Studies no. 41, 149 p.

United Nations, 1973, The determinants and consequences of population trends: New York, United Nations, Department of Economic and Social Affairs, Population Studies no. 51.

United Nations, 1995, World population prospects, the 1994 revision: New York, United Nations, Department for Economic and Social Information and Policy Analysis, Population Division, 886 p.

U.S. Bureau of Mines, 1953-93, Minerals Yearbook for 1950, $1955,1960,1965,1970,1975,1980,1985$, and 1990, Volume 1-Metals and Minerals: Washington, D.C., U.S. Bureau of Mines, variously paged. (Also available online at http://minerals.usgs.gov/minerals/pubs/usbmmyb.html.)

U.S. Census Bureau, [no date], International data base-Countries ranked by total population, 1950-2050: U.S. Census Bureau Web site at http://www.census.gov/ipc/www/ idbrank.html. 
U.S. Geological Survey, 1997 and 2002, Minerals Yearbook for 1995 and 2000, Volume I-Metals and Minerals: Reston, Va., U.S. Geological Survey, variously paged. (Also available online at http://minerals.usgs.gov/minerals/pubs commodity/myb/.) [Publication of the "Minerals Yearbook" moved from the U.S. Bureau of Mines to the U.S. Geological Survey in 1995.]

Vázquez, Rodrigo, Vennemann, T.W., Kesler, S.E., and Russell, Norman, 1998, Carbon and oxygen isotope halos in the host limestone, El Mochito, $\mathrm{Zn}-\mathrm{Pb}-(\mathrm{Ag})$ skarn massive sulfide-oxide deposit, Honduras: Economic Geology, v. 93, no. 1 , p. 15-31.

Williams-Jones, A.E., 1986, Low-temperature metamorphism of the rocks surrounding Les Mines Gaspé, Quebec-Implications for mineral exploration: Economic Geology, v. 81, no. 2 , p. 466-470. 


\title{
Global Mineral Exploration and Production- The Impact of Technology
}

\author{
By Michael D. Doggett
}

\section{Introduction}

Many of the largest, highest grade, closest to surface, closest to market mineral deposits have been depleted or currently are in production. Over the next half century, the competition for land use among diverse sectors of an ever-increasing population will intensify. Mining companies struggling to improve the traditional bottom line will be forced to support a triple bottom line incorporating the costs and benefits of environmental and social responsibilities. Under these conditions, the ability of the international mineral sector to find and produce required amounts of metallic, nonmetallic, and fuel commodities hinges on technological innovation. While it would be naive to trust blindly in technology to overcome all aspects of depletion, it also would be imprudent to ignore past contributions of technology to an industry that ranks among world leaders in productivity. An analysis of global mineral exploration and production over the past 50 years reveals some interesting trends, which can be used to project where the mineral sector is headed in the years to come. A case study focusing on copper supply raises a series of questions about the tradeoffs between depletion and technology.

\section{Database}

This study examines trends in exploration and production for seven metals - copper $(\mathrm{Cu})$, gold $(\mathrm{Au})$, lead $(\mathrm{Pb})$, molybdenum (Mo), nickel (Ni), silver (Ag), and zinc ( $\mathrm{Zn}$ ). Although silver is produced as a primary metal and as a byproduct of both gold and base-metal mines, for the purposes of this study, it is lumped together with base metals. This grouping allows the isolated analysis of gold as an exploration target and primary metal.

Exploration expenditure series have been compiled from a wide range of sources, including Natural Resources Canada, Statistics Canada, Australian Bureau of Statistics (1965-91), Metals Economics Group, and the "Mining Journal," and from previously compiled exploration series in Cranstone and others (1987), Doggett and Mackenzie (1987), Mackenzie and Doggett

${ }^{1}$ Department of Geological Sciences and Geological Engineering, Queen's University, Kingston, Ontario, K7L 3N6, Canada (e-mail: doggett@geol.queensu.ca).
(1989, 1992), Doggett (1994), Mackenzie, Doggett, and Ortiz (1997), and Mackenzie, Doggett, and Thompson (1997). Extrapolating from country statistics tabulated in different ways means that the values presented are approximations. This is particularly true in the early decades covered by the study. The expenditures are meant to represent grassroots and onsite exploration but not costs related to acquisition of properties.

Production statistics have been tabulated from a number of sources as well, including the former U.S. Bureau of Mines (USBM) and Statistics Canada (1946-98). The series for production generally is more complete and reliable than that for exploration expenditures. Some minor inconsistencies exist due to changes over time in recording Western world, nonCommunist world, and total world data.

Value-of-production series have been compiled by using the production series and average annual metal prices for the seven metals. These values represent the gross sales value of the metal production. Wherever possible, the London Metal Exchange prices have been used; otherwise, a number of price references have been consulted, including "Metals Week" (1969-99), Robertson (1986), and USBM (1993).

Conclusions drawn in this study are based on broad trends in exploration and production and are not thought to be particularly sensitive to minor inconsistencies in the series of data. All money values presented are in constant 1999 U.S. dollars.

\section{0-Year Trends in Base-Metal and Gold Exploration Costs}

Table 1 presents exploration expenditure trends in gold and base metals on a decade-by-decade basis for the period 1950-99. Overall, approximately $\$ 76$ billion has been spent on the search for new economic deposits. The results indicate that exploration expenditure levels have been increasing significantly in real terms over time. Exploration increased from $\$ 3.5$ billion in the 1950s to $\$ 12$ billion in the 1970s and to approximately $\$ 28$ billion in the 1990 s. Taken on its own, this trend suggests that discovery costs have been increasing over time. More generally, changing discovery costs over time should provide a measure of the tradeoff between depletion and technological advances. 
Table 1. Global base-metal and gold exploration expenditures.

[All money values in 1999 U.S. dollars, in billions]

\begin{tabular}{|l|c|r|r|}
\hline \multicolumn{1}{|c|}{ Years } & Base metals & \multicolumn{1}{c|}{ Gold } & \multicolumn{1}{c|}{ Total } \\
\hline $1950 \mathrm{~s}$ & $\$ 3.0$ & $\$ 0.5$ & $\$ 3.5$ \\
\hline $1960 \mathrm{~s}$ & $\$ 7.2$ & $\$ 1.3$ & $\$ 8.5$ \\
\hline $1970 \mathrm{~s}$ & $\$ 9.3$ & $\$ 2.7$ & $\$ 12.0$ \\
\hline $1980 \mathrm{~s}$ & $\$ 7.3$ & $\$ 16.7$ & $\$ 24.0$ \\
\hline $1990 \mathrm{~s}$ & $\$ 10.0$ & $\$ 18.0$ & $\$ 28.0$ \\
\hline Total & $\$ 36.8$ & $\$ 39.2$ & $\$ 76.0$ \\
\hline
\end{tabular}

A more detailed analysis of the exploration expenditure series presented in table 1 shows that the overall trend is disguising the two distinct trends for gold and base metals. While gold and base-metal expenditures each accounted for about half of the total expenditure, base-metal expenditures increased in the early decades and then decreased in the 1980s before increasing again to end the study period at approximately $\$ 10$ billion during the 1990s. Gold has shown a steadily increasing trend over the past 50 years and peaked at approximately $\$ 18$ billion in the 1990s.

As we look ahead to the coming decades, exploration expenditures for base metals are likely to continue within the range indicated by the past three decades. Expenditures for gold, on the other hand, are not likely to continue to increase at the same rate in the future. Indeed, it is highly likely that a decrease in the level of gold exploration expenditures from the peak 1990s value will occur over the next decade, as expenditure levels in 2000 and 2001 are projected to be significantly below those in the latter years of the 1990s.

\section{0-Year Trends in Base-Metal and Gold Production Amounts}

To more fully evaluate the importance of the trends in exploration expenditure, comparisons are made with the output of the various metals being considered. Table 2 illustrates the amounts of metals produced over the five decades. Overall base-metal production increased by more than 200 percent over the study timeframe, while gold and silver production increased by more than 100 percent.

Table 2. Global base-metal and gold and silver production.

[Base metals in millions of metric tons; precious metals gold and silver in millions of ounces. For this table only, silver is treated as a precious metal; in the rest of this paper, it is grouped with the base metals]

\begin{tabular}{|l|r|r|r|r|r|c|r|r|}
\hline \multicolumn{1}{|c|}{ Years } & $\mathbf{C u}$ & $\mathbf{P b}$ & $\mathbf{M o}$ & $\mathbf{N i}$ & $\mathbf{Z n}$ & $\begin{array}{c}\text { Total } \\
\text { base } \\
\text { metals }\end{array}$ & $\mathbf{A u}$ & $\mathbf{A g}$ \\
\hline $1950 \mathrm{~s}$ & 34 & 23 & 0.3 & 2 & 31 & 90 & 305 & 2,200 \\
\hline $1960 \mathrm{~s}$ & 54 & 30 & 0.5 & 4 & 46 & 135 & 435 & 2,500 \\
\hline $1970 \mathrm{~s}$ & 75 & 37 & 0.9 & 7 & 61 & 181 & 420 & 3,150 \\
\hline $1980 \mathrm{~s}$ & 81 & 34 & 1.0 & 8 & 65 & 189 & 412 & 4,150 \\
\hline $1990 \mathrm{~s}$ & 104 & 30 & 1.3 & 10 & 73 & 218 & 735 & 4,950 \\
\hline Total & 348 & 154 & 4.0 & 31 & 276 & 813 & 2,307 & 16,950 \\
\hline
\end{tabular}

\section{0-Year Trends in Base-Metal and Gold Discovery Costs}

An exact picture of discovery costs over time would measure the amount of metal discovered per dollar of exploration expenditure. Because we do not have a record of the metals contained in discoveries over the past 50 years, the production of metals has been used as a proxy. Thus, exploration expenditure is measured as a function of the metal produced. Table 3 shows this ratio on a decade-by-decade basis for base metals and gold. These results have been calculated by dividing exploration expenditures from table 1 by metal production from table 2 . The results indicate that exploration costs for base-metal output have fluctuated between 1.5 and 2.4 cents per pound over time, with an average for the entire period of 2.1 cents per pound. These values do not support the notion that discovery costs are increasing with time. With respect to gold exploration, the cost per ounce increased substantially, to more than $\$ 40$ per ounce in the 1980s, as exploration expenditures increased rapidly. The large jump in gold production during the 1990s resulted from increased exploration in the 1980s and pushed the discovery cost back down to under $\$ 25$ per ounce.

\section{0-Year Trends in Base-Metal and Gold Production Values}

Table 4 illustrates the value of production for base metals and gold over the past five decades. The values are expressed in 1999 U.S. dollar equivalents and represent gross value measured by the average annual price times total production for each metal for each year. Several interesting trends emerge from the data. First, the overall trend in value of mineral production increased sharply in the 1960s and 1970s and then leveled off during the 1980s and 1990s. This trend suggests that the increases in production illustrated in table 2 essentially have been offset by decreases in metal prices. Thus, over the past three decades, there has been little overall growth in the sector. This finding has important implications for corporate planning, as most companies have a stated objective of yearover-year growth. Notwithstanding more efficient production and focus on cost cutting, it is highly unlikely that most companies can grow in an industry where the overall value of production has remained essentially flat over a long period.

The other important trend concerns the relative values of base-metal and gold production. Overall, base metals have accounted for roughly two-thirds of the total value, but gold has increased its percentage share in recent decades. Furthermore, gold has increased in value of production each decade, while base metals increased sharply until the 1970s and then decreased during the 1980s and 1990s. The total value of basemetal production in the 1990s in real terms was approximately 22 percent less than in the 1970s in spite of an overall 20 percent increase in the amount of metal produced. 


\section{Exploration Expenditure as a Function of Value of Production}

Results from table 3 suggest that exploration expenditure per unit of metal production has remained relatively flat for base metals and increased, then decreased, for gold. Values of production as shown in table 4, however, have generally decreased for base metals and increased for gold in later decades of the study period. We now want to consider the relation between exploration expenditures and value of production. This ratio provides a measure of the percentage of gross value of production that is being reinvested in exploration. Table 5 presents exploration expenditure per unit of value of production for base-metal and gold production. Overall, the percentage of value of production reinvested in exploration has increased from 1.1 percent to 3.6 percent over the five decades. By commodity grouping, we see that the major increase has been for gold where about 6 percent of value has been reinvested in exploration during the 1980s and 1990s. Given generally low profit levels in the gold sector in recent

Table 3. Global discovery costs per unit of production for base metals and gold.

\begin{tabular}{|l|c|c|}
\hline \multicolumn{1}{|c|}{ Years } & $\begin{array}{c}\text { Base metals } \\
\text { (cents per pound) }\end{array}$ & $\begin{array}{c}\text { Gold } \\
\text { (dollars per ounce) }\end{array}$ \\
\hline $1950 \mathrm{~s}$ & 1.5 & 1.6 \\
\hline $1960 \mathrm{~s}$ & 2.4 & 3.0 \\
\hline $1970 \mathrm{~s}$ & 2.3 & 6.4 \\
\hline $1980 \mathrm{~s}$ & 1.8 & 40.5 \\
\hline $1990 \mathrm{~s}$ & 2.1 & 24.5 \\
\hline Average & 2.1 & 17.0 \\
\hline
\end{tabular}

Table 4. Value of global production for base metals and gold.

[All money values in 1999 U.S. dollars, in billions]

\begin{tabular}{|c|c|c|c|}
\hline Years & Base metals & \multicolumn{1}{c|}{ Gold } & \multicolumn{1}{c|}{ Total } \\
\hline 1950 s & $\$ 250$ & $\$ 60$ & $\$ 310$ \\
\hline $1960 \mathrm{~s}$ & $\$ 400$ & $\$ 75$ & $\$ 475$ \\
\hline $1970 \mathrm{~s}$ & $\$ 625$ & $\$ 125$ & $\$ 750$ \\
\hline $1980 \mathrm{~s}$ & $\$ 520$ & $\$ 270$ & $\$ 790$ \\
\hline $1990 \mathrm{~s}$ & $\$ 485$ & $\$ 300$ & $\$ 785$ \\
\hline Total & $\$ 2,280$ & $\$ 830$ & $\$ 3,110$ \\
\hline
\end{tabular}

Table 5. Exploration expenditures as a function of value of global production, in percent.

\begin{tabular}{|l|c|c|c|}
\hline \multicolumn{1}{|c|}{ Years } & Base metals & Gold & Total \\
\hline $1950 \mathrm{~s}$ & 1.2 & 0.8 & 1.1 \\
\hline $1960 \mathrm{~s}$ & 1.8 & 1.7 & 1.8 \\
\hline $1970 \mathrm{~s}$ & 1.5 & 2.2 & 1.6 \\
\hline $1980 \mathrm{~s}$ & 1.4 & 6.2 & 2.9 \\
\hline $1990 \mathrm{~s}$ & 2.1 & 6.0 & 3.6 \\
\hline Average & 1.6 & 4.6 & 2.4 \\
\hline
\end{tabular}

years, it is unlikely that this ratio is sustainable. For base metals, exploration as a percentage of value of production has remained relatively constant in the 1-2 percent range, with only the 1990 s value exceeding 2 percent.

\section{Depletion Versus Technology-Case Study Involving Copper}

As shown by the evidence presented above, trends in discovery costs, metal prices, and value of production suggest that technology has been able to more than offset any depletion effects during the past 50 years. Can it be assumed that these same trends will continue for the foreseeable future, or are new external factors at play that will fundamentally alter the depletion-technology balance? To address this question, it is necessary to consider the trends in production and the technology factors underlying the trends in costs, prices, and output. While there have been important technological advances at all stages of the mineral supply process from exploration to development to production to reclamation, those having the greatest impact have been in one way or another related either to scale of operation or to processing and metallurgy. To examine these technology factors, consider the case of copper production over the period 1978 to 2000.

\section{Historical Production of Copper}

Table 6 presents the breakdown of total copper production until the end of 1999 (USBM, 1956, 1980; Natural Resources Canada, 1963-2000; Mikesell, 1979). More than 430 million metric tons of copper have been produced. Of this total, 43 percent has been produced in the past 20 years, and 24 percent in the past 10 years. When viewed in this way, the depletion of copper resources has accelerated to the point where nearly one-quarter of all of the copper ever produced was supplied in the 1990s. This raises the important question of whether copper resources can continue to meet this increasing trend as we move into the new century.

Table 6. Historical global copper supply.

[Data from U.S. Bureau of Mines, 1956, 1980; Natural Resources Canada, 1963-2000; Mikesell, 1979]

\begin{tabular}{l|l|c|}
\hline \multicolumn{1}{|c|}{ Period } & $\begin{array}{c}\text { Production } \\
\text { (millions of } \\
\text { metric tons) }\end{array}$ & $\begin{array}{c}\text { Percent } \\
\text { of total }\end{array}$ \\
\hline Pre-1900 & 10 & 2 \\
\hline $1900-50$ & 70 & 16 \\
\hline $1950-99$ & ${ }^{1}>350$ & 82 \\
\hline $1980-99$ & 184 & 43 \\
\hline $1990-99$ & 104 & 24 \\
\hline \multicolumn{2}{|c|}{ Total $>430$} & 100 \\
\hline
\end{tabular}




\section{Scale of Copper Production, 1978-2000}

With respect to scale of copper operations, much of the increased output of metals on a worldwide basis has resulted from the development of huge open-pit operations. Technological advances in mining and processing equipment have enabled enormous increases in mine capacity with resulting decreases in unit operating costs and cutoff grades. A survey of copper mines provides a good example of the staggering increases in capacity. The 10 largest copper mines in terms of annual capacity in 1978 (Mackenzie, 1979) are shown in table 7. The total productive capacity of these mines was 2.145 million metric tons of copper. The single largest mine was Chuquicamata, which had a capacity of 475,000 metric tons of copper. Capacities of the other nine mines ranged from 125,000 to 275,000 metric tons.

Table 7. Annual capacity of the 10 largest copper mines in the world in 1978.

[Capacity in thousands of metric tons. Data from Mackenzie, 1979]

\begin{tabular}{|l|c|}
\hline \multicolumn{1}{|c|}{ Mine, country } & Capacity \\
\hline Chuquicamata, Chile & 475 \\
\hline El Teniente, Chile & 275 \\
\hline Chingola, Zambia & 240 \\
\hline Bingham, U.S.A. & 204 \\
\hline Bougainville, Papua New Guinea & 184 \\
\hline Cuajone, Peru & 180 \\
\hline Kamoto Pit, Congo (D.R.C.) & 172 \\
\hline Mount Isa, Australia & 150 \\
\hline Mufulira, Zambia & 140 \\
\hline Palabora, South Africa & 125 \\
\hline Total & 2,145 \\
\hline
\end{tabular}

Table 8 shows the projected annual capacities of the 10 largest copper mines in 2000 (International Copper Study Group, 1999). The total productive capacity of the 10 mines is 4.895 million metric tons -230 percent higher than comparable production in 1978. This total represents one-third of the productive copper capacity of all operating mines in 2000. In terms of the size of individual producers, 8 of the 10 now have capacities exceeding 300,000 metric tons per year. These huge increases in copper production capacity have been achieved in spite of the lowering of average grade of production in most cases, suggesting that physical mining capacity has increased at an even higher rate. From the perspective of depletion, 3 of the top 10 mines in 1978 are still in the top 10 in 2000, and only 1 of the 10 largest mines in 1978 has been depleted of ore reserves.

Another interesting factor is the geographic distribution of the largest mines. In 1978, 4 of the 10 were located in Africa, 3 in South America, 2 in Australia and Papua New Guinea, and 1 in North America. In 2000, 6 of the 10 largest
Table 8. Projected annual capacity of the 10 largest copper mines in the world in 2000 .

[Capacity in thousands of metric tons. Data from International Copper Study Group, 1999]

\begin{tabular}{|c|c|}
\hline Mine, country & Capacity \\
\hline Escondida, Chile & 905 \\
\hline Grasberg, Indonesia & 730 \\
\hline Chuquicamata, Chile & 680 \\
\hline Morenci, U.S.A. & 490 \\
\hline Noril'sk, Russia & 450 \\
\hline Colluhuasi, Chile & 450 \\
\hline El Teniente, Chile & 350 \\
\hline Bingham, U.S.A. & 310 \\
\hline Los Pelambres, Chile & 280 \\
\hline Andina, Chile & 250 \\
\hline Total & 4,895 \\
\hline
\end{tabular}

mines were located in South America, 2 in North America, 1 in Russia, and 1 in Asia. This changing distribution reflects not only geological endowment but also political factors, particularly in Africa and South America.

\section{Advent of Solvent Extraction Electrowinning Technology}

The second major technological advance affecting copper supply, and ultimately the copper cost curve and copper price, is improved metallurgy. The introduction of hydrometallurgical techniques (such as solvent extraction electrowinning) for the production of copper metal at the mine site, rather than producing a concentrate to ship to a smelter and refinery, has resulted in the reduction of costs for individual producers. The direct production of copper cathode increased from essentially zero in 1978 to approximately 20 percent of total copper supply by the year 2000 .

\section{Future Production Trends for Copper}

Table 9 illustrates a possible future trend in copper supply calculated by assuming a 1.8 percent annual increase over the next 50 years. Total copper supply by the year 2050 , under this scenario, would reach approximately 34 million metric tons per year. Comparing future production levels at this rate of growth in copper supply reveals that copper production from 2000 to 2010 would amount to 38 percent of

Table 9. Projected future global copper supply.

\begin{tabular}{|c|c|c|}
\hline Period & $\begin{array}{c}\text { Production } \\
\text { (millions of } \\
\text { metric tons) }\end{array}$ & $\begin{array}{c}\text { Percent of } \\
\text { pre-2000 } \\
\text { total }\end{array}$ \\
\hline $2000-2010$ & 165 & 38 \\
\hline $2000-2025$ & 350 & 81 \\
\hline $2000-2050$ & 1,200 & 280 \\
\hline
\end{tabular}


all copper produced before the year 2000 (430 million metric tons; see table 6). Similarly, by the year 2025, 81 percent of total pre-2000 production would be achieved, and by 2050 , copper production would be 280 percent of the pre-2000 total.

How would this level of copper supply be attained? How much exploration expenditure would be required to find the required deposits? Is it possible for technology to allow for this enormous increase in supply while continuing to lower costs and prices? To address some of these points, consider the two major technological factors discussed above-scale of operations and metallurgical improvements.

\section{Scale of Operations}

How large can individual copper mines become to meet future needs? Consider the hypothetical case outlined above of a 1.8 percent annual growth in copper supply over the next half century. If the 10 largest mines were to account for one-third of total production as they do today, they would need to produce more than 11 million metric tons of copper on an annual basis. Thus, the average production of the 10 largest mines would be more than 1 million metric tons of copper per year, which is larger than the single largest producer at present. Another important implication of the need for ever-larger producers is the environmental impact of huge open-pit mines. As environmental regulations become ever-more stringent around the world, it is difficult to imagine a scenario where mines are permitted to become large enough to meet this expanded production. Thus, it is unlikely that such increases in capacity will be accomplished by increases in scale of operations like those seen over the past two decades.

\section{Metallurgical Advances}

The other major area of technological advance that is likely to affect future supply of gold and base metals is improved metallurgical processing techniques. As indicated above for copper, hydrometallurgical processing has begun to replace pyrometallurgy. To date, these gains have been made by processing those ores most susceptible to leaching processes-oxide and supergene ores. Future breakthroughs in mineral processing are likely to include treating sulfide ores through leaching or pressure leaching, or even in-place leaching, to produce metals at the mine site. We are at the early stages of this technology, which gradually will replace pyrometallurgical processing over the next 50 years. Thus, unlike the scale-of-operations question discussed above, there is considerable opportunity for advances in processing technology to provide an increased supply of metal by promoting a lower cost structure for processing primary ores.

\section{Conclusions}

- Technology has won the battle with depletion in the past 50 years, primarily by increasing scales of operation and improving processing efficiencies.

- At even moderate rates of increase in demand, metal production in the next 50 years will dwarf all-time historical totals.

- It is unlikely that the rate of increase in scale of operations can be sustained in the longer term because of growing environmental concerns.

- Major metallurgical improvements in the processing of primary ores have only just begun.

- Depletion-driven increases in metal prices may prevail eventually, but technological innovations are expected to keep prices low for at least the next 50 years.

\section{References Cited}

Australian Bureau of Statistics, 1965-91, Mineral exploration, Australia [issued annually]: Canberra, Australian Bureau of Statistics publication with catalog number 8407.0 and ABS reference number 10.41 .

Cranstone, Donald, Mackenzie, B.W., and Doggett, M.D., 1987, Long-term breakeven price for Canadian gold supply, in Long-term prospects for gold mining; Proceedings of the seventeenth CRS Policy Discussion Seminar, October 6-8, 1986, Kingston, Ontario: (Kingston, Ontario) Queen's University, Centre for Resource Studies, Proceedings no. 20.

Doggett, M.D., 1994, Incorporating exploration in the economic theory of mineral supply: Kingston, Ontario, Queen's University, unpublished Ph.D. thesis, 195 p.

Doggett, M.D., and Mackenzie, B.W., 1987, Economic trends in Canadian gold supply: (Kingston, Ontario) Queen's University, Centre for Resource Studies, Working Paper no. $41,77 \mathrm{p}$.

International Copper Study Group, 1999, Directory of copper mines and plants: Lisbon, Portugal, International Copper Study Group, July, 82 p.

Mackenzie, B.W., 1979, Canada's competitive position in copper and zinc markets: (Kingston, Ontario) Queen's University, Centre for Resource Studies, Working Paper no. 16, $43 \mathrm{p}$.

Mackenzie, B.W., and Doggett, M.D., 1989, Economic aspects of gold exploration-How much is too much?: (Kingston, Ontario) Queen's University, Centre for Resource Studies, Working Paper no. 44, 26 p. 
Mackenzie, B.W., and Doggett, M.D., 1992, Worldwide trends in gold exploration: (Kingston, Ontario) Queen's University, Centre for Resource Studies, Working Paper no. 49.

Mackenzie, B.W., Doggett, M.D., and Ortiz, F.J., 1997, Economic potential of mineral exploration in Chile-Evidence from the historical record: (Kingston, Ontario) Queen's Unversity, Centre for Resource Studies, Technical Paper 15, $221 \mathrm{p}$.

Mackenzie, B.W., Doggett, M.D., and Thompson, Mickey, 1997, Economic potential of mineral exploration in Australia-Evidence from the historical record, 1955-91: (Kingston, Ontario) Queen's University, Centre for Resource Studies, Technical Paper 16.

Metals Week, 1969-99: New York, McGraw Hill, v. 40-63.

Mikesell, Raymond, 1979, The world copper industry; Structure and economic analysis: Baltimore, The Johns Hopkins University Press, 393 p.
Natural Resources Canada [and its predecessor agencies], 1963-2000, Canadian minerals yearbook 1960-99: Ottawa, Natural Resources Canada, variously paged. (Also available online at http://www.nrcan.gc.ca/mms/cmy/pref_e.htm.)

Robertson, Neil, 1986, Mineral commodity prices-Computer database assembly and preliminary analysis: (Kingston, Ontario) Queen's University, unpublished B.Sc. thesis.

Statistics Canada, 1946-98 [various periodicals on mining]: Ottawa, Statistics Canada catalog numbers 26-201 (General Review of the Mineral Industries, Mines, Quarries and Sand Pits), 26-202 (Canada's Mineral Production, Preliminary Estimates), 26-209, 26-223 (Metal Ore Mining), 26-224 (Non-metal Mines), 61-205 (Private and Public Investment in Canada, Intentions), 61-206 (Private and Public Investment in Canada, Revised Intentions).

U.S. Bureau of Mines, 1956 and 1980, Mineral facts and problems: U.S. Bureau of Mines Bulletins 556 (1042 p.) and 671 (1060 p.).

U.S. Bureau of Mines, 1993, Metal prices in the United States through 1991: Washington, D.C., U.S. Bureau of Mines, 201 p. 


\title{
Who Will Use a Global Mineral Resource Assessment? An Industry Perspective ${ }^{1}$
}

\author{
By G.E. McKelvey²
}

An assessment of the global mineral endowment, what is known and could remain undiscovered, would be a valuable tool for mineral users, mineral explorers, land planners, international governments, and environmental protectors alike. The mineral industry does not use mineral assessments directly to discover new ore deposits, but an assessment can be a tool that, in concert with other measures of Earth's resources, might provide a logic-based forum for long-term land use planning, coordinating environmental issues, and assisting in related legal issues. As a result, the assessment could help us provide for the sustainable resource needs of the planet's inhabitants. Perhaps such a forum will find the common ground necessary to ensure that the needs of all are equally addressed with logic, planning, and facts. A global mineral assessment, however, can be useful only if the planners, governments, protectors, and all mineral users clearly understand the potentially serious limitations inherent in a mineral assessment.

The first danger we face is that we do not have the data necessary to complete a global mineral assessment. Regardless of the explosion of earth science data and sophistication of assessment techniques, the basic data are incomplete. Large areas are poorly understood; some remain unstudied because of political or social issues. I have yet to see a map or assessment that clearly acknowledges regions and domains where the data are insufficient to assess mineral potential. The recognition that real information is lacking may well be the driver for acquiring meaningful data.

Statistical assessments may provide some measure of the likelihood that we will find new deposits, but some land use planners, government lawmakers, and other users may believe the specific numbers rather than understand the concept of mineral discovery potential and the inherent limitations of discovery. Cold statistics from incomplete data used by people not personally familiar with a region result in an assessment, but I prefer relying on the gut feelings of innovative people who have spent time in the field thinking and mapping and questioning paradigms.

${ }^{1}$ Reprinted from “Geotimes," March 2001, v. 46, no. 3, p. 18-19, with permission. Copyright 2001, the American Geological Institute.

${ }^{2} 9485$ E. Conquitadores Dr., Scottsdale, AZ 85255-4345, U.S.A. (e-mail: gempress@earthlink.net).
The second danger we face is that assessments often are expressed in numbers of deposits or monetary units and then compared with other competing land uses on the basis of preserved value - a tradeoff approach. While we can use and misuse mineral assessment reports from various sources, we should not just accept the cold numbers. Instead, we should understand the limitations of the data we use and, if that information is not enough, get better data. It is the data, not the assessment, that are most valuable to the mineral discovery industry.

A third perilous flaw in any assessment process is dependence on the existing deposit models. By definition, descriptive ore deposit models, genetic models, and the resulting search models are based on what is known. The deposit is known first, and then the model is developed. Even when a description is detailed in every way, when we have a perfect understanding of how a deposit formed and when the unique geologic domain is globally well documented, a mineral assessment can fall short.

The fewer mineral deposit types we know about, the fewer deposits an assessment can estimate. Any user of a mineral assessment should consider not only the numbers but also new deposit types, new products or commodities not yet considered important, new technology that could render poor-quality deposits economically feasible, and a possible lack of relevant data for identifying a domain permissive for the occurrence of new undiscovered mineral deposits. Mineral assessment is not a static process.

A paradigm worth breaking is the misconception that modern, well-managed mineral production and a healthy environment are mutually exclusive concepts. The producing community is taking a proactive role to change this mind set. A history of poor stewardship is not a valid indicator of the future stewardship of the Earth. Every year offers more examples of visionary, well-managed enterprises for extracting minerals in ways that protect the environment. Mining companies protect large areas of the Amazon, for example, from clearcutting, farming, and burning. Times have changed, and the industry is eager to partner sustainable environment practices with sustainable resource development.

The assessment process, like the discovery process, is dynamic. Today's estimates will change tomorrow, but a global mineral resource assessment is long overdue. It may not 
lead directly to new discoveries, but it can be a useful forum to coordinate what are now fragmented, conflicting efforts to manage sustainable growth and environmental stewardship. I urge that we are cautious and that we remember that the process is not perfect and needs to change as we learn more. This inherent imperfection, however, is no reason not to start. 


\title{
Mineral Resource Assessment Methodologies
}

\section{Deposit Models and Their Application in Mineral Resource Assessments}

\author{
By Donald A. Singer ${ }^{1}$ and Vladimir I. Berger ${ }^{1}$
}

\begin{abstract}
Mineral deposit models are important in quantitative resource assessments for two reasons: (1) grades and tonnages of most deposit types are significantly different and (2) types occur in different geologic settings that can be identified from geologic maps. Mineral deposit models are the keystone in combining the diverse geoscience information on geology, mineral occurrences, geophysics, and geochemistry used in resource assessments and mineral exploration. Far too few thoroughly explored mineral deposits are available in most local areas for reliable identification of the important geoscience variables or for robust estimation of undiscovered deposits - thus we need mineral deposit models. Well-designed and well-constructed deposit models allow geologists to know from observed geologic environments the possible mineral deposit types that may exist and allow economists to determine the possible economic viability of these resources in the region. Thus, mineral deposit models play the central role in transforming geoscience information to a form useful to policymakers.

Descriptive and grade and tonnage models are discussed because they are the foundations upon which other kinds of models are built. Examples of deposit density models (which represent the number of deposits per unit area) and economic models are provided. Additionally, new forms of quantitative descriptive models are presented with preliminary examples of deposit mineralogy and deposits spatially associated with gold-rich and molybdenum-rich porphyry copper deposits.
\end{abstract}

\section{Introduction}

Because every mineral deposit is different from every other in some way, models have to represent more than single

${ }^{1}$ U.S. Geological Survey, Mail Stop 901, 345 Middlefield Road, Menlo Park, CA 94025, U.S.A. (e-mail: singer@usgs.gov). deposits. Deposits sharing a relatively wide variety and large number of attributes come to be characterized as a "type," and a model representing that type can be synthesized. Probably the most important part of synthesizing mineral deposit models is the planning stage, in which consideration of the purpose and possible uses of the models should determine the character of the models. Ideally, deposit models would provide the necessary and sufficient information to discriminate (1) possible mineralized environments from barren environments, (2) types of known deposits from each other, and (3) mineral deposits from mineral occurrences. In quantitative assessments, deposit models are used to classify mineralized and barren environments and to classify types of known deposits in the tractdelineation part of the assessment, whereas mineral deposits are distinguished from mineral occurrences in the numberof-deposits estimation part of the assessment. The grade and tonnage parts of deposit models, combined with estimation of the number of undiscovered deposits, provide the foundation for economic analysis.

Although there are many fine compendiums of mineral deposit models (Roberts and Sheahan, 1988; Sheahan and Cherry, 1993; Ekstrand and others, 1995; Rongfu, 1995; AGSO Journal of Australian Geology \& Geophysics, 1998), the focus here is on deposit models applied to quantitative resource assessment. Thus, this discussion is limited to mineral deposit models specifically designed for quantitative assessments, such as those in Cox and Singer (1986), Bliss (1992a), and Rogers and others (1995). The target population of these assessments is the group of undiscovered mineral deposits in which each is defined as a mineral occurrence of such size and grade that it might, under favorable circumstances, be economic. Although history suggests that we can expect discoveries of as-yet-unrecognized deposit types, the kinds of assessments discussed here do not include resources from these deposits.

In most published quantitative mineral resource assessments, two kinds of models have been relied upon-(1) descrip- 
tive and (2) grade and tonnage. Descriptive and grade and tonnage models are discussed first because they are the foundations upon which other kinds of models are built. Examples of deposit density models (which represent the number of deposits per unit area) and economic models have appeared sparingly; each of these kinds of models is discussed briefly below. Additionally, new forms of quantitative descriptive models are discussed.

\section{Descriptive Models}

One of the purposes of a mineral deposit model is to communicate information that helps people to find and evaluate mineral deposits. A mineral deposit model is the systemati- cally arranged information describing the essential attributes (properties) of a class of mineral deposits (Barton, 1993).

Descriptive models, such as those in Cox and Singer (1986), have two parts (table 1). The first describes the geologic environments in which the deposits are found; the second gives identifying characteristics of deposits. The first, the "Geological Environment," provides information under several headings. The headings "Rock Types" and "Textures" describe the favorable host rocks of deposits, as well as the source rocks believed responsible for some deposits. "Age Range" refers to the age of the event responsible for the formation of the deposit. "Depositional Environment" refers to the geologic setting of the deposit. "Tectonic Setting" is concerned with major tectonic features or provinces. "Associated Deposit Types" are listed as deposit types whose presence might indicate suitable conditions for the

Table 1. Example of the descriptive model for porphyry Cu-Mo deposits from Cox (1986).

\section{DESCRIPTIVE MODEL OF PORPHYRY Cu-Mo}

MODEL 21a

By Dennis P. Cox

DESCRIPTION Stockwork veinlets of quartz, chalcopyrite, and molybdenite in or near a porphyritic intrusion. Ratio of Au (in ppm [parts per million]) to Mo (in percent) less than 3.

GENERAL REFERENCE Titley (1982).

\section{GEOLOGICAL ENVIRONMENT}

Rock Types Tonalite to monzogranite stocks and breccia pipes intrusive into batholithic, volcanic, or sedimentary rocks.

Textures Intrusions contemporaneous with ore commonly are porphyries with fine- to medium-grained aplitic groundmass. Porphyry texture may be restricted to small dikes in some deposits (Brenda).

Age Range Mainly Mesozoic to Tertiary, but can be any age.

Depositional Environment High-level intrusive porphyry contemporaneous with abundant dikes, faults, and breccia pipes. Cupolas of batholiths.

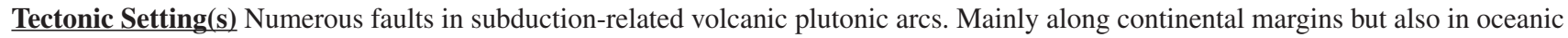
convergent plate boundaries.

Associated Deposit Types $\mathrm{Cu}, \mathrm{Zn}$, or Fe skarns may be rich in gold, gold + base-metal sulfosalts in veins, gold placers. Volcanic-hosted massive replacement and polymetallic replacement.

\section{DEPOSIT DESCRIPTION}

Mineralogy Chalcopyrite + pyrite + molybdenite. Peripheral vein or replacement deposits with chalcopyrite + sphalerite + galena \pm gold . Outermost zone may have veins of $\mathrm{Cu}-\mathrm{Ag}$-Sb-sulfides, barite, and gold.

Texture/Structure Veinlets and disseminations or massive replacement of favorable country rocks.

$\underline{\text { Alteration }}$ Quartz + K-feldspar + biotite (chlorite) \pm anhydrite (potassic alteration) grading outward to propylitic. Late white mica + clay (phyllic) alteration may form capping or outer zone or may affect the entire deposit. High-alumina alteration assemblages may be present in upper levels of the system.

Ore Controls Ore grade is, in general, positively correlated with spacing of veinlets and mineralized fractures. Country rocks favorable for mineralization are calcareous sediments; diabase, tonalite, or diorite.

Weathering Intense leaching of surface; wide areas of iron oxide stain. Fractures coated with hematitic limonite. Supergene copper as chalcocite may form blanket below leached zone. Residual soils may contain anomalous amounts of rutile.

Geochemical Signature $\mathrm{Cu}+\mathrm{Mo}+\mathrm{Ag} \pm \mathrm{W}+\mathrm{B}+\mathrm{Sr}$ center; Pb, Zn, Au, As, Sb, Se, Te, Mn, Co, Ba, and Rb in outer zone. Locally Bi and $\mathrm{Sn}$ form distal anomalies. High $\mathrm{S}$ in all zones. Ratio of $\mathrm{Au}(\mathrm{ppm})$ : Mo (percent) less than 3. Magnetic low.

\section{EXAMPLES}

Brenda, CNBC

Sierrita Esperanza, USAZ
(Soregaroli and Whitford, 1976)

(West and Aiken, 1982) 
formation of deposits of the type portrayed by the model. Thus, this part of the model uses information from the geologic map, geophysical maps, and the known deposits and occurrences. The second part of the descriptive model, the "Deposit Description," provides the identifying characteristics of the deposits themselves, particularly emphasizing aspects by which the deposits might be recognized, such as mineralogy, alteration, and geochemical and geophysical anomalies.

The first part of a descriptive model describes the general setting of the deposit type and plays a primary role in the delineation of tracts of land geologically permissive for the occurrence of undiscovered deposits. The second part helps classify known deposits and occurrences into types, which aids the delineation process. In some cases, the types of known deposits and occurrences identify geologic environments not indicated on geologic maps. The organization of the models constitutes a classification of deposits. The arrangement used emphasizes easy access to the models by focusing on host-rock lithology and tectonic setting, the features most easily obtained from a geologic map.

\section{Grade and Tonnage Models}

Frequency distributions of tonnages and average grades of well-explored deposits of each type are used as models for

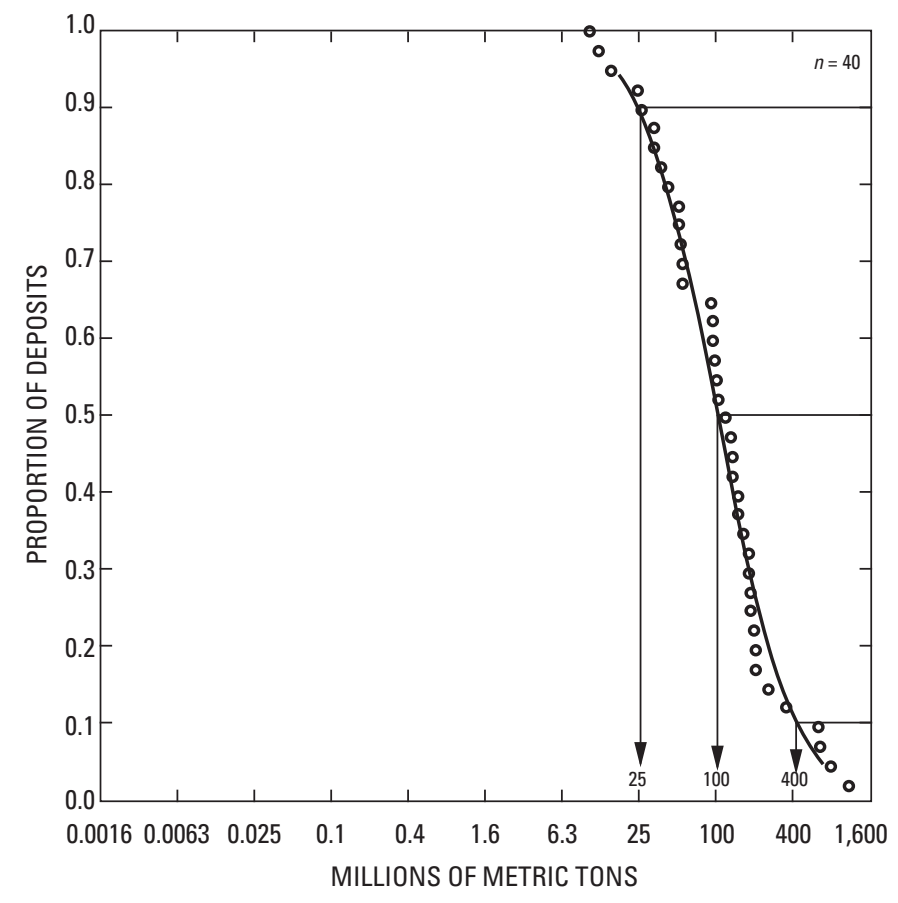

Figure 1. Example of tonnage part of model for porphyry Cu-Au deposits (modified from Singer and Cox, 1986, fig. 78). Each dot represents an individual deposit. Deposits are cumulated in ascending grade or tonnage. Smoothed curves, representing percentiles of a lognormal distribution having the same mean and standard deviation as observed data, are plotted through the points. Intercepts for the 90th, 50th, and 10th percentiles of the lognormal distributions are constructed. grades and tonnages of undiscovered deposits of the same type in geologically similar settings. Grade and tonnage models (Cox and Singer, 1986; Bliss, 1992a) combined with estimates of number of undiscovered deposits are the fundamental means of translating geologists' resource assessments into a language that economists can use. Grade and tonnage models specifically prepared for assessments, such those cited above, show the frequencies of different sizes (for example, fig. 1) and grades (for example, fig. 2) of each of more than 60 mineral deposit types based on more than 2,500 deposits from around the world. For each deposit type, these models help define a deposit, as opposed to a mineral occurrence or a weak manifestation of an ore-forming process. Data utilized to construct these models include average grades of each metal or mineral commodity of possible economic interest and the associated tonnage based on the total production, reserves, and resources at the lowest possible cutoff grade. These data represent an estimate of the endowment of each of many known deposits so that the final models can accurately represent the endowment of all undiscovered deposits (Singer, 1994a).

An important consideration at the data-gathering stage is the question of what the sampling unit should be (Cox and others, 1986; Singer, 1993). Grade and tonnage data are available to varying degrees for districts, deposits, mines, and shafts. In many cases, old production data are available for some deposits, and recent resource estimates are available for other deposits. Prob-

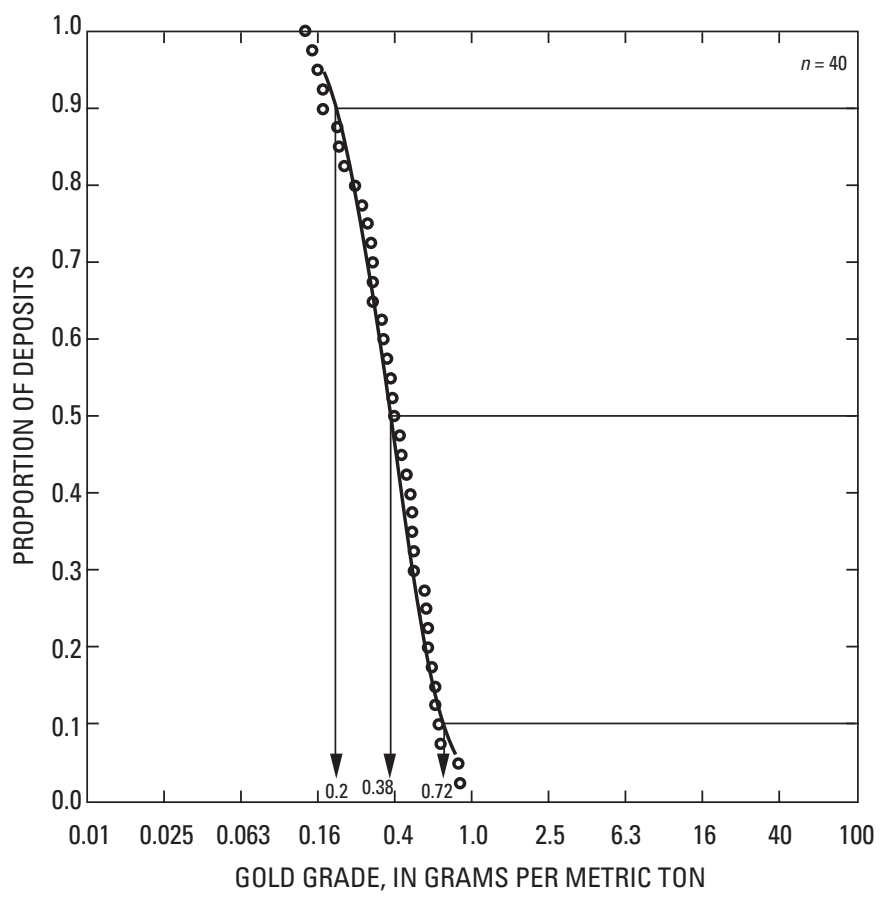

Figure 2. Example of gold grade part of model for porphyry Cu-Au deposits (modified from Singer and Cox, 1986, fig. 80). Each dot represents an individual deposit. Deposits are cumulated in ascending grade or tonnage. Smoothed curves, representing percentiles of a lognormal distribution having the same mean and standard deviation as observed data, are plotted through the points. Intercepts for the 90th, 50th, and 10th percentiles of the lognormal distributions are constructed. 
ably the most common error in constructing grade and tonnage models is mixing old production data from some deposits with resource data from other deposits. It is critical that all data used in the model represent the same sampling unit because mixing data from deposits and districts, or old production and recent resource estimates, usually produces bimodal or at least nonlognormal distributions and may introduce correlations among the variables that are artifacts of the mixed sampling units. Models constructed by using data from mixed sampling units are of questionable value because the frequencies of tonnage and grade observed are directly related to the proportion of deposits from each sampling unit and are unlikely to be representative of the proportion in the undiscovered deposits being estimated in an assessment.

It has been suggested that the grade and tonnage models should be extended to include not only deposits but also occurrences, which are typically very small concentrations of a mineral. If the problem of possible biases due to incomplete exploration of these occurrences is neglected, then it is possible to construct such models; the tonnage model would of course have a much lower median. Because quantitative assessments require that the estimated number of undiscovered deposits be consistent with the grade and tonnage model, the process of estimating the number of deposits might be more difficult because of the much larger number of "deposits" (including occurrences) to be estimated. An economic analysis of the results of this assessment would show that the occurrences and probably some of the estimated undiscovered deposits would be uneconomic. Thus, the effect of including occurrences in the grade and tonnage model would be to make more work in the assessment and not affect the final answer in any way.
The application of these models to resource assessments helps to identify how the models should be augmented. To avoid the situation where every deposit is considered unique and therefore prediction is not possible, the deposits in an area should be tested to determine if they are different from the general model. If the well-explored (that is, completely drilled) deposits are significantly different in size or grade, then the local deposits should be examined to see if they belong to a geologically homogeneous subset of the original grade and tonnage model. Only if all of these conditions are met should a new submodel be constructed, along with a consistent descriptive model. The revised model would then be used in conjunction with the number of deposits estimates.

\section{Deposit Density Models}

A key function of many quantitative mineral resource assessments is estimation of the number of undiscovered deposits. Numerous techniques can be used directly or as guidelines to make these estimates. Most robust of these methods is a form of mineral deposit model wherein the numbers of deposits per unit area from well-explored regions are counted (Bliss and Menzie, 1993) and the resulting frequency distribution is used either directly for an estimate or indirectly as a guideline in some other method. Ratios of number of deposits per unit area can be used in histograms to show how common are different deposit densities. It is not necessary that the base areas be explored completely, but it is necessary that

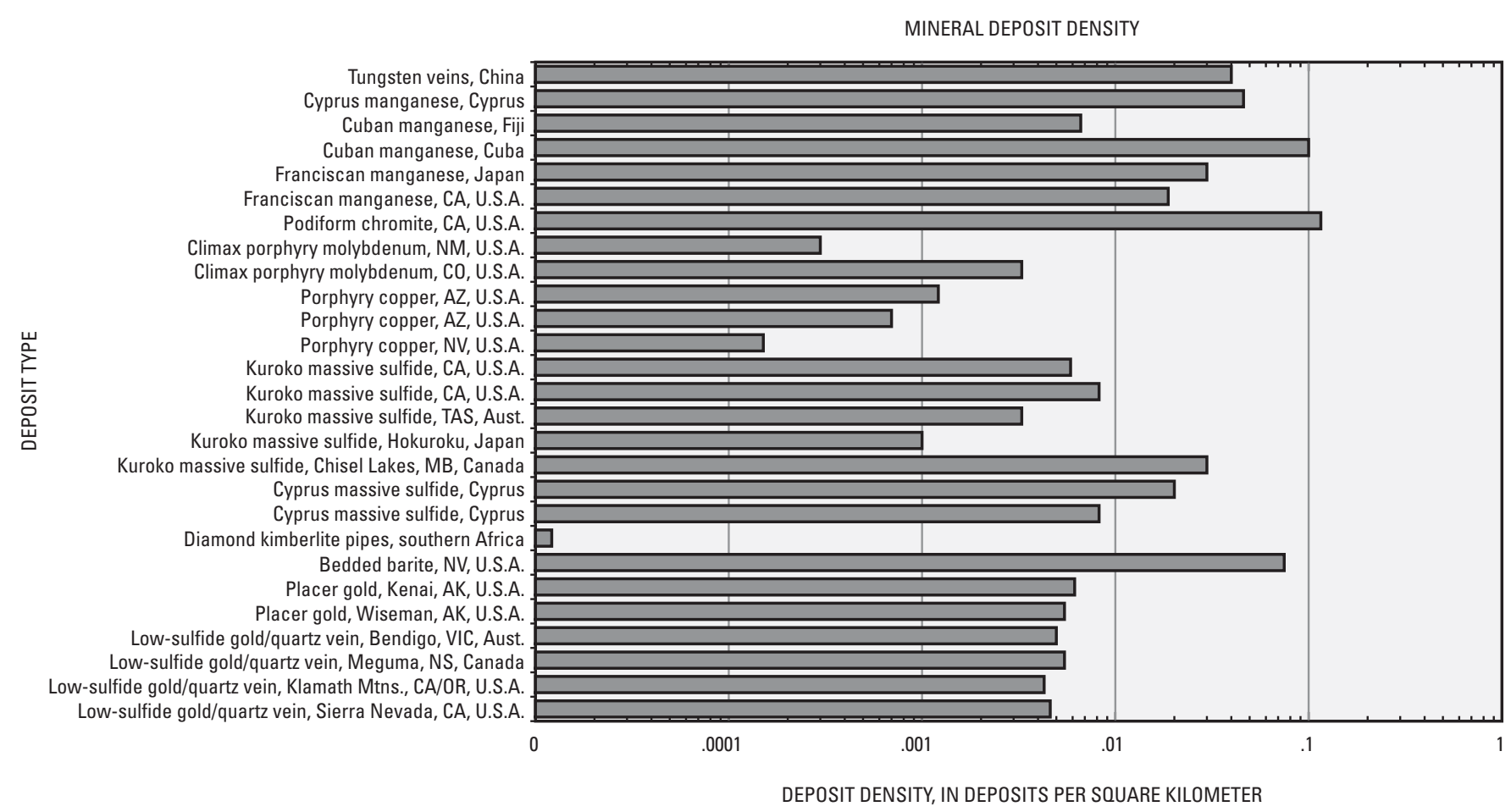

Figure 3. Graph of numbers of deposits per unit area by deposit type from well-explored regions, as reported by Singer and others (2001). MB, Manitoba; NS, Nova Scotia; TAS, Tasmania; VIC, Victoria. 
the number of deposits found and the proportion of the area explored be estimated. Examples of mineral deposit density models were presented by Bliss (1992b), Bliss and Menzie (1993), and Singer (1994b). Singer and others (2001) summarized these estimates and added new deposit densities (fig. 3). As in the case of other kinds of models designed for quantitative resource assessment, deposit density models need to be constructed so that they are consistent with these other models.

For example, densities for low-sulfide quartz gold vein deposits were discussed by Bliss and Menzie (1993). These mesothermal deposits were defined in the descriptive model, and the deposit density model also was consistent with the grade and tonnage model. It is important to note that the same proximity rule used to construct the grade and tonnage model (workings within 1.6 kilometers of each other were treated as part of the same deposit) was used to define deposits for the deposit densities.

Many of the specially selected areas where deposit densities have been reported (fig. 3) provide standards to identify what should be high estimates of number of undiscovered deposits in most situations. Thus, many of these examples probably are best considered as guides to upper limits of the density of deposits. General deposit density models that can be used for estimating the number of deposits, given the area of the permissive tract, were provided for podiform chromite deposits (Singer, 1994b) and for porphyry copper deposits (Singer and others, 2005).

\section{Economic Models}

In resource assessments of undiscovered mineral deposits and in the early stages of exploration, including planning, a need exists for prefeasibility cost models. These models, which separate economic from uneconomic deposits, help to focus on targets that can benefit the exploration enterprise. In resource assessment, these models can be used to eliminate deposits that would probably be uneconomic even if discovered. As noted by Singer (1993), varying numbers of deposits used to construct the grade and tonnage models are not, or were not, economic. The former U.S. Bureau of Mines (USBM) previously developed simplified cost models for such problems (Camm, 1991). These cost models estimate operating and capital expenditures for a mineral deposit, given the appropriate mining method and the deposit's tonnage, grade, and depth. These cost models also were incorporated in USBM prefeasibility software (Smith, 1992).

In a previous study (Singer and others, 1998), Camm's simplified cost models for U.S. open-pit gold-silver deposit operations were modified to reflect higher capacities observed in heap-leach processing with autoclave, carbon-in-leach, carbon-in-pulp, and Merrill Crowe mills. For heap-leach operations, equations for estimating operating cost and capital expenditure also were modified. Explanations of these various processing methods are available in Camm (1991). For a

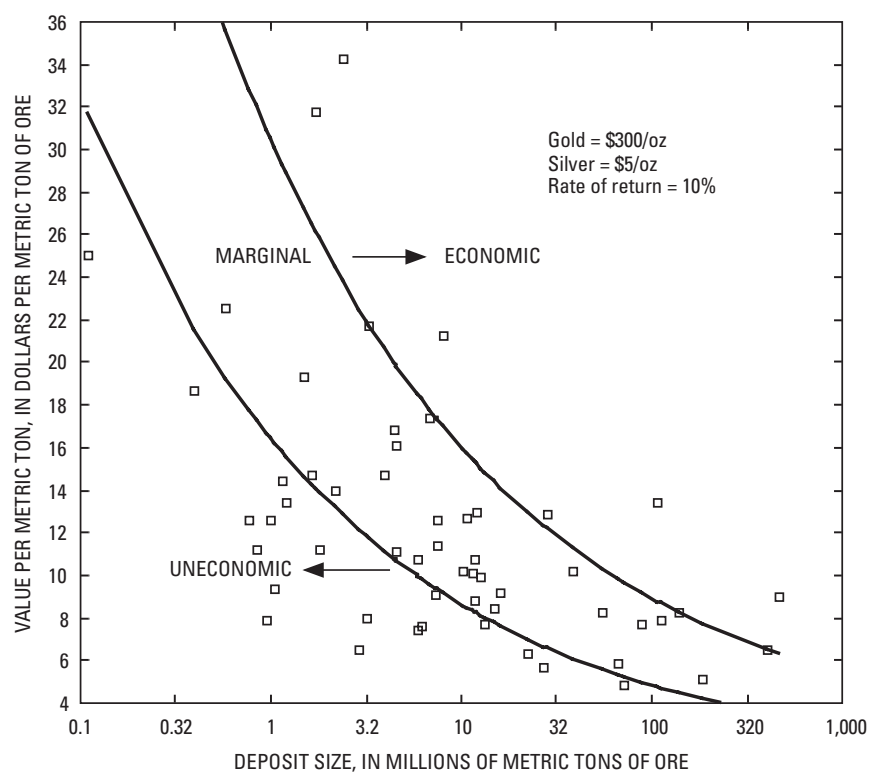

Figure 4. Graph showing relation between value per metric ton and deposit size (in millions of metric tons of ore) for some U.S. open-pit, heap-leach gold-silver deposits when prices and the rate of return are as shown.

particular tonnage, the dividing (or break-even) line between economic and uneconomic can be estimated by adding the estimated operating cost to the capital expenditure divided by capacity times operating days per year times the present value of a dollar for the life of the mine. To account for variation and uncertainties in most of the inputs to these estimates, 0.7 and 1.3 of this break-even value are plotted to estimate boundaries for uneconomic, marginal, and economic deposits (fig. 4.).

For underground mining of massive sulfide deposits using each of five different mining methods, capacity and cost estimates using the USBM models with observed mines were compared (Singer and others, 2000). Based on analysis of the economic relations in mines on 28 massive sulfide deposits in this study, no reason was found to reject the simplified cost models for underground mining operations presented by Camm (1991). The deposits represent at least six different deposit types and are located in seven different countries. For cut-and-fill, room-and-pillar, crater retreat, shrinkage stope, and sublevel longhole mining, with or without shafts, the equations for estimating operating cost and capital expenditure are consistent with known operations. The resultant equations appear to provide reasonable estimates of costs (fig. 5). Similar results were found for open-pit mining and heapleach recovery of copper deposits in the United States (Long and Singer, 2001). Camm's methods and subsequent refinements have been incorporated in a computer program used to combine estimated number of deposits with grade and tonnage models (Duval, 2004). Nonetheless, all such estimates can be wrong because of factors such as poor metal recovery or errors in estimated future metal prices. 




Figure 5. Graph showing relation between value per metric ton and deposit size (in millions of metric tons of ore) for some zinclead skarn deposits. All deposits are assumed to be mined at a depth of 800 feet, with half of each mined by cut-and-fill methods and half by shrinkage stope methods. Prices and the rate of return are shown in the graph.

\section{Quantitative Models}

The descriptive models discussed above have been developed on the basis of expert knowledge. An alternative, more time consuming, method of developing descriptive models is to gather data from well-explored deposits of each type to determine how commonly different attributes and combinations of attributes occur. Quantifying mineral deposit attributes is the necessary and sufficient next step in statistically classifying known deposits by type. To determine if quantified mineral deposit models would be useful, data on the minerals reported present in 55 different types of deposits were compiled (Singer and others, 1997) and were used to statistically discriminate 8 of the deposit types. Using 58 minerals and 6 generalized rock types, over 90 percent of the unknown deposits were accurately classified into the correct eight types (Singer and Kouda, 1997); clearly digital mineralogy can be useful in classifying well-studied deposits. An example of the usefulness of this kind of data is shown by a plot (fig. 6) of a few of the minerals present in three subtypes of porphyry copper deposits. Gold, alunite, covellite, and actinolite are more common in gold-rich porphyry copper deposits, whereas pyrrhotite, fluorite, and rutile are more common in the more deeply emplaced molybdenum-rich porphyry copper deposits. Although based on preliminary data, a similar pattern emerges when one looks at the proportion of porphyry copper deposits that have other deposit types within 10 kilometers of the porphyry (fig. 7). Epithermal quartz-alunite gold-silver, epi- thermal Comstock gold-silver, and polymetallic replacement zinc-lead are more common near gold-rich porphyry copper deposits, but zinc-lead skarn deposits are more common near molybdenum-rich porphyry copper deposits.

This kind of information is necessary but not sufficient to discriminate barren from mineralized environments; quantifying the attributes of barren environments also is necessary for this task. To be useful in quantitative assessments, the

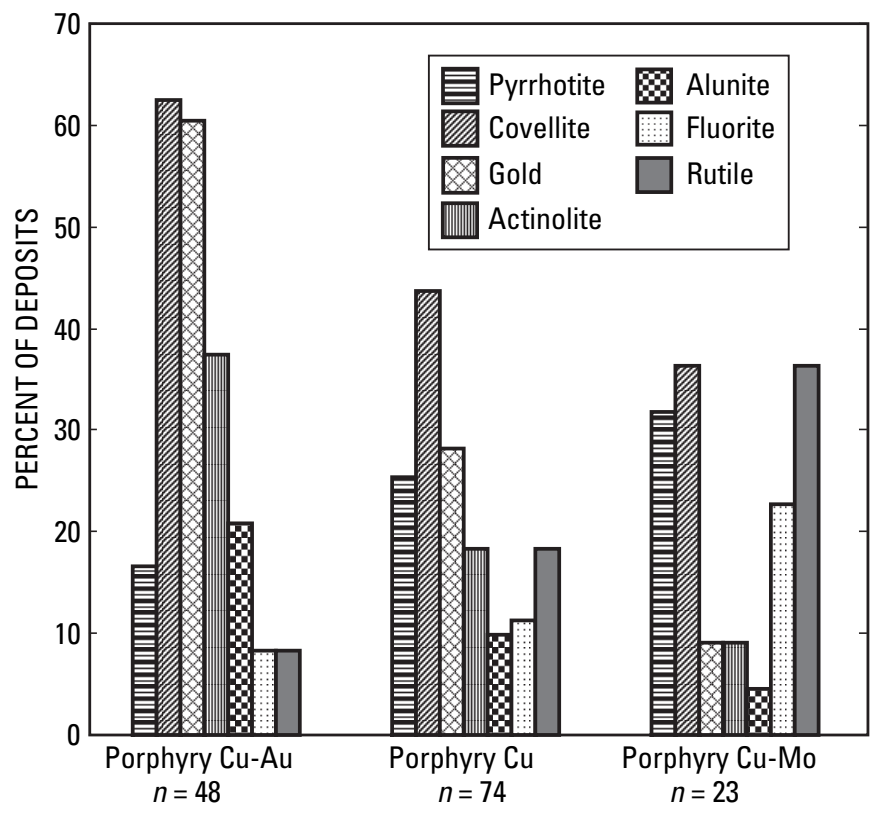

Figure 6. Graph showing the proportion of subtypes of porphyry copper deposits reporting the presence of several mineral species.

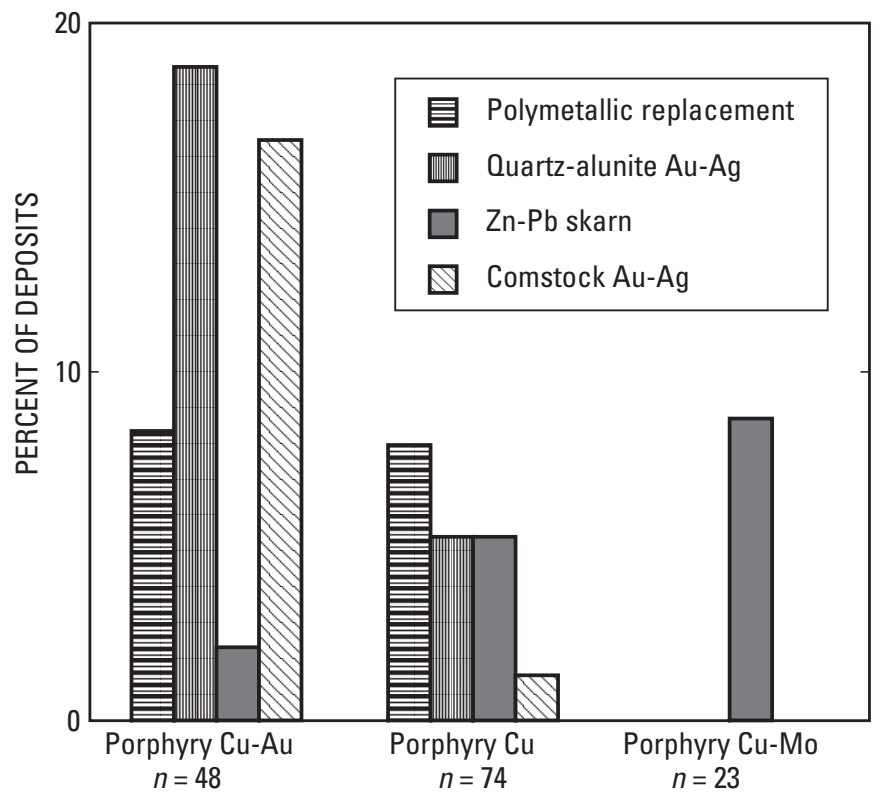

Figure 7. Graph showing the proportion of subtypes of porphyry copper deposits reporting the presence of different deposit types occurring within 10 kilometers. 
models of number of deposits per unit area and the attempts to quantify deposit attributes must be constructed so that they are consistent with the present descriptive and grade and tonnage models. Otherwise, the resulting resource assessments will be internally inconsistent.

\section{Conclusions}

Consistency in quantitative assessments is dependent on the internal consistency required in the construction of the descriptive, grade and tonnage, and deposit density models. New models of number of deposits per unit area and other quantitative extensions to the present models also need to be consistent with the other parts of the models. That is, these models must be constructed from deposits that are located in geologic settings that match the descriptive models and that are consistent with the appropriate grade and tonnage models. These new versions of deposit models, the quantification of models in general, and the development of guidelines or direct methods of estimation of number of undiscovered deposits will all be successful to the extent that they are consistent with the other models used in assessments.

\section{References Cited}

AGSO Journal of Australian Geology \& Geophysics, 1998, Exploration models for major Australian mineral deposit types [a group of 23 separately authored articles]: AGSO (Australian Geological Survey Organisation) Journal of Australian Geology \& Geophysics, v. 17, no. 4, p. 69-258.

Barton, P.B., Jr., 1993, Problems and opportunities for mineral deposit models, in Kirkham, R.V., Sinclair, W.D., Thorpe, R.I., and Duke, J.M., eds., Mineral deposit modeling: Geological Association of Canada Special Paper 40, p. 7-13.

Bliss, J.D., ed., 1992a, Developments in mineral deposit modeling: U.S. Geological Survey Bulletin 2004, 168 p. (Also available online at http://pubs.usgs.gov/bul/b2004/.)

Bliss, J.D., 1992b, Grade-tonnage and other models for diamond kimberlite pipes: Nonrenewable Resources, v. 1, no. 3, p. 214-230.

Bliss, J.D., and Menzie, W.D., 1993, Spatial mineral deposit models and the prediction of undiscovered mineral deposits, in Kirkham, R.V., Sinclair, W.D., Thorpe, R.I., and Duke, J.M., eds., Mineral deposit modeling: Geological Association of Canada Special Paper 40, p. 693-706.

Camm, T.W., 1991, Simplified cost models for prefeasibility mineral evaluations: U.S. Bureau of Mines Information Circular 9298, 35 p.
Cox, D.P., 1986, Descriptive model of porphyry Cu-Mo [copper-molybdenum deposits], in Cox, D.P., and Singer, D.A., eds., Mineral deposit models: U.S. Geological Survey Bulletin 1693, p. 115. (Also available online at http://pubs.usgs.gov/bul/b1693/Md21a.pdf.)

Cox, D.P., Barton, P.B., and Singer, D.A., 1986, Introduction, in Cox, D.P., and Singer, D.A., eds., Mineral deposit models: U.S. Geological Survey Bulletin 1693, p. 1-10. (Also available online at http://pubs.usgs.gov/bul/b1693/Intro.pdf.)

Cox, D.P., and Singer, D.A., eds., 1986, Mineral deposit models: U.S. Geological Survey Bulletin 1693, 379 p. (Also available online at http://pubs.usgs.gov/bul/b1693/.)

Duval, J.S., 2004, Version 2.0 of EMINERS-Economic mineral resource simulator: U.S. Geological Survey Open-File Report 2004-1344, available only online at http://pubs.usgs.gov/of/2004/1344/.

Ekstrand, O.R., Sinclair, W.D., and Thorpe, R.I., eds., 1995, Geology of Canadian mineral deposit types, v. P-1 of The geology of North America: Boulder, Colo., Geological Society of America, 640 p. (Produced as part of the Decade of North American Geology Project; also designated as Geological Survey of Canada, Geology of Canada no. 8.)

Long, K.R., and Singer, D.A., 2001, A simplified economic filter for open-pit mining and heap-leach recovery of copper in the United States: U.S. Geological Survey Open-File Report 01-218, 21 p., available only online at http://geopubs.wr.usgs.gov/open-file/of01-218/.

Roberts, R.G., and Sheahan, P.A., eds., 1988, Ore deposit models: Geoscience Canada Reprint Series 3, 200 p.

Rogers, M.C., Thurston, P.C., Fyon, J.A., Kelly, R.I., and Breaks, R.W., 1995, Descriptive mineral deposit models of metallic and industrial deposit types and related mineral potential assessment criteria: Ontario Geological Survey Open-File Report 5916, 241 p.

Rongfu, Pei, ed., 1995, Mineral deposit models of China: Beijing, Geological Publishing House, 357 p. (In Chinese with English abstract and table of contents.)

Sheahan, P.A., and Cherry, M.E., eds., 1993, Ore deposit models, v. II: Geoscience Canada Reprint Series 6, 160 p.

Singer, D.A., 1993, Development of grade and tonnage models for different deposit types, in Kirkham, R.V., Sinclair, W.D., Thorpe, R.I., and Duke, J.M., eds., Mineral deposit modeling: Geological Association of Canada Special Paper 40, p. 21-30.

Singer, D.A., 1994a, The relationship of estimated number of undiscovered deposits to grade and tonnage models in threepart mineral resource assessments, in 1994 International Association for Mathematical Geology Annual Conference, Papers and Extended Abstracts for Technical Programs, October 3-5, 1994, Mont Tremblant, Quebec, Canada: p. 325-326. 
Singer, D.A., 1994b, Conditional estimates of the number of podiform chromite deposits: Nonrenewable Resources, v. 3, no. 3, p. 200-204.

Singer, D.A., Berger, V.I., Menzie, W.D., and Berger, B.B., 2005, Porphyry copper deposit density: Economic Geology, v. 100 , p. $491-514$.

Singer, D.A., and Cox, D.P., 1986, Grade and tonnage model of porphyry $\mathrm{Cu}-\mathrm{Au}$ [copper-gold deposits], in Cox, D.P., and Singer, D.A., eds., Mineral deposit models: U.S. Geological Survey Bulletin 1693, p. 110-114. (Also available online at http://pubs.usgs.gov/bul/b1693/Md20c.pdf.)

Singer, D.A., and Kouda, Ryoichi, 1997, Classification of mineral deposits into types using mineralogy with a probabilistic neural network: Nonrenewable Resources, v. 6, no. 1, p. 27-32.

Singer, D.A., Menzie, W.D., and Long, K.R., 1998, A simplified economic filter for open-pit gold-silver mining in the United States: U.S. Geological Survey Open-File Report 98-207, 10 p. (Also available online at http://geopubs.wr.usgs.gov/open-file/of98-207/.)

Singer, D.A., Menzie, W.D., and Long, K.R., 2000, A simplified economic filter for underground mining of massive sulfide deposits: U.S. Geological Survey Open-File Report 00-349, $20 \mathrm{p}$.
Singer, D.A., Menzie, W.D., Sutphin, D.M., Mosier, D.L., and Bliss, J.D., 2001, Mineral deposit density-An update, chap. A of Schulz, K.J., ed., Contributions to global mineral resource assessment research: U.S. Geological Survey Professional Paper 1640, p. A1-A13. (Also available online at http://pubs.usgs.gov/prof/p1640a/.)

Singer, D.A., Waller, Nichelle, Mosier, D.L., and Bliss, J.D., 1997, Digital mineralogy data for 55 types of mineral deposits-Macintosh version: U.S. Geological Survey Open-File Report 97-160, one 3.5-inch disk.

Smith, R.C., 1992, PREVAL—Prefeasibility software program for evaluating mineral deposits: U.S. Bureau of Mines Information Circular 9307, 35 p.

Soregaroli, A.E., and Whitford, D.F., 1976, Brenda, in Sutherland Brown, A., ed., Porphyry deposits of the Canadian Cordillera; A volume dedicated to Charles S. Ney: Canadian Institute of Mining and Metallurgy Special Volume 15, p. 186-194.

Titley, S.R., 1982, The style and progress of mineralization and alteration in porphyry copper systems; American Southwest, in Titley, S.R., ed., Advances in geology of the porphyry copper deposits, southwestern North America: Tucson, University of Arizona Press, p. 93-116.

West, R.J., and Aiken, D.M., 1982, Geology of the SierritaEsperanza deposit, Pima mining district, Pima County, Arizona, in Titley, S.R., ed., Advances in geology of the porphyry copper deposits, southwestern North America: Tucson, University of Arizona Press, p. 433-466. 


\title{
Estimating Amounts of Undiscovered Mineral Resources
}

\author{
By Donald A. Singer ${ }^{1}$
}

\section{Abstract}

The purpose of the three-part form of mineral resource assessments is to make unbiased quantitative assessments in a format needed in decision-support systems so that consequences of alternative courses of action can be examined. It is argued that the internally consistent descriptive, grade and tonnage, deposit density, and economic models and the design of the three-part form of assessments reduce the chances of biased estimates of the undiscovered resources. One part of three-part assessments, mineral deposit models, is discussed in Singer and Berger (this volume). Here the principal ideas of delineation of tracts of land and estimation of the number of undiscovered mineral deposits therein are presented. Linkage of the models with delineation and with estimation of deposits further reduces possible biases. Additionally, seven guidelines and some examples are provided to reduce biases in estimates of numbers of deposits. Experience from meteorology suggests that consensus schemes perform better than individual estimators and that the best estimates are made when objective estimates such as those from guidelines are part of the information supplied to subjective estimators.

\section{Introduction}

Information from mineral resource assessments is used for making decisions concerning mineral supply, land use, the environment, development, and exploration and for shaping mineralsrelated domestic and foreign policy. Quantitative assessments are required to make resource assessments and their associated uncertainties explicit and reproducible and to allow economic analysis. The goal is to make unbiased quantitative assessments in a format needed in decision-support systems so that the consequences of alternative courses of action can be examined.

Of the many kinds of quantitative mineral resource assessments (Harris, 1984; Shulman and others, 1992), there is one, called a three-part assessment (Singer, 1993; Drew and others, 1999), that was designed to respond to the broad goal above. In three-part assessments, (1) areas are delineated according to the types of deposits permitted by the geology, (2) the amount of metal and some ore characteristics are

${ }^{1}$ U.S. Geological Survey, Mail Stop 901, 345 Middlefield Road, Menlo Park, CA 94025, U.S.A. (e-mail: singer@usgs.gov). estimated by means of grade and tonnage models, and (3) the number of undiscovered deposits of each type is estimated. To these parts, economic analysis and the proper combinations of the parts by simulation (Root and others, 1992) can be applied.

Considerable care must be exercised in quantitative resource assessments to prevent the introduction of biased estimates of undiscovered resources. In three-part assessments, estimates are internally consistent in that delineated tracts are consistent with descriptive models, grade and tonnage models are consistent with descriptive models, grade and tonnage models are consistent with known deposits in the area, and estimates of the number of deposits are consistent with grade and tonnage models. Biases can be introduced into these estimates either by a flawed grade and tonnage model or by the lack of consistency of the grade and tonnage model with estimates of the number of deposits.

Issues about the consistency of mineral deposit models are discussed in a companion paper (Singer and Berger, this volume), as are grade and tonnage models that are the second part of three-part assessments. In this paper, the focus is on (1) delineating tracts of land in which the geology permits the occurrence of the undiscovered deposits and (2) reducing bias in estimating the number of undiscovered deposits.

\section{Delineation of Permissive Tracts}

To be able to consistently assess the undiscovered mineral resources of regions, we delineate areas where geology permits the existence of deposits of one or more specified types. These areas, called permissive tracts, are based on geologic criteria derived from deposit models that are themselves based on studies of known deposits within and outside the study area. Permissive boundaries are defined such that the probability of deposits of the type delineated occurring outside the boundary is negligible; that is, less than 1 in 100,000.

One delineation strategy is to move boundaries outward from known deposits fig. 1). This strategy might be considered the delineation of favorable areas; however, in three-part assessments, we try to delineate permissive areas. Although favorable areas are a subset of permissive areas, they represent very different concepts. Their boundaries will coincide only if exploration coverage is very thorough and completely effective - a fairly unusual situation. In addition, delineations of favorable areas frequently are applied in different ways by dif- 

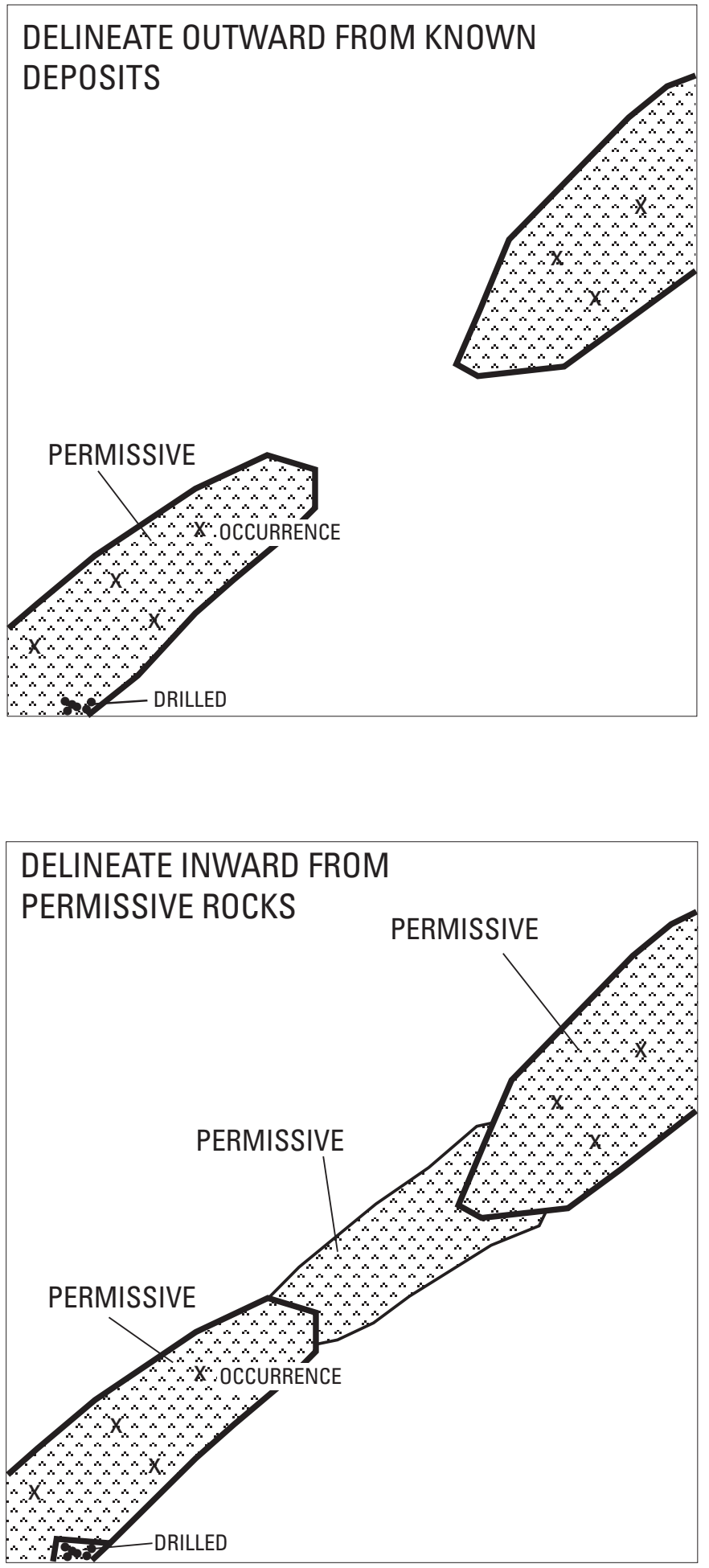

Figure 1. Maps showing delineation of tracts by two different strategies. The upper map shows the strategy of moving outward from known deposits; this strategy might be considered the delineation of favorable areas, which are a subset of permissive tracts, and it is not used in the three-part form of mineral resource assessments. The lower map shows the strategy of moving inward from permissive rocks to delineate permissive tracts. ferent people because of the difficulty of defining a commonly acceptable operational rule.

The preferred delineation strategy is to move inward from permissive rocks (fig. 1). Known deposits and occurrences serve to identify and expand permissive tracts, not constrain them. By using this definition, it is possible to subdivide a permissive tract into two or more parts that have different kinds of information, different numbers of undiscovered deposits, or possibly different amounts of uncertainty about the number of deposits.

Tracts may or may not contain known deposits. Areas are excluded from these tracts only on the basis of geology, knowledge about unsuccessful exploration, or the presence of barren overburden exceeding some predetermined thickness. A geologic map is the primary local source of information for delineating tracts and identifying which areas are permissive for different deposit types. Probably the second most important kind of information is an inventory of known mineral deposits and occurrences in and near the region being assessed. Because of incomplete deposit descriptions, it often is difficult to identify deposit types for many occurrences and some deposits, but those that can be identified increase confidence in tracts delineated for the deposit type. Occurrences may indicate the possibility of some deposit types and place limits on the kinds and sizes of deposits elsewhere. The map of deposits classified by deposit type then serves as a check on the accuracy of the delineation of tracts permissive for that type rather than a determinant of the delineation. Geochemistry of stream sediments may suggest deposit types and aid delineation of tracts for some deposit types. Geophysical surveys contribute by identifying extensions of permissive rock units under cover and identifying rock units in poorly mapped areas; in some cases, geophysical data can identify favorable rock units, such as hydrothermally altered rocks. Both stream sediment and rock geochemistry can provide similar benefits to large regional assessments.

Tracts are outlined for the possibility of the existence of one or more deposit types as inferred by analogy with deposits in similar geologic settings elsewhere. Mineral deposit models provide the means to make the links between geologic settings and deposit type. In every case, the boundaries of the tracts are based first on mapped or inferred geology. Original boundaries are reduced only where it can be firmly demonstrated that a deposit type could not exist. For some deposit types, extensive exploration can provide such evidence, but for many deposit types, only closely spaced drilling or overburden thicker than the delineation limit can be used to exclude areas.

Designation of a tract as permissive does not imply any special favorability for the occurrence of a deposit, nor does it address the likelihood that a deposit will be discovered there if it exists. Favorability for a deposit type is represented by the number of undiscovered deposits that are perceived to exist in a tract.

\section{Estimation of the Number of Deposits}

The third part of an assessment is the estimation of some fixed, but unknown, number of deposits of each type that exist 
in the delineated tracts. Until the area being considered is thoroughly and extensively drilled, this fixed number of undiscovered deposits, which could be any number including 0 , will not be known with certainty.

Estimates of the number of deposits explicitly represent the probability (or degree of belief) that some fixed but unknown number of undiscovered deposits exist in the delineated tracts. As such, these estimates reflect both the uncertainty of what may exist and a measure of the favorability of the existence of the deposit type. Uncertainty is shown (fig. 2 by the spread of the number of deposits estimates associated with the 90 percent quantile and the 10 or 1 percent quantile; a large difference in the numbers suggests great uncertainty. Favorability can be represented by the estimated number of deposits associated with a given probability level or by the expected (mean) number of deposits.

Estimates are by deposit type and must be consistent with the grade and tonnage model and not with the population of mineral occurrences or weak manifestations of an ore-forming process (Singer, 1994a). Thus, the estimated number of deposits must match the percentile values of the grade and tonnage model. For example, for any estimate, approximately half of the estimated undiscovered deposits should be larger than the median tonnage and about 10 percent of the deposits should be as large as the upper 10 percent of the deposits in the tonnage model. If the grade and tonnage model is based on district data, then the number of undiscovered districts should be estimated. Some mineral deposit models, such as kuroko massive sulfide deposits, were constructed with spatial distance rules such as a 500-meter rule for combining mineralization-the same rule must be applied when the number of undiscovered deposits is estimated. Deposits in the study area that have published grades and tonnages are counted as discovered deposits, whereas those without published estimates are counted as undiscovered to avoid double counting.

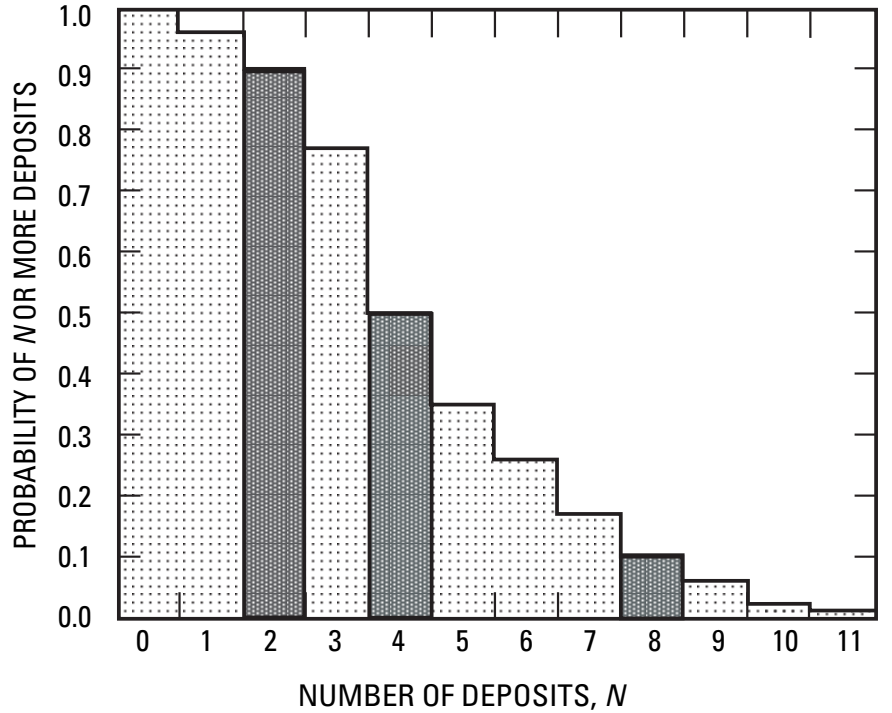

Figure 2. Graph showing three estimates (dark bars) of the number of undiscovered deposits along with interpolated values (light bars). The estimates were made at the 90,50, and 10 percent quantiles. A large difference in the estimates at 90 and 10 percent would suggest great uncertainty, but this graph shows a relatively small difference.

\section{Guidelines for Estimates}

There are no fixed methods for making estimates of the number of undiscovered deposits. On the basis of experience and logic, however, at least seven different ways can be used directly or as guidelines to make these estimates (table 1). Each guideline represents some form of analogy. Most robust of these is a form of mineral deposit model wherein the number of deposits of each type per unit area from well-explored regions (Bliss and Menzie, 1993; Singer and others, 2001, 2005 ) is counted and the resulting frequency distribution is

Table 1. Guidelines for estimation of the number of deposits.

[Modified from Singer, 1993]

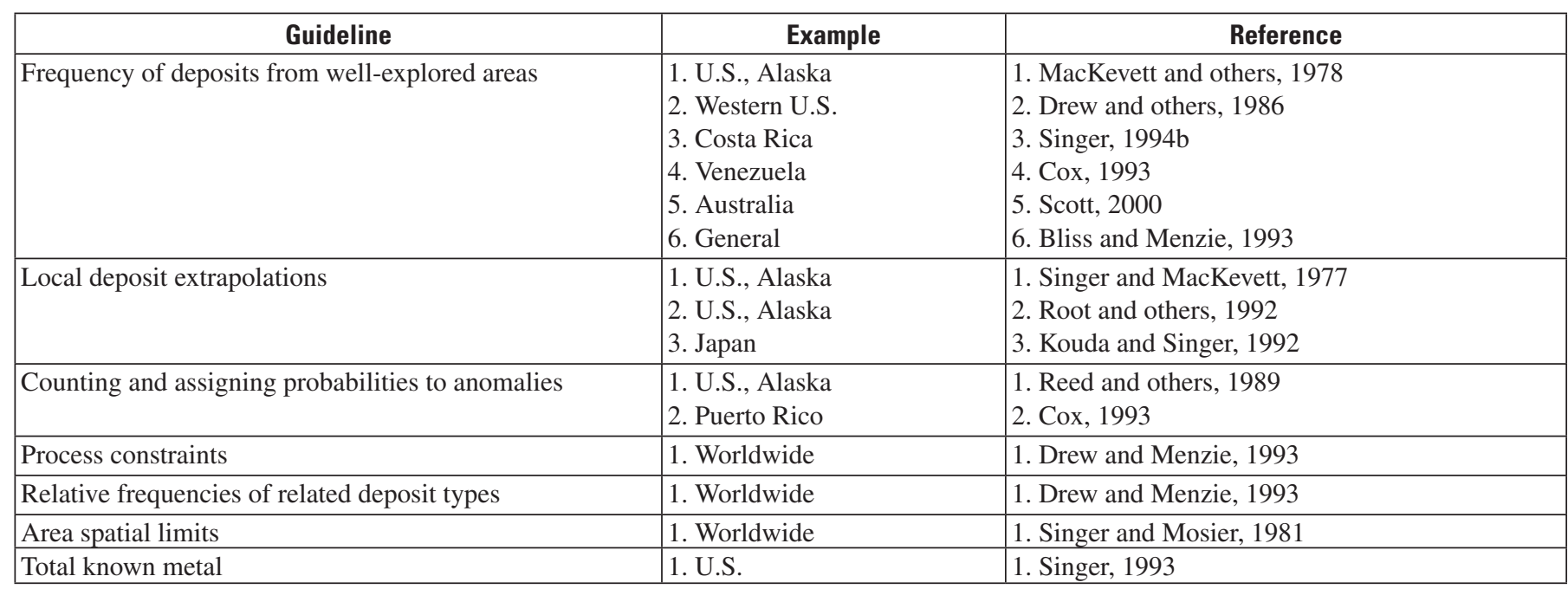


used either directly for an estimate or indirectly as a guideline in some other method. Although Allais (1957) used this method of estimating the number of undiscovered deposits, many kinds of deposits were mixed together in his analysis.

In most three-part assessments, the final estimates were made subjectively, and many estimators used one or more of the above methods as guidelines. For example (see Singer and others, 2001), in the State of Nevada there are seven known deposits that are defined in the same way as deposits in the porphyry copper descriptive and grade and tonnage models. The tract permissive for all pluton-related deposits, including porphyry copper, covers about 41 percent of the area of the State (Cox and others, 1996). The well-explored, exposed permissive rocks in Nevada cover an area of about 32,800 square kilometers; five of the known porphyry copper deposits are in this exposed region. Areas covered by more than 1 kilometer of overburden are excluded from consideration. Concealed permissive areas within 1 kilometer of the surface are about 84,500 square kilometers in extent. Two of the known porphyry copper deposits are completely covered by younger materials and cannot be considered to belong to the population of deposits that are well explored and exposed.

If we assume that there are no additional porphyry copper deposits to be discovered in the exposed plutons in Nevada, then 5 deposits per 32,800 square kilometers (exposed permissive area) equals 0.00015 porphyry copper deposits per square kilometer. We can use this density of deposits to estimate the expected (mean) number of undiscovered porphyry copper deposits in Nevada. Thus, 0.00015 porphyry copper deposits per square kilometer times 84,500 square kilometers of covered permissive area equals an expected 12.9 concealed deposits; subtracting the 2 discovered deposits leaves 11 undiscovered concealed deposits that are defined in the same way as the deposits in the porphyry copper grade and tonnage model. For comparison purposes, the subjective estimate of the number of undiscovered porphyry copper deposits in Nevada by Cox and others (1996) is 8.7 deposits.

In an unpublished example, four scientists (participants A-D) made subjective probabilistic estimates of the number of undiscovered hot-spring mercury deposits in a 1:250,000-scale quadrangle in Alaska. They made independent estimates at the 90th, 50th, and 10th complementary percentiles (table 2). The estimate at the 10th percentile, for example, is the number of

Table 2. Independent estimates by four scientists (A, B, C, and $D)$ of the number of undiscovered hot-spring mercury deposits in a quadrangle in Alaska.

\begin{tabular}{lllll}
\hline \multirow{2}{*}{ Percentile } & \multicolumn{5}{c}{ Estimates by participant } \\
\cline { 2 - 5 } & A & B & C & D \\
\hline $\begin{array}{c}\text { 90 percent chance of at least the number } \\
\text { of deposits listed }\end{array}$ & 1 & 1 & 2 & 9,000 \\
$\begin{array}{c}50 \text { percent chance of at least the number } \\
\text { of deposits listed }\end{array}$ & 3 & 2 & 4 & 10,000 \\
$\begin{array}{c}10 \text { percent chance of at least the number } \\
\text { of deposits listed }\end{array}$ & 6 & 6 & 7 & 11,000 \\
\hline
\end{tabular}

deposits for which there is at least a 10 percent chance of that number of deposits or more. It was pointed out to participant $\mathrm{D}$ that, because the number of deposit estimates must be consistent with the grade and tonnage model, his estimates imply that there is more undiscovered mercury in this quadrangle than has been found in the world in this deposit type. He replied that he was estimating wisps of cinnabar, not deposits consistent with the grade and tonnage model. In this case, knowledge of the total known amount of metal provided a guide to a flawed estimate. Using a variety of different guidelines for estimates provides a useful crosscheck of assumptions that may have been relied upon.

\section{Estimation Strategies}

In practice, a small group of scientists who are knowledgeable about the deposit type (and advised by the regional experts) typically make consensus estimates. Two general strategies tend to be used (Menzie and Singer, 1990). In one, individual occurrences, prospects, and indicators are assigned probabilities, and the results are combined. In the other, the estimator recalls from experience many other areas that are geologically similar to the area being assessed and are well explored and uses the proportions of undiscovered deposits in these other areas to make the estimates for the new area. In each case, the scientists must weigh the geoscience and exploration information. A number of the guidelines for making these estimates listed in table 1 were used by a team estimating undiscovered resources in Nevada (Cox and others, 1996). Some estimators used the number of known deposits per unit area of exposed permissive rocks multiplied by the area of permissive rock concealed by less than 1 kilometer of overburden (postmineralization rocks and sedimentary deposits), as in the above example of porphyry copper deposits. Some based their estimates on the number of deposits known in well-studied areas of similar geology elsewhere in the world. Others depended on the number of occurrences that might become deposits as a result of more complete exploration, and still others were influenced by the number of exploration "plays" that could be visualized for the deposit type in question. Until more estimation guidelines and density of deposits models are available, it seems prudent to rely on mineral deposit specialists to make subjective estimates because they can bring their experiences and observations to the process.

Subjective probabilities such as those used here variously have been called degrees of belief or propositional probabilities. Geologists commonly make similar estimates that, although not explicitly quantitative, are subjective and have uncertainty, such as making geologic cross sections. Examples from different fields of study (Murphy and Winkler, 1984; Stern, 1991) demonstrate that, under some conditions, subjective estimates can be unbiased and reliable. The decades of experience of subjective and objective forecasting in meteorology provide insight into how the process of making subjective assessments in mineral resources might be improved. Murphy 
and Winkler (1984) found that consensus schemes performed better than almost all individual forecasters and that the best forecasts were made when objective forecasts were part of the information supplied to subjective forecasters. Among their recommendations were more effective use of many information sources, motivation to encourage forecasters to improve their performance, provision of formal procedures to assist forecasters in quantifying their uncertainty in terms of probability, and quick and extensive feedback concerning performance. Quick and extensive feedback might be difficult to apply in mineral resource assessments, except possibly through training exercises.

Sensitivity analysis shows that the greatest opportunity for reducing uncertainty in exploration and resource assessment lies with lowering the uncertainty associated with tonnage estimates (Singer and Kouda, 1999). Consequently, selection of the proper grade and tonnage model is probably more critical to the final assessment than small errors in estimates of the number of deposits.

\section{Conclusions}

The goal of many assessors is to make unbiased quantitative assessments in a format needed in decision-support systems so that the consequences of alternative courses of action can be examined. Internally consistent descriptive, grade and tonnage, deposit density, and economic models and the design of three-part assessments reduce the chances of biased estimates of the undiscovered resources. Biases can be introduced into these estimates either by a flawed grade and tonnage model or by the lack of consistency of the grade and tonnage model with estimates of the number of deposits.

Estimates of the number of undiscovered deposits explicitly represent the probability (or degree of belief) that some fixed but unknown number of undiscovered deposits exist in the delineated tracts. As such, these estimates reflect both the uncertainty of what may exist and a measure of the favorability of the existence of the deposit type. Although there are no fixed methods for making estimates of the number of undiscovered deposits, guidelines to help make these estimates are available. Using a variety of different guidelines for estimates both provides a useful crosscheck of assumptions that may have been relied upon and significantly reduces the chances of biased estimates.

Until more estimation guidelines and deposit density models are available, it seems prudent to rely on mineral deposit specialists to make subjective estimates because the specialists can bring their experiences and observations to the process. This kind of activity is not unusual; geologists commonly make estimates that, although not explicitly quantitative, are subjective and have uncertainty, such as making geologic cross sections. Experience from meteorology suggests that consensus schemes perform better than almost all individual estimators and that the best estimates are made when objective estimates such as those from guides (table 1) are part of the information supplied to subjective estimators.

Sensitivity analysis shows that the greatest opportunity for reducing uncertainty in exploration and resource assessment lies with lowering the uncertainty associated with tonnage estimates. Consequently, selection of the proper grade and tonnage model is probably more critical to the final assessment than small errors in estimates of the number of deposits.

\section{References Cited}

Allais, M., 1957, Method of appraising economic prospects of mining exploration over large territories-Algerian Sahara case study: Management Science, v. 3, no. 4, p. 285-347.

Bliss, J.D., and Menzie, W.D., 1993, Spatial mineral deposit models and the prediction of undiscovered mineral deposits, in Kirkham, R.V., Sinclair, W.D., Thorpe, R.I., and Duke, J.M., eds., Mineral deposit modeling: Geological Association of Canada Special Paper 40, p. 693-706.

Cox, D.P., 1993, Estimation of undiscovered deposits in quantitative mineral resource assessments-Examples from Venezuela and Puerto Rico: Nonrenewable Resources, v. 2, no. 2 , p. $82-91$.

Cox, D.P., Ludington, Steve, Berger, B.R., Moring, B.C., Sherlock, M.G., Singer, D.A., and Tingley, J.V., 1996, Delineation of mineral resource assessment tracts and estimates of numbers of undiscovered deposits in Nevada, chap. 12 of Singer, D.A., ed., An analysis of Nevada's metal-bearing mineral resources: Nevada Bureau of Mines and Geology Open-File Report 96-2, p. 12.1-12.25, 3 sheets, scale $1: 1,000,000$. (Also available online at http://www.nbmg.unr.edu/dox/ofr962/index.htm.)

Drew, L.J., Bliss, J.D., Bowen, R.W., Bridges, N.J., Cox, D.P., DeYoung, J.H., Houghton, J.C., Ludington, S.D., Menzie, W.D., Page, N.J, Root, D.H., and Singer, D.A., 1986, Quantitative estimation of undiscovered mineral resources-A case study of U.S. Forest Service wilderness tracts in the Pacific Mountain system: Economic Geology, v. 81, no. 1, p. $80-88$.

Drew, L.J., and Menzie, W.D., 1993, Is there a metric for mineral deposit occurrence probabilities?: Nonrenewable Resources, v. 2, no. 2, p. 92-105.

Drew, L.J., Singer, D.A., Menzie, W.D., and Berger, B.R., 1999, Mineral-resource assessment-State of the art, in Ódor, László, Korpás, László, McCammon, R.B., and Hofstra, A.H., eds., Deposit modeling and mining-induced environmental risks: Geologica Hungarica Serie Geologica, v. 24 , p. $31-40$. 
Harris, D.P., 1984, Mineral resources appraisal; Mineral endowment, resources, and potential supply-Concepts, methods, and cases: Oxford, Oxford University Press, 445 p.

Kouda, Ryoichi, and Singer, D.A., 1992, A resource assessment of kuroko deposits in the Akita region of Japan [abs.]: International Geological Congress, 29th, Kyoto, 1992, Abstracts, v. 1, p. 83.

MacKevett, E.M., Jr., Singer, D.A., and Holloway, C.D., 1978, Maps and tables describing metalliferous mineral resource potential of southern Alaska: U.S. Geological Survey OpenFile Report 78-1-E, 45 p., 2 sheets, scale 1:1,000,000.

Menzie, W.D., and Singer, D.A., 1990, A course on mineral resource assessment, in Proceedings of ISME-AI'90International Symposium on Mineral Exploration, The Use of Artificial Intelligence, 1990, Tokyo and Tsukuba, Japan: Tokyo, Mining and Materials Processing Institute of Japan, p. 177-188.

Murphy, A.H., and Winkler, R.L., 1984, Probability forecasting in meteorology: Journal of the American Statistical Association, v. 79, no. 387, p. 489-500.

Reed, B.L., Menzie, W.D., McDermott, M., Root, D.H., Scott, W., and Drew, L.J., 1989, Undiscovered lode tin resources of the Seward Peninsula, Alaska: Economic Geology, v. 84, no. 7, p. 1936-1947.

Root, D.H., Menzie, W.D., and Scott, W.A., 1992, Computer Monte Carlo simulation in quantitative resource estimation: Nonrenewable Resources, v. 1, no. 2, p. 125-138.

Scott, Margaretha, 2000, Valuing Australian state geological surveys-Quantitative analysis for strategic planning: St. Lucia, The University of Queensland, Ph.D. dissertation, $541 \mathrm{p}$.

Shulman, M., Burger, H., Kliem, C., and Skala, W., 1992, Review of resource analysis and related studies-Working Group, Mathematical Geology, freie Universität Berlin: Nonrenewable Resources, v. 1, no. 1, p. 97-106.
Singer, D.A., 1993, Basic concepts in three-part quantitative assessments of undiscovered mineral resources: Nonrenewable Resources, v. 2, no. 2, p. 69-81.

Singer, D.A., 1994a, The relationship of estimated number of undiscovered deposits to grade and tonnage models in threepart mineral resource assessments, in 1994 International Association for Mathematical Geology Annual Conference, Papers and Extended Abstracts for Technical Programs, Oct. 3-5, 1994, Mont Tremblant, Quebec, Canada: p. 325-326.

Singer, D.A., 1994b, Conditional estimates of the number of podiform chromite deposits: Nonrenewable Resources, v. 3, no. 3, p. 200-204.

Singer, D.A., Berger, V.I., Menzie, W.D., and Berger, B.R., 2005, Porphyry copper deposit density: Economic Geology, v. 100 , no. 3 , p. 491-514.

Singer, D.A., and Kouda, Ryoichi, 1999, Examining risk in mineral exploration: Natural Resources Research, v. 8, no. 2, p. 111-122.

Singer, D.A., and MacKevett, E.M., Jr., 1977, Mineral resources map of the McCarthy quadrangle, Alaska: U.S. Geological Survey Miscellaneous Field Studies Map MF-773-C, 1 sheet, scale 1:250,000.

Singer, D.A., Menzie, W.D., Sutphin, D.M., Mosier, D.L., and Bliss, J.D., 2001, Mineral deposit density-An update, chap. A of Schulz, K.J., ed., Contributions to global mineral resource assessment research: U.S. Geological Survey Professional Paper 1640, p. A1-A13. (Also available online at http://pubs.usgs.gov/prof/p1640A/.)

Singer, D.A., and Mosier, D.L., 1981, The relation between exploration economics and the characteristics of mineral deposits, in Ramsey, J.B., ed., The economics of exploration for energy resources: Greenwich, Connecticut, JAI Press, p. 313-326.

Stern, Hal, 1991, On the probability of winning a football game: American Statistician, v. 45, no. 3, p. 179-183. 


\title{
Overview of Methodology of Combined Regional Metallogenic and Tectonic Analysis
}

\author{
By Warren J. Nokleberg, ${ }^{1}$ Thomas K. Bundtzen, ${ }^{2}$ Kenneth M. Dawson, ${ }^{3}$ \\ Roman A. Eremin, ${ }^{4}$ Nikolai A. Goryachev, ${ }_{1}^{4}$ Alexander I. Khanchuk, ${ }^{4}$ \\ James W.H. Monger, ${ }^{5}$ Alexander A. Obolenskiy, ${ }^{4}$ Leonid M. Parfenov, ${ }^{6}$ \\ Vladimir V. Ratkin, ${ }^{4}$ Sergey M. Rodionov ${ }^{4}$ and Vladimir I. Shpikerman ${ }^{7}$
}

\section{Abstract}

The compilation, synthesis, description, and interpretation of metallogenesis and tectonic history of major regions, such as the Circum-North Pacific (Russian Far East, Alaska, and Canadian Cordillera) and Northeast Asia, constitute a complex process. The complex process includes (1) definitions of key terms, (2) compilation of a regional geologic base map that can be interpreted according to modern tectonic concepts and definitions, (3) compilation of a mineral deposit database that enables the determination of mineral deposit models, relation of deposits to host rocks, and tectonic origins, (4) synthesis of a series of mineral deposit models that characterize the known mineral deposits and inferred undiscovered deposits of the region, (5) compilation of a series of maps of metallogenic belts constructed on the regional geologic base map, and (6) formulation of a metallogenic and tectonic model. This paper presents an overview of the methodology used for the Circum-North Pacific and Northeast Asia and an example of a metallogenic and tectonic model for the origin of Late Cretaceous and early Tertiary igneous-arc-related deposits in the Circum-North Pacific. This paper also describes how a high-quality metallogenic and tectonic analysis and synthesis of an associated metallogenic and tectonic model will provide the following benefits: (1) refinement of mineral deposit models and of the understanding of deposit genesis, (2) improvement of assessments of undiscovered mineral resources as part of quantitative mineral resource assessment studies, (3)

${ }^{1}$ U.S. Geological Survey, Mail Stop 901, 345 Middlefield Road, Menlo Park, CA 94025, U.S.A. (e-mail: wnokleberg@usgs.gov).

${ }^{2}$ Alaska Division of Geological and Geophysical Surveys; currently at Pacific Rim Geological Consulting, Inc.

${ }^{3}$ Geological Survey of Canada; currently at Terra Geological Consultants.

${ }^{4}$ Russian Academy of Sciences.

${ }^{5}$ Geological Survey of Canada.

${ }^{6}$ Deceased; formerly at Russian Academy of Sciences.

${ }^{7}$ Russian Academy of Sciences; currently at Russian Ministry of Natural Resources. data to consider in land use and mineral exploration planning, (4) improvement of interpretations of origins of host rocks, mineral deposits, and metallogenic belts, and (5) guidelines for new research.

\section{Introduction}

This paper presents an overview of the methodology and key definitions for combined regional metallogenic and tectonic analysis, provides a theoretical example of this type of analysis, and describes an example for this type of analysis for Late Cretaceous and early Tertiary igneous-arc-related deposits in the Circum-North Pacific (Russian Far East, Alaska, and Canadian Cordillera). The major sections of this paper are (1) definitions, compilations, and syntheses needed for a combined metallogenic and tectonic analysis, (2) theoretical example of methodology, (3) synthesis of a combined metallogenic and tectonic model, (4) benefits of performing a combined regional metallogenic and tectonic analysis, and (5) summary.

In the past, three types of problems have limited some metallogenic and tectonic analyses: (1) a concentration of some metallogenic studies on the features of mineral deposits and districts without any regional compilation, synthesis, and interpretation, (2) a lack of integration of regional studies of host rocks, structures, and tectonic origins with respect to contained suites of mineral deposits, and (3) in some regions, application of a stabilistic tectonic philosophy. In contrast, this paper demonstrates the power of a combined regional and metallogenic and tectonic analysis that requires (1) use of modern concepts and mineral deposit databases, (2) formulation of mineral deposit models, (3) construction of regional geologic and metallogenic belt maps, (4) interpretation of major geologic units and contained mineral deposits according to latest tectonic methods, and (5) synthesis of an integrated metallogenic and tectonic model.

This paper is derived from relatively recent metallogenic studies by the U.S. Geological Survey, including (1) a series of 
regional geologic, mineral deposit, and metallogenic belt maps of the Russian Far East, Alaska, and the Canadian Cordillera (Nokleberg and others, 1997a,b,c; Nokleberg, West, and others, 1998), (2) a series of metallogenic and tectonic analyses of the same region (Nokleberg and others, 1995, 2000, 2001, 2003; Scotese and others, 2001), and (3) a series of similar publications being prepared for Northeast Asia (Eastern Russia, Mongolia, Northeast China, South Korea, and Japan) (Nokleberg and others, 1999).

\section{Definitions, Compilations, and Syntheses Needed for a Combined Metallogenic and Tectonic Analysis}

For a metallogenic and tectonic analysis, the key goal is to define, analyze, and interpret the crustal origin and evolution of mineralizing systems. To achieve this goal, the following materials are needed: (1) definitions of key terms, (2) a regional geologic base map that can be interpreted according to modern tectonic concepts and definitions, (3) a mineral deposit database that enables the determination of mineral deposit models, relation of deposits to host rocks, and tectonic origins, (4) a series of mineral deposit models that characterize the known mineral deposits and inferred undiscovered deposits of the region, (5) a series of metallogenic belt maps constructed on the regional geologic base map, and (6) a metallogenic and tectonic model. Figure 1 illustrates these materials and the methodology for synthesizing a combined metallogenic and tectonic model. In this figure, parts 1 and 2 portray a regional geologic base map and a metallogenic belt overlay. Part 3 portrays a mineral deposit database and mineral deposit models. Part 4 portrays the major steps for synthesizing a metallogenic and tectonic model. Part 5 portrays one stage of the model. Part 6 portrays the applications resulting from this type of analysis. These applications provide the following benefits: (1) refinement of mineral deposit models and of the understanding of deposit genesis, (2) improvement of assessments of undiscovered mineral resources as part of quantitative mineral resource assessment studies, (3) data to consider in land use and mineral exploration planning, (4) improvement of interpretations of origins of host rocks, mineral deposits, and metallogenic belts, and (5) guidelines for new research.

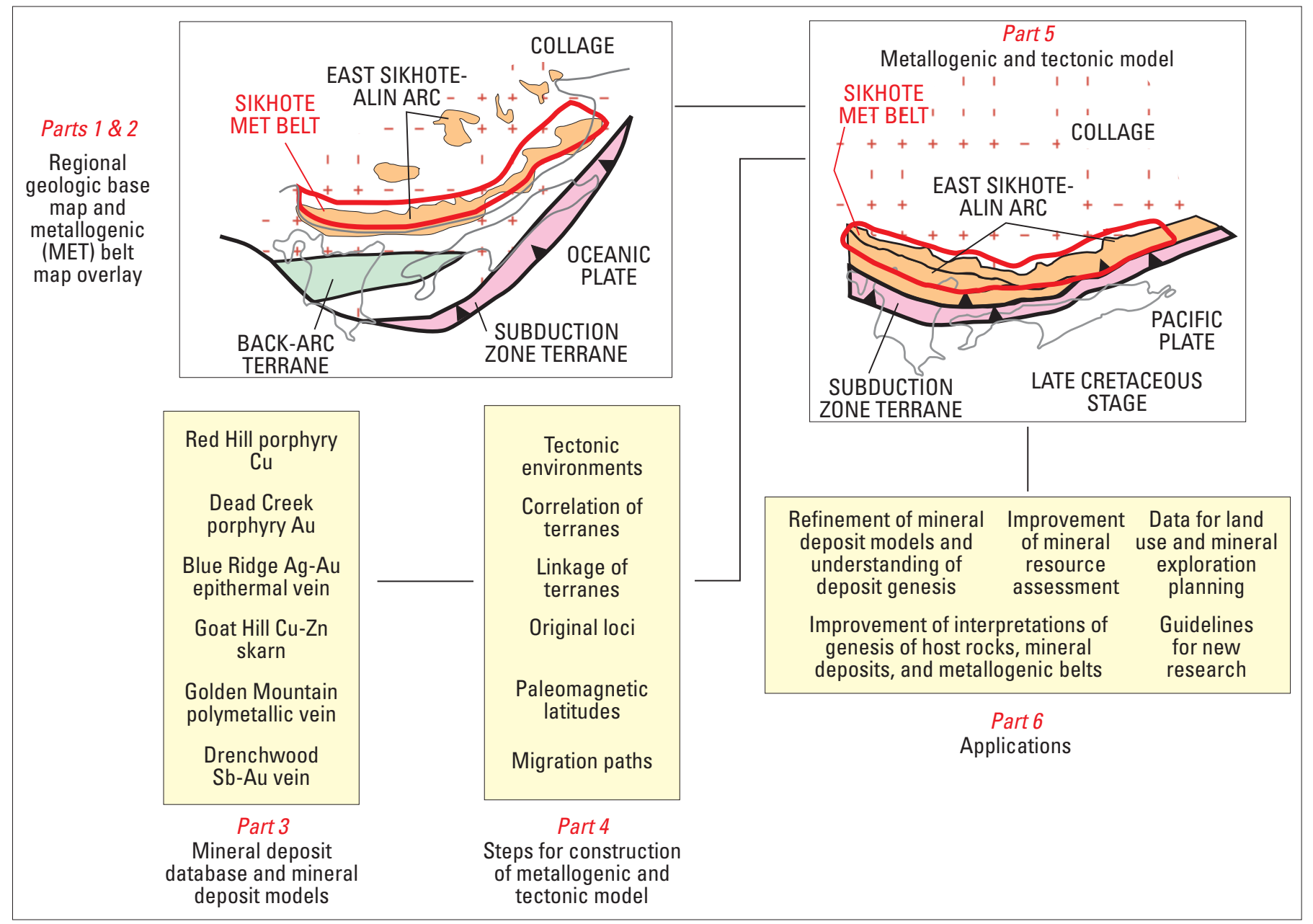

Figure 1. Diagram showing major components of a metallogenic analysis and synthesis of a metallogenic and tectonic model. 


\section{Key Definitions for a Metallogenic and Tectonic Analysis}

For the compilation, synthesis, description, and interpretation of metallogenic belts, the following mineral deposit, metallogenic, and tectonic definitions are used. The definitions are adapted from Coney and others (1980), Jones and others (1983), Howell and others (1985), Monger and Berg (1987), Wheeler and others (1988), Nokleberg, Bundtzen, and others (1994), Nokleberg, Parfenov, and others (1994), Nokelberg and others (2001), and Scotese and others (2001).

accretion Tectonic juxtaposition of two or more terranes, or tectonic juxtaposition of terranes to a craton margin. Accretion of terranes to one another or to a craton margin also defines a major change in the tectonic evolution of terranes and craton margins.

accretionary wedge and subduction-zone terrane Fragment of a mildly to intensely deformed complex consisting of varying amounts of turbidite deposits, continental-margin rocks, oceanic crust and overlying units, and oceanic mantle. Divided into units composed predominantly of turbidite deposits or predominantly of oceanic rocks. Units are interpreted to have formed during tectonic juxtaposition in a zone of major thrusting of one lithosphere plate beneath another, generally in zones of thrusting along the margin of a continent or an island arc. May include large faultbounded units having a coherent stratigraphy. Many subductionzone terranes contain fragments of oceanic crust and associated rocks that exhibit a complex structural history, occur in a major thrust zone, and possess blueschist-facies metamorphism. collage of terranes Groups of tectonostratigraphic terranes, generally in oceanic areas, for which insufficient data exist to separate units.

continental-margin arc terrane Fragment of an igneous belt of coeval plutonic and volcanic rocks and associated sedimentary rocks that formed above a subduction zone dipping beneath a continent. Inferred to possess a sialic basement. craton Chiefly regionally metamorphosed and deformed shield assemblages of Archean and Early Proterozoic sedimentary, volcanic, and plutonic rocks, and overlying platform successions of Paleoproterozoic, Paleozoic, and local Mesozoic and Cenozoic sedimentary rocks containing some volcanic rocks.

craton margin Chiefly Late Proterozoic through Jurassic sedimentary rocks deposited on a continental shelf or slope. Consists mainly of platform successions. Locally has, or may have had, an Archean and Early Proterozoic cratonal basement. cratonal terrane Fragment of a craton.

deposit A general term for any lode or placer mineral occurrence, mineral deposit, prospect, and (or) mine.

island-arc terrane Fragment of an igneous belt of plutonic rocks, coeval volcanic rocks, and associated sedimentary rocks that formed above an oceanic subduction zone. Inferred to possess a simatic basement.

metallogenic belt A geologic unit (area) that either contains or is favorable for a group of coeval and genetically related, significant lode and placer deposits described by deposit models (Nokleberg and others, 1997a,b; Nokelberg, West, and others 1998). A metallogenic belt (1) is favorable for known or inferred mineral deposits of a specific type or types, (2) can be of irregular shape and variable size, (3) need not contain known deposits, and (4) is based on a geologic map as the primary source of information for delineating areas that are favorable for deposits described by various deposit models. An essential part of the definition is that a belt is defined as the geologically favorable area for a group of coeval and genetically related mineral deposits. This definition provides a predictive character for undiscovered deposits in each belt.

metamorphic terrane Fragment of a highly metamorphosed or deformed assemblage of sedimentary, volcanic, or plutonic rocks that cannot be assigned to a single tectonic environment because the original stratigraphy and structure are obscured. Includes intensely deformed structural mélanges that contain intensely deformed fragments of two or more terranes. metamorphosed-continental-margin terrane Fragment of a passive continental margin, in places moderately to highly metamorphosed and deformed, that cannot be linked with certainty to the nearby craton margin. May be derived either from a nearby craton margin or from a distant site.

mine A site where valuable minerals have been extracted. mineral deposit A site having concentrations of potentially valuable minerals for which grade and tonnage estimates have been made.

mineral occurrence A site having potentially valuable minerals on which no visible exploration has occurred or for which no grade and tonnage estimates have been made. oceanic crust, seamount, and ophiolite terrane Fragment of part or all of a suite of eugeoclinal deep-marine sedimentary rocks, pillow basalt, gabbro, and ultramafic rocks that are interpreted as oceanic sedimentary and volcanic rocks and the upper mantle. Includes both inferred offshore oceanic and marginal ocean basin rocks, minor volcaniclastic rocks of magmatic arc derivation, and major marine volcanic accumulations formed at a hotspot, fracture zone, or spreading axis. overlap assemblage A postaccretion unit of sedimentary or igneous rocks deposited on, or intruded into, two or more adjacent terranes. The sedimentary and volcanic parts either depositionally overlie, or are interpreted to have originally depositionally overlain, two or more adjacent terranes or terranes and the craton margin. Overlapping plutonic rocks, which may be coeval and genetically related to overlap volcanic rocks, link or stitch together adjacent terranes or a terrane and a craton margin.

passive-continental-margin terrane Fragment of a craton margin.

postaccretion rock unit Suite of sedimentary, volcanic, or plutonic rocks that formed in the late history of a terrane, after accretion. May occur also on adjacent terranes or on the craton margin either as an overlap assemblage or as a basinal deposit. A relative-time term denoting rocks formed after tectonic juxtaposition of one terrane to an adjacent terrane.

preaccretion rock unit Suite of sedimentary, volcanic, or plutonic rocks that formed in the early history of a terrane, 
before accretion. Constitutes the stratigraphy and igneous geology inherent to a terrane. A relative-time term denoting rocks formed before tectonic juxtaposition of one terrane to an adjacent terrane.

prospect A site having potentially valuable minerals in which excavation has occurred.

significant mineral deposit A mine, mineral deposit, prospect, or occurrence that is judged as important for the metallogenesis of a geographic region.

subterrane A fault-bounded unit within a terrane that exhibits similar, but not identical, geologic history relative to another fault-bounded unit in the same terrane.

superterrane An aggregate of terranes that is interpreted to share either a similar stratigraphic kindred or affinity or a common geologic history after accretion (Moore, 1992). An approximate synonym is "composite terrane" (Plafker and Berg, 1994).

tectonic linkage The interpreted association of a suite of coeval tectonic units that formed in the same region and as the result of the same tectonic processes. An example is the linking of a coeval continental-margin arc, fore-arc deposits, a back-arc rift assemblage, and a subduction-zone complex, all related to the underthrusting of a continental margin by oceanic crust.

tectonostratigraphic terrane A fault-bounded geologic entity or fragment that is characterized by a distinctive geologic history that differs markedly from that of adjacent terranes (Jones and others, 1983; Howell and others, 1985).

transform continental-margin arc An igneous belt of coeval plutonic and volcanic rocks and associated sedimentary rocks that formed along a transform fault that occurs along the margin of a craton, passive continental margin, and (or) collage of terranes accreted to a continental margin.

turbidite basin terrane Fragment of a basin filled with deepmarine clastic deposits in either an orogenic fore-arc or back-arc setting. May include continental-slope and continental-rise turbidite deposits and submarine-fan turbidite deposits deposited on oceanic crust. May include minor epiclastic and volcaniclastic deposits.

\section{Regional Geologic Base Map}

To define a metallogenic belt map for a metallogenic analysis, a regional geologic base map must be constructed that permits the display of a belt as a function of the hostrock geology or host-rock structures (Nokleberg and others, 1997a,b,c; Nokleberg, West, and others, 1998). To facilitate analysis of geologic relations and permit the estimation of undiscovered mineral deposits, the geologic base map must be constructed at the scale of the assessment and show the major geologic data that can be related to the presence of mineral deposits in each belt. Because metallogenic belts are generally of large areal extent, interpretation of the tectonic origin of host-rock geologic units must be considered in order to display the geologic controls over formation of groups of mineral deposits in a specific metallogenic belt.

An example of regional geologic base maps is portrayed in figure 2, which illustrates (1) a regional terrane and overlap assemblage (regional geologic) map for the Russian Far East (derived from Nokleberg and others, 1997b,c; Nokleberg, West, and others, 1998) and (2) major Late Cretaceous and early Tertiary igneous-arc-related metallogenic belts for the region. On the figure are the major Cretaceous and Cenozoic continental-margin arcs that host a large suite of igneous-arcrelated metallogenic belts. The two major arcs are the East Sikhote-Alin arc and the Okhotsk-Chukotka arc. As background, the map also displays cratons, craton margins, previously accreted terranes of various types (cratonal, island arc, continental-margin arc, subduction zone, accretionary wedge), fore-arc and back-arc basins, major faults (sutures) bounding terranes, major active continental-margin arcs (Kuril-Kamchatka and Aleutian arcs), companion, outboard active subduction zones, and active faults.

Two major considerations exist for constructing a regional geologic map for a metallogenic analysis. (1) The regional geologic base map should display host-rock geology and structures that are related to metallogenic belts. For the Russian Far East (fig. 2), the regional geologic map displays the extent of surface outcrops of the major volcanic-plutonic arcs (East Sikhote-Alin and Okhotsk-Chukotka) that have and (or) are assessed to have potential for undiscovered igneousrock-related mineral deposits described by deposit models (Nokleberg and others, 1997b,c; Nokleberg, West, and others, 1998). (2) Inclusion of graphic and descriptive data on the tectonic origin of host-rock geologic units is needed to establish the geologic controls for formation of groups of mineral deposits in metallogenic belts.

\section{Tectonic Environments}

For a modern metallogenic and tectonic analysis, interpretation of tectonic environments is essential for interpreting the geologic origin of major units and contained mineral deposits and metallogenic belts. The interpretation of tectonic environment is a key method for linking geologic origins of these sometimes disparate datasets. In addition, as described below, interpretation of tectonic environments for mineral deposits is also an important facet of developing mineral deposit models. For tectonic analyses of the Circum-North Pacific and Northeast Asia (Nokleberg and others, 1999, 2001, 2003; Scotese and others, 2001), major geologic units (terranes, overlap assemblages, plates), mineral deposits, mineral deposit types, and metallogenic belts are described according to the following interpreted dominant tectonic environments: (1) cratonal, (2) passive continental margin, (3) metamorphosed continental margin, (4) continental-margin arc, (5) island arc, (6) oceanic crust, seamount, or ophiolite, (7) accretionary wedge and subduction zone, (8) turbidite basin, and (9) metamorphic, for terranes that are so highly deformed and 


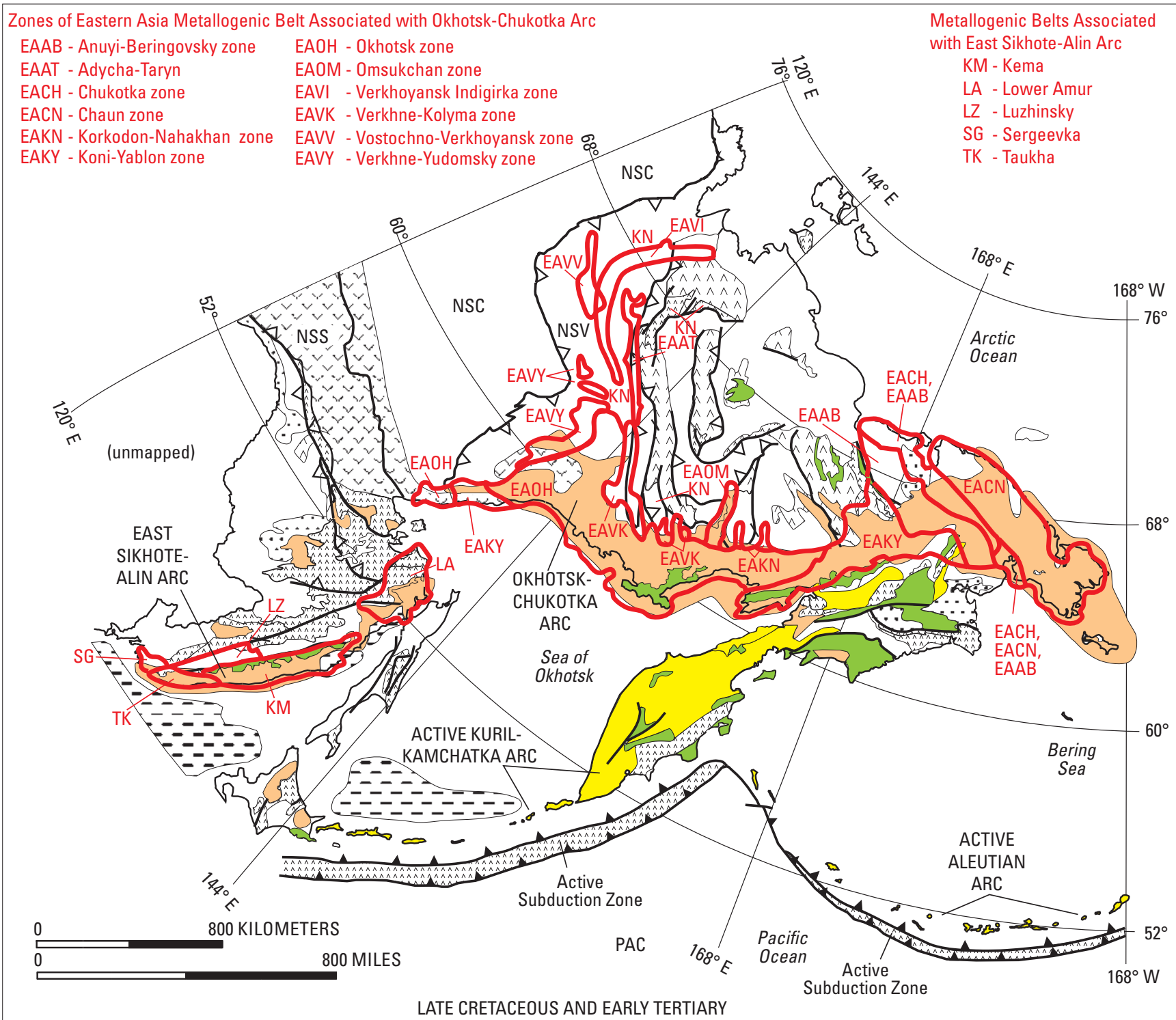

LATE CRETACEOUS AND EARLY TERTIARY

EXPLANATION
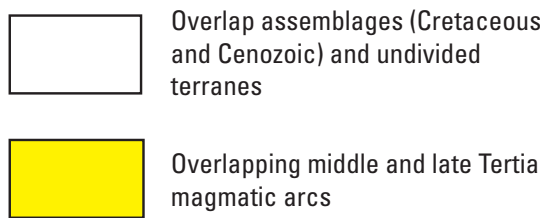

Overlapping middle and late Tertiary magmatic arcs

\section{Middle and late Tertiary back-arc - ----1 units}

Overlapping Cretaceous and early Tertiary magmatic arcs

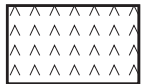

Overlapping Middle Jurassic and Early Cretaceous magmatic arcs and fore-arc and back-arc basins

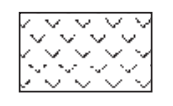

Overlapping Jurassic continentalmargin arcs and back-arc basins; emplaced across NSS

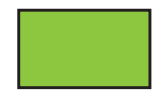

Jurassic and Cretaceous islandarc terranes

Jurassic, Cretaceous, and Tertiary accretionarywedge and subduction-zone terranes

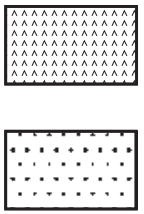

Predominantly oceanic rocks

Clastic sedimentary basins (Jurassic, Cretaceous, Tertiary)
Craton, craton-margin, and passive continentalmargin terranes

\section{NSC North Asian Craton}

NSS North Asian Craton - Stanovoy Block

NSV North Asian Craton Margin

KN Kular-Nera

PAC Pacific oceanic plate

2 RM Metallogenic belt CONTACTS AND FAULTS

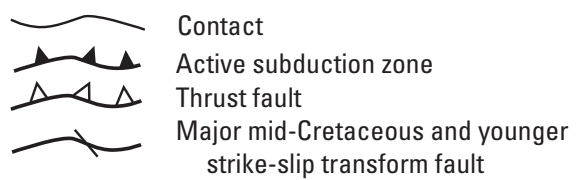

Figure 2. Regional geologic and tectonic map showing major postaccretionary, igneous-arc-related metallogenic belts hosted in Late Cretaceous through early Tertiary continental-margin igneous arcs in the Russian Far East. Adapted from Nokleberg and others (1997b,c) and Nokleberg, West, and others (1998). 
(or) metamorphosed that determination of the original tectonic environment is difficult. For terranes having complex geologic histories, the chosen tectonic environment is the one most prevalent during the history of the terrane. Definitions of these tectonic environments are provided above.

\section{Mineral Deposit Descriptions}

Part of the core dataset for a metallogenic analysis is a high-quality description of the significant known mineral deposits of the region. The descriptions need to systematically characterize the significant mineral deposits with sufficient detail that one can determine their classification by mineral deposit model and origin, and the descriptions should provide tonnage and grade data if available (Nokleberg and others, 1997a). The term "significant mineral deposit" is often used. As an example of mineral deposit data for a metallogenic analysis, table 1 provides sample descriptions of selected Cretaceous igneous-arc-related deposits for the Russian Far East.

\section{Mineral Deposit Models}

Modern metallogenic analyses of large regions require that mineral deposit models appropriate for the region be characterized, synthesized, and grouped so that they can be correlated with the regional tectonic processes that formed the known deposits. The beginning of this type of correlation between models and tectonic process is evident in many of the classic compilations of mineral deposit models (Eckstrand, 1984; Cox and Singer, 1986; Singer, 1993). As an example of mineral deposit models used in a large region, table 2 lists the mineral deposit models that were defined and described for a metallogenic analysis of the Circum-North Pacific (Russian Far East, Alaska, and the Canadian Cordillera). For this large and complex region, a suite of 38 mineral deposit models was sufficient to describe the characteristic features of the 1,079 lode deposits and 148 placers (Nokleberg and others, 1996, 1997a). The models include previous descriptions from Eckstrand (1984) and Cox and Singer (1986), with modifications by the authors.

The mineral deposit models listed in table 2 usually consist of both descriptive and genetic information that is systematically arranged to define the essential properties of a class or type of mineral deposits. However, some model types are based mainly on descriptive (empirical) information, in which instance the various attributes are recognized as essential even though their relations are unknown. An example of a descriptive mineral deposit model is the basaltic $\mathrm{Cu}$-type, in which the empirical datum of a geologic association of $\mathrm{Cu}$ sulfides with relatively $\mathrm{Cu}$-rich metabasalt or greenstone is the essential attribute. Some other types of models are defined by genetic (theoretical) considerations, in which case the attributes are related through some fundamental geologic process. An example is the W skarn deposit model, in which the genetic process of contact metasomatism is the essential attribute. For additional information on the methodology for defining mineral deposit models, the reader is referred to discussions by Eckstrand (1984) and Cox and Singer (1986).

Correlation of major tectonic events and environments with mineral deposit types (models) allows the necessary synthesis of mineral deposit models for a modern metallogenic analysis (Nokleberg and others, 1997a,b). Detailed analysis reveals that only a few types of tectonic events and corresponding environments exist for a wide array of mineral deposit models for this region. For the Russian Far East, Alaska, and the Canadian Cordillera (table 3), only seven tectonic environments are needed to classify the origins of the 1,079 lode deposits of this large and complex region (Nokleberg and others, 2000, 2001, 2003). These tectonic environments are (1) subduction-related arc, (2) collisional (anatectic)-related arc, (3) postcollisional extension, (4) oceanic rift, (5) continental rift, (6) back-arc rift, and (7) transform continental-margin faulting and associated bimodal volcanic-plutonic belt.

\section{Metallogenic Belt Map}

Metallogenic belt maps, along with an underlying regional geologic map (for example, terrane and overlap assemblage map), are basic elements of a regional metallogenic and tectonic analysis. For delineation of metallogenic belts, the following main principles are used (Nokleberg and others, 2000).

1. Mineral deposit association. Each metallogenic belt includes deposits described by a single mineral deposit model or by a group of mineral deposit models describing coeval, closely located, and genetically related deposits.

2. Tectonic event for formation of mineral deposits. Each metallogenic belt includes a group of coeval and genetically related mineral deposits that were formed as the result of a specific tectonic event (for example, subduction-related igneous arc, collision, accretion, rifting).

3. Favorable geological, geochemical, and geophysical environment. Each metallogenic belt contains host rocks, structures, geochemical anomalies or signatures, and geophysical anomalies or signatures that are favorable for the occurrence of a particular suite of mineral deposit types.

4. Geological or tectonic boundaries. Each metallogenic belt usually is bounded by contacts of favorable stratigraphic or magmatic units or by major faults (sutures) along which substantial translations commonly have occurred.

For the example of a metallogenic analysis for the Russian Far East, a regional metallogenic belt map fig. 2) portrays areas that contain and (or) are assessed to have potential for undiscovered igneous-rock-related deposits. The models for these deposits include $\mathrm{Au}-\mathrm{Ag}$ epithermal vein, volcanic-hosted $\mathrm{Hg}$ (Plamennoe type), polymetallic vein, $\mathrm{Sb}-\mathrm{Au}$ vein (simple $\mathrm{Sb}$ deposit), $\mathrm{Cu}( \pm \mathrm{Fe}, \mathrm{Au}, \mathrm{Ag}, \mathrm{Mo})$ skarn, $\mathrm{Zn}-\mathrm{Pb}( \pm \mathrm{Ag}, \mathrm{Cu}, \mathrm{W})$ skarn, $\mathrm{Au}, \mathrm{Co}$, and As skarn, Fe ( $\pm \mathrm{Au}$, 
Table 1. Examples of selected granitoid-related Au deposits for the Russian Far East.

[Adapted from Nokleberg and others (1997a). g/t, grams per metric ton; t, metric ton]

\begin{tabular}{|c|c|c|c|}
\hline $\begin{array}{c}\text { Deposit No. } \\
\text { Latitude } \\
\text { Longitude } \\
\text { Summary and References }\end{array}$ & $\begin{array}{c}\text { Deposit Name } \\
\text { Metallogenic Belt }\end{array}$ & $\begin{array}{l}\text { Major Metals } \\
\text { Minor Metals } \\
\text { Deposit Model }\end{array}$ & Grade and Tonnage \\
\hline $\begin{array}{l}\text { K53-10 } \\
425218 \mathrm{~N} \\
1324946 \mathrm{E}\end{array}$ & $\begin{array}{l}\text { Progress } \\
\text { Sergeevka }\end{array}$ & $\begin{array}{l}\mathrm{Au} \\
\text { Granitoid-related } \mathrm{Au}\end{array}$ & Average grade of $5.89 \mathrm{~g} / \mathrm{t} \mathrm{Au}$. \\
\hline
\end{tabular}

Consists of sulfide-poor pyrite-arsenopyrite-gold-quartz veins, small veinlets, poorly mineralized fracture zones, zones of mylonite, and zones altered to metasomatic carbonate-chlorite-sericite rocks. Deposit hosted in a Late Cretaceous granitic pluton that cuts a sequence of granite and gabbro of Sergeevka Complex with a Cambrian age of 500 to 527 Ma (J.N. Aleinikoff, written commun., 1992). The deposit is prospected to depths of a few tens of meters. This lode is also the source for nearby placer Au deposits. References: A.N. Rodionov, written commun., 1991.

\begin{tabular}{|l|l|l|l}
\hline N51-03 & $\begin{array}{l}\text { Kirovskoe } \\
542700 \mathrm{~N}\end{array}$ & $\mathrm{Au}$ & About $10 \mathrm{t}$ Au produced. \\
$1241400 \mathrm{E}$ & Granitoid-related $\mathrm{Au}$ & \\
\hline
\end{tabular}

Consists of northwest-striking gold-quartz-sulfide veins hosted in an Early Cretaceous granodiorite stock. Veins commonly occur along contacts of diabase porphyry dikes that cut the granodiorite. Contacts of veins are generally sharp, although host rock is hydrothermally altered. Veins range from 0.5 to 1.0 meter in thickness, and the surrounding altered rock ranges from 5.0 to 9.0 meters in thickness. Altered rocks consist mainly of quartz, albite, sericite, and hydromica; the veins consist predominantly of 40 to 95 percent quartz. Main sulfides are pyrrhotite, arsenopyrite, and chalcopyrite, with less abundant galena, sphalerite, bismutite, and tennantite-tetrahedrite. Gold ranges up to 0.28 millimeter in diameter. Fineness of 844 to 977 . Deposit source for the placer deposits of the Dzhalinda, Yannan, and Ingagli Rivers, the largest in the Russian Far East. Mined until 1961. References: Gurov, 1969; G.P. Kovtonyuk, written commun., 1990.

\begin{tabular}{|l|l|l|c|}
\hline $\begin{array}{l}\text { N52-02 } \\
532700 \mathrm{~N} \\
1262700 \mathrm{E}\end{array}$ & $\begin{array}{l}\text { Pioneer } \\
\text { North Bureya }\end{array}$ & Au & $\begin{array}{c}\text { Average grade of 2.7 g/t Au and } \\
5.2 \mathrm{~g} / \mathrm{t} \mathrm{Ag} . \text { Reserves of } 17.1 \mathrm{t} \\
\mathrm{Au} \text { and } 20.1 \mathrm{t} \mathrm{Ag} .\end{array}$ \\
\hline
\end{tabular}

Consists of quartz, quartz-feldspar, quartz-tourmaline, and quartz-carbonate veins and zones of altered quartz-potassium feldsparsericite-albite rocks. Zones are 1 to 50 meters thick and in plan commonly branch and change trends. Ore zones are large, have low Au content and no visible boundaries. Extent of deposit determined by geochemical sampling. Gold and gold-sulfide ore assemblages are distinguished. Gold assemblage consists of quartz-adularia-carbonate veins; gold-sulfide assemblage consists of quartz veins with pyrite, galena, stibnite, and silver sulfosalts. Deposit hosted along margin of an Early Cretaceous granodiorite intrusion, both within the intrusion and in adjacent contact metamorphosed Jurassic sandstone and siltstone. References: N.E. Malyamin and V.E. Bochkareva, written commun., 1990; V.N. Akatkin, written commun., 1991.

\begin{tabular}{|c|c|c|c|}
\hline $\begin{array}{l}\text { P55-35 } \\
612732 \mathrm{~N} \\
1484809 \mathrm{E}\end{array}$ & $\begin{array}{l}\text { Shkolnoe } \\
\text { Eastern Asia-Arctic, Verkhne- } \\
\text { Kolyma zone }\end{array}$ & $\begin{array}{l}\mathrm{Au} \\
\mathrm{Bi}, \mathrm{Te}, \mathrm{Ag} \\
\text { Granitoid-related } \mathrm{Au}\end{array}$ & $\begin{array}{l}\text { Total reserves } 32 \mathrm{t} \mathrm{Au} \text {. Aver- } \\
\text { ages } 29 \mathrm{~g} / \mathrm{t} \mathrm{Au} \text { and } 45 \mathrm{~g} / \mathrm{t} \mathrm{Ag} \text {. } \\
\text { Has produced } 17 \mathrm{t} \mathrm{Au} \text { and } 17 \\
\mathrm{t} \mathrm{Ag} \text { since start of mining in } \\
1991 . \text { Annual production of } \\
3 \mathrm{t} \mathrm{Au} \text { and } 3 \mathrm{t} \mathrm{Ag.}\end{array}$ \\
\hline \multicolumn{4}{|c|}{$\begin{array}{l}\text { An en echelon system of quartz veins trending generally east-west. Veins occur in a multiphase granitoid stock about } 4 \text { square } \\
\text { kilometers in size composed mainly of granodiorite and adamellite. Stock is intruded by dikes of granite-porphyry, rhyolite, } \\
\text { pegmatite, aplite, and lamprophyre. Quartz veins are surrounded by zones of beresitic and argillic alteration; skarnlike and } \\
\text { greisenlike alteration is present locally. Mineralization occurred in two stages separated by intrusion of lamprophyre dikes: (1) } \\
\text { gold-polymetallic stage marked by molybdenite, arsenopyrite, loellingite, native bismuth, bismuth tellurides, and native gold; } \\
\text { (2) the most economically important stage, marked by arsenopyrite, pyrite, polymetallic sulfides, gold, electrum, freibergite, } \\
\text { tetrahedrite, lead-antimony and silver sulfosalts, argentite, and stibnite. Gold ore bodies extend to great depth into a large zone of } \\
\text { complicated mineralogy, geochemistry, and structure. References: Orlov and Epifanova, 1988; Palymsky and Palymskaya, 1990; } \\
\text { Voroshin and others, written commun., 1990; Banin, written commun., 1993; Goncharov, 1995. }\end{array}$} \\
\hline
\end{tabular}


Table 2. List of lode mineral deposit models used for metallogenic analysis of the Russian Far East, Alaska, and the Canadian Cordillera.

[Adapted from Nokleberg and others (1997a,b, 2000). Only some of these models were needed to describe the characteristic features of the 1,079 lode deposits]

\begin{tabular}{|c|c|}
\hline Deposit group & Deposit model \\
\hline Deposits related to marine felsic to mafic extrusive rocks & $\begin{array}{l}\text { Kuroko } \mathrm{Zn}-\mathrm{Pb}-\mathrm{Cu} \text { massive sulfide }(\mathrm{Ag}, \mathrm{Au}, \mathrm{Cd}, \mathrm{Sn}, \mathrm{Sb}, \mathrm{Bi} \text {, barite) } \\
\text { Besshi } \mathrm{Cu}-\mathrm{Zn} \text { massive sulfide }(\mathrm{Cu}, \mathrm{Zn}, \mathrm{Ag}) \\
\text { Cyprus } \mathrm{Cu}-\mathrm{Zn}-\mathrm{Ag} \text { massive sulfide }(\mathrm{Au}, \mathrm{Pb}, \mathrm{Cd}, \mathrm{Sn}) \\
\text { Volcanogenic } \mathrm{Mn} \\
\text { Volcanogenic } \mathrm{Fe}\end{array}$ \\
\hline Deposits related to subaerial extrusive rocks & $\begin{array}{l}\text { Au-Ag epithermal vein } \\
\text { Volcanic-hosted } \mathrm{Hg} \text { (Plamennoe type) } \\
\text { Hot-spring } \mathrm{Hg} \\
\text { Silica-carbonate } \mathrm{Hg} \\
\text { Volcanic-hosted } \mathrm{Sb}(\mathrm{Au}, \mathrm{Ag}, \mathrm{As}) \text { vein } \\
\text { Rhyolite-hosted } \mathrm{Sn} \\
\text { Sulfur-sulfide }\left(\mathrm{S}, \mathrm{FeS}_{2}\right)\end{array}$ \\
\hline $\begin{array}{l}\text { Stratiform deposits in fine-grained clastic and siliceous sedi- } \\
\text { mentary rocks }\end{array}$ & $\begin{array}{l}\text { Sedimentary-exhalative } \mathrm{Zn}-\mathrm{Pb}-\mathrm{Ag} \\
\text { Bedded barite }\end{array}$ \\
\hline Deposits in carbonate and chemical-sedimentary rocks & $\begin{array}{l}\text { Kipushi } \mathrm{Cu}-\mathrm{Pb}-\mathrm{Zn} \\
\text { Southeast Missouri Pb-Zn } \\
\text { Korean } \mathrm{Pb}-\mathrm{Zn} \text { massive sulfide } \\
\text { Ironstone (Superior Fe) } \\
\text { Stratabound W (Austrian Alps-type) } \\
\text { Carbonate-hosted Hg (Khaidarkan type) } \\
\text { Stratiform } \mathrm{Zr} \text { (Algama Type) } \\
\text { Sedimentary phosphorite }\end{array}$ \\
\hline $\begin{array}{l}\text { Deposits related to calc-alkaline and alkaline granitic intrusions } \\
\text { - veins and replacement deposits }\end{array}$ & $\begin{array}{l}\text { Polymetallic veins } \\
\text { Sb-Au veins (simple Sb deposits) } \\
\text { Sn quartz veins (Rudny Gory or replacement Sn) } \\
\text { Sn silicate-sulfide veins (Cornish type) } \\
\text { Sn polymetallic veins (Southern Bolivian type) } \\
\text { Co-arsenide polymetallic veins } \\
\text { Carbonatite-related Ta, Nb, REE stockwork and vein }\end{array}$ \\
\hline $\begin{array}{l}\text { Deposits related to calc-alkaline and alkaline granitic intrusions } \\
\text { - skarns and greisens }\end{array}$ & $\begin{array}{l}\mathrm{Cu}( \pm \mathrm{Fe}, \mathrm{Au}, \mathrm{Ag}, \mathrm{Mo}) \text { skarn (contact metasomatic) } \\
\mathrm{Zn}-\mathrm{Pb}( \pm \mathrm{Ag}, \mathrm{Cu}, \mathrm{W}) \text { skarn (contact metasomatic and associated Manto } \\
\quad \text { replacement deposits) } \\
\mathrm{Au}, \mathrm{Co} \text {, and As skarn } \\
\mathrm{W} \text { skarn and greisen } \\
\mathrm{Fe}( \pm \mathrm{Au}, \mathrm{Cu}, \mathrm{W}, \mathrm{Sn}) \text { skarn } \\
\mathrm{Sn} \text { greisen and skarn } \\
\mathrm{Sn}-\mathrm{B}(\mathrm{Fe}) \text { skarn (Ludwigtite type) } \\
\text { Boron skarn (datolite type) } \\
\text { Fluorite greisen }\end{array}$ \\
\hline $\begin{array}{l}\text { Deposits related to calc-alkaline and alkaline granitic intrusions } \\
\text { - porphyry and granitic pluton-hosted deposits }\end{array}$ & $\begin{array}{l}\text { Porphyry } \mathrm{Cu}-\mathrm{Mo}(\mathrm{Au}, \mathrm{Ag}) \\
\text { Porphyry } \mathrm{Mo}( \pm \mathrm{W}, \mathrm{Sn}, \mathrm{Bi}) \\
\text { Porphyry } \mathrm{Sn} \\
\text { Granitoid-related } \mathrm{Au} \\
\text { Felsic plutonic U-REE } \\
\text { W vein }\end{array}$ \\
\hline
\end{tabular}


Table 2. List of lode mineral deposit models used for metallogenic analysis of the Russian Far East, Alaska, and the Canadian Cordillera.-Continued

\begin{tabular}{|l|l|}
\hline \multicolumn{1}{|c|}{ Deposit group } & \multicolumn{1}{|c|}{ Deposit model } \\
\hline Deposits related to mafic and ultramafic rocks & $\begin{array}{l}\text { Zoned mafic-ultramafic Cr-PGE ( } \pm \mathrm{Cu}, \mathrm{Ni}, \mathrm{Au}, \mathrm{Co}, \mathrm{Ti}, \text { or Fe) (Alaskan PGE) } \\
\text { Zoned ultramafic, mafic, felsic, and alkalic PGE-Cr and apatite-Ti } \\
\text { Anorthosite apatite-Ti-Fe } \\
\text { Gabbroic Ni-Cu } \\
\text { Podiform } \mathrm{Cr} \\
\text { Hornblende-peridotite Cu-Ni } \\
\text { Serpentine-hosted asbestos }\end{array}$ \\
\hline Deposits related to regionally metamorphosed rocks & $\begin{array}{l}\text { Au quartz veins (includes concordant vein, and shear-zone Au) } \\
\text { Disseminated Au-sulfide (Maiskoe type) } \\
\text { Clastic sediment-hosted Sb-Au } \\
\text { Cu-Ag quartz vein (vein Cu) } \\
\text { Kennecott Cu }\end{array}$ \\
\hline
\end{tabular}

Table 3. Summary of major tectonic events and associated mineral deposit models derived from a metallogenic analysis of the Russian Far East, Alaska, and the Canadian Cordillera.

[Adapted from Nokleberg and others (1997a,b, 2000), Nokleberg, West, and others (1998), and Scotese and others (2001)]

\begin{tabular}{|c|c|c|c|}
\hline Time & Areas & Tectonic event(s) & Major mineral deposit models \\
\hline $\begin{array}{l}\text { Late Proterozoic, Late Devonian, Early } \\
\text { Carboniferous }\end{array}$ & $\begin{array}{l}\text { Northeast Asia and North } \\
\text { American craton margin }\end{array}$ & Rifting & Sedimentary-exhalative $\mathrm{Zn}-\mathrm{Pb}$. \\
\hline Late Triassic through mid-Cretaceous & $\begin{array}{l}\text { Offshore of North Asia and } \\
\text { North American craton } \\
\text { margins }\end{array}$ & Island arc and back arc & $\begin{array}{l}\text { Porphyry, epithermal vein, } \\
\text { polymetallic vein, skarn. }\end{array}$ \\
\hline Jurassic through mid-Cretaceous & $\begin{array}{l}\text { North Asian and North Ameri- } \\
\text { can continental margins }\end{array}$ & Accretion & $\begin{array}{l}\text { Low-sulfide Au quartz vein, } \\
\text { granitoid-related Au. }\end{array}$ \\
\hline Mid-Cretaceous through present & $\begin{array}{l}\text { North Asian and North Ameri- } \\
\text { can continental margins }\end{array}$ & $\begin{array}{l}\text { Continental-margin arc and } \\
\text { back arc }\end{array}$ & $\begin{array}{l}\text { Porphyry, epithermal vein, } \\
\text { polymetallic vein, skarn. }\end{array}$ \\
\hline $\begin{array}{l}\text { Late Jurassic through Early Cretaceous, } \\
\text { Late Cretaceous through early Ter- } \\
\text { tiary, and middle Tertiary }\end{array}$ & North Asian continental margin & $\begin{array}{l}\text { Transform continental-margin } \\
\text { faulting and associated bi- } \\
\text { modal volcanic-plutonic belt }\end{array}$ & $\begin{array}{l}\text { Zoned mafic-ultramafic } \\
\text { PGE, Cr, and Ti; W skarn; } \\
\text { porphyry Cu-Mo; Au-Ag } \\
\text { epithermal vein. }\end{array}$ \\
\hline Late Cretaceous through present & $\begin{array}{l}\text { North America continental } \\
\text { margin }\end{array}$ & $\begin{array}{l}\text { Transform continental-margin } \\
\text { faulting and associated bi- } \\
\text { modal volcanic-plutonic belt }\end{array}$ & $\begin{array}{l}\text { Displacement of previously } \\
\text { formed metallogenic belts } \\
\text { and host rocks. }\end{array}$ \\
\hline
\end{tabular}

$\mathrm{Cu}, \mathrm{W}, \mathrm{Sn}$ ) skarn, Sn greisen and skarn, boron skarn (datolite type), porphyry $\mathrm{Cu}-\mathrm{Mo}$, porphyry $\mathrm{Sn}$, granitoid-related $\mathrm{Au}$, and $\mathrm{W}$ vein deposit models. The figure illustrates that these metallogenic belts are hosted in Cretaceous and Cenozoic volcanic-plutonic belts constituting major overlap assemblages that formed from Late Cretaceous through early Tertiary continental-margin arcs.

When the above definitions and principles are applied, the areas defined for metallogenic belts encompass favorable geological environments and possess a specific mineral deposit type and associations. For the Russian Far East example (fig. 2), the various metallogenic belts delineate areas that contain and (or) are favorable (predictive) for igneous-arcrelated deposits that are hosted in major Late Cretaceous and early Tertiary continental-margin arc units. The synthesis and compilation of metallogenic belt maps provide an extremely powerful tool for a variety of purposes because the metallogenic belts constitute favorable areas for undiscovered mineral resources. This predictive methodology is extremely useful for land use planning, environmental studies, and exploration planning and for establishing guidelines for future research.

\section{Theoretical Example of Methodology}

The first parts of the methodology for metallogenic and tectonic analysis are illustrated in figure 3 (derived from Nokleberg and others, 1997a). Figure 3A is a schematic map that portrays a suite of metallogenic belts that are hosted in several geologic units, including cratons, terranes, and overlap 


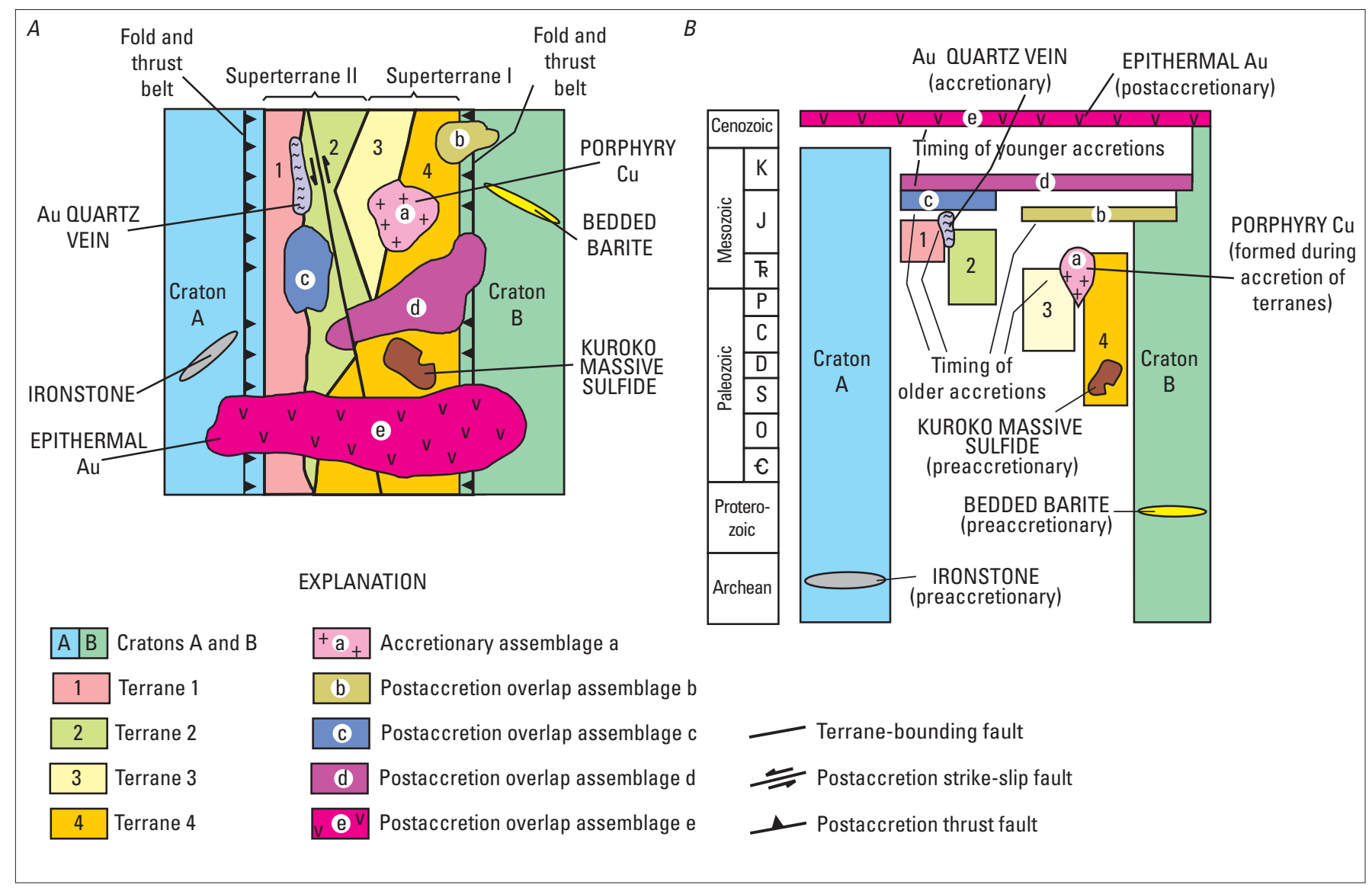

Figure 3. Schematics illustrating the methodology for metallogenic analysis of cratons, terranes, accretionary assemblages, overlap assemblages, and contained metallogenic belts. $A$, Map view of orogenic belt. $B$, Stratigraphic columns for orogenic belt. Adapted from Nokleberg and others (1997a).

assemblages, or along major faults between terranes. Figure $\sqrt{B B}$, a series of stratigraphic columns for the units depicted in figure $3 A$, illustrates the stratigraphic and metallogenic history of the map area.

The steps in this theoretical example follow.

1. A regional geologic base map is constructed. Figure 3A, a map view of an orogenic belt (consisting of two cratons and several intervening terranes), portrays two major cratons (A, B), several fault-bounded terranes $(1,2,3,4)$ between the two cratons, one accretionary assemblage (a), and four postaccretion overlap assemblages (b, c, d, e).

2. A series of mineral deposit models appropriate for the geology is identified and defined, and a mineral deposit database is prepared. For this theoretical example, the major mineral deposit models are low-sulfide Au quartz vein, ironstone, epithermal $\mathrm{Au}$ vein, porphyry $\mathrm{Cu}$, bedded barite, and kuroko massive sulfide.

3. Metallogenic belts are delineated. For simplicity in this example, each belt is assumed to contain only a single mineral deposit type. The two cratons (A, B) each contain distinctive, preaccretionary metallogenic belts with deposits that formed early in their geologic history-ironstone in craton $\mathrm{A}$ and bedded barite in craton $\mathrm{B}$. Island-arc terrane 4 contains a preaccretionary belt of kuroko massive sulfide deposits. Between terranes 3 and 4 is accretionary assemblage a, which consists of a collisional granitic pluton with a porphyry $\mathrm{Cu}$ belt that formed during accretion of terrane 3 against terrane 4 . Between terranes 1 and 2 is an assemblage of rocks that contains a belt of Au quartz vein deposits that formed during accretion of terrane 1 against terrane 2. Overlying all terranes and both cratons is postaccretion overlap assemblage e containing a metallogenic belt with epithermal Au vein deposits.

4. The genesis of bedrock geologic units, structures, and contained metallogenic belts and mineral deposits is interpreted by using modern tectonic concepts (fig. 3B. Examples are kuroko massive sulfide deposits forming in an island-arc environment, porphyry $\mathrm{Cu}$ and low-sulfide $\mathrm{Au}$ quartz vein deposits forming in a collisional environment, and epithermal Au vein deposits forming in a continental-margin igneous-arc environment.

5. Because each metallogenic belt is carefully defined to be the geologically favorable area for a group of coeval and genetically related mineral deposits, a predictive character is established within the belt for undiscovered deposits. 


\section{Synthesis of a Combined Metallogenic and Tectonic Model}

In the following discussion, the methodology for synthesis of a metallogenic and tectonic model, as practiced in recent international collaborative projects in the Circum-North Pacific (Nokleberg and others, 1995, 1997a,b,c; Nokleberg, Kuzmin, and others, 1998; Nokleberg, West, and others, 1998) and in Northeast Asia (Nokleberg and others, 1999), consists of the following steps.

1. A regional geologic base map, mineral deposit database, and metallogenic belt maps are compiled and synthesized.

2. The tectonic environments for the cratons, craton margins, orogenic collages of terranes, overlap assemblages, and contained metallogenic belts are assigned from regional compilation and synthesis of stratigraphic, structural, metamorphic, isotopic, faunal, and provenance data (Nokleberg, Parfenov, and others, 1994; Nokleberg and others, 1997c; Greninger and others, 1999).

3. Correlations are made among terranes, fragments of overlap assemblages, and fragments of contained metallogenic belts.

4. Coeval terranes and their contained metallogenic belts are assigned a single metallogenic and tectonic origin, such as a single island-arc or subduction-zone terrane.

5. Igneous-arc and subduction-zone terranes that are interpreted as being tectonically linked together, and their contained metallogenic belts, are grouped into coeval, curvilinear arc-subduction-zone-complexes.

6. By use of geologic, faunal, and paleomagnetic data, the original positions of terranes and their metallogenic belts are interpreted.

7. The paths of tectonic migration of terranes and contained metallogenic belts are constructed.

8. The timings and nature of accretions of terranes and contained collision-related metallogenic belts are determined from geologic, age, and structural data.

9. The timings of postaccretionary overlap assemblages and contained metallogenic belts are determined from geologic and age data.

10. A series of time-stage diagrams is drawn that portrays the successive major metallogenic and tectonic events for the region.

11. The interpretation of the time-stage diagrams is written.

One time stage of the metallogenic and tectonic model is illustrated in figure 4, which shows the tectonic origin for continental-margin igneous-arc-related metallogenic belts in this region for the Late Cretaceous through early Tertiary (Nokleberg and others, 2000, 2001, 2003; Scotese and others, 2001). In addition to depicting the major continental-margin igneous- arc-related metallogenic belts, the model also illustrates, for this time stage, the configuration of cratons, craton margins, previously accreted terranes, actively migrating terranes, continental-margin arcs forming major overlap assemblages, and oceanic ridges.

For this time stage, the major metallogenic-tectonic events are (Nokleberg and others, 2000, 2001, 2003; Scotese and others, 2001) described below.

1. Continuation of a series of continental-margin arcs (East Sikhote-Alin, Okhotsk-Chukotka, Kluane, and Coast arcs), associated metallogenic belts (East Sikhote-Alin, Eastern Asia, Alaska, and Cordilleran), and companion subduction-zone assemblages around the Circum-North Pacific.

2. Completion of opening of the Arctic Basin.

3. Completion of accretion of the Wrangellia superterrane.

4. A change to dextral transpression in the eastern part of the Circum-North Pacific between the Kula Ocean plate and the North American continental margin.

5. Oblique subduction of the Kula-Farallon oceanic ridge under the margins of southern and southeastern Alaska.

6. Northward migration of previously accreted terranes along the margin of the North American Cordillera.

The major metallogenic belts forming during this time span are the East Sikhote-Alin belt hosted in the East SikhoteAlin arc, the Eastern Asia belt formed in the Okhotsk-Chukotka arc, the Alaska belt formed in the Kluane arc, and the Cordilleran belt formed in the Coast arc. The major mineral deposit types in these belts are porphyry $\mathrm{Cu}$, porphyry $\mathrm{Cu}-\mathrm{Au}$, porphyry $\mathrm{Cu}-\mathrm{Mo}$, porphyry Mo, porphyry Sn, granitoidrelated $\mathrm{Au}, \mathrm{Au}-\mathrm{Ag}$ epithermal vein, polymetallic vein, $\mathrm{Sb}-\mathrm{Au}$ vein, $\mathrm{Sn}$ greisen and skarn, Cu skarn, $\mathrm{Zn}-\mathrm{Pb}$ skarn, Fe skarn, and $\mathrm{Hg}$ hot-spring types. Detailed descriptions of the 12 time stages for the metallogenic and tectonic model were provided by Nokleberg and others $(2001,2003)$ and Scotese and others (2001).

\section{Benefits of Performing a Combined Regional Metallogenic and Tectonic Analysis}

As described above, a high-quality metallogenic and tectonic analysis and synthesis of an associated metallogenic and tectonic model will provide the following benefits (fig. 1): (1) refinement of mineral deposit models (Eckstrand, 1984; Cox and Singer, 1986; Singer and Cox, 1988) and of the understanding of deposit genesis, (2) assessments of undiscovered mineral resources as part of quantitative mineral resource assessment studies (Cox, 1993; Singer, 1993, 1994; Ludington 


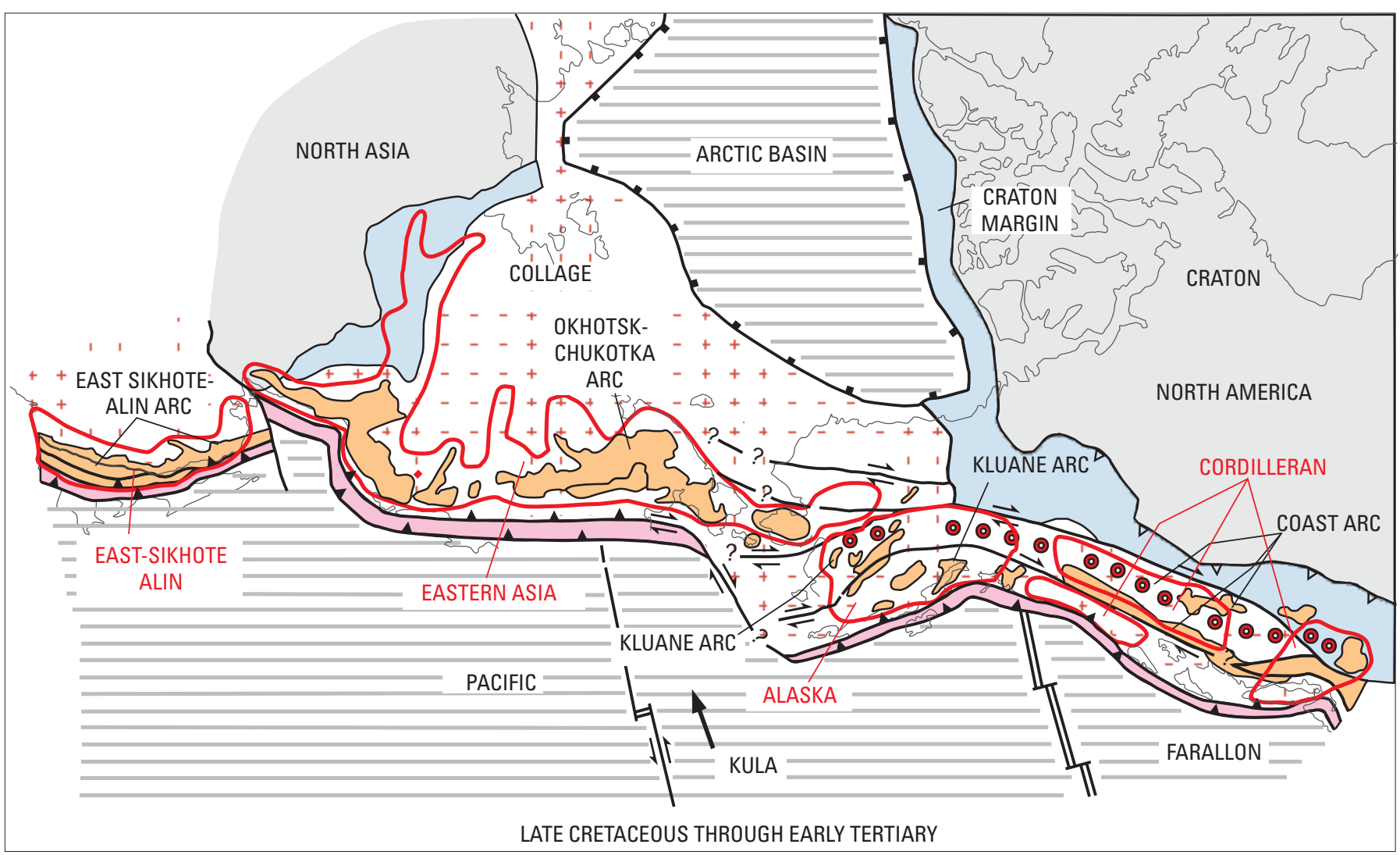

EXPLANATION

HOST ROCK TECTONIC ENVIRONMENTS

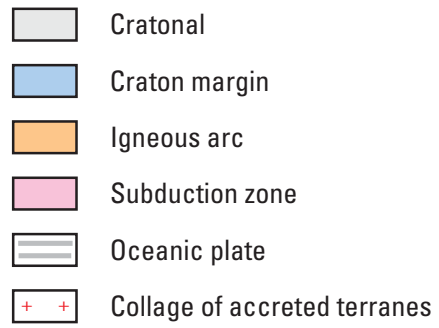

CONTACTS AND FAULTS

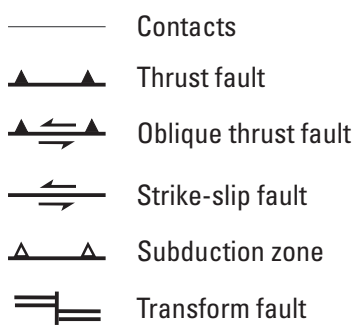

SYMBOLS

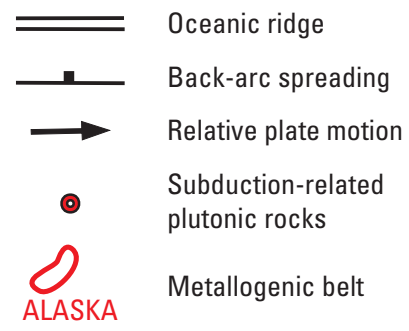

Figure 4. Late Cretaceous and early Tertiary stage of the metallogenic and tectonic model illustrating the tectonic setting for igneousarc-related metallogenic belts hosted in Late Cretaceous through early Tertiary continental-margin igneous arcs in the Russian Far East, Alaska, and the Canadian Cordillera. Adapted from Nokleberg and others (2000, 2001, 2003; Scotese and others, 2001).

and others, 1996), (3) data to consider in land use and mineral exploration planning, (4) improvement of interpretations of origins of host rocks, mineral deposits, and metallogenic belts, and (5) guidelines for new research.

Following are three examples of these benefits.

1. The in-depth understanding of the tectonic and metallogenic origins of potential host rocks for mineral deposits makes it possible to anticipate the types of mineral deposits that can occur in these rocks. It is crucial to have this capability because permissive tracts (that is, areas having potential for undiscovered mineral deposit types) for a mineral resource assessment must be drawn for each mineral deposit type permitted by the geology and geologic processes that operated in the assessment area.

2. Regional metallogenic and tectonic analyses, such as those performed for the Circum-North Pacific and Northeast Asia, make it possible to identify and locate the continuations of ore-hosting terranes and permissive tracts separated around the world by the myriad of platetectonic processes operating throughout the Earth's long 
history. Suppose that a suite of metallogenic belts containing porphyry $\mathrm{Cu}$ deposits is hosted in various fragments of island-arc terranes that are now dispersed in a collage of terranes in the center of a continent. Tectonic analysis of the origin of the island-arc terranes, and possible correlations with each other, will result in grouping of these terranes and their contained metallogenic belts into an originally continuous island arc and a single, large metallogenic belt. This enlargement of the host-rock area and contained metallogenic belt will provide a larger dataset that should greatly improve the quality studies for metallogenic analysis and (or) for mineral resource assessment.

3. An understanding of the metallogenic setting and history of host rocks and ore-forming processes often is important for estimating numbers of undiscovered mineral deposits in a permissive tract for a mineral resource assessment. For example, the number of volcanogenic massive sulfide deposits estimated in a permissive tract containing poorly exposed and poorly described mafic to felsic volcanic rocks may vary, depending on whether the tract is located in a volcanic fore-arc, axial-arc, or back-arc tectonic setting. Conversely, deposits of this type might not be estimated for a tract of similar rocks in an extensional cratonic setting.

\section{Summary}

This paper presents an overview of the methodology of combined regional metallogenic and tectonic analysis. The paper also provides a theoretical example of this type of analysis and describes an example of this type of analysis for a metallogenic and tectonic model for the origin of Late Cretaceous and early Tertiary igneous-arc-related deposits in the Circum-North Pacific (Russian Far East, Alaska, and Canadian Cordillera). This paper also describes how a high-quality metallogenic and tectonic analysis and synthesis of an associated metallogenic and tectonic model will provide the following benefits: (1) refinement of mineral deposit models and of the understanding of deposit genesis, (2) improvement of assessments of undiscovered mineral resources as part of quantitative mineral resource assessment studies, (3) data to consider in land use and mineral exploration planning, (4) improvement of interpretations of origins of host rocks, mineral deposits, and metallogenic belts, and (5) guidelines for new research.

\section{Acknowledgments}

In the last three decades, many persons have assisted the authors in developing and using the concepts of combined regional metallogenic and tectonic analysis and in developing methods for synthesizing a metallogenic and tectonic model. These persons include D.P. Cox, Kazuya Fujita, D.L. Jones, E.M. MacKevett, Jr., I.O. Norton, D.H. Richter, D.W. Scholl,
C.R. Scotese, D.A. Singer, and D.B. Stone. The constructive reviews by Klaus J. Schulz and Joseph A. Briskey (both of the U.S. Geological Survey) are appreciated.

\section{References Cited}

Coney, P.J., Jones, D.L., and Monger, J.W.H., 1980, Cordilleran suspect terranes: Nature, v. 288, no. 5789, p. 329-333.

Cox, D.P., 1993, Estimation of undiscovered deposits in quantitative mineral resource assessments-Examples from Venezuela and Puerto Rico: Nonrenewable Resources, v. 2, no. 2, p. 82-91.

Cox, D.P., and Singer, D.A., eds., 1986, Mineral deposit models: U.S. Geological Survey Bulletin 1693, 379 p. (Also available online at http://pubs.usgs.gov/bul/b1693/.)

Eckstrand, O.R., 1984, Canadian mineral deposit types-A geological synopsis: Geological Survey of Canada Economic Geology Report 36, 86 p.

Goncharov, V.I., 1995, Geologic review of commercial mineralization types of the Okhotsk-Chukchi volcanic belt, in Bundtzen, T.K., Fonseca, A.L., and Mann, Roberta, eds., The geology and mineral deposits of the Russian Far East-Alaska Miners Association Special Symposium, v. 1: Anchorage, Alaska, Glacier House Publications, p. 134-140.

Greninger, M.L., Klemperer, S.L., and Nokleberg, W.J., 1999, Geographic information systems (GIS) compilation of geophysical, geologic, and tectonic data for the CircumNorth Pacific (Nokleberg, W.J., and Diggles, M.F., eds.): U.S. Geological Survey Open-File Report 99-422, one CD-ROM. (Also available online at http://pubs.usgs.gov/ of/1999/of99-422/.)

Gurov, L.P., 1969, Gold-bearing mineral formations of the Kirovskoe deposit, in Radkevich, E.D., ed., Gold formations of the Russian Far East: Moscow, Nauka, p. 74-92. (In Russian.)

Howell, D.G., Jones, D.L., and Schermer, E.R., 1985, Tectonostratigraphic terranes of the Circum-Pacific regionPrinciples of terrane analysis, in Howell, D.G., ed., Tectonostratigraphic terranes of the Circum-Pacific region: Houston, Tex., Circum-Pacific Council for Energy and Mineral Resources, p. 3-31.

Jones, D.L., Howell, D.G., Coney, P.J., and Monger, J.W.H., 1983, Recognition, character, and analysis of tectonostratigraphic terranes in western North America, in Hashimoto, M., and Uyeda, S., eds., Accretion tectonics in the CircumPacific regions-Proceedings of the Oji International Seminar on Accretion Tectonics, September 1981, Tomakomai, Japan: Tokyo, Terra Scientific Publishing Company, p. 21-35. 
Ludington, Steve, Cox, Dennis, and McCammon, Richard, eds., 1996, Data base for a national mineral-resource assessment of undiscovered deposits of gold, silver, copper, lead, and zinc in the conterminous United States: U.S. Geological Survey Open-File Report 96-96, one CD-ROM. (Also available online at http://pubs.usgs.gov/of/1996/of96-096/.)

Monger, J.W.H., and Berg, H.C., 1987, Lithotectonic terrane map of western Canada and southeastern Alaska: U.S. Geological Survey Miscellaneous Field Studies Map MF-1874B, 1 sheet, scale 1:2,500,000, 12 p.

Moore, T.E., 1992, The Arctic Alaska superterrane, in Bradley, D.C., and Dusel-Bacon, Cynthia, eds., Geologic studies in Alaska by the U.S. Geological Survey, 1991: U.S. Geological Survey Bulletin 2041, p. 238-244.

Nokleberg, W.J., Bundtzen, T.K., Berg, H.C., Brew, D.A., Grybeck, Donald, Robinson, M.S., Smith, T.E., and Yeend, Warren, 1994, Metallogeny and major mineral deposits of Alaska, in Plafker, George, and Berg, H.C., eds., The geology of Alaska, v. G1 of The geology of North America: Boulder, Colo., Geological Society of America, p. 855-904.

Nokleberg, W.J., Bundtzen, T.K., Brew, D.A., and Plafker, George, 1995, Metallogenesis and tectonics of porphyry $\mathrm{Cu}$ and $\mathrm{Mo}(\mathrm{Au}, \mathrm{Ag}$ ), and granitoid-hosted $\mathrm{Au}$ deposits of Alaska, in Schroeter, T.G., ed., Porphyry deposits of the northwestern Cordillera of North America: Canadian Institute of Mining, Metallurgy, and Petroleum Special Volume 46, p. 103-141.

Nokleberg, W.J., Bundtzen, T.K., Dawson, K.M., Eremin, R.A., Goryachev, N.A., Koch, R.D., Ratkin, V.V., Rozenblum, I.S., Shpikerman, V.I., Frolov, Y.F., Gorodinsky, M.E., Melnikov, V.D., Diggles, M.F., Ognyanov, N.V., Petrachenko, E.D., Petrachenko, R.I., Pozdeev, A.I., Ross, K.V., Wood, D.H., Grybeck, Donald, Khanchuk, A.I., Kovbas, L.I., Nekrasov, I.Y., and Sidorov, A.A., 1997a, Significant metalliferous and selected non-metalliferous lode deposits and placer districts for the Russian Far East, Alaska, and the Canadian Cordillera: U.S. Geological Survey Open-File Report 96-513-B, one CD-ROM. (The report in hardcopy is cited below.)

Nokleberg, W.J., Bundtzen, T.K., Dawson, K.M., Eremin, R.A., Goryachev, N.A., Koch, R.D., Ratkin, V.V., Rozenblum, I.S., Shpikerman, V.I., Frolov, Y.F., Gorodinsky, M.E., Melnikov, V.D., Ognyanov, N.V., Petrachenko, E.D., Petrachenko, R.I., Pozdeev, A.I., Ross, K.V., Wood, D.H., Grybeck, Donald, Khanchuk, A.I., Kovbas, L.I., Nekrasov, I.Y., and Sidorov, A.A., 1996, Significant metalliferous and selected non-metalliferous lode deposits and placer districts for the Russian Far East, Alaska, and the Canadian Cordillera: U.S. Geological Survey Open-File Report 96-513-A, 385 p. (The report on CD-ROM is cited above.)
Nokleberg, W.J., Bundtzen, T.K., Dawson, K.M., Eremin, R.A., Ratkin, V.V., Shpikerman, V.I., Goryachev, N.A., Khanchuk, A.I., Koch, R.D., Rozenblum, I.S., Gorodinsky, M.E., Frolov, Y.F., Pozdeev, A.I., Parfenov, L.M., and Sidorov, A.A., comps., 1997b, Mineral deposit and metallogenic belt maps of the Russian Far East, Alaska, and the Canadian Cordillera: Geological Survey of Canada Open File 3446, 2 sheets, scale 1:5,000,000; 5 sheets, scale 1:10,000,000.

Nokleberg, W.J., Bundtzen, T.K., Dawson, K.M., Monger, J.W.H., Khanchuk, A.I., Parfenov, L.M., and Shpikerman, V.I., 2000, Tectonic controls for Phanerozoic metallogenesis of the Russian Far East, Alaska, and the Canadian Cordillera [abs.]: Geological Society of America Abstracts with Programs, v. 32, no. 6, p. A-59.

Nokleberg, W.J., Bundtzen, T.K., Eremin, R.A., Ratkin, V.V., Dawson, K.M., Shpikerman, V.I., Goryachev, N.A., Byalobzhesky, S.G., Frolov, Y.F., Khanchuk, A.I., Koch, R.D., Monger, J.W.H., Pozdeev, A.I., Rozenblum, I.S., Rodionov, S.M., Parfenov, L.M., Scotese, C.R., and Sidorov, A.A., 2003, Metallogenesis and tectonics of the Russian Far East, Alaska, and the Canadian Cordillera: U.S. Geological Survey Open-File Report 03-434, 425 p. (Superseded in 2005 by USGS Professional Paper 1697, available online at http://pubs.usgs.gov/pp/pp16971.)

Nokleberg, W.J., Naumova, V.V., Kuzmin, M.I., and Bounaeva, T.V., eds., 1999, Preliminary publications book 1 from Project on Mineral Resources, Metallogenesis, and Tectonics of Northeast Asia: U.S. Geological Survey OpenFile Report 99-165, one CD-ROM. (Also available online at http://geopubs.wr.usgs.gov/open-file/of99-165/index.htm, )

Nokleberg, W.J., Parfenov, L.M., Monger, J.W.H., Baranov, B.V., Byalobzhesky, S.G., Bundtzen, T.K., Feeney, T.D., Fujita, Kazuya, Gordey, S.P., Grantz, Arthur, Khanchuk, A.I., Natal'in, B.A., Natapov, L.M., Norton, I.O., Patton, W.W., Jr., Plafker, George, Scholl, D.W., Sokolov, S.D., Sosunov, G.M., Stone, D.B., Tabor, R.W., Tsukanov, N.V., and Vallier, T.L., 1997c, Summary Circum-North Pacific tectonostratigraphic terrane map: U.S. Geological Survey Open-File Report 96-727, 1 sheet, scale 1:10,000,000. (Also released as Geological Survey of Canada Open File 3428, 1 sheet, scale 1:10,000,000.)

Nokleberg, W.J., Parfenov, L.M., Monger, J.W.H., Baranov, B.V., Byalobzhesky, S.G., Bundtzen, T.K., Feeney, T.D., Fujita, Kazuya, Gordey, S.P., Grantz, Arthur, Khanchuk, A.I., Natal'in, B.A., Natapov, L.M., Norton, I.O., Patton, W.W., Jr., Plafker, George, Scholl, D.W., Sokolov, S.D., Sosunov, G.M., Stone, D.B., Tabor, R.W., Tsukanov, N.V., Vallier, T.L., and Wakita, Koji, 1994, Circum-North Pacific tectonostratigraphic terrane map: U.S. Geological Survey Open-File Report 94-714, 221 p., 2 sheets, scale 1:5,000,000; 2 sheets, scale 1:10,000,000. 
Nokleberg, W.J., Parfenov, L.M., Monger, J.W.H., Norton, I.O., Khanchuk, A.I., Stone, D.B., Scotese, C.R., Scholl, D.W., and Fujita, Kazuya, 2001, Phanerozoic tectonic evolution of the Circum-North Pacific: U.S. Geological Survey Professional Paper 1626, 126 p. (Also available online at http://pubs.usgs.gov/pp/2000/1626/.)

Nokleberg, W.J., West, T.D., Dawson, K.M., Shpikerman, V.I., Bundtzen, T.K., Parfenov, L.M., Monger, J.W.H., Ratkin, V.V., Baranov, B.V., Byalobzhesky, S.G., Diggles, M.F., Eremin, R.A., Fujita, Kazuya, Gordey, S.P., Gorodinskiy, M.E., Goryachev, N.A., Feeney, T.D., Frolov, Y.F., Grantz, Arthur, Khanchuk, A.I., Koch, R.D., Natalin, B.A., Natapov, L.M., Norton, I.O., Patton, W.W., Jr., Plafker, George, Pozdeev, A.I., Rozenblum, I.S., Scholl, D.W., Sokolov, S.D., Sosunov, G.M., Stone, D.B., Tabor, R.W., Tsukanov, N.V., and Vallier, T.L., 1998, Summary terrane, mineral deposit, and metallogenic belt maps of the Russian Far East, Alaska, and the Canadian Cordillera: U.S. Geological Survey Open-File Report 98-136, one CD-ROM. (Also available online at http://wrgis.wr.usgs.gov/open-file/of98-136/.)

Orlov, A.G., and Epifanova, A.P., 1988, On ore-formational position of one Central Kolyma ore deposit [abs.]: U.S.S.R. Academy of Sciences, North-Eastern Interdisciplinary Research Institute, Magadan, v. 1, Ore Formations in Zone of Continent-to-Ocean Transition, p. 127-128. (In Russian.)

Palymsky, B.F., and Palymskaya, Z.A., 1990, Gold-sulfosalttype of gold-silver formation in Central Kolyma-Ore-magmatic systems of the U.S.S.R. Northeast: Khabarovsk Polytechnic Institute, Magadan Branch, p. 64-71. (In Russian.)

Plafker, George, and Berg, H.C., 1994, Overview of the geology and tectonic evolution of Alaska, in Plafker, George, and Berg, H.C., eds., The geology of Alaska, v. G1 of The geology of North America: Boulder, Colo., Geological Society of America, p. 989-1022.
Scotese, C.R., Nokleberg, W.J., Monger, J.W.H., Norton, I.O., Parfenov, L.M., Khanchuk, A.I., Bundtzen, T.K., Dawson, K.M., Eremin, R.A., Frolov, Y.F., Fujita, Kazuya, Goryachev, N.A., Pozdeev, A.I., Ratkin, V.V., Rodinov, S.M., Rozenblum, I.S., Shpikerman, V.I., Sidorov, A.A., and Stone, D.B., 2001, Dynamic computer model for the metallogenesis and tectonics of the Circum-North Pacific (Nokleberg, W.J., and Diggles, M.F., eds.): U.S. Geological Survey Open-File Report 01-261, one CD-ROM. (Also available online at http://pubs.usgs.gov/of/2001/of01-261/.)

Singer, D.A., 1993, Basic concepts in three-part quantitative assessments of undiscovered mineral resources: Nonrenewable Resources, v. 2, no. 2, p. 69-81.

Singer, D.A., 1994, The relationship of estimated number of undiscovered deposits to grade and tonnage models in three-part mineral resource assessments, in 1994 International Association for Mathematical Geology Annual Conference, Papers and Extended Abstracts for Technical Programs, October 3-5, 1994, Mont Tremblant, Quebec, Canada, p. 325-326.

Singer, D.A., and Cox, D.P., 1988, Applications of mineral deposit models to resource assessments, in United States Geological Survey Yearbook Fiscal Year 1987: Reston, Va., U.S. Geological Survey, p. 55-57.

Wheeler, J.O., Brookfield, A.J., Gabrielse, H., Monger, J.W.H., Tipper, H.W., and Woodsworth, G.J., comps., 1988, Terrane map of the Canadian Cordillera: Geological Survey of Canada Open File Report 1894, scale 1:2,000,000, 9 p. (Superseded in 1991 by Geological Survey of Canada Map 1713A.) 


\title{
Data Needs and Availability
}

\section{Digital Inventory of Bedrock and Mineral Deposit Geology}

\author{
By Lesley Chorlton, ${ }^{1}$ Robert Laramée, ${ }^{1}$ David Sinclair, ${ }^{1}$ and Elizabeth Hillary'
}

\section{Goals and Background}

The goal of the World Minerals Geoscience Database Project (WMGDP), Geological Survey of Canada (GSC), is to provide high-quality datasets of global scope to describe (1) mineral deposits and (2) bedrock geology. These datasets are meant to facilitate resource assessment, environmental modeling, land use planning, and paleotectonic visualization to better understand our land masses and mineral wealth. The compilation of the initial framework will be accomplished in two 2-year cycles (1998-2000 and 2000-2002) under industry sponsorship. It is understood that compilations of this scope never will be truly complete or up to date. The aim by the end of the project is to provide datasets substantial enough in content to be a stimulating source of global information, which may in turn stimulate improvement of the database over the long term.

The WMGDP originated as the indirect result of compilations of global copper deposits that R.V. Kirkham and his associates began two decades ago. The idea of plotting deposit distributions on a world map of generalized bedrock age was inspired by the "World Atlas of Geology and Mineral Deposits" (Derry, 1980). Continent-scale diagrams from this volume were fitted to a wall map that underlay the plotted distribution of sediment-hosted copper deposits used for poster displays during the middle 1980s. To reap the advantages of reusing a geology backdrop with other data, the geology was recompiled in 1993 by generalizing it from UNESCO (United Nations Educational, Scientific and Cultural Organization) and other official maps so that it could be georeferenced for use as a geographic information system (GIS) digital information product. Attributes of general rock type as well as age were added to the dataset to test the feasibility of creating alternative thematic maps from different combinations of these elements. Paper maps showing the global distribution of sediment-hosted copper deposits (Kirkham, Carrière, and others, 1994), seafloor hydrothermal deposits (Hannington and others, 1994), and bedrock age and rock class domains (Kirkham, Chorlton,

\footnotetext{
${ }^{1}$ Mineral Resources Division, Geological Survey of Canada, 601 Booth Street, Ottawa, Ontario, Canada, K1A 0E8.
}

and Carrière, 1994) and the digital data on CD-ROM (Geological Survey of Canada, 1995) were released to the public at the end of the project.

A 2-year industry-sponsored World Map Project to add other global mineral deposit databases and enhance the geology subsequently was organized by R.V. Kirkham. This project resulted in the production of databases and distribution maps for porphyry and epithermal deposits (Kirkham and Dunne, 2000) and nickel deposits (Eckstrand and Good, 2000) and a database for volcanogenic massive sulfide (VMS) and sedimentary-exhalative deposits (Jenkins and Lydon, 2002). The geological dataset was revised to incorporate information such as better age ranges and magmatic composition to complement magma-related deposit databases.

Enhancements to the data and revisions to many areas from new sources still are incomplete but are sufficient to provide thematic backdrops for the release of hardcopy maps showing the distribution of nickel deposits (Eckstrand and Good, 2000) and porphyryrelated deposits (Kirkham and Dunne, 2000).

Designers of the WMGDP have responded to the need to make the various mineral deposit databases uniform in structure and content, while accommodating new categories of information in the structure. Feedback from compilers, colleagues, and industry sponsors is being used to enhance a preliminary deposit database schema that was adapted from one of the preexisting databases and that already accommodated many of the descriptive parameters for mineral deposits (Eckstrand, 1984; Cox and Singer, 1986; Eckstrand and others, 1995). The consequent alterations to the mineral deposit schema, data content, and terminology should ensure that the information most critical for describing a wide variety of deposit types in a global context can be captured. The bedrock geology database is undergoing continued update and will in future include a new database component describing geotectonic provinces and their timing. Project participants and their roles are listed in table 1.

\section{General Approach}

WMGDP is a compilation project that includes data from a wide range of sources - maps of many origins, scientific 
Table 1. Makeup of the World Minerals Geoscience Database Project team.

[Asterisks mark participants in the previous World Map Project. GSC, Geological Survey Canada; ON, Ontario; BC, British Columbia; ESS, Earth Sciences Sector of Natural Resources Canada; GIS, geographic information system; PGE, platinum-group elements]

\begin{tabular}{|c|c|c|}
\hline Name & Location & Roles \\
\hline W. Dave Sinclair & GSC Ottawa, ON & Project coordinator, publicity, communication, and administration. \\
\hline Lesley Chorlton* & GSC Ottawa, ON & $\begin{array}{l}\text { GIS data, geology compilation, mineral deposit database design and data management, technical } \\
\text { and compiler support coordinator. }\end{array}$ \\
\hline Don F. Sangster & Ottawa, ON & Compiler: Sedimentary-exhalative and Mississippi-Valley-type deposits. \\
\hline O. Roger Eckstrand* & Ottawa, ON & Compiler: Nickel-PGE-chromite deposits. \\
\hline Quentin Gall & Ottawa, ON & Compiler: Nickel-PGE-chromite deposits (tectonic setting; ages; PGE). \\
\hline Benoît Dubé & GSC Quebec & Compiler: Gold deposits. \\
\hline Patrice Gosselin & GSC Quebec & Compiler: Gold deposits. \\
\hline Rod V. Kirkham* & Delta, BC & Compiler: Porphyry-related and sediment-hosted copper deposits. \\
\hline Kathryn Dunne* & Williams Lake, BC & Compiler: Porphyry-related deposits. \\
\hline Antonio Rafer & Vancouver, BC & Compiler: Sediment-hosted copper deposits. \\
\hline Mario Méthot* & ESS Ottawa, ON & Cartography. \\
\hline
\end{tabular}

literature, reports, other national and provincial databases, and preexisting GSC databases. Terminology, levels of detail, and classification vary among sources. Gaps in the information available must be accommodated in the datasets and influence the design of the databases. For example, sources may record that host rocks are of a given geologic age but not indicate the type of host rock. Obtaining accurate and consistent locations from these varied sources also is a problem that may take a long time to overcome.

Because of the compiled nature of the databases, a referencing system has been added to all databases; this system can house all the information necessary to provide full bibliographic citations as output in any reference style. References can be extracted for use on the surrounds of maps and in reports or scientific papers using the information as illustration or evidence. Any number of references can be linked to each deposit or geology record, and provisions are included for identifying which general categories of data came from each source. Data source has been filled in fairly thoroughly for the geology database because the compiler had an immediate need to filter references according to the types of information required for individual thematic maps to provide a textual reference list to insert into cartographic surrounds. Auxiliary goals in developing the geology and current versions of the mineral deposit databases include streamlining the production of alternative integrated maps, diagrams, and reports directly from the databases and automating typing, symbolization, and legend tasks as much as possible.

The geological content of the WMGDP databases includes primarily parameters that are most significant for geology and mineral deposit settings on a global scale. The level of detail may therefore be considered low or superficial to many geologists. However, to accommodate geological complexity adequately, the databases must be able to represent the one-to-many and many-to-many relations among data elements that are endemic to geological information. Relational databases accommodate these kinds of relations, and relational database software is widely available to the public and to sponsors. Therefore, both the mineral deposit and geology databases are implemented in relational database style.

On the other hand, the needs of cartographers and geological end users having low-end GIS software must be accommodated by the system. These users generally prefer to work with data in spreadsheets and spreadsheet-style GIS files. Partial datasets in flat file formats, customized to emphasize different portions of the databases (themes) depending on the end use at hand, therefore, are the main outputs of these databases. This system will ensure that only portions of data that have been reasonably well populated are published and that, if a working group ensures that the thematic data are adequately populated for a certain theme, it is possible to name the group members as the compilers or authors of the thematic product. The export datasets are prepared by using programs that rely on the structural integrity of the database and the consistency of the data content.

Experience in generating export products has shown that it is useful to have rock-type data described by using a hierarchy of different levels of generality. Broad classifiers, alone or in combination with others, can be used to filter or group the data for particular end uses, such as explanations for plots, charts, and spreadsheets. Both the mineral deposit and geology databases allow the description of rock types in three levels. The most general category indicates whether a rock component is mainly sedimentary, volcanic, intrusive, metamorphic, 
or tectonic. This description can be modified by more specific, but still general, classifiers such as broad suite names and predominant magma series for intrusive rocks and, for volcanic rocks, by the familiar compositional terms, magma series, and depositional setting. Any number of more specific details such as actual lithologies, internal structures, external forms, depositional settings (for sedimentary rocks), and protoliths (for metamorphic and tectonic rocks) are entered into tables found at deeper levels in the database. This structure allows compilers to add as much detail as they want to qualify the general terms.

A different approach is being taken for geologic ages. Timing is critical to the understanding of the links between tectonic activity and metallogenesis. Therefore, ages are being captured in the most specific terms available from data sources. They are rolled up into user-specified age ranges for the generalization of export data products by using a numerically calibrated lookup table. Although time calibrations constantly are being revised, one internally consistent and fairly complete source was selected for most numerical start ages and end ages (Harland and others, 1990). These calibrations were supplemented from Plumb (1991) for the new Precambrian time scale and Okulitch (1995) for miscellaneous North American subdivisions.

The mineral deposit and geology databases contain explicit, unhidden tables describing their internal content. These tables include a catalog of component tables, fields, links among tables, domain values (pick lists), and captions. These tables are being used for automating backups and the transfer of data from one format into another. They eventually will be used with programs to fill out some parts of one of the upcoming international standard metadata formats if the datasets are to be made accessible over the World Wide Web. They also may be used to transfer the data into an entirely new structure and format, such as the North American Geologic Data Model (B.R. Johnson, Boyan Brodaric, and Gary Raines, unpub. data, 1997).

\section{Mineral Deposit Databases}

Mineral deposits being compiled into WMGDP databases include porphyry and related epithermal, nickel-PGE (platinum-group elements)-chromite, gold, sedimentary-exhalative, Mississippi-Valley-type, sediment-hosted copper, and ironoxide-copper-gold (Olympic Dam-Kiruna) deposits (table 1). Compilers are based in diverse locations and have a range of desktop computer facilities, a situation that also characterizes our industry clients, with their many international branch offices and project sites. Microsoft Access (version 7.0) was chosen as a platform because it was available to compilers and industry sponsors worldwide. The graphical utilities for entering data and navigating the database have been developed in Delphi and operate on the database through Windows connectivity mechanisms. The utilities can be used for databases that may be either upgraded to later versions of Microsoft Access or transferred onto other database management platforms.

The design of these deposit databases has evolved in stages. At the beginning of the WMGDP, the design of one of the World Map Project databases was adopted because it accommodated most of the information initially considered essential from a global perspective and was applicable to most deposit types. Preexisting databases for porphyry, nickel, gold (Jenkins and others, 1997), VMS, and sedimentary-exhalative deposits were translated into the schema to provide seed databases for additional compilation. As compilers began their literature research and data entry during cycle one of the project, they realized that some significant categories of information could not be accommodated in the existing schema, and so the schema was modified accordingly. The addition or removal of fields and tables, or changes to field definitions, is done by using upgrade programs, which automate the process without endangering the existing data. In some cases, some of the existing data must be remapped manually because the process requires geological judgment. Feedback will be used to make further adjustments, although the deposit data schema is now relatively stable. The standardization of equivalent terminology among databases is now being addressed.

A mineral deposit database is made up of tables that describe six types of entities-deposits, deposit groups (meaning a group of related deposits such as in a camp), mines, production numbers, resource numbers, and references. The overall view fig. 1) shows how the first five entities relate to one another in many-to-many relations, except for mines and deposit groups, which are not directly connected. This lack of connection results because deposit groups may have several deposits, a mine can have more than one production record and exploit more than one deposit, and a resource record can be linked to more than one deposit or mine. The many-tomany relations are reduced to one-to-many through the use of

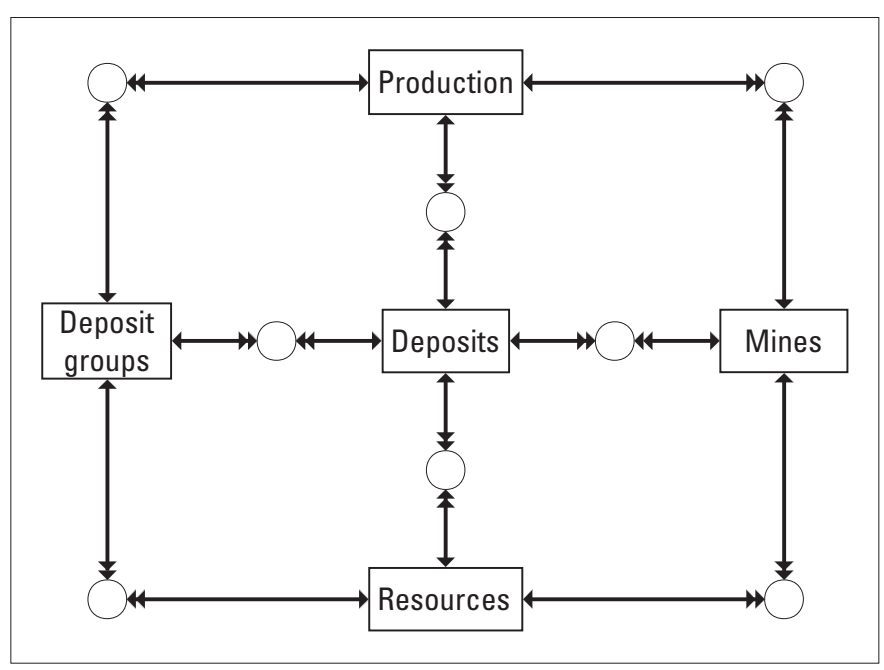

Figure 1. Overview of the mineral deposit schema. The circles represent junction tables; the double arrowheads, the many ends of one-to-many relations. 
junction tables. References (not shown in fig. 1) are linked to all other entities.

The portion of the schema that describes a mineral deposit (fig. 2) is very similar to that for a deposit group. Each entity is made of a master table, here "Deposit Geology,"

which contains general data applicable to the entity for which there is only one value, such as the location and most general deposit classifier. Tables referred to as detail tables to the master table house the following information categories: names; deposit status; commodities; tectonic settings for mineralization, hosts, and so on; geologic ages for mineralization, hosts, and so on; radiometric (isotopic) ages for mineralization, hosts, and so on; related magmatic rocks; host rocks; country rocks; controlling structures; metallic signatures; alteration signatures; mineralization styles; and mineralogy. The detail tables are connected to the master table in one-to-many rela- tions and contain data that can have multiple occurrences for each entity. There also are some subdetail tables, such as individual lithologies, that are themselves detail tables to detail tables (one-to-many-to-many relations). Figure 3 shows how these detail and subdetail tables would appear to a compiler. Compilers are free to use as many or as few detail tables as dictated by the nature of the data and deposit types that they are compiling. Ideal conceptual design had to be compromised in some ways because of information gaps in the database that provided seed data and (or) in the literature. For example, although it seems logical that the host-rock age should be a detail table to host rocks, a compiler must be able to enter host-rock ages even if there is no available information to justify describing host rocks.

Figure 2 also shows how references are used with deposits. Each record in the References junction table makes the

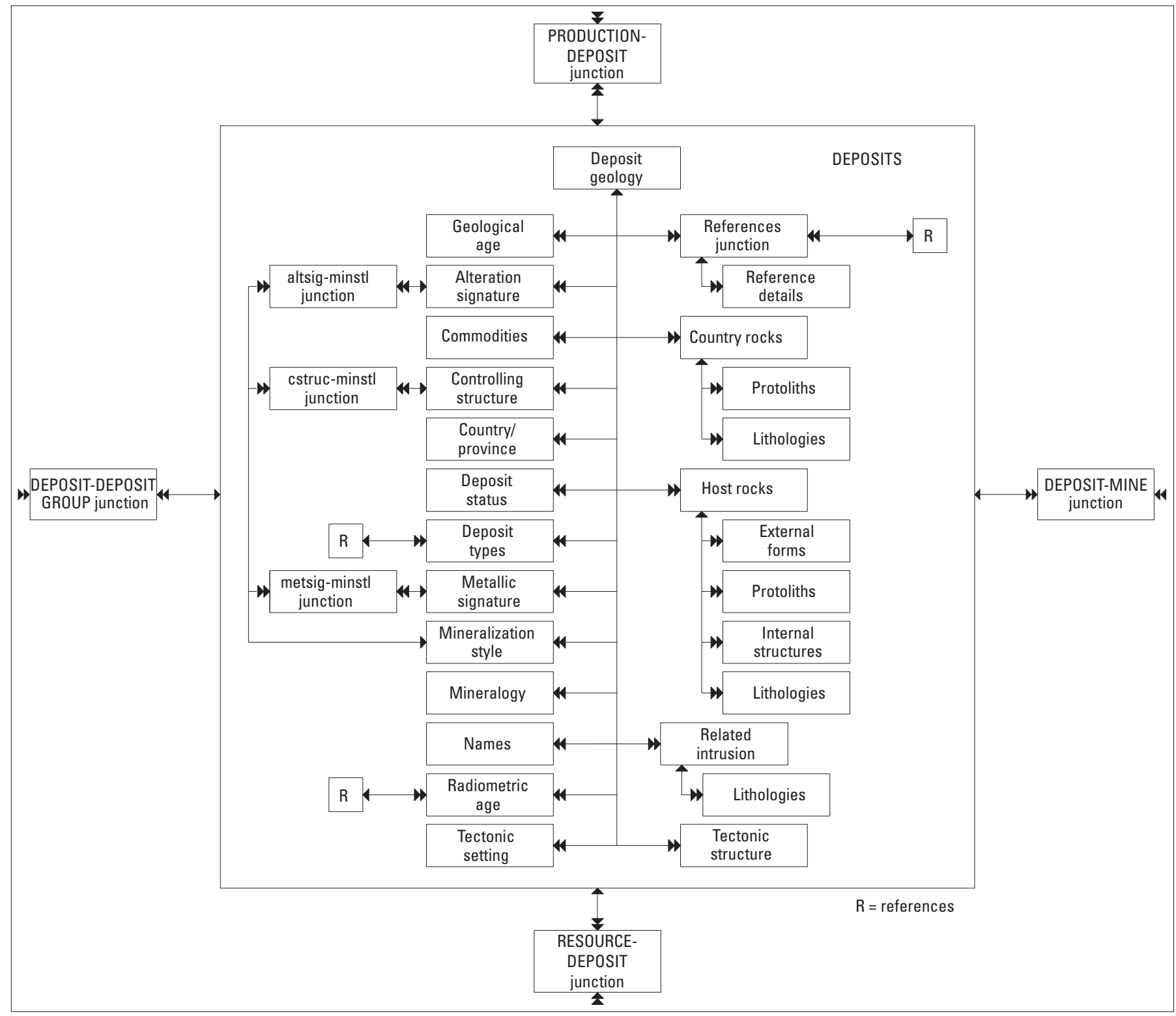

Figure 2. Schema for mineral deposits, particularly their geology. 


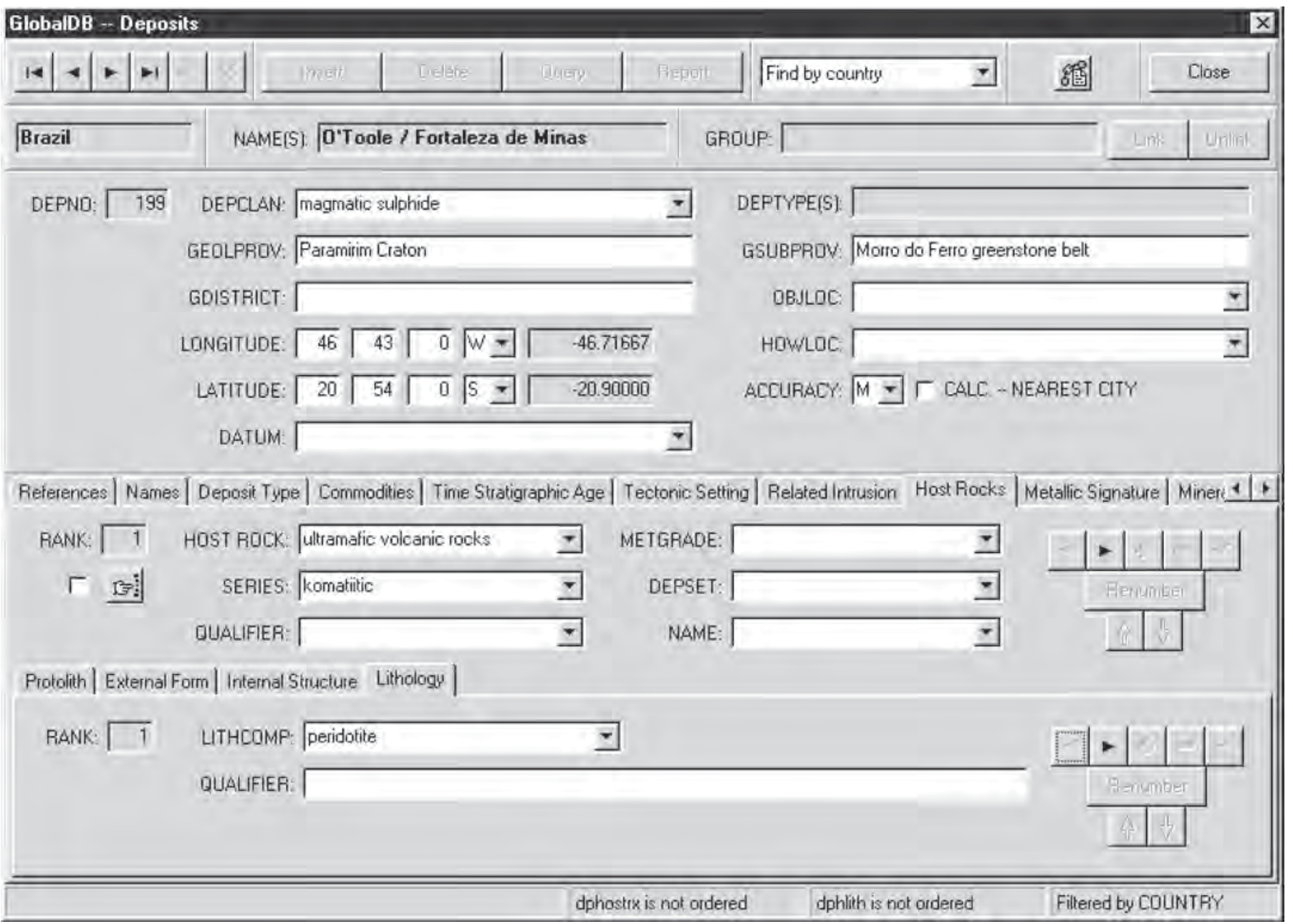

Figure 3. Data entry screen for deposits.

bridge between a single deposit and a single reference. Each deposit can have several references, and each reference can apply to multiple deposits. The subdetail table "Reference Details" contains specific information such as page numbers and Yes/No fields to indicate what type of data came from which reference. Each record of the "Deposit Types" or the "Radiometric Age" detail tables can be linked to a single reference by storing the corresponding reference number value in a reference number field. The same is true for "Production," "Resource," and "Mine" records.

Many of the data fields in these tables are meant to contain values selected from fairly short and well-constrained value lists stored in lookup tables and made available during data entry by means of "combo" boxes. Although most of the lookup tables initially were filled with suggested values, the content of these lists has been under the control of the compilers so that they could chose the terms they needed to best describe the type of deposits they were dealing with. This method was used so that compilers would be comfortable keeping their lookup tables fairly short and the data in their deposit descriptions well constrained. During the early stages of project cycle two, the contents and terminology of the existing mineral deposit databases have been under review. Common descriptive lookup-table terms that meet the needs of these databases and their compilers, but which have varied between databases in spelling and grammatical form, gradually are being standardized, and appropriate terms are being substituted into the databases. Terminology for deposit status, tectonic settings, commodities, and host rocks and related magmatic rocks has been tackled to date. Host rocks are defined as those rocks containing, or in contact with, mineralization. The greatest adjustment is to the way of describing host rocks and related magmatic rocks. Generalized classifiers for host rocks and related magmatic rocks have been substituted for individual lithologies that were entered in some of the databases, and the lithologies have been moved down one level in the database where several may be linked to one general host-rock category. Protoliths, internal structures, and external forms also are available at the lithology level to describe host rocks.

The most appropriate generalized terms for country rock have yet to be determined. These should be more general than those used for host rocks. Country rocks are not necessarily adjacent to the deposit, and are unrelated to the mineralization event, but for some deposits, country rocks may have been a factor influencing deposit characteristics. Examples can 
include a tonalite-granodiorite-gneiss complex, granite-greenstone terrane, or carbonate platform.

The schemas for production and resource numbers are illustrated in figure 4. Included in the master table for each production or resource number are overall tonnage values; whether the number applies to ore, metal, or concentrate; time periods for production; date of estimate of resources; the compiler's recommendation for using or not using the number for summary reports; and a reference number. The production master table includes a check box to indicate whether or not the number is cumulative. The resource master table includes a field for resource category and a check box to indicate whether the number is a combined production and resource number. It also contains check boxes to indicate whether the number refers to an anomaly within a larger resource or represents one of multiple zones for which separate resource estimates are reported. Anomalies and adjacent zones then are linked to the related primary number. Actual grades or metal weights are accommodated in detail tables, and any number of commodities can be reported. Cutoff grades also can be entered into resource detail tables. Each production and resource number should be linked to the most precise entity that it refers to and can be linked to more than one if this is indicated in the data source. The linkage is made through junction tables; if more than one entity is linked to a number, then a proportion of the number is allocated to each entity so that the total linked adds up to no more than 100 percent.

Production and resource numbers come from data sources that conform to a variety of industry standards. Different sources use different units of weight and grade, and the criteria for the classification of resource estimates vary widely. It was decided that the units and categories of the sources should be captured as is to assist verification. There is no solution for the variable resource category classifications; however, quantitative units will be recalculated to metric units by using a conversion table for summary spreadsheets and reports.

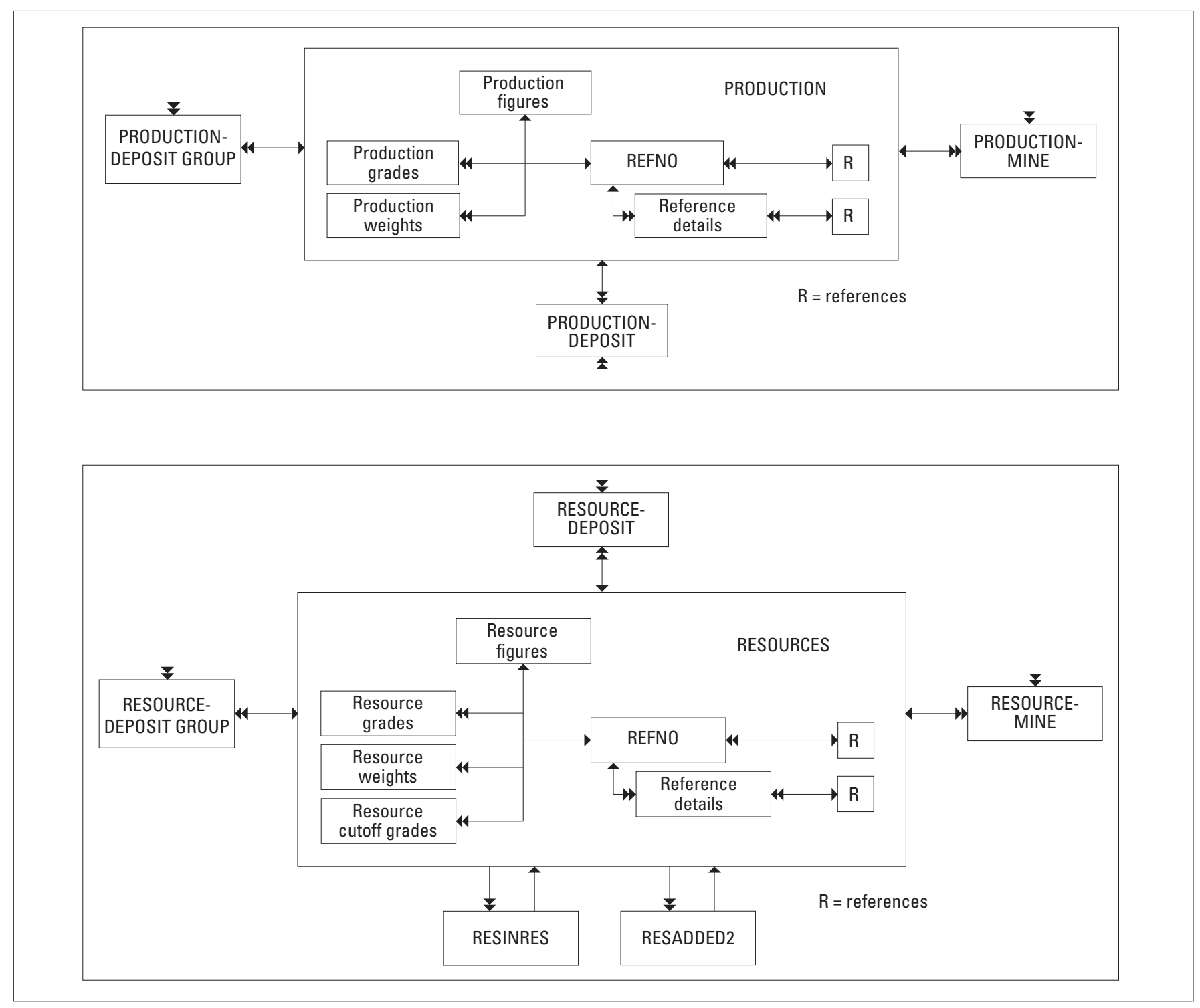

Figure 4. Schemas for production and resource numbers. 
Although the mineral deposit schema covers abundant subject matter and consequently contains more than 100 tables, it will seem simple and logical to an economic geologist when viewed through the data entry interface (fig. 3). The deposit databases now are being made more accessible for end users through a personal-computer-based graphical query interface that will allow interactive filtering and the extraction of custom output that can be used in spreadsheets, displays, and reports. Use of this interface should make the benefits of standardization and generalized terminology evident to compilers and end users alike.

\section{Geology Database}

The geology database, which has evolved from Kirkham and others (1995), describes bedrock surface domains, major faults, and geotectonic provinces (fig. 5). ArcInfo is the software used to prepare the geospatial data and house the attribute database. Export datasets for desktop GIS are prepared by using Arc Macro Language scripts and then are imported into ArcView and MapInfo to create convenient end-user datasets.

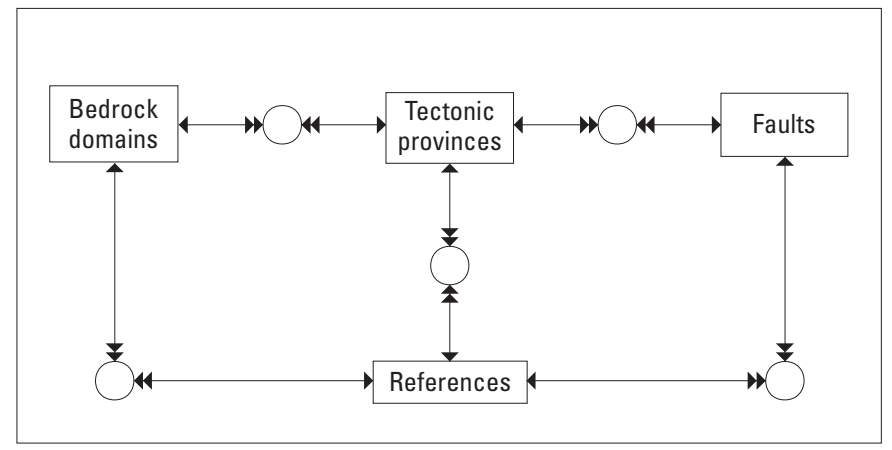

Figure 5. Overview of the geology schema.

The original simple database has been translated to a new, more comprehensive schema that better represents age ranges and rock types. Data for North America, Greenland, South America, Australia, and Africa have been substantially replaced from new sources, and updates to Asia and Europe are underway. Most effort has been directed toward bedrock domains. Data addition focused on the magmatic composition of intrusive and volcanic units to complement the concurrent compilations of nickel-PGE (platinumgroup elements)-chromite and porphyry-related deposits.

The development of the geology database is as much a prototypal exercise as the development of the databases for mineral deposits because it is imperative that intact data products be released to industry sponsors during the course of the project. The arrangement of fields and tables, and the terminology, has been adjusted during the course of the WMGDP and the World Map Project to better represent the source data. Terminology still requires feedback, and users may recommend substitutions for some terms. The main objective in proceeding is to build the best framework possible under the circumstances and to test it by preparing thematic export prod- ucts that can be used for diverse purposes within and outside the scope of the project.

The level of generalization of the geospatial features is being kept high for several reasons. It is primarily the distribution of elements of interest that is important in visualizing global patterns, not the geometry reflected exactly from more detailed map sources. Important elements, such as clusters of small intrusions, must be exaggerated so that they can show up on a global plot. In addition, the projection parameters of many paper source maps are missing and have had to be estimated. Many topographic bases poorly fit the standard World Data Bank II base used for the world geology or the nearly identical Digital Chart of the World; therefore, depicting too much detail would be misleading.

\section{Bedrock Surface Domains}

The bedrock surface database consists of a set of geospatial features (a polygon coverage in ArcInfo) that can be linked to an attribute database of tables describing the age range, rock-type components, names, tectonic settings, and significant commodities of input source units (fig. 6). Attributes housed by the source unit master table include primary and foreign keys, a textual input unit code or description of color or pattern on the original input map source(s), whether the unit is exposed onshore or offshore, and whether it is the default unit for quick plots. In complex areas where many very small, fragmented units are exposed, or in areas where multiple important units are exposed that may be too small to portray to scale on a global map, one polygon may be delin-

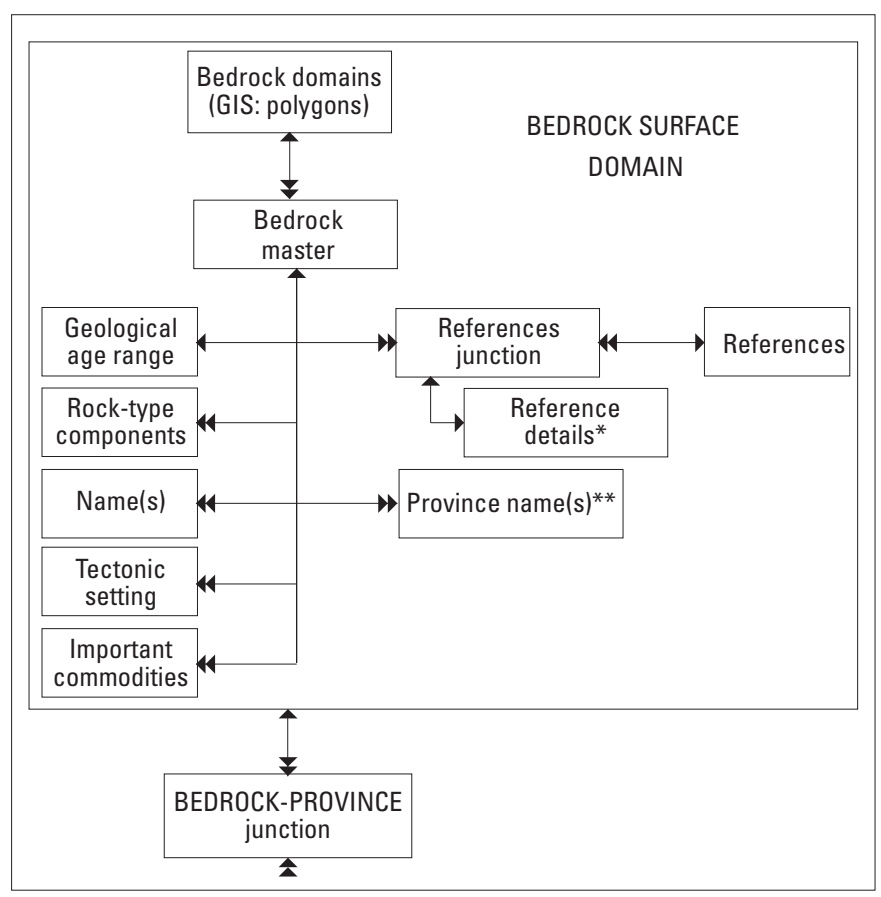

Figure 6. Schema for bedrock surface domains. GIS, geographic information system. 
eated and linked to many units in the attribute database. The unit occupying the greatest cumulative area is tagged as the default unit. Alternative units for display may be retrieved on the basis of underlying attributes according to a specific end use. This generalization technique permits the derivation of alternative map views or export layers based on user-defined queries emphasizing different aspects of the attribute database. Different export layers will be superimposed appropriately when displayed with desktop GIS because they will be derived from the same geospatial framework.

The most significant and most thoroughly populated sets of descriptors for the unit are age and type. There can be many rock-type components for each unit but only one age range. The terms used for start age and end age are as close as possible to the terms used by the best age data source, and age-rollups are performed with the use of the numerically calibrated lookup table.

Rock-type components are described hierarchically, with broadly grouped classifiers at the top level and progressive levels of ungrouping deeper in the database. The most general classifiers are sedimentary, volcano-sedimentary, volcanic, intrusive, crystalline-metamorphic, and tectonic. Most of the bedrock domains in the dataset have been classified to this level. These top-level classifiers are stored in a rock-type table that links directly to the master table (fig. 7). Different attribute types and different terms normally are used to describe each class in more detail and therefore are stored in separate tables one level further down in the database (fig. 7). The status qualifiers that indicate whether components are the only components in the unit (SIMPLE or MIXED), and whether they are described in more than one type of detail table (DUAL or DUAL/MIXED), are stored with the general rock group. Whereas a sedimentary component should lead to only one record in the sedimentary detail table, a primarily metamorphic component showing significant sedimentary attributes could be described in sedimentary as well as metamorphic terms by placing one record in each table. A volcano-sedimentary component also may have details in either or both of the sedimentary and volcanic detail tables. If a component requires more than one entry in one of these detail tables, then it should be recorded as more than one component.

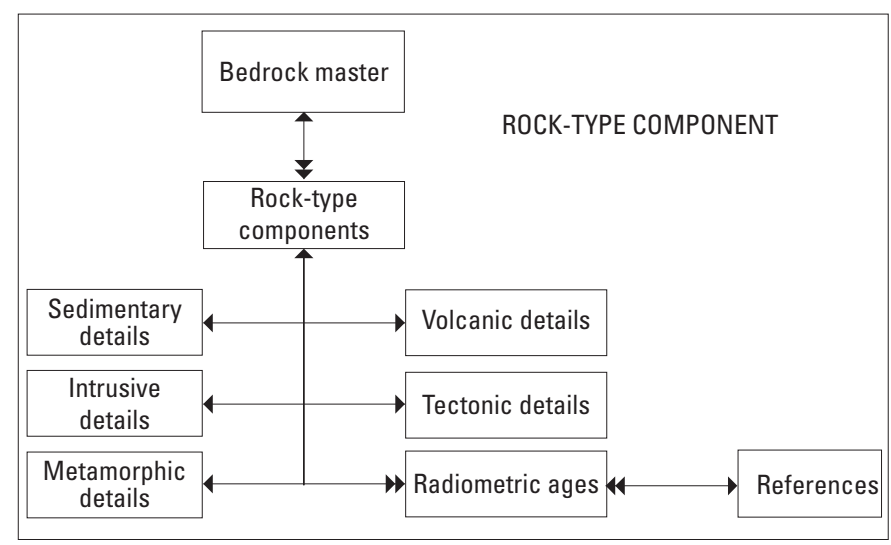

Figure 7. Schema for rock types.
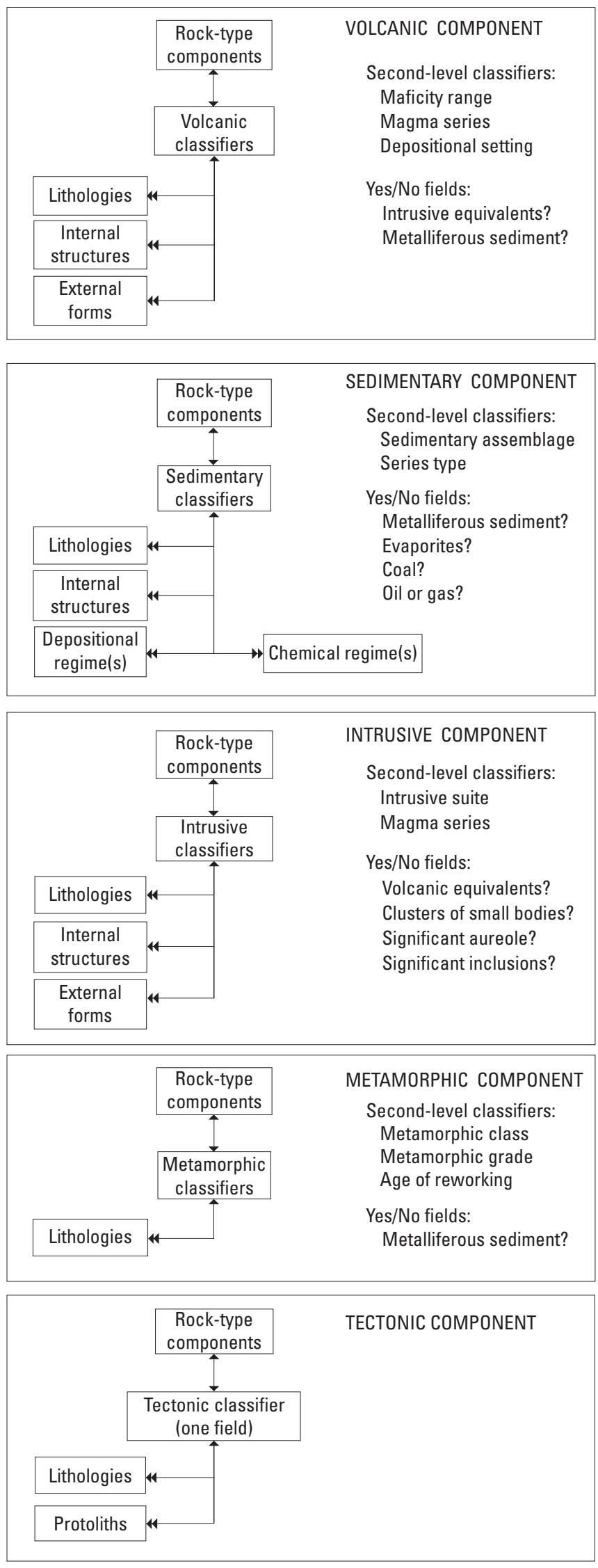

Figure 8. Schemas showing details for volcanic, sedimentary, intrusive, metamorphic, and tectonic rocks. 
The structures and contents of the five rock-type detail tables are illustrated in figure 8. The main second-level classifiers are chosen from commonly used terms, mainly of broadly compositional nature, and are single valued for each component. The second-level classifiers may be further qualified by multiple lithologies, depositional settings and chemical regime (sediments), internal structures, or external forms. Whether a volcanic component is mafic, intermediate, intermediatefelsic, felsic, or ultramafic commonly is depicted on geologic maps and constitutes the main second-level classifier. Information about predominant magma series and depositional setting can be entered into separate fields. Intrusive rocks may be compositionally complex and are best grouped in terms of broad suites, such as granite suite, granodiorite-tonalite suite, gabbro-diorite suite, or mafic-ultramafic suite. The term "monzonite suite," or the alternative term "quartz monzonitemonzogabbro suite" used to reflect a possibly broad compositional range, may be applied to a large number of Cordilleran intrusive complexes. There indeed will be overlap between terms, and geological judgment will be required at times to pick the most appropriate suite name.

Sedimentary rocks, which commonly are interbedded mixtures, have been the most difficult to classify broadly. The initial approach has been to identify significant sedimentary components named in generalized but familiar terms that are commonly found in general map legends. These terms are applied in the lateral sense to avoid nuances because it often is uncertain exactly how the terms were applied in the original data sources. The term "mudstone" includes shale; "conglomerate" includes breccia; "quartzite" includes quartz arenite; and "carbonate" includes limestone, dolomite, dolostone, and even marble if the sedimentary detail table is being used to describe a metamorphic rock. The terms for the most substantial components in the sedimentary assemblage then are strung together in an order set by the system, which keeps the list of possible values within reason. An alternative method is to record the significant presence of any of these components as Yes/No fields in a small index file, together with the Yes/No fields for presence of metalliferous sediment, evaporite, coal, and oil or gas. This method may make it easier for a compiler to enter the information, but it may be more awkward to query by using the generic query interface. In any case, even minimal sedimentary information is harder to acquire than shallow magmatic information; therefore, the sedimentary information will be relatively incomplete at the end of the project.

The tectonic setting parameters for each unit also are significant in a global context. These include the realm, overall deformation environment, and the tectonic element by name. These fields are duplicated in the new geotectonic provinces dataset and are explained under that heading in table 2.

In some cases, judgment must be exercised in deciding exactly how to enter the data from an input unit with more than one rock-type component. The production of default export datasets will be automated in batch by a program that applies a series of age and rock-type queries to the dataset, attributes a copy of the geospatial data to produce a flat file, and discards redundant contacts (fig. 9). For example, a unit of a certain general age may be described in the source explanation as being sedimentary but containing felsic volcanic components and dolerite dykes. If all components are included in one unit and it is tagged as a default, then the output rock type will be classified as sedimentary and volcanic rocks or sedimentary, volcanic, and intrusive rocks, depending on how many components are requested by the program. If the unit normally is viewed locally as overwhelmingly sedimentary, then it would be preferable to store the three components as separate units in the database, thus making the sedimentary unit the default, so that just sedimentary rocks would be assigned to the output rock type. This storage method would not preclude the use of the felsic volcanic component for a more specialized theme that emphasizes the maximum extent of felsic volcanism. There is now provision in the attribute data for approximate quantification at the master and rocktype levels that could be used to solve this problem, although very little of this information has been entered.

\section{Faults}

The fault data schema (fig. 10) is very similar to the bedrock schema. Major faults are notorious for focusing different types of displacement at during different periods of Earth history. Therefore, there may be more than one master record in the fault-attribute database for each fault feature (arc) in the geospatial data. Although each period of fault activity has one age range, the fault may have exhibited different displacement

Table 2. Explanation of the attributes of the geotectonic province dataset.

\begin{tabular}{ll}
\hline $\begin{array}{c}\text { Field } \\
\text { name }\end{array}$ & \multicolumn{1}{c}{ Explanation } \\
\hline Name & Geotectonic province name. \\
Basis & The type of activity that the province is defined to represent, such as sedimentation, sedimentation and deformation, or magmatism. \\
Realm & Realm of deposition, such as continental, oceanic, continental marginal, or ocean plate marginal. \\
Regime & Deformation regime descriptor, such as extensional, stable, or transpressional. \\
Element & Basic tectonic element class, such as arc, basin, platform, or orogenic belt. \\
Qualifier & Refinement of element class, such as back-arc, fore-arc, or foreland. \\
Start age & Start geologic age. \\
End age & End geologic age.
\end{tabular}



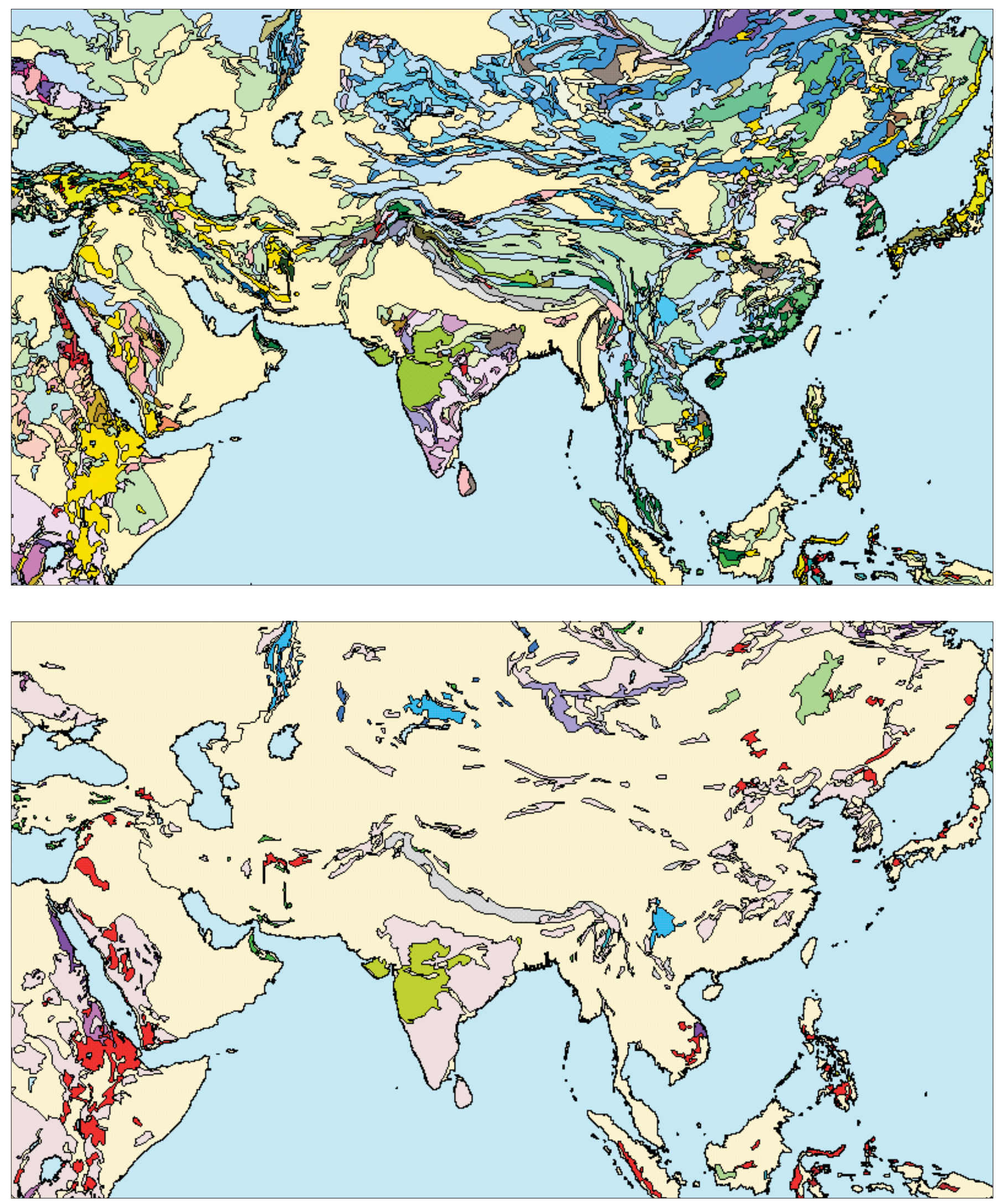

Figure 9. Maps showing alternative desktop geographic information system datasets derived from the generalized geology bedrock dataset. Default rock type (top) and mafic and (or) ultramafic intrusive and volcanic rocks (bottom), both subdivided by era-level age ranges. 
components during this period. For the purpose of this database, fault displacements are classified as overthrust or nappe, high-angle reverse, normal, strike slip, shear zone, or unknown. Displacement senses are chosen as the quadrant pointing toward the overriding sheet, the downdip subquadrant, or the rotational sense, depending on the class of fault. Name(s) and tectonic regimes are accommodated in exactly the same way as they are in the bedrock surface database. Despite the enhancement of the data framework for faults, it has not expanded greatly in content since Kirkham and others (1995) because it ranks below bedrock geology as a context for mineral deposits.

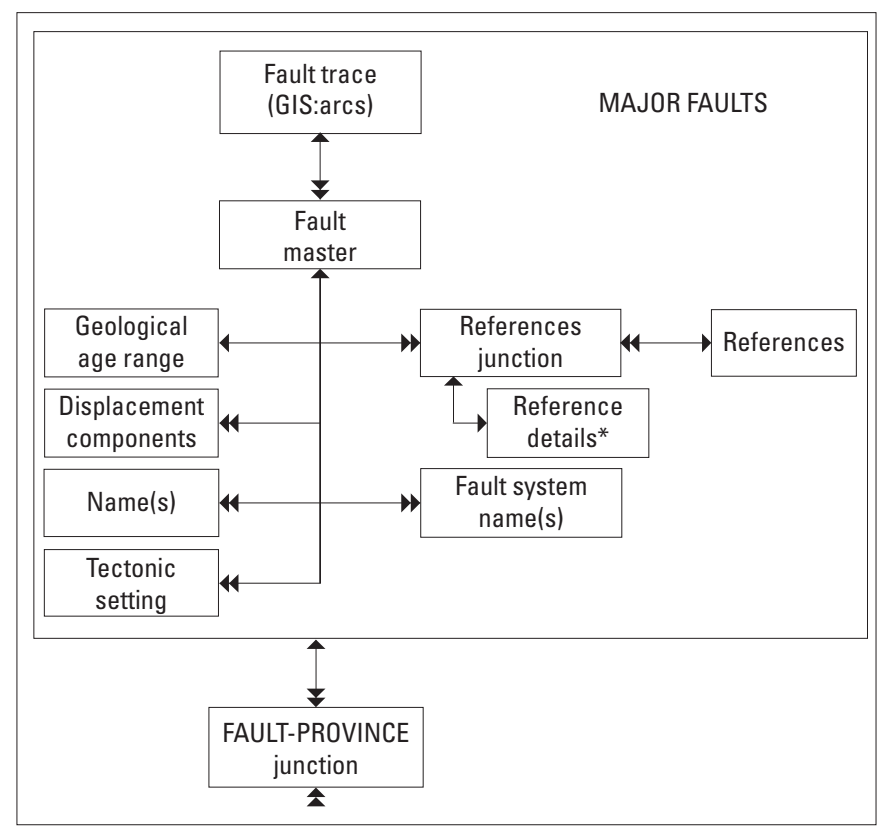

Figure 10. Schema for major faults. GIS, geographic information system.

\section{Geotectonic Provinces}

The geotectonic provinces dataset is in its early stages, and its schema still is undergoing refinement. It will contain information about basins, platforms, arcs, trenches, orogenic belts, and sutures. Data from the U.S. Geological Survey World Energy Project (Persits and others, 1997; Wandrey and Law, 1997; Steinshouer, and others, 1999) are being modified for the initial geospatial framework of world provinces. The emphasis in these source datasets is on petroleum basins. Therefore, the boundaries of the other province types will be redefined, and new province boundaries will be added.

The attributes that are being compiled for these provinces are name, basis of definition, realm, deformation regime, general element classifier, qualifier, start age, and end age table 2). Many provinces have undergone different types of tectonic activity over different periods of time, and some include the remnants of earlier, completely unrelated tectonic provinces. These complexities will be accommodated in the schema in the same way that they are accommodated for faults and bedrock domains. The tectonic provinces dataset can be linked to bedrock surface domains and faults through junction tables (fig. 5), but this will not be attempted in the near future.

\section{Discussion}

Members of the World Minerals Geoscience Database Project aspire to have a moderately comprehensive data framework on world geology and mineral deposits available to the public after 2002 and to provide a source of maps and visualization layers to support and communicate global mineral exploration strategy. Questions posed to the mineral deposit databases about timing, host rocks or related intrusions, and tectonic setting may be posed independently to the geology database to discover areas permissive for the occurrence of undiscovered mineral deposits and can lead explorationists to examine more detailed data sources for further clarification. Perhaps the most intriguing potential academic use for these data will involve extracting data subsets for mineral deposits, bedrock, faults, and geotectonic provinces for user-defined intervals of time. Software that manipulates GIS data for plate tectonic reconstruction is now available.

The subject matter of these data overlaps that of the larger scale metallogenic maps prepared for the Commission for the Geological Map of the World (CGMW), also being prepared now in GIS format (Veselinovic-Williams and others, 1999). In some ways, these data also may complement the CGMW datasets by providing generalized world overviews for visualization, and by incorporating subjective interpretation to a greater degree. Subjective interpretation that is not desirable for an official international map series (for example, Veselinovic-Williams and others, 1999) may be stimulating for visualization, provided that it is kept up to date.

The mineral deposit databases overlap the MRDS (Mineral Resources Data System) and MAS/MILS (Minerals Availability System/Minerals Industry Location System) databases of the U.S. Geological Survey (McFaul and others, 2000; U.S. Geological Survey, 2005), both in geological subject matter and global scope, but lack some of the administrative division information and provision for free-form comments available in MRDS and MAS/MILS. The datasets will be complementary, will be useful for cross-verification, and may be used to supplement one another for resource assessment applications, especially if some of the overlapping, generalized terminology were to be standardized between datasets.

The flexibility of the generalized geology dataset as a source of custom display output, as well as its high level of generalization, may make it useful in the communication of global resource assessment results. The dataset lacks the spatial resolution required for a final quantified global resource assessment but could provide test data while methods of automation are being refined. If it is used to supplement spatial information in areas for which greater detail is unavailable, then these areas must be cut out and reprojected because global projections misrepresent area values too grossly for any area-based analy- 
sis. On the other hand, the geotectonic province component of the database may be a useful starting point for the definition of metallogenic tracts (see also Nokleberg and others, 1997) in regions that have not yet been subjected to modern metallogenic study (Nokleberg and others, this volume).

\section{Acknowledgments}

We are grateful to Dr. Wayne Goodfellow for the constructive review, which resulted in improvement to this manuscript. We also thank the Geochronology Subsection, Continental Geoscience Division, Geological Survey of Canada, for advice regarding the handling of age ranges. We are grateful especially to our mineral deposit database compilers for their useful feedback and considerable patience. This paper is Geological Survey of Canada Contribution Number 2001004.

\section{References Cited}

Cox, D.P., and Singer, D.A., eds., 1986, Mineral deposit models: U.S. Geological Survey Bulletin 1693, 379 p. (Also available online at http://pubs.usgs.gov/bul/b1693/.)

Derry, D.R., 1980, World atlas of geology and mineral deposits: London, Mining Journal Books Ltd., 110 p.

Eckstrand, O.R., 1984, Canadian mineral deposit types-A geological synopsis: Geological Survey of Canada Economic Geology Report 36, 86 p.

Eckstrand, O.R., and Good, D.J., comps., 2000, World distribution of nickel deposits: Geological Survey of Canada Open File 3791a (19 p., 3 diskettes) and b (1 map, scale $1: 35,000,000)$.

Eckstrand, O.R., Sinclair, W.D., and Thorpe, R.I., eds., 1995, Geology of Canadian mineral deposit types: Geological Survey of Canada, Geology of Canada, no. 8, 640 p. (Also designated as v. P-1 of The geology of North America, a series by the Geological Society of America.)

Geological Survey of Canada, 1995, Generalized geological map of the world and linked databases: Geological Survey of Canada Open File 2915d, one CD-ROM.

Hannington, M.D., Petersen, Sven, Jonasson, I.R., and Franklin, J.M., comps., 1994, Hydrothermal activity and associated mineral deposits of the seafloor: Geological Survey of Canada Open File 2915c, 1 map, scale 1:35,000,000.

Harland, W.B., Armstrong, R.L., Cox, A.V., Craig, L.E., Smith, A.G., and Smith, D.G., 1990, A geologic time scale, 1989: New York, Cambridge University Press, 263 p.
Jenkins, C.L., and Lydon, J.W., 2002, A mineral deposit data base structure and a data base of VMS and sedex deposits: Geological Survey of Canada Open File 4165, one CDROM.

Jenkins, C.L., Vincent, Raynald, Robert, François, Poulsen, K.H., Garson, D.F., and Blondé, J.A., comps., 1997, Indexlevel database for lode gold deposits of the world: Geological Survey of Canada Open File 3490, 18 p., 1 diskette.

Kirkham, R.V., Carrière, J.J., Laramée, R.M., and Garson, D.F., comps., 1994, Global distribution of sediment-hosted stratiform copper deposits and occurrences: Geological Survey of Canada Open File 2915b, 1 map, scale 1:35,000,000.

Kirkham, R.V., Chorlton, L.B., and Carrière, J.J., comps., 1994, Generalized geology of the world; Rock type, age/era remains: Geological Survey of Canada Open File 2915a, 1 map, scale 1:35,000,000.

Kirkham, R.V., Chorlton, L.B., and Carrière J.J., comps., 1995, Generalized geology of the world, in Geological Survey of Canada, Generalized geological map of the world and linked databases: Geological Survey of Canada Open File 2915d, CD-ROM.

Kirkham, R.V., and Dunne, K.P.E., comps., 2000, World distribution of porphyry, porphyry-associated skarn, and bulk-tonnage epithermal deposits and occurrences: Geological Survey of Canada Open File 3792a (26 p., 1 diskette) and 3792b (map, scale 1:35,000,000). (An updated (2003) version of this database is available online at http://gdr.nrcan.gc.ca/minres/metadata_e.php?id=6.)

McFaul, E.J., Mason, G.T., Jr., Ferguson, W.B., and Lipin, B.R., 2000, U.S. Geological Survey mineral databasesMRDS and MAS/MILS: U.S. Geological Survey Digital Data Series DDS-52, two CD-ROMs.

Nokleberg, W.J., Bundtzen, T.K., Dawson, K.M., Eremin, R.A., Goryachev, N.A., Koch, R.D., Ratkin, V.V., Rozenblum, I.S., Shpikerman, V.I., Frolov, Y.F., Gorodinsky, M.E., Melnikov, V.D., Diggles, M.F., Ognyanov, N.V., Petrachenko, E.D., Petrachenko, R.I., Pozdeev, A.I., Ross, K.V., Wood, D.H., Grybeck, Donald, Khanchuk, A.I., Kovbas, L.I., Nekrasov, I.Y., and Sidorov, A.A., 1997, Significant metalliferous and selected non-metalliferous lode deposits and placer districts for the Russian Far East, Alaska, and the Canadian Cordillera: U.S. Geological Survey Open-File Report 96-513-B, one CD-ROM.

Okulitch, A.V., 1995, Geological time chart, 1995: Geological Survey of Canada Open File 3040, 1 sheet. 
Persits, F.M., Ulmishek, G.F., and Steinshouer, D.W., 1997, Maps showing geology, oil and gas fields and geologic provinces of the former Soviet Union: U.S. Geological Survey Open-File Report 97-470-E, one CD-ROM. (Also available online at http://pubs.usgs.gov/of/1997/ofr-97-470/ OF97-470E, )

Plumb, K.A., 1991, New Precambrian time scale: Episodes, v. 14 , no. 2 , p. 139-140.

Steinshouer, D.W., Qiang, Jin, McCabe, P.J., and Ryder, R.T., comps., 1999, Maps showing geology, oil and gas fields, and geologic provinces of the Asia Pacific region: U.S. Geological Survey Open-File Report 97-470-F, one CD-ROM. (Also available online at http://pubs.usgs.gov/of/1997/ofr97-470/OF97-470F,)
U.S. Geological Survey, 2005, Mineral Resources Data System: Reston, Va., U.S. Geological Survey database available online at http://tin.er.usgs.gov/mrds.

Veselinovic-Williams, Milica, Hammerbeck, E.C.I., and Wolmarans, L.G., comps., 1999, 1:5000 000 international digital metallogenic map of Africa, sheets $5 \& 6$ (south of the Equator): Pretoria, South Africa Council for Geoscience and Commission for the Geological Map of the World, scale 1:5,000,000, one CD-ROM, introductory leaflet. (A printed map was published in 2002 on 3 sheets.)

Wandrey, C.J., and Law, B.E., 1997, Maps showing geology, oil and gas fields and geologic provinces of South Asia: U.S. Geological Survey Open-File Report 97-470-C, one CD-ROM. (Also available online at http://pubs.usgs.gov of/1997/ofr-97-470/OF97-470C.) 


\title{
Status of Metallogenic Mapping in the World Today- With Special Reference to the Digital Metallogenic Map of Africa
}

\author{
By Erik Hammerbeck ${ }^{1}$ and Milica Veselinovic-Williams ${ }^{2}$
}

\section{Historical Background}

Although the study of mineral deposits has preoccupied geologists since the very beginnings of the earth sciences, the concept of metallogeny is less than 100 years old; the term was coined by Louis Auguste de Launay in 1913 (quoted by Lindgren, 1933). The debate on what the concept of metallogeny means by definition and in terms of contemporary geological theory, how it should be depicted on maps, and how it can be used as an exploration tool has largely subsided (Lindgren, 1933; Turneaure, 1955; Petrascheck, 1965; Guild, 1971, 1972, 1974; Routhier, 1983; Guilbert and Park, 1986). Today there is some convergence toward two dominant schools of thought regarding metallogenic maps, the French and northern American. There are, however, equally as many exceptions or adaptations to these two approaches, as for example in the recent maps produced in the United Kingdom, Australia, and Canada. A third type of metallogenic map, exemplified by Russian maps of the Soviet era, has found less acceptance in view of the complexity of their legends, although some examples of this type have been published only very recently for Angola and Mozambique. Consensus on the matter of how best to present metallogenic information is unlikely ever to be reached, although it would help the cause of global resource assessment tremendously.

We advocate the French legend for its simplicity (the symbols are easy to relate to), its descriptiveness (being largely factual rather than interpretive), and the cartographic clarity of representation. One of the best examples is the "International Mineral Deposits Map of Africa," of which only sheet 1 was published (Emberger, 1991). Emberger's map legend, which was used as the basis for the "International Digital Metallogenic Map of Africa" (VeselinovicWilliams and others, 1999), can be converted into geographic information system (GIS) format with only minimal adaptations, and it was found to lend itself perfectly to metallogenic modeling.

${ }^{1}$ Deceased; formerly President of the Subcommission for Metallogenic Maps of the Commission for the Geological Map of the World (CGMW).

${ }^{2}$ Council for Geoscience, Private Bag x112, Pretoria 0001, South Africa.

\section{Metallogenic Maps-Culmination of Data Synthesis}

Invariably, metallogenic maps are complex, portraying a multitude of data on current knowledge about geological processes that may have contributed to the formation of mineral deposits. As such, they represent a most valuable store of information about the mineral potential of countries, regions, or continents. In this point lie both their strength and their Achilles' heel. One might expect that metallogenic maps would be regarded as being indispensable tools for mineral exploration, land use planning, teaching, and research in economic geology, but often that does not seem to be the case.

One reason is that metallogenic maps are generally far too complex to be useful for non-geoscientist planners and decisionmakers. Another is that comprehensive maps can be compiled only for regions where the geology is well understood and which are reasonably well explored, often at a time long after exploration activities have passed. So, if metallogenic maps indeed come too late, so to speak, to be indispensable tools for mineral exploration, or remain grossly undervalued in land use planning and even by the geological community at large, what is their worth?

The obvious answer lies in regional or global mineral resource assessments. Without the systematic collation and synthesis of mineral-resource data embodied in metallogenic maps, it is not possible to arrive at a meaningful overview of the mineral potential of a country or region. As a result, a large number of metallogenic and related mineral maps have been published over the past three or four decades on national, regional, or continental scales. To provide a review of the worldwide availability of such maps is beyond the scope of this paper. Whereas large- and medium-scale metallogenic maps (up to 1:250,000) continue to serve a useful purpose to synthesize and document details of selected mineralized terranes, maps at scales of 1:1,000,000 and smaller lend themselves best to metallogenic analysis.

Mineral exploration is an iterative process and, as making new discoveries becomes ever more difficult, success depends very much on acquiring and applying new knowledge in innovative ways. For this reason, it must be stressed that it is in the interest of countries, regions, or continents with emerg- 
ing mining industries to produce metallogenic maps that are topical and timely to attract mining investment, which remains one of the pillars of economic development.

On a global scale, the Commission for the Geological Map of the World (CGMW), and more precisely its Subcommission for Metallogenic Maps, endeavors to promote this cause through international collaborative projects. Presently, projects carried out under its auspices include the international metallogenic maps of Africa and of South America, both at 1:5 million scale, and it is a goal to add a map of the Middle East to this series. In addition, a new thematic global map of exceptionally large mineral deposits is being compiled at a scale of 1:25 million, primarily by a joint Chinese-Russian research project. A large database on the deposits included on this map is being compiled at the Vernadtsky State Geological Museum in Moscow. The effort to understand exceptionally large mineral deposits may benefit from current Russian research on the role of deep crustal structures (Konstantinov and others, 1999).

\section{Metallogeny in the Information Age}

The electronic media have changed the nature of metallogenic maps during the last decade or so. Since the early 1980s, many geological surveys have started to develop mineral deposit databases, and today GIS and digital mapmaking are commonplace. More important, however, is the ability to exchange data and to integrate the information, more or less at will, with other datasets. In addition, GIS technology brings the power to query and manipulate data and to produce any number of customized products for a multitude of research and consumer needs. Much of the power of present-day metallogeny, therefore, lies in access to digital data sources that enable users for the first time ever to create their own innovative derivative products.

Restrictions on access to data and information and copyright issues, however, often inhibit this process. Clear distinctions must be drawn here between legal copyright issues and self-imposed restrictions to protect partisan interests. According to Gueiros (2000), the availability of intellectually protected documents on the World Wide Web is causing a legal revolution, in that new rules must be developed on how to regulate intellectual property in cyberspace.

In an attempt to promote the free exchange of data and information, it may help to clearly define the issues at stake and to recognize that-

- Copyright can apply only to intellectual property. In other words, copyright applies only to definitive information products that express specific interpretations or viewpoints at the time when that product was generated. At present, copyright is governed by the Berne Convention on authors' rights (United Nations, World Intellectual Property Organization, 1979) and the copyright legislation of various countries.
- Copyright is vested in the source of that information product; for example, the institution or author of the product or in the client in terms of a commercial agreement.

- Data are neither a product in their own right, nor can data be regarded as intellectual property.

- Data and information are tradeable commodities, but they are not free when classified as confidential and thus specifically protected and restricted.

The "International Digital Metallogenic Map of Africa" (Veselinovic-Williams and others, 1999) is a case in point. Comprehensive electronic data have been compiled from published nonproprietary hardcopy information, from data received directly or indirectly from every geological survey of Africa participating in this project, and from other data sources. While the CD-ROM containing these data is being sold at a nominal cost to defray expenses, it is copyright protected, meaning the data may not be resold. The users who have acquired the data, however, are permitted to utilize it to their best advantage, to merge it with other data sources, or to create any number of new information products. It is anticipated that, in the near future, a fully compatible global database can be compiled using the new standard established for metallogenic mapping and with the added ability to seamlessly integrate the African data with data for South America and, eventually, with data for the Middle East.

\section{The Metallogenic Map of Africa as a Deposit Modeling Tool}

The "International Digital Metallogenic Map of Africa" (Veselinovic-Williams and others, 1999), and particularly the Metallogenic Map of Africa (MMA) database that was created, is ideally suited to describe the essential attributes of all mineral deposits of Africa. This use not only greatly facilitates the description of definitive ore deposit types but also helps scientists to understand their genetic association and their comparison in space and time.

The MMA is based on an advanced GIS data model, comprising various data layers (coverages) carrying the pertinent data on which the parameters for descriptive and genetic deposit models can be defined, as summarized in tables 1 and 2. It is a modern, relational database developed in Corel Paradox and is fully compatible with Oracle, ArcInfo, ArcView, and similar application software.

Although genetic deposit model type data are not carried in the database because of their subjective nature, such models can be easily derived from the available data by association, combination, and interpolation of the various data elements and parameters. Metallogenic analysis is facilitated by predefined parameters, as shown in table 3 . 
Table 1. The database model of the Metallogenic Map of Africa database.

[The Metallogenic Map of Africa (MMA) database was created during compilation of the "International Digital Metallogenic Map of Africa" (VeselinovicWilliams and others, 1999)]

\begin{tabular}{|l|l|l|l|}
\hline \multicolumn{1}{|c|}{ Coverages } & \multicolumn{1}{|c|}{ Attribute tables } & Standard tables & Cartographic tables \\
\hline GMS & Lithology, chronostratigraphy & $\begin{array}{c}\text { Numerous lookup tables to standardize } \\
\text { and validate data entries. }\end{array}$ & $\begin{array}{l}\text { Numerous tables defining the symbology, hatchings, } \\
\text { colors, and text to be used for map outputs. }\end{array}$ \\
\hline GME & Geotectonic environment & & \\
\hline GMO & Orogeny & & \\
\hline GSL & Geological structures & & \\
\hline MDP & Mineral deposits & & \\
\hline
\end{tabular}

Table 2. The Metallogenic Map of Africa database structure, with some examples.

[The Metallogenic Map of Africa (MMA) database was created during compilation of the "International Digital Metallogenic Map of Africa" (Veselinovic-Williams and others, 1999)]

\begin{tabular}{|c|c|c|c|}
\hline \multicolumn{3}{|c|}{ Geological data (with examples) } & \multirow{2}{*}{\begin{tabular}{|l|}
\multicolumn{2}{|c}{ Mineral deposit data } \\
Latitude/longitude \\
\end{tabular}} \\
\hline Coverage and specific item & Lookup table & Code & \\
\hline \multicolumn{4}{|l|}{ GMS } \\
\hline Polygon key & & 12S (Gweru) Greenstone belt & Deposit number \\
\hline Chronostratigraphy & GMS & MARC & State or country \\
\hline Lithology & LIT & BASLT & Commodities present $(1,2,3)$ \\
\hline Lithology qualifier & LILA & GBELT & Deposit size (according to size classification) \\
\hline \multicolumn{3}{|l|}{ GME } & Deposit name \\
\hline Polygon key & & $2 \mathrm{E}$ & Deposit status (active, dormant, occurrence) \\
\hline Environment & GME & OROG & Deposit shape and orientation \\
\hline \multicolumn{3}{|l|}{ GMO } & Host-rock lithology \\
\hline Polygon key & & $3 \mathrm{AO}$ & Host-rock lithostratigraphic name and age \\
\hline Main orogeny & GMO & MGND & Ore genesis \\
\hline Main orogeny age & GMO & 2 to $1.8 \mathrm{Ga}$ & Ore mineralogy \\
\hline 2 d orogeny & SCO & ZMBZ & Resources and production \\
\hline $2 \mathrm{~d}$ orogeny age & SCO & 1 to $0.5 \mathrm{Ga}$ & Comments \\
\hline
\end{tabular}

Table 3. Selected parameters in the Metallogenic Map of Africa database to facilitate deposit modeling and metallogenic analysis.

[The Metallogenic Map of Africa (MMA) database was created during compilation of the "International Digital Metallogenic Map of Africa" (Veselinovic-Williams and others, 1999)]

\begin{tabular}{lll}
\hline \multicolumn{1}{c}{ Geological data } & \multicolumn{1}{c}{ Physical and other data } & Genetic criteria \\
\hline Chronostratigraphic classification & Commodities present $(1,2,3)$ & Magmatic: \\
Host-rock lithology & Shape (morphology) of deposit & • Intrusive \\
Host-rock environment: & Size classification & - Extrusive \\
- Continental & Status (active, dormant, occurrence) & Hydrothermal \\
- Paralic & Mineralogy of ore & Sedimentary \\
- Marine & Mineralization age & Diagenetic \\
- Plutonic & & Pedogenic \\
- Orogenic* & & Metamorphic \\
\hline *Orogenic name and age. & &
\end{tabular}




\section{Precambrian African Metallogeny- Unlimited Deposit Modeling Options}

The African continent has had a complex geologic and orogenic history, too diverse for a detailed discussion in this paper. The interested reader is referred to the many benchmark books and papers, including those by Cahen and others (1984), Petters (1991), Milesi and others (1992), Windley (1995), and De Wit and Ashwal (1997). Here we attempt only to highlight some important metallogenic aspects, based on views generated from the MMA database, which presents countless modeling scenarios.

\section{Archean}

The Archean rocks in Africa (fig. 1) consist of various lithologic assemblages in greenstone belts and high-grade metamorphic terranes. Greenstone belts consist of thick volcanosedimentary sequences that have mostly experienced low-grade metamorphism but that have reached granulite facies locally (De Wit and Ashwal, 1997). The belts represent supracrustal cover to the granitic basement rocks, which originated in three Archean magmatic stages: (1) 3.5-3.2 Ga, tonalite/trondhjemite gneisses, (2) 3.2-2.7 Ga, porphyritic migmatite/gneiss, and (3) 2.8-2.5 Ga, syn- to post-orogenic granites.
Of particular metallogenic interest are the Archean greenstone terranes of the Kaapvaal, Zimbabwe, Kivu-Democratic Republic of the Congo (DRC)-West Nile, Tanzania, NtemChaillu, Leo-Man, and Reguibat metallogenic provinces ffig. 11), as described in various papers in De Wit and Ashwal (1997). Mineral deposits associated with greenstone belts include gold, antimony, iron, chromium, nickel-copper, and copper-zinc. Figure 2 shows the classic Zimbabwe craton, in which various ages of greenstone formation have been identified, each with its own metallogenic characteristics. The lowermost ultramafic units of some of these greenstone belts contain significant deposits of chromite, nickel-copper, and chrysotile asbestos (for example, Selukwe, Empress, and Shangani deposits).

Gold is widely distributed in all the Archean greenstone belts of the continent (Foster and Piper, 1993). Historically, the most productive and best developed gold deposits have been those in the Kaapvaal and Zimbabwe cratons. However, at present, the focus is on Tanzania, where numerous new gold deposits have recently been discovered (De Klerk, 2001). Further gold discoveries can be expected in other terranes having lesser known, but locally important, Archean gold deposits once these areas become more accessible to exploration. The Ituri belt of the DRC (de Kun, 1963), including Kilo-Moto, and the Gabon craton are examples of such potentially very important terranes. In general, gold is concentrated in struc-

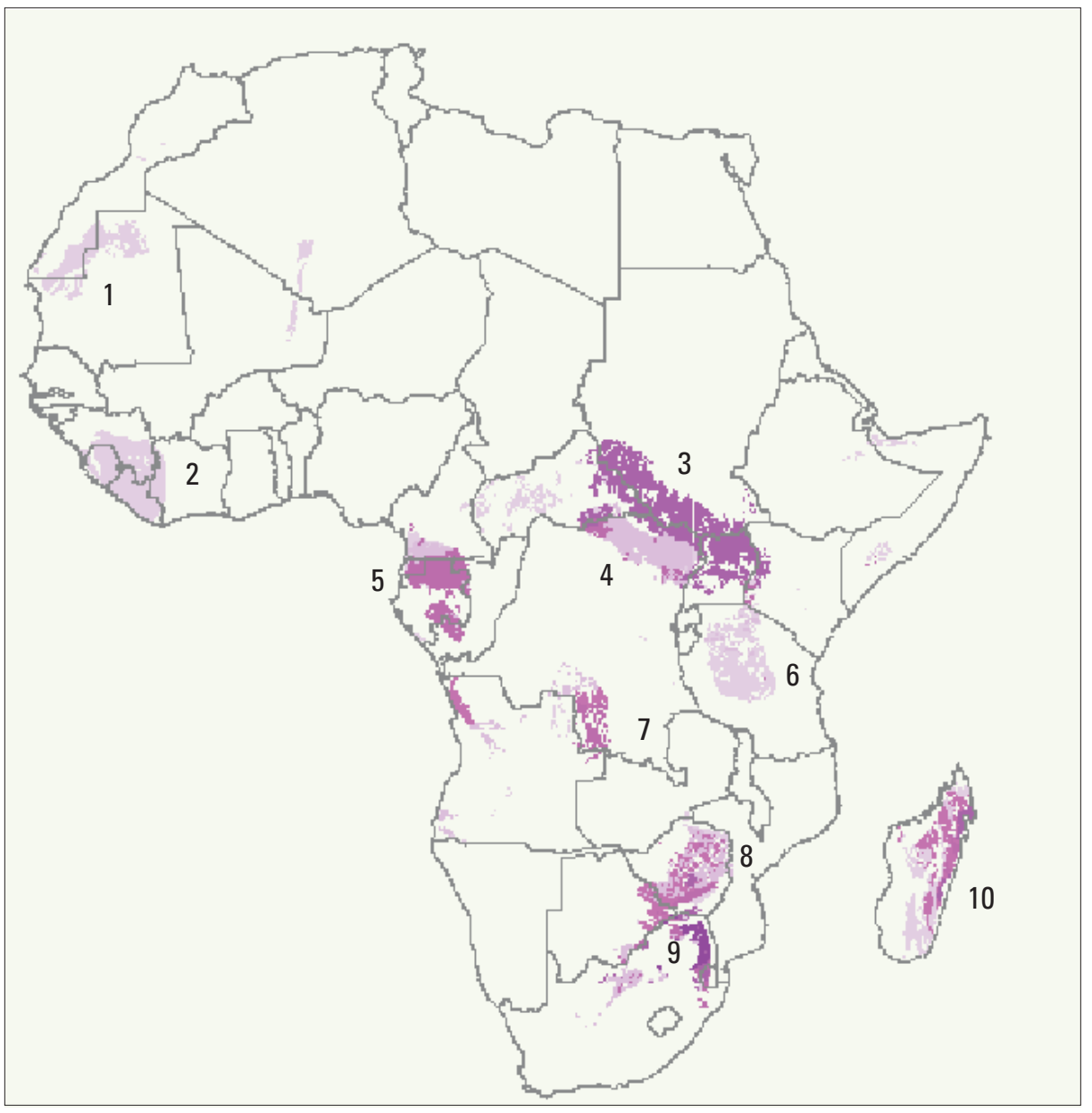

Figure 1. Map showing Archean cratonic terranes (purple areas) of Africa: 1, Reguibat; 2, Leo-Man; 3, West Nile; 4, Kivu-Democratic Republic of the Congo (DRC); 5, NtemChaillu; 6, Tanzania; 7, Kasai; 8, Zimbabwe; 9, Kaapvaal; 10, Antongilian. Map was derived from the Metallogenic Map of Africa (MMA) database, which was created during compilation of the "International Digital Metallogenic Map of Africa" (Veselinovic-Williams and others, 1999). 


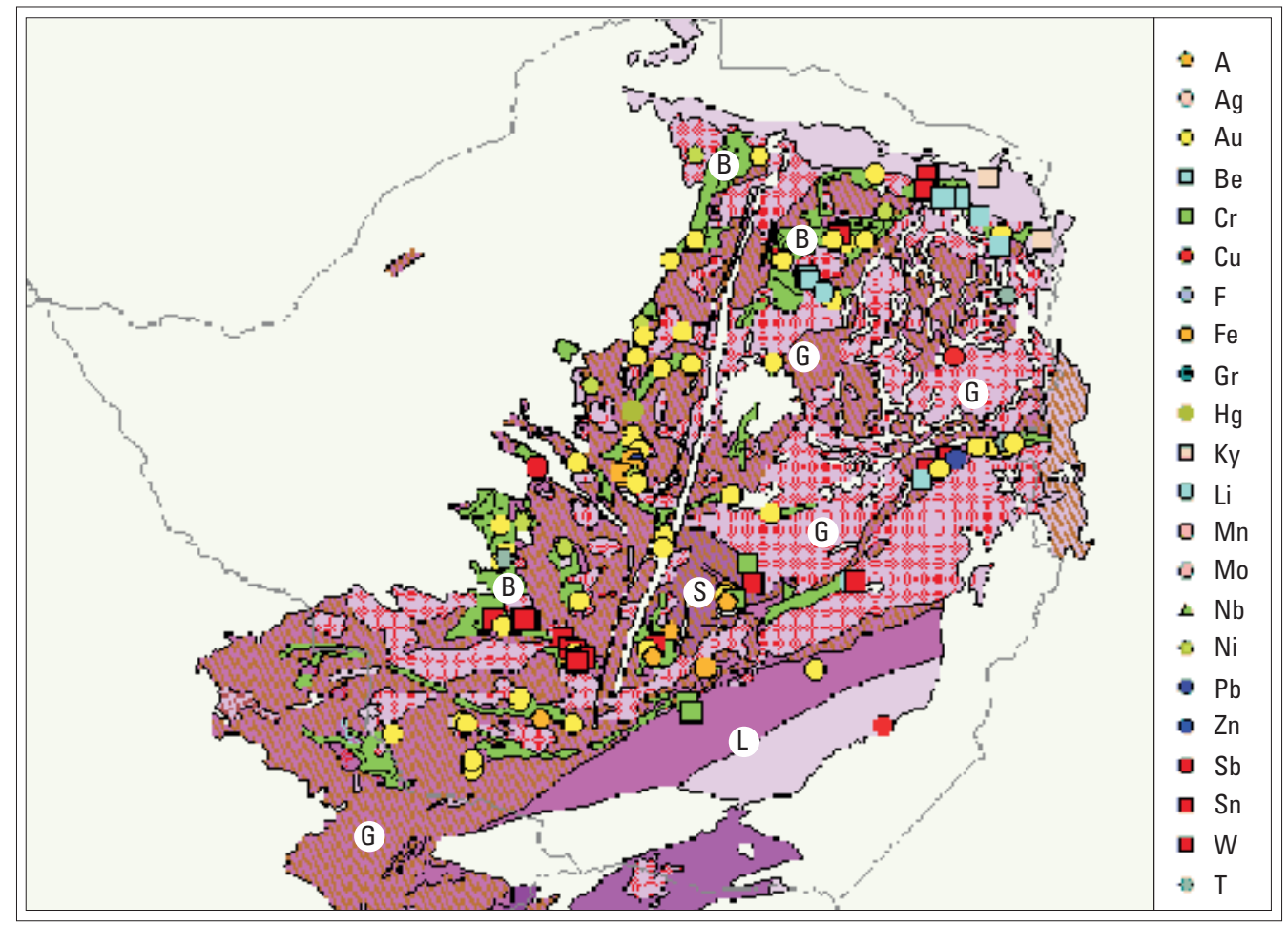

Figure 2. Map showing the Zimbabwe craton (colored areas), the main elements of which include the Sebakwean Group (S) (3.6 Ga), the Bulawayan Supergroup (B) $(2.8-2.7 \mathrm{Ga})$, various associated syntectonic and posttectonic gneisses and granites $(G)$, and the Limpopo belt (L). Map was derived from the Metallogenic Map of Africa (MMA) database, which was created during compilation of the "International Digital Metallogenic Map of Africa" (VeselinovicWilliams and others, 1999). turally controlled vein deposits that cut basic to intermediate igneous rocks in the marginal and stratigraphically upper parts of the greenstone belts.

Algoma-type iron formations, associated with the volcanic successions of many greenstone belts, are chemical sediments formed by subaqueous volcanogenic exhalations. Locally, the iron formations constitute economic deposits of iron; for example, Buchwa in Zimbabwe and Nimba in Liberia.

Cratonized lithospheric plates developed during the late Archean in South Africa. This development led to the widespread formation of sedimentary basins, platform sediments, and continental-margin troughs and foreland basins at a time when greenstone belts were still forming farther north in Africa and elsewhere (in the time span 3.0-2.6 Ga). Examples on the Kaapvaal craton include the Dominion Group (3.075 $\mathrm{Ga}$ ) and the Pongola ( 2.9 Ga), Witwatersrand ( 2.9-2.8 Ga), and Ventersdorp (2.62 Ga) Supergroups. Primary syndepositional placer-type gold-uranium mineralization was deposited in the intracratonic Witwatersrand basin, South Africa, and is unique in that it was coeval with a worldwide event of basic to ultrabasic submarine volcanism associated with Late Archean greenstone belts. Three postdepositional events are recognized during which the ores were reconstituted and enriched. These are dated at 2,550 Ma, 2,300 Ma, and 2,000 Ma (Robb and Robb, 1998).

Important mineral deposits associated with pegmatites occur in the granitic terranes of the Zimbabwe craton (for example, Bikita) and the Kaapvaal craton (for example, the Mopane and Mica fields). These include deposits of tin, tungsten, tantalum, niobium, lithium, mica, and beryllium.

\section{Paleoproterozoic}

During the Paleoproterozoic (2.5-1.6 Ga), many events affected metallogenesis; the following events are the most noteworthy in terms of their metallogenic significance (Olson, 2000):

- Repeated platform sedimentation and volcanism, notably the Francevillian of Gabon, the Luizien of the DRC, and the Transvaal, Magondi, and Kheis of southern Africa.

- Anorogenic magmatism, associated with formation of features such as the Great Dyke, the Bushveld Complex, and the Kunene Complex, all of which resulted from tensional conditions subsequent to the stabilization of the cratons or from a combination of tectonothermal events linked to accretionary processes.

- The development of accretionary and collisional orogens of the Ubendian/Rusizian (central and southern Africa) and the Birimian of West Africa.

Evolutionary changes in the Earth's atmosphere, hydrosphere, and biosphere during this time had a major influence on processes leading to metal accumulation. Intracratonic basins that formed during this time host important stratabound iron, manganese, asbestos, and copper mineralization. Enriched Superiortype iron formations occur in South Africa (for example, Sishen and Thabazimbi), Angola (Cassinga), Mozambique (Honde), and Gabon (Belinga). The deposits of Moanda (Gabon) and the Kalahari (South Africa) constitute the world's largest resources of manganese. One of the first appearances of stratabound sedimentary copper mineralization occurs at several stratigraphic levels within the thick sequence of early Proterozoic rocks of the 
Piriwiri-Lomagundi basin, northwestern Zimbabwe (for example, Mangula, Shackleton, Alaska, and Shamrocke).

Of great metallogenic importance are the anorogenic basic to ultrabasic intrusions, including the Great Dyke (Zimbabwe), which formed at $2.5 \mathrm{Ga}$, and the Bushveld Complex (South Africa), now tightly constrained at $2.05 \mathrm{Ga}$, as well as the Molopo (Botswana), Atchiza (Mozambique), and Kunene (Namibia-Angola) complexes. The Great Dyke and the Bushveld Complex, in particular, host very large economic deposits of chrome, platinum-group elements, iron, titanium, vanadium, and nickel-copper mineralization. The copper-rich Phalaborwa carbonatite $(2.05 \mathrm{Ga})$ and the much younger Premier diamondiferous kimberlite pipe $(1.15 \mathrm{Ga})$ are both manifestations of extensional tectonic regimes prevalent within the thick, stable Kaapvaal craton since the late Archean. The greater Kaapvaal craton (including its younger accreted additions) seems to have been exceptionally well suited for the subsequent development of diamondiferous kimberlites, and it has a significant region of diamond formation in its structural root.

The Birimian belt of West Africa formed at 2.2-2.0 Ga and represents a series of juvenile, accreted terranes (Milesi and others, 1992). These terranes consist of supracrustal belts very similar to Archean greenstone belts and contain basaltic pillow lava flows, andesitic to dacitic pyroclastic rocks and lava flows, volcanogenic turbidites, and manganiferous cherts, as well as flysch-type turbidites. All these rocks were metamorphosed to greenschist facies and intruded by peraluminous granitic plutons. A great variety of mineral deposits occurs in the Birimian greenstone belts, especially gold, manganese, iron, and small but economic lead, copper, antimony, silver, nickel, cobalt, tin, and tungsten deposits. The following genetic types of gold mineralization have been recognized: mesothermal load (Ashanti, Prestea, Marlu, all in Ghana), tourmalinized turbidite sandstone (Loulo, Mali), quartz veins with native gold (Poura, Bouroum, Guiro, all in Burkina Faso), shear-zone-hosted disseminated (Bogosu, Konogo, Ghana), intrusive disseminated (Ayenfuri, Ghana), porphyry coppergold (Diénémera, Burkina Faso), and paleoplacers (Tarkwa, Ghana).

Collisional mobile belts such as the Ubendian-Rusizian (1.8-2.0 Ga) and Toro of eastern Africa are generally poorly mineralized. An exception is the important stratiform syngenetic copper-cobalt deposit at Kilembe in the Toro Supergroup, Uganda. Hydrothermal deposits of lead (Mukwamba), copper (Lufusi), and gold (Lupa district) occur in Tanzania, related to late-orogenic Ubendian igneous activity.

\section{Mesoproterozoic}

The Mesoproterozoic (1.6 Ga-950 Ma) was marked by one of the most distinctive orogenic events in Africa, which is known as the Kibaran orogeny (1,400-950 Ma); figure 3 shows the regional distribution of rocks formed during this orogeny (the Kibaran metallogenic province or belt), including the Irumide, Nampula, and Namaqua-Natal belts. Pohl (1994) and Olson (2000) linked the metallogeny of the Kibaran to a series of events related to rifting, sedimentation, magmatism, metamorphism, and tectonic deformation. The crosscutting

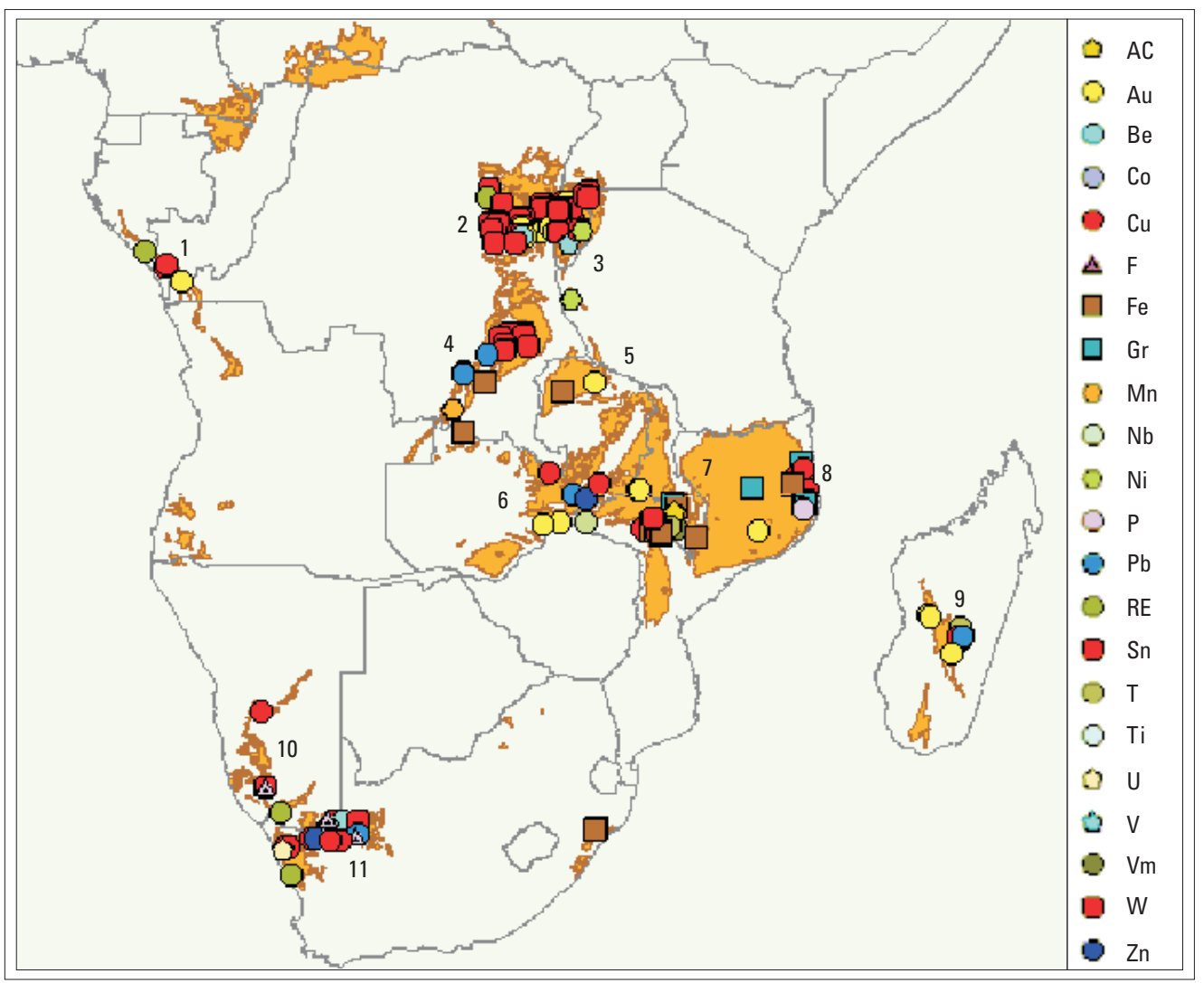

Figure 3. Map showing the Mesoproterozoic Kibaran metallogenic province (orange areas) of central and southern Africa. Numbered belts: 1, Mayombe; 2, Burundian; 3, Karagwe-Ankolean; 4, Shaba; 5, Mporokoso; 6 , Zambia (including the Irumide belt); 7, Malawi; 8, Nampula; 9, Madagascar; 10, Sinclair; 11, NamaquaNatal. Map was derived from the Metallogenic Map of Africa (MMA) database, which was created during compilation of the "International Digital Metallogenic Map of Africa" (Veselinovic-Williams and others, 1999). 
nature of the Kibaran belt with the Ubendian-Rusizian belt and the fact that it is also flanked by Archean massifs to the east and west support the contention that the Kibaran belt developed intracratonically. Mineralization within the different parts of the Kibaran belt differs markedly. The intracratonic Kibaran belt of central Africa, for example, defines a major tin (-tungsten) province in the northern DRC, Burundi, and Rwanda. Tin and tungsten tend to occur in quartz veins associated with lateorogenic granitic intrusions. Beryllium, columbo-tantalite, and lithium ores occur in pegmatite zones close to, but separated from, the hydrothermal tin-tungsten mineralization.

The Kibaran-age Irumide belt defines a red-bed-type copper province in a rift-bounded succession of mainly clastic sedimentary rocks, extending discontinuously from Ghanzi in northwestern Botswana to Witvlei and Klein Aub in Namibia. Sedimentary-exhalative massive sulfide mineralization (copper, lead-zinc, silver) occurs in Namaqualand (Aggeneys, Broken Hill, Gamsberg). Volcanogenic exhalative base-metal deposits are found in a long north-south-trending belt adjacent to the western margin of the Kaapvaal craton. The nowdefunct Prieska copper-zinc deposit, like the other deposits in the belt, is stratabound in a basic metavolcanic unit composed mainly of amphibolites and amphibole gneisses.

\section{Neoproterozoic and Early Paleozoic}

The Pan-African tectonothermal event affected much of Africa during the Neoproterozoic and early Paleozoic in the period from at least $950 \mathrm{Ma}$ to about $450 \mathrm{Ma}$ (fig. 4). The PanAfrican belts developed through a complex sequence involving an initial rifting phase with related sedimentation and magmatism, followed by ocean opening, subduction and plate collision, and postcollisional magmatism. The Katanga belt (Zambia and DRC) forms a broad curved zone of deformed sedimentary rocks, known as the Lufilian arc, which host major copper (-cobalt) deposits. These deposits are confined to specific shale or conglomerate horizons, which may represent a rift-bounded succession. Apart from copper and cobalt, other significant deposits in the Copperbelt contain uranium-gold (Shinkolobwe, DRC) and lead-zinc-copper-cadmium (Kipushi, DRC).

The Damara Supergroup (Miller, 1983; Pirajno, 1998) in Namibia is dated at 900-600 Ma and is one of the best developed orogenic belts in Africa. It is composed of a northern arm (Kaokoland) and a southern arm (Gariep), both of which have undergone full Wilson cycles, and a northeast-trending intracratonic rift zone, all of which carry important mineralization (fig. 5). The Matchless amphibolite is closely associated with

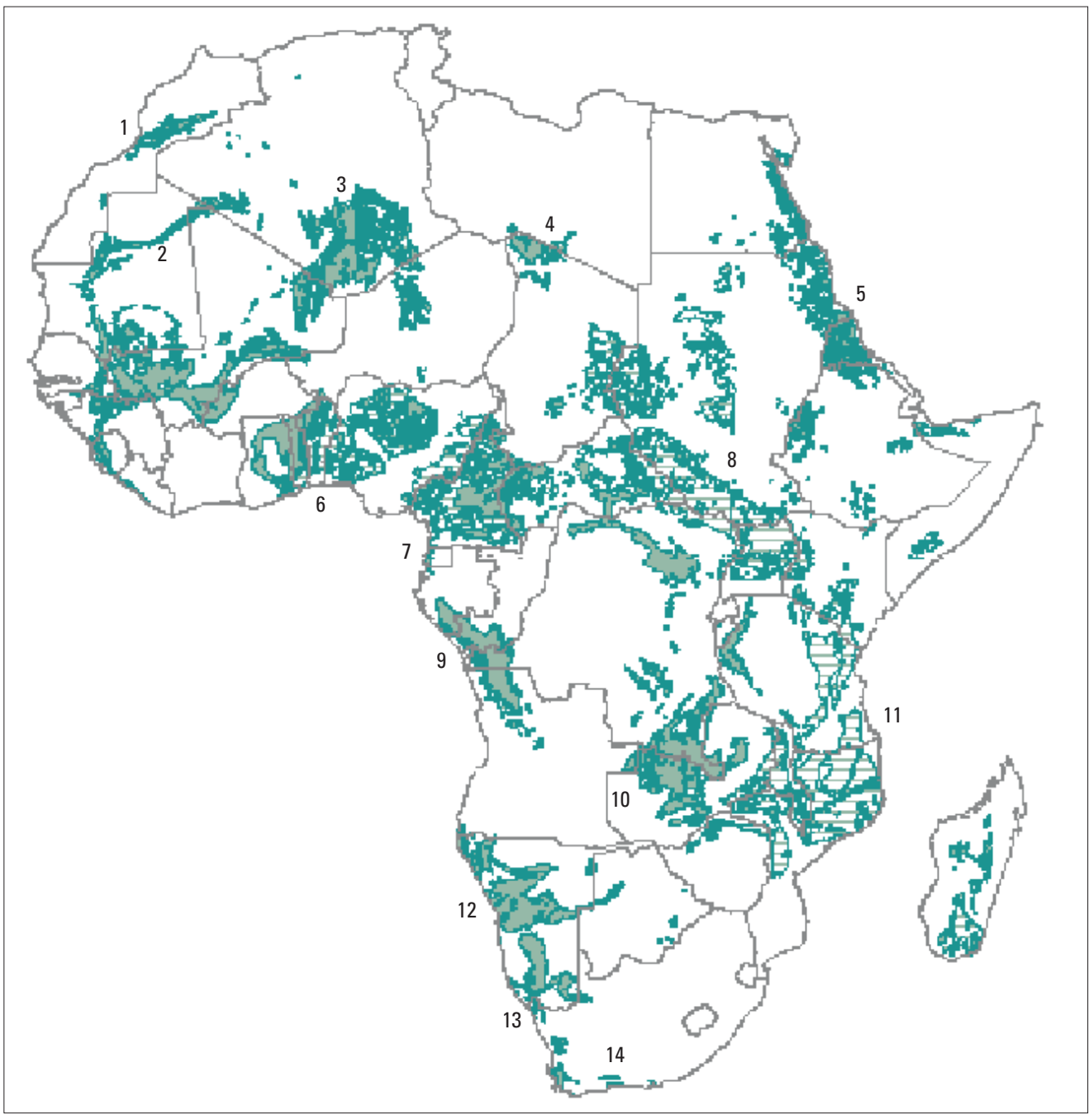

Figure 4. Map showing belts (areas tinted and striped in green) formed during the Neoproterozoic and early Paleozoic Pan-African orogeny: 1, Anti-Atlas; 2, Mauritanide; 3, Hoggar; 4, Tibesti; 5, Nubian Shield; 6, Benin-Nigerian; 7, Oubanguide; 8, West Nile; 9, West Congolian; 10, Katanga; 11, Mozambique; 12, Damara; 13, Gariep; 14, Saldania. Map was derived from the Metallogenic Map of Africa (MMA) database, which was created during compilation of the "International Digital Metallogenic Map of Africa" (Veselinovic-Williams and others, 1999). 
a number of volcanogenic exhalative massive sulfide deposits. The Otjihase and Matchless cupriferous pyrite bodies are the two most important deposits of this group. Similar massive sulfide mineralization occurs in the Gariep belt, as exemplified by the Rosh Pinah (primary zinc, lead, copper) and Skorpion (secondary zinc) deposits, whereas sedimentary-exhalative massive sulfides are found in the Kaokoland arm at Tsonguarri and Otjorongwari. Carbonate-hosted (Mississippi-Valley-type) base-metal mineralization is well developed at Tsumeb, Kombat, Berg Aukas, and Abenab on the Northern Platform of the intracratonic shelf. Mineralization associated with highly fractionated posttectonic Damara granites in the central Damara belt includes tin, pegmatite-suite minerals, uranium, and gold. Small deposits of beryl, pollucite, columbo-tantalite, and lepidolite occur in zoned pegmatites, particularly in the Karibib area (that is, Rubicon). A group of subparallel northeast-trending tin belts constitute probably the largest tin province in Africa (fig. 5). Gold-bearing skarn-type mineralization occurs at Navachab, and the metamorphogenic alaskite-hosted Rössing uranium deposit is the largest of its type in the world. Details on most of these deposits are provided by the Namibia Geological Survey (1992).
The Mozambique belt ( $660 \mathrm{Ma})$ can be traced over 4,000 kilometers along the entire eastern side of the African continent (fig. 4) and is characterized by high-grade metamorphism. Like the Zambezi belt, it is a result of Pan-African rejuvenation of older rocks. The Mozambique belt hosts numerous pegmatite-associated deposits with rare earth elements, tantalum, niobium, beryllium, mica, and emerald.

The Arabian-Nubian Shield is related to an assemblage of accreted island arcs that formed between $870 \mathrm{Ma}$ (rifting phase) and $540 \mathrm{Ma}$ (postcollisional granite phase) and is a superb manifestation of relatively young greenstone belts (Berhe, 1997). The shield comprises juvenile crust, which formed during a complete tectonic cycle, from rifting, the formation of ocean floor and arcs, to collision and postcollisional deformation (Agar, 1992; Windley, 1995). The arc-related volcano-sedimentary terranes host hydrothermal gold-quartz and gold-carbonate vein-type mineralization in Ethiopia (for example, Lega Dembi, Adola Greenstone Belt) and Eritrea (Gash-Setit Goldfield). Volcanogenic massive sulfide (copper, lead, zinc, silver, gold), stratabound sulfide, and sedimentary-exhalative sulfide deposits are also present. Disrupted ophiolites of the Arabian-Nubian Shield occur in linear belts up to

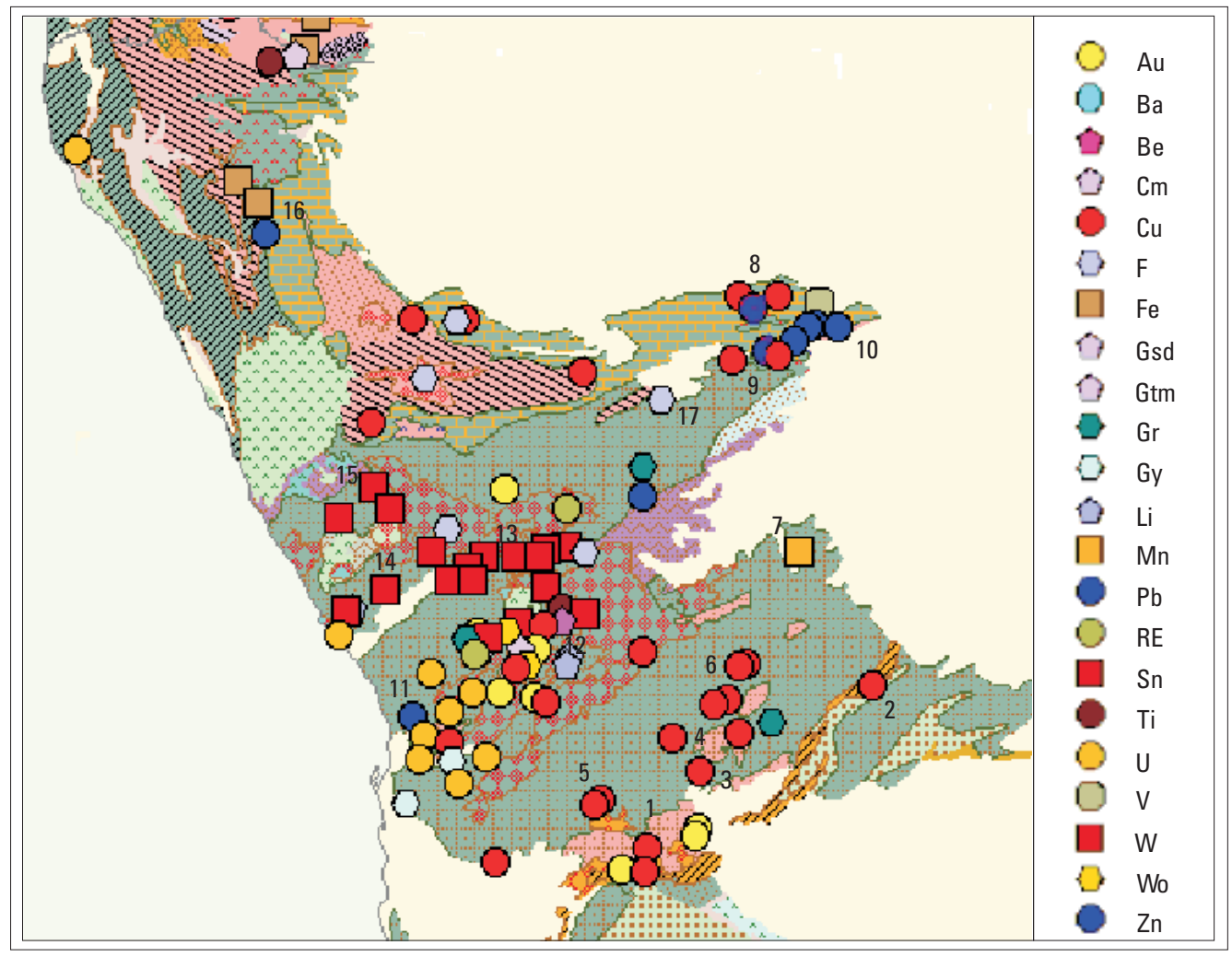

Figure 5. Map showing highlights of the Damara metallogenic province, a result of the classical Damara orogen. Klein Aub (1), Witvlei (2), Oamites (3), and Hobewarte (4) are of pre-Damara age; Matchless (5) and 0tjihase (6) are examples of Beshi-type volcanogenic massive sulfide deposits, and Otjosondu (7) may also be rift related; Mississippi-Valley-type deposits of Tsumeb (8), Kombat (9), and Berg Aukas (10) are situated on the Northern Platform; the Rössing-Goanikontes uranium province (11) is in high-grade metamorphic terrane (possibly representing a hot spot), whereas Navachab (12) is a skarn-type gold deposit; the Sandamap-Krantzberg-Karibib (13), Uis-Strathmore (14), and Brandberg West-Goantagab (15) pegmatite fields are all related to syntectonic and posttectonic granites of the collisional phase; Tsonguarri (16) is one of a group of sedimentary-exhalative deposits in the northern coastal extensional arm (Kaokoland belt); and the Okorusu fluorspar deposit (17) is part of a large postDamara group of alkaline intrusions. Modified from Killick (1986), Namibia Geological Survey (1992), and Pirajno (1998). 
900 kilometers long and locally contain stratabound nickel-sulfide deposits. Chromium mineralization occurs as podiform ore bodies in ultramafic host rocks of Sudan. Tantalum-niobium mineralization is commonly found in late-tectonic alkali granites and (or) pegmatites, whereas tin-tungsten mineralization is related to latetectonic greissenized and albitized alkali granites.

\section{The Search for Undiscovered Resources}

A perception exists in some investment circles that many parts of the world have been explored to the extent that the chance of making major new discoveries must be very small. This view, as far as geological risk factors are concerned, can be true only if one takes the present state of knowledge as a point of departure. The crux lies in continuously adding value to the knowledge base and significantly reducing the admittedly higher investment risk.

This need to keep adding to the knowledge base requires detailed geological mapping, high-density geophysical surveys, and geochemical mapping. Perhaps more important, however, is adding value to the knowledge base by producing state-ofthe-art thematic maps, developing advanced data modeling and interpretation techniques and facilities, and generating innovative outputs to stimulate mineral exploration. The archiving of geological and mineral resource data and the availability of such data are crucial issues, not only for those countries that need to attract mining investment to stimulate their economic development, but indeed for the mining industry itself. Progressive thinking and bold decisions are required to exponentially increase the availability of data by unleashing the enormous potential locked up in proprietary data. Goldcorp's Red Lake initiative in Canada (Viljoen, 2000) is a most inspiring example.

Africa is one of the last mining frontiers and is largely underresearched, poorly mapped, and underexplored. Consequently, the continent has a large potential for undiscovered resources; for instance, in the cratonic environments of central and western Africa. The availability of data, particularly in digital format, is critical in this regard, as it will facilitate unconstrained metallogenic analysis. It has been argued that the biggest value of digital data lies in the ability of a wide spectrum of users to utilize these data at will, to merge various sets of data, and to be innovative. The "International Digital Metallogenic Map of Africa" (Veselinovic-Williams and others, 1999) is an attempt to stimulate this process.

Of particular interest in this regard are potentially mineralized terranes that are hidden under large tracts of cover, either of Quaternary sediments or of other younger formations. The Kalahari and the Karoo basins of southern and central Africa are salient examples. Attempts to unravel the basin structure and the underlying geology of the Kalahari (Haddon, 2000, 2001), for example, will undoubtedly facilitate renewed metallogenic analysis and exploration, which may lead to new discoveries. Advanced metallogenic synthesis and analysis of environments that are conducive for large, hidden ore deposits remain a vital endeavor to locate undiscovered ore deposits. A current CGMW project to produce a map of exceptionally large deposits on a worldwide scale $(1: 25,000,000)$ is directed at this goal.

It is clear that a great deal of diligent work remains to be done to expand our knowledge by continued observation and documentation and particularly by adding value through the integration of relevant data sources, especially regional geophysical and geochemical data, and through the application of advanced data-modeling techniques. Metallogenic maps are indispensable in this regard but must continue to evolve to become useful predictive tools, lest they be rendered obsolete.

\section{References Cited}

Agar, R.A., 1992, The tectono-metallogenic evolution of the Arabian Shield: Precambrian Research, v. 58, p. 169-194.

Berhe, S.M., 1997, The Arabian-Nubian Shield, in De Wit, M.J., and Ashwal, L.D., eds., Greenstone belts: Oxford, Clarendon Press, p. 761-771.

Cahen, L., Snelling, N.J., Delhal, J., and Vail, J.R., 1984, The geochronology and evolution of Africa: Oxford, Clarendon Press, 512 p.

De Klerk, S.-L., comp., 2001, Gold deposits in the SADC [South African Development Community] region: South Africa Council for Geoscience, Mineral Resources Survey Programme, no. 4, 126 p., maps in pocket.

De Kun, Nicolas, 1963, The mineralogenetic provinces of Africa: Economic Geology, v. 58, no. 5, p. 774-790.

De Wit, M.J., and Ashwal, L.D., eds., 1997, Greenstone belts: Oxford, Clarendon Press, 809 p.

Emberger, André, 1991, Carte internationale des gîtes minéraux de l'Afrique [International mineral deposits map of Africa], 1:5,000,000, [sheet] 1, Rabat-Accra: Paris, Commission for the Geological Map of the World and UNESCO, scale 1:5,000,000.

Foster, R.P., and Piper, D.P., 1993, Archaean lode gold deposits in Africa-Crustal setting, metallogenesis and cratonization: Ore Geology Reviews, v. 8, no. 3-4, p. 303-347.

Gueiros, N., Jr., 2000, Intellectual property of scientific papers: IGC News, 31st International Geological Congress, August 6-17, 2000, Rio de Janeiro, Brazil.

Guilbert, J.M., and Park, C.F., Jr., 1986, The geology of ore deposits: New York, Freeman, 985 p.

Guild, P.W., 1971, Metallogeny-A key to exploration: Mining Engineering, v. 23, no. 1, p. 69-72. 
Guild, P.W., 1972, Metallogeny and the new global tectonics: 24th International Geological Congress, Section 4, Mineral Deposits, p. 17-24.

Guild, P.W., 1974, Distribution of metallogenic provinces in relation to major earth features, in Petrascheck, W.E., ed., Metallogenetische und geochemische Provinzen, Metallogenetic and geochemical provinces, [-Proceedings of a] symposium [organized with regard to the International Geological Correlation Program], Leoben [Austria], November 1972: Österreichische Akademie der Wissenschaften [Vienna], Erdwissenschaftliche Kommission, Schriftenreihe [Austrian Academy of Sciences, Earth Sciences Commission, Publication Series], v. 1, p. 10-24. (Article in English with abstract in German.) (Published by Springer-Verlag, Vienna and New York.)

Haddon, I.G., comp., 2000, Isopach map of the Kalahari Group: Pretoria, South Africa Council for Geoscience, scale $1: 2,500,000$.

Haddon, I.G., comp., 2001, Sub-Kalahari geological map: Pretoria, South Africa Council for Geoscience, scale $1: 2,500,000$.

Killick, A.M., 1986, A review of the economic geology of northern South West Africa/Namibia, in Anhaeusser, C.R., and Maske, S., eds., Mineral deposits of southern Africa: Johannesburg, Geological Society of South Africa, v. 2, p. 1709-1717.

Konstantinov, M.M., Cherkasov, S.V., Dankovtsev, R.F., and Egorkin, A.V., 1999, Specific crustal features for large and superlarge endogenic gold deposits (Siberia and Far East regions): Global Tectonics and Metallogeny, v. 7, no. 2, p. 143-147.

Lindgren, W., 1933, Mineral deposits (4th ed.; 3d impression revised): New York, McGraw-Hill, 930 p.

Milesi, J.-P., Ledru, Patrick, Feybesse, J.-L., Dommanget, Alain, and Marcoux, Eric, 1992, Early Proterozoic ore deposits and tectonics of the Birimian orogenic belt, West Africa: Precambrian Research, v. 58, p. 305-344.

Miller, R., McG., 1983, The Pan-African Damara orogen of South West Africa/Namibia, in Miller, R., McG., ed., The evolution of the Damara orogen of South West Africa/ Namibia: Geological Society of South Africa Special Publication $11,515 \mathrm{p}$.

Namibia Geological Survey, 1992, Mineral resources of Namibia: [Windhoek] variously paged. (Also available on CD-ROM.)

Olson, S.F., 2000, The Proterozoic evolution of Africa: University of Witwatersrand, Economic Geology Research Unit, Information Circular 343, 61 p.
Petrascheck, W.E., 1965, Typical features of metallogenic provinces: Economic Geology, v. 60, no. 8, p. 1620-1634.

Petters, S.W., 1991, Regional geology of Africa: New York, Springer-Verlag, 717 p.

Pirajno, F., 1998, Geology and mineral deposits of Namibia, in Vearncombe, Susan, and Ho, S.E., eds., Africa-Geology and mineral exploration: Australian Institute of Geoscientists Bulletin 25, p. 61-66.

Pohl, W., 1994, Metallogeny of the northeastern Kibara belt, Central Africa-Recent perspectives: Ore Geology Reviews, v. 9, p. 105-130.

Robb, L.J., and Robb, V.M., 1998, Gold in the Witwatersrand basin, in Wilson, M.G.C., and Anhaeusser, C.R., eds., The mineral resources of South Africa (6th ed.): South Africa Council for Geoscience Handbook 16, p. 294-349.

Routhier, Pierre, 1983, Where are the metals for the future?The metal provinces; An essay on global metallogeny (translation into English by Alexis Moiseyev and others): Orléans, France, Bureau de Recherches Géologiques et Minières, 399 p.

Turneaure, F.S., 1955, Metallogenic provinces and epochs, in Bateman, A.M., ed., Economic Geology, fiftieth anniversary volume, 1905-1955: Urbana, Ill., Economic Geology Publishing Company, pt. 1, p. 38-98.

United Nations, World Intellectual Property Organization, 1979, Berne Convention for the Protection of Literary and Artistic Works [as amended in 1979]: Geneva, available online at http://www.wipo.int/treaties/en/ip/berne/ trtdocs_wo001.htm.

Veselinovic-Williams, Milica, Hammerbeck, E.C.I., and Wolmarans, L.G., comps., 1999, 1:5000 000 international digital metallogenic map of Africa, sheets $5 \& 6$ (south of the Equator): Pretoria, South Africa Council for Geoscience and Commission for the Geological Map of the World, scale 1:5,000,000, one CD-ROM, introductory leaflet. (A printed map was published in 2002 on 3 sheets.)

Viljoen, R.P., 2000, Effective use of geodata-The Goldcorp challenge: Geological Society of South Africa Geobulletin, v. 43 , no. 4 , p. $17-18$.

Windley, B.F., 1995, The evolving continents (3d ed.): Chichester, U.K., John Wiley \& Sons, 526 p. 


\title{
The Use of Mineral Occurrence and Geologic Databases in Quantitative Mineral Resource Assessment
}

\author{
By Bruce R. Lipin ${ }^{1}$ and Walter J. Bawiec ${ }^{1}$
}

\section{Introduction}

Quantitative mineral resource assessments of undiscovered mineral deposits in a regional setting are relatively new in geology. The U.S. Geological Survey (USGS), among others, has pioneered this activity and has developed a procedure known as the three-part quantitative assessment of undiscovered mineral resources (Singer, 1993).

Input into the three-part assessment consists of a variety of mineral-resource-related thematic data. Ideally, the following information is evaluated for a quantitative assessment: mineral occurrence data, to locate known mineral localities and their attributes; geologic map data, to determine geologic history and the current disposition of genetically related geologic map units; geophysical data, including both gravity and aeromagnetic data, to interpret lithologies and geologic structure beneath the surface; geochemical data, to locate anomalies of metallic or pathfinder elements at the surface; and exploration history, to determine if commodities of a particular mineral deposit type previously have been explored and to what result. These datasets, when compiled systematically, constitute databases.

Different aspects of these databases become important depending on the commodity and type of deposit being assessed. For example, geophysical data for an area may show positive gravity and magnetic anomalies combined with geologic data that show that mafic-ultramafic units are important in assessing specific mineral deposit types, such as chromite deposits. Other databases (for example, stream sediment geochemical data) may be important in the assessment of Carlintype gold deposits.

This paper describes the use of databases of two different themes, mineral occurrences and geology, in performing a preliminary mineral resource assessment of porphyry copper deposits in Peru. This preliminary assessment of porphyry copper deposits in Peru was prepared for use in a workshop on mineral assessment conducted in Lima, Peru (unpub. data, February 27-March 1, 2001). In the following discussion, we will describe and compare the mineral and geologic databases, then review successes and challenges in how these databases were used.

${ }^{1}$ U.S. Geological Survey, 954 National Center, 12201 Sunrise Valley Drive, Reston, VA 20192-0002, U.S.A. (e-mail: blipin@usgs.gov).

\section{USGS Mineral Databases}

The USGS is in the process of combining two large mineral resource databases, MRDS (Mineral Resources Data System) and MAS/MILS (Minerals Availability System/Minerals Industry Location System). MRDS was created and is maintained by the USGS, and MAS/MILS was created and maintained by the former U.S. Bureau of Mines (USBM). Both databases were started around 1970 and have evolved through many different formats over the years. In 1996, Congress eliminated the Bureau of Mines, and MAS/MILS was transferred to the USGS.

The two databases were compiled for different purposes and contain very different information. For example, MAS/MILS contains information on mining and development costs, details of mining methods, and results from feasibility studies. In addition, MAS/MILS contains records for fossil fuel deposits and for mineral processing plants (mills and smelters) that are not in MRDS. MRDS has mineralogical and geologic data that are not contained in MAS/MILS. Because MRDS and MAS/MILS are mineral databases, they also contain some information in common, such as location, name(s) of sites, and commodities present.

Both databases are international in scope but have an emphasis on the United States. MRDS contains over 110,000 records, of which about 80,000 pertain to the United States, and MAS/MILS contains about 220,000 records, of which 210,000 pertain to the United States. Because the USGS and the USBM had limited resources, neither database has been systematically updated on a periodic basis. Both organizations added to or corrected records in the databases by a variety of means that included hiring contractors, entering into cooperative agreements with State geological surveys in the United States and national geological surveys in other countries, and entering data from areas in which there were ongoing USGS or USBM projects. The result of this approach is that each record is a snapshot of a given deposit at the time the data were either first entered or last updated. If a deposit has undergone a significant change in status since the data were entered, but we have not had reason to revisit the area in which the deposit lies, then we commonly do not have updated information.

The USGS has merged the data in the two databases into one Oracle format with the goals of cleaning the data and 
eliminating duplicate records. The new structure has about 250 available fields for data. Because of increasing emphasis on environmental aspects of mining, information on mineral processing plants in the MAS/MILS database was retained. The USGS did not retain data on energy resources from the old USBM database because the USGS already has energy databases that cover those deposits. The USGS published a CD-ROM set containing the original MRDS and MAS/MILS databases (McFaul and others, 2000) and has the MRDS online (USGS, 2005).

\section{Other Relevant Mineral Databases}

As part of a study to determine if a global quantitative mineral resource assessment is feasible using the USGS threepart form of assessment, a preliminary assessment of porphyry copper deposits in Peru was initiated. INGEMMET, the Instituto Geológico Minero y Metalúrgico of Peru, provided their unpublished geology and mineral deposits databases. Most countries have good databases for deposits within their borders but do not keep information on other countries.

The following mineral resource databases were used for the preliminary quantitative mineral resource assessment of Peru:

- MRDS and MAS/MILS (USGS, McFaul and others, 2000)

- $\quad$ Peru database of mineral deposits (INGEMMET, unpub. data)

- Giant porphyry-related camps of the world-A database (Mutschler and others, 1999)

- World distribution of porphyry, porphyry-associated skarn, and bulk-tonnage epithermal deposits and occurrences (Kirkham and Dunne, 2000)

- An informal, unpublished database compiled by D.A. Singer (USGS). The database was subsequently released as USGS Open-File Report 02-268 (Singer and others, 2002)

Other sources included the following:

- Peru database of geology (INGEMMET, unpub. data, scale 1:1 million)

- Database of exploration targets compiled from press releases and various trade magazines (D.R. Wilburn, USGS, unpub. data)

- Many published reports on copper deposits and geology of the Andes

The INGEMMET database of mineral deposits in Peru has a structure similar to that of MRDS because of a cooperative agreement between USGS and INGEMMET when the
Peruvian database was first developed. However, there are several important differences among the four mineral resource databases (MRDS, INGEMMET, Mutschler and others, and Kirkham and Dunne) used in the preliminary assessment of Peru. First, the USGS and INGEMMET databases have many more data fields than the other two (MRDS, 230; INGEMMET, 140; Mutschler and others, 30; and Kirkham and Dunne, $\sim 50)$. This disparity exists because databases compiled by geological surveys are usually used for many different purposes, whereas databases compiled by individual researchers are commonly designed for specific purposes. Moreover, compilers of the USGS and INGEMMET databases tried to capture everything from the small occurrences to the largest producers, whereas compilers of the other two databases concentrated on giant or significant deposits; this difference also reflects a difference in the philosophy of the compilers. The result is that the USGS and INGEMMET databases have more records of small occurrences classified as porphyry copper deposits. Many of these identified porphyry copper occurrences never have been, and probably never will be, mined.

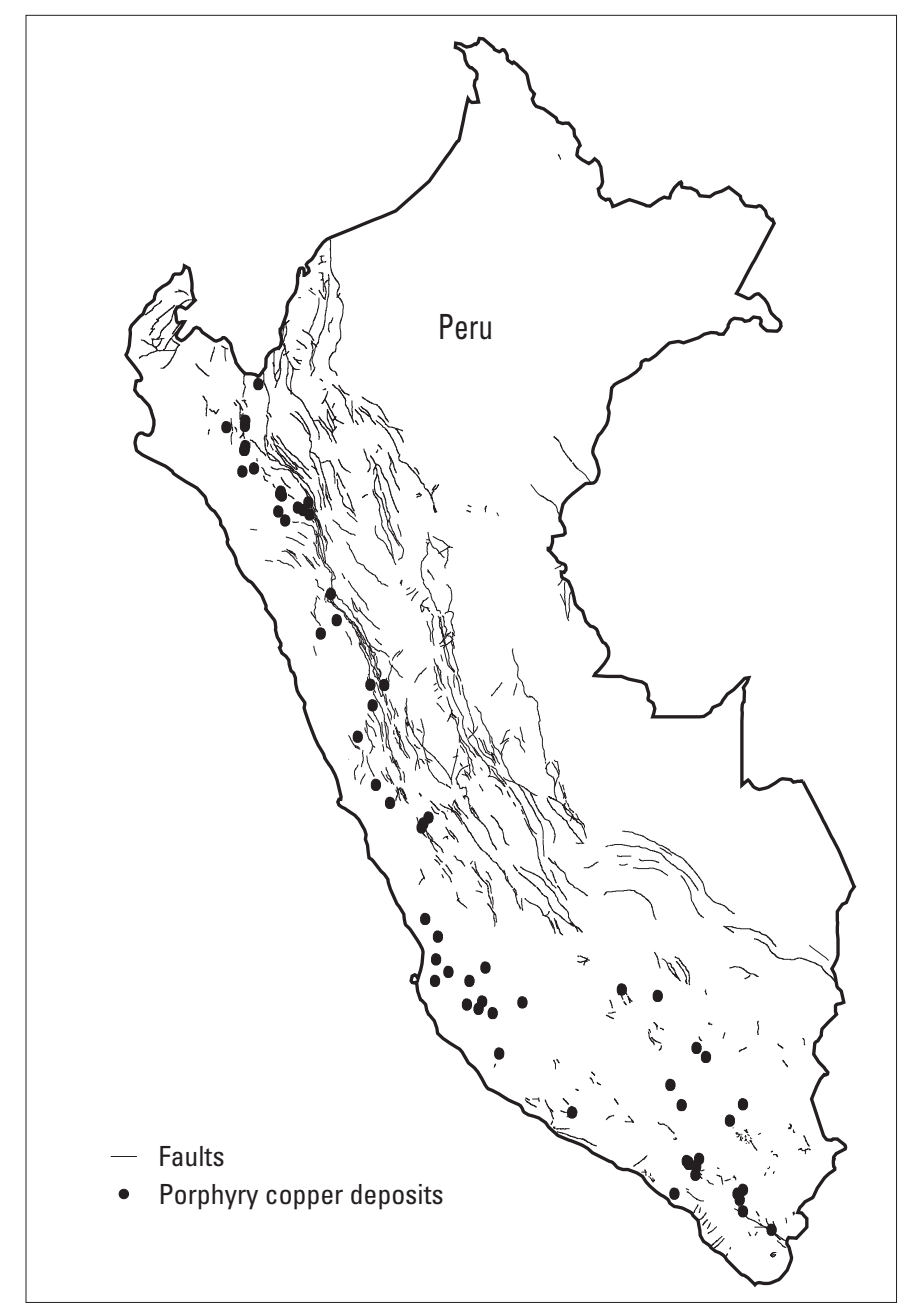

Figure 1. Map showing locations of porphyry copper and porphyry-copper-related deposits in Peru used in the preliminary quantitative mineral resource assessment. 
The most obvious difference among the databases is that the USGS and INGEMMET databases cover all types of mineral deposits, whereas the other two were designed to cover only porphyry and related deposits. All the databases were useful because of some unique piece of information they contained and because of the confirmation of deposit type classifications from multiple sources. When there was disagreement among the databases, the references provided were useful in resolving them. Sixty-four deposits were identified as porphyry copper or porphyry copper related. The locations of these deposits are depicted in figure 1.

\section{Geologic Database}

Although geologic maps have been available for many years as paper products, the relatively recent advent of digital geologic maps and associated databases has brought a new era to their application in fields such as land use planning and mineral exploration. This technology is new and evolving quickly; thus, standards for development have not yet been fully established and accepted.

In the first phase of evolution of digital geologic maps, they simply are representations of previously published paper maps. The databases and attribute tables that accompany these digital maps reflect only the information contained within the hardcopy media. A typical geologic map for an area would contain geologic map units, including stratigraphic units and geologic ages; structural data, including faults and strike and dip symbols; and regional tectonic and depositional settings. Digitizing paper maps can convey only the information that was on the paper originally. Thus, digitized maps are not superior to paper maps in quality or accuracy.

The geologic data provided by INGEMMET were contained in two files, geology and faults, that together represent the geology of Peru. These were compiled at a scale of 1:1 million. The digital geology contains 113 different map units, which are attributed to approximately 6,700 polygons. The fault coverage contains attributes reflecting movement and the degree of exposure or level of confidence in fault location. This amount of information, although important for many types of studies, is far too detailed for a countrywide mineral resource assessment. For instance, the original data set showed 19 different types of Cretaceous intrusions. These were combined into a single category because it was concluded that their common age range was enough information for the purposes of the mineral resource assessment. Therefore, the geologic map units are combined into 10 time-stratigraphic units on the basis of their temporal relations to episodes of porphyry copper deposit formation in Peru. The simplified map is displayed in figure 2. The 10 time-stratigraphic units formed before, during, between, and after the various episodes of porphyry copper formation. Aside from the ease of manipulation of digital geologic maps to create other derivative maps, all of these maps are easily combined with other thematic data as layers, such as aeromagnetic data, gravity data, geochemical anomalies, remote sensing images, and of course mineral occurrences.

\section{Challenges and Successes}

Before discussion of challenges and successes, a brief explanation of the three-part mineral resource assessment is in order. This is a procedure for a quantitative assessment of the mineral resources of a given area. Singer (this volume) states the following, "In three-part assessments, (1) areas are delineated according to the types of deposits permitted by the geology, (2) the amount of metal and some ore characteristics are estimated by means of grade and tonnage models, and (3) the number of undiscovered deposits of each type is estimated." Deposit models play a very important role in the first two parts of the process. In the first part, we use descriptive mineral deposit models to determine what types of deposits are permissible in the area. In the second part, we use grade and tonnage models of each deposit type. By building databases of mineral deposits that contain the attributes of the deposits (such as age, host rock(s), ore minerals, gangue minerals, structural setting, grade, and tonnage), we are able to develop the required descriptive and grade and tonnage models to carry out the three-part assessments. In addition, we may be able to classify individual deposits if sufficient information is contained in a database.

The first challenge for the Peru assessment was the interpretation of the mineral deposit databases. Some deposit types may be spatially and genetically related to porphyry systems, such as skarns, manto deposits, polymetallic veins, and epithermal gold deposits. However, it is not mandatory that those deposit types be related to porphyry systems. In addition, many copper deposits in the USGS and INGEMMET databases were classified as either stockwork or disseminated, which are descriptive terms but not very helpful in assigning them to a specific mineral deposit model. The other three porphyry databases were of some assistance in this effort because they pointed to literature that confirmed that some of the stockwork and disseminated deposits were indeed porphyry or porphyry-related deposits. However, many of the deposits labeled stockwork or disseminated were small nonproducers and were not included in the databases by Mutschler and others (1999), Kirkham and Dunne (2000), or Singer and others (2002). Additional work was needed to classify these small deposits, including examining such data as ore mineralogy, host-rock type, associated-rock type, and mineralization age and consulting many published references. Through this effort we were able to better classify some of the small deposits. Nonetheless, some deposits in both the USGS and INGEMMET databases remain unclassified because of insufficient data; these are being examined in conjunction with INGEMMET.

All the databases were in substantial agreement on almost all the significant deposits with respect to name, deposit type, 


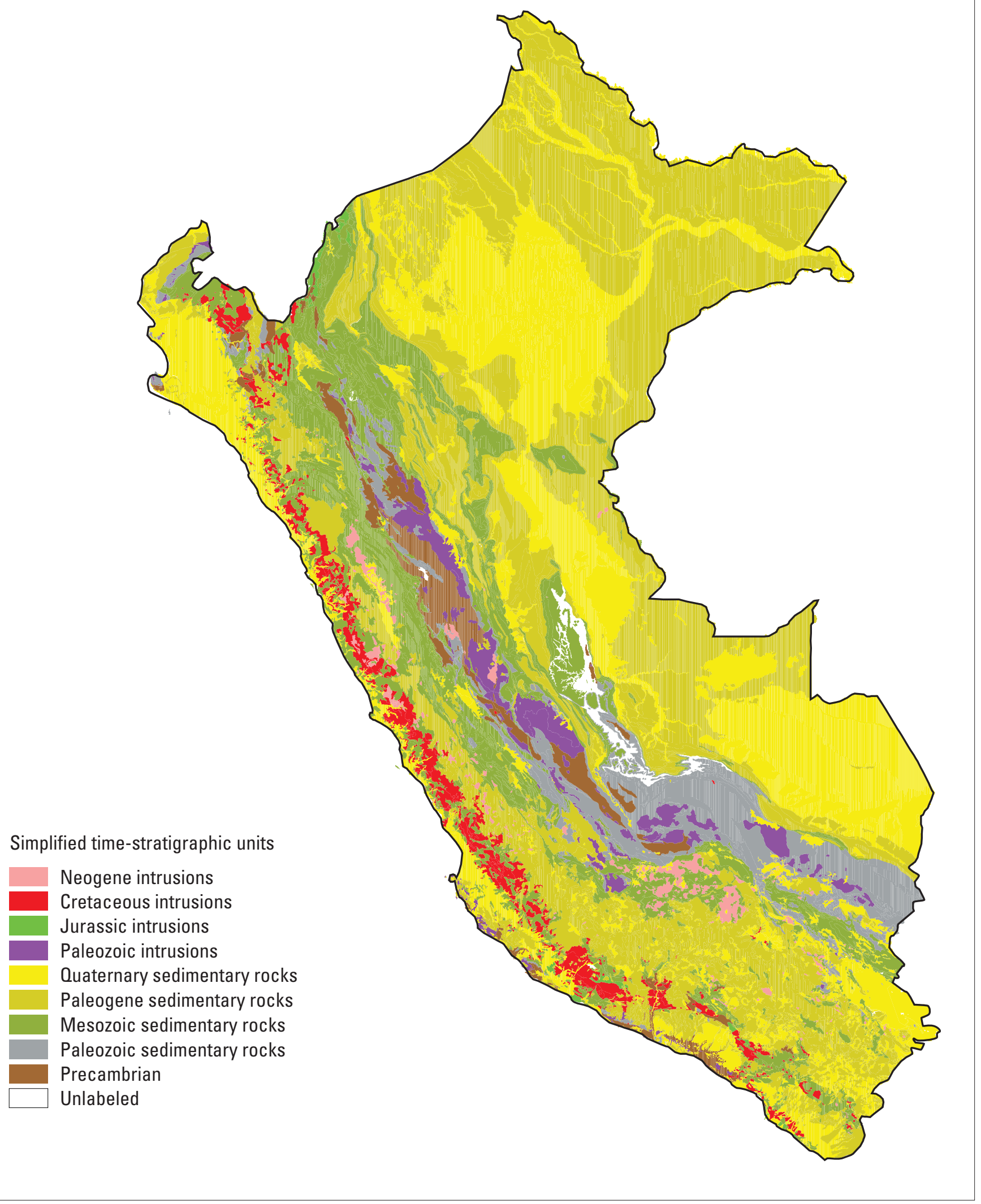

Figure 2. Simplified time-stratigraphic map of Peru. 
and location. Many locations were close but not exactly the same among the databases. Because mines tend to be large, one location may be based on the entrance to the mine, and another may be based on the location of the headframe. Both locations are correct but different. Many of the discrepancies were small, however, commonly a few seconds or less (a second is about 185 meters at the Equator). This was considered an acceptable level of uncertainty at a scale of 1:2 million, which was the scale at which the assessment was conducted. In cases where significant discrepancies existed, we deferred to locations used in the INGEMMET database.

The geologic map and fault databases were useful in matching rock type to known deposits. They also can be useful in identifying structural settings of deposits and their proximity to various types of faults as a way of trying to predict where other, perhaps hidden, deposits may occur. However, in the case of the fault file provided by INGEMMET, plotting the porphyry and related deposits with the faults did not show any direct relation, possibly because, at the 1:1 million scale at which it was compiled, smaller faults of significance to the deposits are not included. Satellite images are being used at a much larger scale to further examine the structural setting of some of the porphyry deposits.

The unpublished worldwide exploration database compiled by D.R. Wilburn (USGS, Denver) was found to be very helpful in the assessment. The exploration database contains information on items such as the number of meters drilled on exploration sites and status of exploration (from early prospecting to final feasibility study). Thus, it is possible to judge the chances of a given porphyry prospect becoming a producer. Another value of the exploration database was that it provided information on whether a prospect was in a known mining district or in an area in which few, if any, deposits had been found. A major challenge in this dataset was getting accurate locations because press releases and articles in trade journals, which are the sources for most of the records in this database, use location descriptions such as " 400 kilometers NE of Lima" and rarely give precise locations. If a porphyry prospect is in an area that has not previously been explored or in which no other deposits were known to exist, it can have a profound effect on the estimate of the number of undiscovered deposits.

\section{Conclusions}

This exercise to assess the porphyry copper deposit potential in Peru by using the three-part form of assessment has been very helpful. A great deal was learned about the usefulness of different types of data and the limitations of existing databases. Priorities now can be established for the type of information needed about mineral deposits and occurrences for future assessments of a country or group of countries. For mineral occurrence databases, the priorities are-
- Accurate locations of mineral occurrences

- Previous names of deposits for matching and reconciling data from different sources

- Host-rock type and age

- Associated-rock type and age (we distinguish between host rock and associated rock in that a porphyry-related skarn may be hosted by a limestone and the associated rock may be a porphyritic monzonite)

- Ages of mineralization

- List of ore and non-ore minerals

- Genetic, descriptive, and grade and tonnage characterization of the known deposits in the region of interest

For geology databases, the priorities are-

- Digitized records of all information on paper maps (because one cannot predict what data may be useful)

- Lithologic descriptions of all map units

- Geologic ages of map units

- Types of faults and apparent movement

- Relative ages of map units, including whether they formed before, during, between, or after the various episodes of ore formation

- Map projection parameters to allow combining a geologic map with other thematic datasets

\section{References Cited}

Kirkham, R.V., and Dunne, K.P.E., comps., 2000, World distribution of porphyry, porphyry-associated skarn, and bulk-tonnage epithermal deposits and occurrences: Geological Survey of Canada Open File 3792a (26 p., 1 diskette) and 3792b (map, scale 1:35,000,000). (An updated (2003) version of this database is available online at http://gdr.nrcan.gc.ca/minres/metadata_e.php?id=6.)

McFaul, E.J., Mason, G.T., Jr., Ferguson, W.B., and Lipin, B.R., 2000, U.S. Geological Survey mineral databasesMRDS and MAS/MILS: U.S. Geological Survey Digital Data Series DDS-52, two CD-ROMs.

Mutschler, F.E., Ludington, Steve, and Bookstrom, A.A., 1999, Giant porphyry-related metal camps of the world-A database: U.S. Geological Survey Open-File Report 99-0556, version 1.0, available online at http://geopubs.wr.usgs.gov/open-file/of99-556.

Singer, D.A., 1993, Basic concepts in three-part quantitative assessments of undiscovered mineral resources: Nonrenewable Resources, v. 2, no. 2, p. 69-81. 
Singer, D.A., Berger, V.I., and Moring, B.C., 2002, Porphyry copper deposits of the world-Database, maps, and preliminary analysis: U.S. Geological Survey Open-File Report 02-268, available online at http://geopubs.wr.usgs.gov/ open-file/of02-268. (An updated version of the file is available in USGS Open-File Report 2005-1060, available online at http://pubs.usgs.gov/of/2005/1060/.)
U.S. Geological Survey, 2005, Mineral Resources Data System: Reston, Va., U.S. Geological Survey database available online at http://tin.er.usgs.gov/mrds. 


\title{
Example of Continental-Scale Mineral Resource Assessments
}

\author{
U.S. Geological Survey National Mineral Resource Assessment- \\ An Estimate of Undiscovered Deposits of \\ Gold, Silver, Copper, Lead, and Zinc in the United States
}

\author{
By Klaus J. Schulz' and Joseph A. Briskey
}

\section{Introduction}

The U.S. Geological Survey (USGS) conducted a 5-year scientific study - the National Mineral Resource Assessment-to estimate in probabilistic terms, for the first time, the amounts of gold, silver, copper, lead, and zinc that could be present in yet-to-be discovered mineral deposits 1 kilometer or less below the surface of the United States. Results for the conterminous United States were published in 1996 (Ludington and others, 1996). Results for the entire United States, including Alaska, were released in 2000 (U.S. Geological Survey National Mineral Resource Assessment Team, 2000). The national assessment shows that it is likely that the United States still contains at least as much gold, silver, copper, lead, and zinc in conventional-type deposits as has already been discovered.

\section{Why a National Mineral Resource Assessment Was Needed}

The USGS undertook the National Mineral Resource Assessment to provide timely, objective, credible mineral resource information for land and resource planning and decisionmaking. As the Nation's economy matures, progressively greater attention is given to land use and environmental quality, as well as to sustainability of mineral supplies to provide for the needs of future generations. National mineral resource assessments provide a framework for addressing these issues by monitoring the Nation's mineral wealth and by contributing to deliberations about resource extraction and protecting the

${ }^{1}$ U.S. Geological Survey, 954 National Center, 12201 Sunrise Valley Drive, Reston, VA 20192-0002, U.S.A. (e-mail: kschulz@usgs.gov). environment. Responsible stewardship of the Nation's lands, resources, and environment requires information on where future mineral resources may exist, the amounts of a mineral commodity or commodities that these resources might contain, and what environmental impacts might result from extraction and development of such resources.

Starting in the early 1990s, the tempo and politicization of land, resource, and environmental planning and decisionmaking in the United States began accelerating (again). An estimated 190 million acres of public lands, although lacking modern mineral assessments, was being proposed for withdrawal from areas available for mineral exploration, discovery, and production. This situation virtually assured that large deposits of undiscovered mineral resources would be withdrawn unknowingly and without consideration of alternative supplies.

For a number of reasons, detailed conventional largescale mineral assessments were an impractical response to the burgeoning need for minerals information that accompanied the accelerating planning and decisionmaking process. (1) Deadlines were too short and unpredictable to conduct new assessments targeted to specific areas under consideration for withdrawal. (2) Locations of areas of concern were unpredictable and the areas under consideration were becoming very large (up to tens of millions of acres). (3) The boundaries of these areas were uncertain.

Because of this growing unpredictability, it was recognized that what was needed was a nationwide mineral assessment database available in advance of the planning process for all areas of the country. Unfortunately, the cost of providing such comprehensive data at traditional large, detailed scales was too high. For example, we estimated that collecting comprehensive mineral resource data just for public and enclosed private lands at a scale of 1:250,000 would cost between $\$ 2$ billion and $\$ 3$ billion over a period of 15 years. Such a cost was too high, and the time too long. The National Mineral Resource Assessment described herein was proposed 
and conducted as an alternative mechanism for developing, organizing, consolidating, augmenting, and maintaining large geological, geochemical, geophysical, and mineral resource digital databases capable of supporting mineral resource and associated mineral environmental assessments and research, at multiple scales and levels of detail throughout the country.

\section{How the Assessment Was Done}

The nature of available data and current technology, combined with limitations of time and money, dictated that the national assessment be undertaken from a regional perspective. The country was divided into 19 geographic regions that were selected to provide broad geologic groupings of the Nation's mineral-producing areas. Each region was assessed by a scientific team composed of from 6 to 24 geologists, geochemists, geophysicists, and resource analysts knowledgeable about the region and its mineral deposits.

The method used to estimate the quantity and quality of undiscovered deposits of gold, silver, copper, lead, and zinc was the three-part quantitative assessment procedure (Singer, 1993), applied by the USGS increasingly since 1975 . This procedure is based on mineral deposit models, which consist of sets of geoscience data that describe a group of deposits having similar geologic settings and distinctive grade and tonnage characteristics.

The first part of the three-part assessment is to prepare maps that identify and delineate tracts permissive for the occurrence of undiscovered deposits by deposit type (fig. 1.). A permissive tract is defined by its geographic boundaries such that the probability of deposits of the type delineated occurring outside the boundary is negligible. Tracts for the national assessment were delineated to allow estimates of undiscovered resources to be made to a depth of 1 kilometer below the surface where possible. Areas that were covered by more than 1 kilometer of rock known or inferred to be barren were excluded from the assessment. Permissive tracts were delineated by interpreting and integrating existing geologic, geophysical, and geochemical data and information available on known deposits in the area, all compiled onto maps at scales of 1:500,000 and 1:1,000,000.

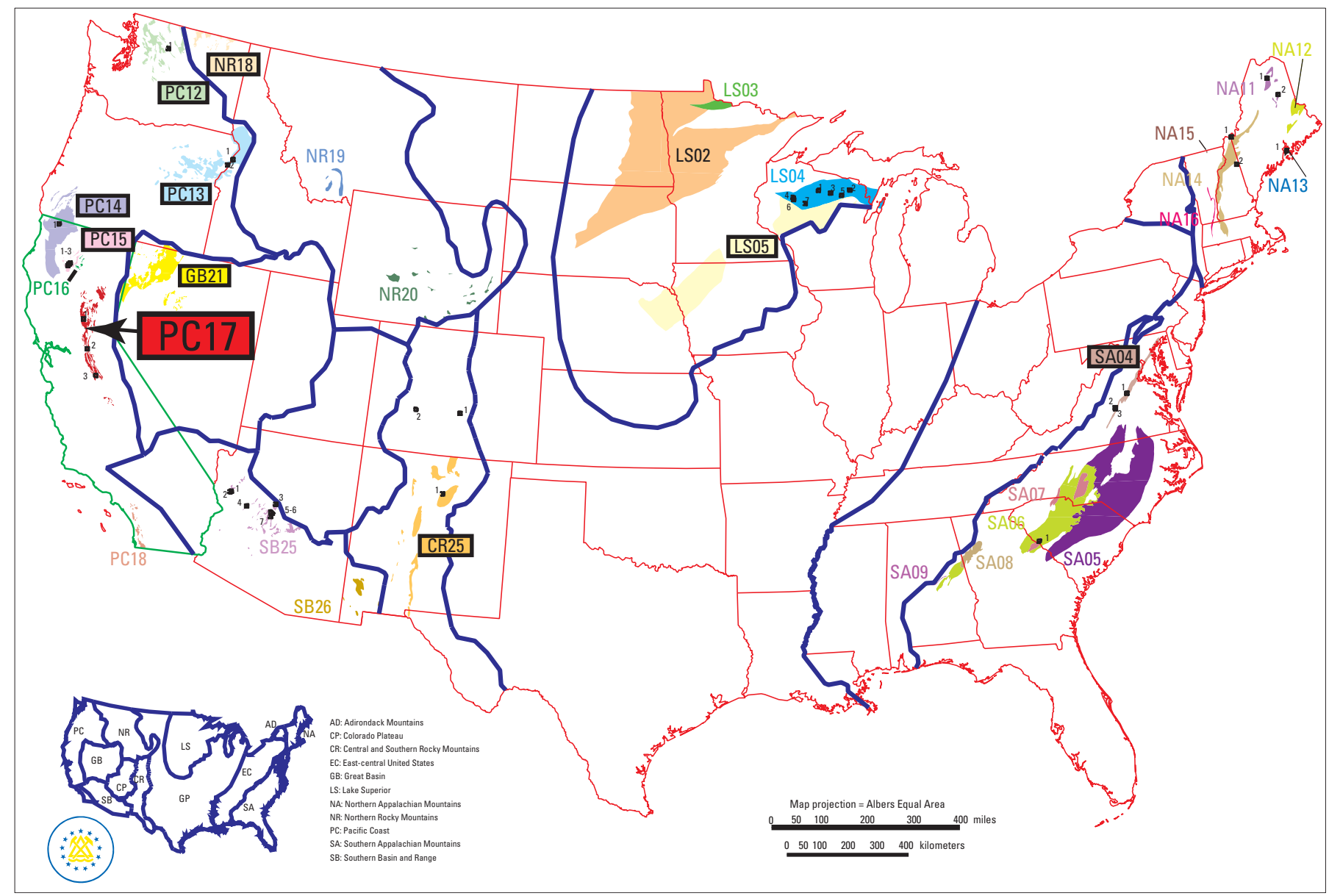

Figure 1. Tract map for kuroko massive sulfide deposits in the conterminous United States showing areas where the geology is permissive for the formation of this type of deposit. Favorable areas are shown by different colors and labels. From Luddington and others (1996). Estimates of undiscovered deposits and metal resources in tract PC-17 are shown in figures 2 and 3. 
The second part of the assessment method is estimating the number of undiscovered deposits of each deposit type in those permissive tracts where available information allows quantitative estimates. The number of undiscovered deposits is expressed as a probability distribution, with estimates of the number of undiscovered deposits made at the 90th, 50th, and 10th percentile confidence levels and sometimes at the 5 th and 1 st levels (fig. 2). The estimates are made by subjective interpretation and extrapolation of available earth science information by geoscientists having detailed knowledge about the area and (or) the selected deposit type(s). The estimates of numbers of undiscovered deposits are constrained by the

\section{Estimated Undiscovered Deposits}

There is a $90 \%$ or greater chance of 2 or more deposits. There is a $50 \%$ or greater chance of 13 or more deposits. There is a $10 \%$ or greater chance of 25 or more deposits. There is a $5 \%$ or greater chance of 25 or more deposits. There is a $1 \%$ or greater chance of 25 or more deposits.

\section{Estimated amounts of contained metal and mineralized rock, in metric tons}

\begin{tabular}{rrrrrrrr|}
\multicolumn{1}{c}{ Quantile } & \multicolumn{1}{c}{$\mathrm{Cu}$} & $\mathrm{Au}$ & $\mathrm{Zn}$ & $\mathrm{Ag}$ & $\mathrm{Pb}$ & \multicolumn{1}{c}{ Rock } \\
\cline { 2 - 8 } & 700 & 0 & 0 & 0 & 0 & 97,000 \\
0.95 & 12,000 & 0 & 12,000 & 18 & 0 & 690,000 \\
0.50 & 140,000 & 16 & 260,000 & 710 & 46,000 & $8,500,000$ \\
0.10 & 310,000 & 45 & 815,000 & 2,700 & 200,000 & $19,000,000$ \\
0.05 & 360,000 & 55 & 990,000 & 3,400 & 250,000 & $22,000,000$ \\
Mean & 160,000 & 20 & 340,000 & 1,100 & 76,000 & $9,200,000$ \\
Probability of mean & 0.46 & 0.43 & 0.40 & 0.38 & 0.38 & 0.46 \\
Probability of zero & 0.04 & 0.06 & 0.06 & 0.05 & 0.10 & 0.04 \\
\cline { 3 - 7 } & & & & & &
\end{tabular}

Figure 2. Chart summarizing probabilistic subjective estimates by experts of numbers of undiscovered kuroko massive sulfide deposits in tract PC-17, California (see fig. 1). From Ludington and others (1996). Corresponding amounts of contained metal and mineralized rock were estimated by Monte Carlo simulation.

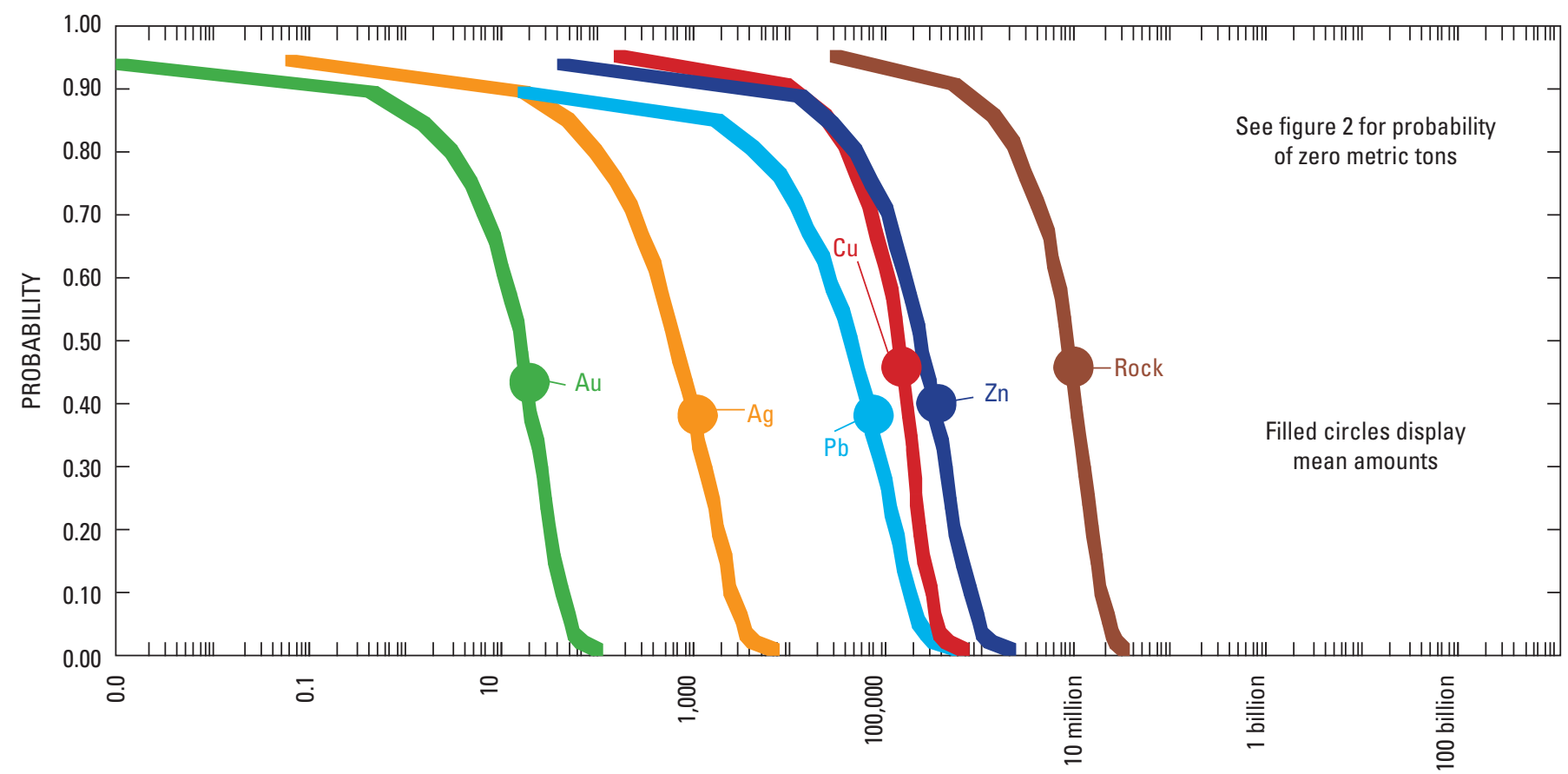

Figure 3. Graph showing cumulative distributions of contained metal and mineralized rock (in metric tons) in undiscovered kuroko massive sulfide deposits estimated in tract PC-17, California (see figs. 1 and 2). From Ludington and others (1996). 
requirement that these deposits have grades and tonnages similar to the deposit model appropriate to the tract. Most models used in the national assessment were those described by Cox and Singer (1986) and Bliss (1992).

The third part of the assessment method uses a Monte Carlo simulation computer program to combine the probability distribution of the number of undiscovered deposits with the grade and tonnage datasets associated with each deposit model to obtain the probability distribution for the undiscovered metal in each tract (Root and others, 1992, 1997). For the national assessment, the resulting cumulative probability distributions represent the estimated quantities of gold, silver, copper, lead, and zinc in each tract and allow various fractals and the mean estimates to be obtained for the tracts (fig. 3).

\section{Results of the Assessment}

In the national assessment, 55 major deposit models and submodel types were used to delineate 447 permissive tracts. Quantitative estimates of undiscovered mineral resources were possible in 305 of these tracts. In addition to estimating gold, silver, copper, lead, and zinc in undiscovered mineral deposits, the national assessment (Long and others, 1998; U.S. Geological Survey National Mineral Resource Assessment Team, 2000) also estimated resources of these metals remaining in, and produced from, identified deposits, as follows:

- In undiscovered deposits minable with existing technology-18,000 metric tons (t) of gold, 460,000 t of silver, 290,000 kilotons (kt) of copper, 85,000 kt lead, and $210,000 \mathrm{kt}$ of zinc.

- In identified deposits-15,000 t of gold, 160,000 t of silver, 260,000 kt of copper, 51,000 kt of lead, and 55,000 kt of zinc.

- $\quad$ Past production from the largest identified U.S. deposits (accounting for about 99 percent of cumulative domestic production through 1996) - 12,000 t of gold, 170,000 t of silver, 91,000 kt of copper, 41,000 kt of lead, and 44,000 $\mathrm{kt}$ of zinc.

\section{Some Implications}

The USGS National Mineral Resource Assessment provides the first quantitative estimate of the amounts of undiscovered gold, silver, copper, lead, and zinc in the United States. The results suggest that, for conventional-type deposits of these five metals, the United States still contains about as much in undiscovered deposits as was discovered previously.

Along with providing estimates of the quantity and quality of undiscovered mineral resources, the national assessment provides a consistent, systematic database of current geologic and mineral resource information at a national scale. This database permits, at least at some minimum level, evaluation of the impact of land use decisions on the Nation's undiscovered mineral resources. Large parts of the areas delineated as permissive for occurrence of undiscovered deposits already are unavailable for future mineral exploration and development because of their use for urban, transportation, and other development and their withdrawal for wilderness, scenic areas of various kinds, national parks and monuments, wildlife refuges, endangered species protection, and so on. The national assessment database provides Federal, State, and local land management agencies information with which to estimate the potential cumulative environmental impact of possible exploration and mining activities, to evaluate the potential economic benefits of mining in comparison with other land uses, to evaluate and plan for the potential impact of mining activities on other land uses, and to appraise the fair market value of land proposed for leasing, sale, exchange, or taking. The permissive tracts delineated as part of the national assessment also permit industry to focus mineral exploration programs on the areas and regions most promising for new discoveries.

National assessments conducted on a recurring basis can provide a means to help ensure adequate mineral supplies and effective stewardship of environmental and other resources in the future. The national assessment methodology may serve as a guide for undertaking assessments at continental and global scales.

\section{References Cited}

Bliss, J.D., ed., 1992, Developments in mineral deposit modeling: U.S. Geological Survey Bulletin 2004, 168 p. (Also available online at http://pubs.usgs.gov/bul/b2004/.)

Cox, D.P., and Singer, D.A., eds., 1986, Mineral deposit models: U.S. Geological Survey Bulletin 1693, 379 p. (Also available online at http://pubs.usgs.gov/bul/b1693.)

Long, K.R., DeYoung, J.H., and Ludington, S.D., 1998, Database of significant deposits of gold, silver, copper, lead, and zinc in the United States: U.S. Geological Survey Open-File Report 98-206-A (33 p., Database description and analysis) and 98-206-B (diskette, Digital database). (Also available online at http://geopubs.wr.usgs.gov/open-file/of98-206/.)

Ludington, Steve, Cox, Dennis, and McCammon, Richard, eds., 1996, Data base for a national mineral-resource assessment of undiscovered deposits of gold, silver, copper, lead, and zinc in the conterminous United States: U.S. Geological Survey Open-File Report 96-96, one CD-ROM. (Also available online at http://pubs.usgs.gov/of/1996/of96-096/.)

Root, D.H., Menzie, W.D., and Scott, W.A., 1992, Computer Monte Carlo simulation in quantitative resource assessment: Nonrenewable Resources, v. 1, no. 2, p. 125-138. 
Root, D.H., Scott, W.A., Jr., and Selner, G.I., 1997, Computer program for aggregation of probabilistic assessments of mineral resources: U.S. Geological Survey Open-File Report 96-94, 1 diskette.

Singer, D.A., 1993, Basic concepts in three-part quantitative assessments of undiscovered mineral resources: Nonrenewable Resources, v. 2, no. 2, p. 69-81.
U.S. Geological Survey National Mineral Resource Assessment Team, 2000, 1998 Assessment of undiscovered deposits of gold, silver, copper, lead, and zinc in the United States: U.S. Geological Survey Circular 1178, 21 p., one CD-ROM in pocket. (Also available online at http://pubs.usgs.gov/circ/c1178/.) 


\section{Author Biographies}

\section{Walter J. Bawiec \\ U.S. Geological Survey, Reston, Va., U.S.A.}

Walter J. Bawiec is a research geologist in the Eastern Mineral Resources Team of the U.S. Geological Survey (USGS), based in Reston, Va. His current assignments are (1) project leader responsible for geographic information systems (GIS) and computer infrastructure of the Eastern Mineral Resources Team, (2) task leader responsible for GIS in the Global Mineral Resource Assessment Project (GMRAP), and (3) participant in a project to make data produced by the Minerals Program of the USGS available to the public. He has been involved in studies related to the assessment of mineral and petroleum resources and is considered an expert in GIS. He received a B.S. in geology from Waynesburg College, Pa., and an M.S. in geology from the George Washington University, Washington, D.C. He is a member of the Geological Society of America and the American Geophysical Union. He has been employed by the U.S. Geological Survey full time since 1974. He served 3 years (1970-73) in the U.S. Army field artillery. He is author or coauthor of more than 35 scientific papers.

\section{Jens Dieter Becker-Platen}

Bundesanstalt für Geowissenschaften und Rohstoffe, Hannover, Germany

Dr. Becker-Platen has been vice president of the Bundesanstalt für Geowissenschaften und Rohstoffe BGR (Federal Institute for Geosciences and Natural Resources and the Lower Saxony Geological Survey NLfB) since 1992. Beginning in 1958, he studied geology at the Universities of Freiburg i. Br., Braunschweig, and Bonn. He received his doctorate from the University of Hannover. He was involved in technical cooperation projects concerned with lignite exploration in Greece and Turkey. He joined the NLfB and BGR in 1968, and since then he has held various management positions in the NLfB, mainly in the mineral deposits and applied geology fields. He was president of the International Peat Society from 1995 to 2000.

\section{Vladimir I. Berger}

\section{U.S. Geological Survey, Menlo Park, Calif., U.S.A.}

Dr. Berger was born in 1931 in Moscow, Russia. In Tadjikistan, he graduated from Dushanbe State University in 1953 as an economic geologist. A career in prospecting and exploration began in 1949 in the Pamirs Mountains and continued in central Kazakhstan and Yakutia until 1962. Then he became a research geologist followed by team leader in the All-Russian Geological Research Institute (VSEGEI) in St. Petersburg. He received degrees of Candidate of Sciences in Geology (1964) in St. Petersburg School of Mines and Doctor of Sciences in Geology (1979) in VSEGEI. His main research and publications are related to geology and exploration of rock crystal, mercury, antimony, and gold-antimony deposits; regional metallogeny; and assessment of mineral resources. In 1991, he immigrated to the United States and settled in California after a year in Maryland. He worked as a volunteer in the Maryland University and in the U.S. Geological Survey, Menlo Park, Calif. As a consulting geologist, he participated in gold prospecting in Australia for the Varuno Company and for ASARCO and, briefly, Newmont, in the Russian Far East. During the last 7 years, he worked as a contract geologist with the USGS, compiling worldwide databases of major ore deposit types with Don Singer and assisting Ted Theodore in geologic mapping in northeastern Nevada.

\section{Joseph A. Briskey \\ U.S. Geological Survey, Reston, Va., U.S.A.}

Dr. Briskey graduated from Oregon State University in 1975 with a Ph.D. in geology and economic geology and a doctoral thesis on the "Geology, Petrology, and Geochemistry of the Jersey, East Jersey, Huestis, and Iona Porphyry CopperMolybdenum Deposits, Highland Valley, British Columbia." He joined the U.S. Geological Survey in Menlo Park, Calif., in 1975, where he conducted geologic and mineral deposit modeling research and served as commodity geologist for zinc and lead. His research there also included geologic research and mineral resource assessments of 2-degree quadrangles and of Indian lands in the Western United States, together with studies of Mississippi-Valley-type zinc deposits in the southern Appalachians. In 1985, Dr. Briskey became associate chief of the Branch of Western Mineral Resources and, in 1988, was transferred to USGS headquarters in Reston, Va., to become deputy chief of the Office of Mineral Resources and program coordinator for the National Mineral Resources Assessment Program. In 1994, Dr. Briskey was awarded a Brookings Institution LEGIS Congressional Fellowship and served for 2 years on personal and committee staff of the United States Senate.

Dr. Briskey presently is conducting research and research development in three major areas: (1) a feasibility study for a global nonfuel mineral resource assessment; (2) resource and environmental assessments of iron and steel slag along the shore of Lake Michigan; and (3) a new integrated science 
project with the USGS Biological Resources Division to investigate uses of "Mineral-Resource Assessments for Protecting Ecosystem Biodiversity and Health While Planning Nonfuel Mineral Supply in the Next Century." Dr. Briskey serves on a number of committees for the American Geological Institute, Society of Economic Geologists, and International Association on the Genesis of Ore Deposits (IAGOD).

\section{Thomas K. Bundtzen}

\section{Pacific Rim Geological Consulting, Inc., Fairbanks, Alaska,} U.S.A.

Thomas K. Bundtzen is a senior mineral deposits and regional geologist for Alaska. While participating in the associated project for the paper in this volume, he was a senior geologist in the Alaska Division of Geological and Geophysical Surveys. Currently, he is the president of a major consulting company, Pacific Rim Geological Consulting, Inc., Fairbanks, Alaska.

\section{Lesley Chorlton \\ Geological Survey of Canada, Ottawa, Canada}

Lesley Chorlton is a graduate of McGill University (B.S., 1968; M.S., 1973) and Memorial University of Newfoundland (Ph.D., 1984). She was regional geologist, Southwest Newfoundland, for the Government of Newfoundland and Labrador during the federally and provincially funded agreement to complete geological mapping of Newfoundland, 1977-82. After working as a regional economic geologist for the Ontario Geological Survey, 1984-89, she redirected her career to geological applications of geographical information systems, obtaining a diploma at Sir Sanford Fleming School of Natural Resources. Developing an information system for the generalized geology of the world and functioning as data manager for the world mineral deposit databases of the World Minerals Geoscience Database Project, Geological Survey of Canada, have since been her principal occupations.

\section{Charles G. (Skip) Cunningham U.S. Geological Survey, Reston, Va., U.S.A.}

Charles (Skip) Cunningham is a research geologist with the U.S. Geological Survey in Reston, Va. He is an economic geologist specializing in ore deposits in volcanic and subvolcanic environments, fluid-inclusion geothermometry and geobarometry, and light-stable isotopes, as applied to problems of ore genesis and mineral resource evaluation. He received his B.A. degree from Amherst College in 1967, a Masters from the University of Colorado in 1969, and his Ph.D. from Stanford University in 1973. Skip has worked at the USGS for almost 30 years on ore deposit projects throughout the Western United States and the Circum-Pacific. He has published numerous maps and papers about the Colorado Mineral Belt, Marysvale volcanic field, and
Nevada gold deposits and topical subjects such as paleothermal anomalies and fluid-inclusion studies of mineralizing systems. Skip is known throughout the Andes for his studies on oreforming processes related to volcanic domes and calderas. His administrative responsibilities have included program coordinator for the Development of Assessment Techniques Program (USGS Ore Deposit Research Program), vice president of the Society of Economic Geologists, USGS acting eastern regional geologist, and co-manager of a cooperative project on volcanic processes and precious-metal mineralization in the central Andes with the geological surveys of Peru, Chile, and Bolivia.

\section{Kenneth M. Dawson \\ Terra Geological Consultants, Vancouver, Canada}

Kenneth M. Dawson is a senior mineral deposits geologist for the Canadian Cordillera. While participating in the associated project for the paper in this volume, he was a senior scientist at the Geological Survey of Canada in Vancouver, British Columbia. He is currently the leader of Terra Geological Consultants in Vancouver, British Columbia.

\section{Nikolai L. Dobretsov}

\section{United Institute of Geology, Geophysics and Mineralogy, Siberian Branch, Russian Academy of Sciences (SB RAS), Novosibirsk, Russia}

Academician Dobretsov was born in Leningrad (now St. Petersburg) in 1936. He graduated from the Leningrad Mine Institute in 1957. During 1957-60, he worked as a geologist, then a party chief in the Altai region. He was a research fellow, head of laboratory, and head of department in the Institute of Geology and Geophysics, SB RAS, Novosibirsk (1960-80); director of the Geological Institute, Buryat Affiliate of SB RAS, Ulan-Ude (1980-88); chairman of Presidium, Buryat Scientific Center (1987-89); director of the Institute of Geology and Geophysics, SB RAS, Novosibirsk (since 1988) and, after it was reorganized in 1990, director general of the United Institute of Geology, Geophysics and Mineralogy SB RAS. He served as the first deputy chairman (since 1990) and chairman (since 1997) of the Siberian Branch, Russian Academy of Sciences, vice president of RAS. He was a professor (1966-80) and head of a faculty at the Novosibirsk State University (1991-97).

Nikolai Dobretsov took an active part in and provided guidance for many national and international projects on ophiolites, geodynamics, mineral resources, and global environmental and climatic change; he helped promote the establishment of the Association of Asian Academies of Sciences. He was elected the first vice president (2000) and president (2002) of the association. Nikolai Dobretsov authored and coauthored more than 450 scientific articles, including 20 monographs dedicated to the problems of geology, mineralogy, magmatic and metamorphic petrology, tectonics, plutonic geodynamics, and mineral deposits. 
Michael D. Doggett

Queen's University, Kingston, Canada

Michael Doggett is the director of the Mineral Exploration Master's Program and associate professor in the Department of Geological Sciences and Geological Engineering at Queen's University, Kingston, Canada. He is also a visiting international professor at the Western Australian School of Mines in Perth, Australia. He holds degrees in geology and mineral economics from Mount Allison University and Queen's University. Dr. Doggett has carried out a wide range of assignments on mineral policy and planning issues for exploration and mining companies, governments, and international agencies. His main areas of teaching and research relate to the economic analysis of mineral exploration and acquisition at both the corporate and industrywide levels. Current research includes evaluating mineral development potential in northern Canada, assessing mining legislation changes in China, and determining the impact of world-class deposits on corporate exploration and acquisition strategies.

\section{Roman A. Eremin (retired) formerly Russian Academy of Sciences, Magadan, Russia}

Roman A. Eremin is a senior mineral deposits geologist for the Russian Northeast. While participating in the associated project for the paper in this volume, he was a senior research scientist at the Northeast Integrated Scientific Research Institute, Russian Academy of Sciences, Magadan, Russian. He currently is retired and lives in Belarus.

\section{Nikolai A. Goryachev \\ Russian Academy of Sciences, Magadan, Russia}

Nikolai A. Goryachev is a senior mineral deposits and regional geologist for the Russian Northeast. He is the associate director for the Northeast Integrated Scientific Research Institute, Russian Academy of Sciences, Magadan, Russia.

\section{Erik Hammerbeck (deceased) formerly Council for Geoscience, Pretoria, South Africa}

Erik Hammerbeck was born and raised in Namibia and studied geology at the universities of Stellenbosch and Pretoria in South Africa. In 1969, he spent a year in Germany under a Von Humboldt Fellowship. After a short spell at the Tsumeb Mine in Namibia, he joined the Geological Survey of South Africa. He worked most of his life in economic geology and metallogeny and was instrumental in the production of various publications on the mineral resources of southern Africa, metallogenic maps, and the creation of mineral resource databases. The Mineral Resources Handbooks and Metallogenic Maps of South Africa (scale 1:1 million) and the "Interna- tional Digital Metallogenic Map of Africa" (scale 1:5 million), with its attendant database, are cases in point. Internationally he participated in various endeavors, notably the International Strategic Minerals Inventory (ISMI), the Commission for the Geological Map of the World (CGMW), and the International Association on the Genesis of Ore Deposits (IAGOD). He was formerly president of the CGMW's Subcommission for Metallogenic Maps and president of IAGOD; he served the Geological Society of South Africa as president in 1992-93. Erik was manager of strategic planning for the Council for Geoscience (formerly the Geological Survey of South Africa). He passed away on April 24, 2006.

\section{Lief R. Horwitz \\ U.S. Geological Survey, Seattle, Wash., U.S.A.}

Lief Horwitz received an M.A. in urban and regional planning from the Virginia Polytechnic Institute and State University in 1998. He joined the Biological Resources Division of the USGS in 1998 as a Presidential Management Intern and initially worked in the capacity of a budget analyst. Since February 1999, he has been a program analyst in the USGS Gap Analysis Program, where he is primarily involved in new initiative and partnership development, education, and outreach.

\section{Alexander V. Kanygin United Institute of Geology, Geophysics and Mineralogy, Siberian Branch, Russian Academy of Sciences (SB RAS), Novosibirsk, Russia}

Alexander V. Kanygin was born in Omsk on January 10, 1936. He graduated from the Moscow State University in 1960. During 1960-62, he worked in the Novosibirsk geological party. He was a postgraduate, junior, and then senior research fellow at the Institute of Geology and Geophysics, SB RAS (since 1962); head of laboratory (since 1975), and head of paleontology and stratigraphy department (since 1987). After the reorganization of the Institute of Geology and Geophysics and foundation of the Institute of Geology (1989) and Institute of Petroleum Geology (1996) at the United Institute of Geology, Geophysics and Mineralogy, he occupied the same positions. He has served as professor (since 1998) and head of the faculty of historical geology and paleontology at the Novosibirsk State University (since 1999). A. Kanygin authored and coauthored more than 240 scientific articles, including 2 personal and 8 composite monographs dedicated to the problems of stratigraphy, paleogeography, paleontology, paleoecology, biosphere evolution, and regional and petroleum geology of Siberia. He took part in a number of regional, Federal, and international projects on geological correlation, global environmental change, and petroleum reserves of Siberia. 


\section{Stephen E. Kesler}

University of Michigan, Ann Arbor, Mich., U.S.A.

Steve Kesler is professor of economic geology and associate chair in the Department of Geological Sciences at the University of Michigan, Ann Arbor, Mich. His research and teaching interests include the geology and geochemistry of ore deposits, mineral exploration, and mineral economics, as well as environmental geochemistry related to the recovery and use of minerals. He is the author of "Our Finite Mineral Resources" (1976, McGraw-Hill, 120 p.) and "Mineral Resources, Economics and the Environment" (1994, Macmillan, 391 p.). Along with his students, he has worked on a wide range of geologic problems related to ore deposits with an emphasis on gold and porphyry copper deposits. He has also been active in exploration and mining efforts in a number of areas, particularly in the Caribbean-Central America region. Steve has been active in a number of professional organizations and served as president of the Society of Economic Geologists in 1998.

\section{Alexander I. Khanchuk Russian Academy of Sciences, Vladivostok, Russia}

Alexander I. Khanchuk is a senior regional geologist and tectonist for the Russian Southeast, director of the Far East Geological Institute, and vice president of the Far East Branch of the Russian Academy of Sciences, Vladivostok, Russia.

\section{Alexey E. Kontorovich}

Institute of Petroleum Geology of the United Institute of Geology, Geophysics and Mineralogy, Siberian Branch, Russian Academy of Sciences (SB RAS), Novosibirsk, Russia

Alexey Emilievich Kontorovich, born in 1934 in Kharkov, now the Ukraine, graduated from the Tomsk State University in 1956. In 1958-89, he served as senior scientist, head of laboratory, head of department, and deputy director of the Siberian Scientific Research Institute of Geology, Geophysics, and Mineral Resources. Beginning in 1989, he was deputy director general of the United Institute of Geology, Geophysics and Mineralogy SB RAS, and in 1997, he was director of the Institute of Petroleum Geology as a part of the United Institute of Geology, Geophysics and Mineralogy of the SB RAS. Since 1983, he has been a professor at the Novosibirsk State University (NSU) and, since 1988, head of the department of mineral deposits of the NSU. He is a full member of the Russian Academy of Sciences (1991), member of the Presidium of the Siberian Branch of RAS (1991), and chairman of the Scientific Council of RAS on the problems of geology and development of oil and gas fields (2002). He is the supervisor of regional and Federal state programs on the studies of oil and gas resources in Siberia and throughout Russia.

A. Kontorovich is the author and coauthor of more than 500 scientific works, including more than 30 monographs on the problems of regional geology of Siberia, naphthidogenesis, petroleum geology, isotopic and molecular organic geochemistry, quantitative prediction of petroleum potential and methods of simulational mathematical modeling of geologic exploration, and prediction of development of the oil and gas complex in Siberia and Russia. He is the winner of the State Prize of the Russian Federation and prizes of the Russian Federation Government and was awarded orders and medals.

\section{Penny Flick Langhammer \\ Conservation International, Washington, D.C., U.S.A.}

Penny Langhammer is senior manager for Africa-Eurasia Conservation Outcomes in the Center for Applied Biodiversity Science (CABS) at Conservation International (CI). In her role at CABS, Penny provides scientific and technical support to CI's regional programs and partners in the definition of biodiversity conservation targets at the species, site, and landscape levels. Her region of focus includes the biodiversity hotspots and wilderness areas in Africa and Eurasia. She holds a degree in environmental management from Duke University's Nicholas School of the Environment.

\section{Robert Laramée}

\section{Geological Survey of Canada, Ottawa, Canada}

Robert Laramée is a geologist and computer scientist. He obtained his B.S. in geology in 1969 from the Université de Montréal and a Certificat en informatique de gestion in 1984 from the Université du Québec à Hull. Robert first worked for the Geological Survey of Canada in 1967 and joined the Geomathematics Section, Mineral Resources Division, in the fall of 1971. He also taught computer science at the Université du Québec à Hull in 1989. Robert's main interest is in the application of information technology to the solution of geological (especially mineral deposit) problems. His activities have ranged from programming geographic coordinate conversions to designing mineral deposit databases. Robert is currently working on the World Minerals Geoscience Database Project as mineral deposits database specialist. His main activity is the development of a database schema suitable for any type of mineral deposits on a world scale and of accompanying software tools to enter and edit data, to safely upgrade the database schema, to interrogate the database, and to produce output in a variety of formats.

\section{Bruce R. Lipin}

\section{U.S. Geological Survey, Reston, Va., U.S.A.}

Bruce R. Lipin was born in New York City, U.S.A., in 1947. He attended undergraduate school at City College of New York and graduated with a B.S. in geology. He received his Ph.D. in mineralogy-petrology from The Pennsylvania State University in 1975. He has been with the U.S. Geologi- 
cal Survey since 1974 and has done research in lunar experimental petrology and the origin and distribution of mineral deposits-specializing in chromite and platinum, layered igneous complexes, especially the Stillwater Complex in Montana, U.S.A. He is currently the chief of the USGS minerals database project and is a part of the global mineral resource assessment feasibility team.

\section{Gregory Ellis McKelvey}

Global Mine Discovery Partnership, LLC, Scottsdale, Ariz., U.S.A.

Gregory E. McKelvey has 35 years of exploration and mineral discovery experience. He is presently manager of Global Mine Discovery Partnership, LLC, a private consulting and mineral discovery company that he founded after retiring from Phelps Dodge Exploration Corporation as vice president for Latin America exploration. He has held positions with the U.S. Geological Survey (1989-91), Cominco American Resources, Incorporated (1975-88), Homestake Mining Company (1974 and 1975), Bear Creek Mining Company (196574), and Nicol Industrial Minerals (summers of 1961-64). He received a B.A. in geology from the University of Montana at Missoula in 1966 and an M.S. degree in geology from Franklin and Marshall College, Lancaster, Pa., in 1967.

\section{James W. H. Monger Geological Survey of Canada, Vancouver, Canada}

James W.H. Monger is a senior regional tectonist for the Canadian Cordillera. While participating in the associated project for the paper in this volume, he was a senior research scientist for the Geological Survey of Canada, Vancouver, British Columbia. He is currently an emeritus research geologist for the Geological Survey of Canada.

\section{Warren J. Nokleberg \\ U.S. Geological Survey, Menlo Park, Calif., U.S.A.}

Dr. Warren J. Nokleberg is a research geologist in the Western Mineral Resources Team of the U.S. Geological Survey, based in Menlo Park, Calif. His current assignment is regional coordinator for Northeast Eurasia for the Global Mineral Resource Assessment Project (Russia, Belarus, Ukraine, Mongolia, and China, South Korea, and Japan). His past assignment was leader of a project on the Mineral Resources and Metallogenesis of Northeast Asia (Siberia, Mongolia, northeastern China, South Korea, and Japan). Since starting graduate school in 1965, his major research emphases have been on the mineral deposits, metallogenesis, bedrock geology, and tectonics of the central Sierra Nevada in California, the Stillwater Complex in Montana, eastern Alaska, the Russian Far East, and Northeast Asia. He received a B.A. in geol- ogy from the University of California Los Angeles in 1961 and a Ph.D. in geology from the University of California Santa Barbara in 1970. He is a fellow of the Geological Society of America, a fellow of the Society of Economic Geologists, and a member of the American Geophysical Union. He has been employed by the USGS on a part-time or full-time basis since 1966 and recently completed 32 years of full-time U.S. Government service. He was a Regular Line Officer, U.S. Navy for 4 years (1961-65), was an associate professor of geology at California State University, Fresno, for 6 years (1970-76), and is author or coauthor of more than 240 scientific papers.

\section{George A. Nooten (retired) formerly United Nations Revolving Fund for Natural Resources Exploration (UNRFNRE), New York, U.S.A.}

George A. Nooten has been in the service of UNRFNRE for the past 21 years. He has acquired extensive international experience through designing, planning, negotiating agreements, and managing the execution of mineral exploration programs in several developing countries, including Tanzania, Mozambique, Cote d'Ivoire, Sierra Leone, Ghana, Yemen, and Sri Lanka. His most recent discoveries are the Geita Hill and Nyamulilima gold deposits in northwestern Tanzania. The 12-million-ounce Geita mine was opened on August 3, 2000. Prior to joining the UNRFNRE in 1979, he worked as chief geologist for the bauxite mines in Linden, Guyana, and as a geologist for the Iron Ore Company of Canada, INCO, and the Quebec Ministry of Natural Resources. He took his undergraduate studies in geology at Queen's University, Kingston, Canada, and received a M.S. (Minex) from the same university. George retired in 2002.

\section{Alexander A. Obolenskiy Russian Academy of Sciences, Novosibirsk, Russia}

Alexander A. Obolenskiy is a senior mineral deposits geologist for eastern Siberia. For more than 50 years, he has studied the mineral deposits and regional geology of this region as a senior scientist in the Institute of Geology, Russian Academy of Sciences, Novosibirsk, Russia.

\section{Leonid M. Parfenov (deceased) formerly Russian Academy of Sciences, Yakutsk, Russia}

Leonid M. Parfenov was a senior regional geologist and tectonist for eastern Siberia and the Russian Far East. He was a senior scientist and laboratory chief in institutes of the Russian Academy of Sciences in Novosibirsk, Khabarovsk, and Yakutsk. Most recently, he was vice president of the Yakutian Academy of Sciences and director of the Institute of Diamonds and Noble Metal Geology, Russian Academy of Sciences, Yakutsk. Leonid passed away in August of 2002. 


\section{Vladimir V. Ratkin \\ consulting geologist, Russia}

Vladimir V. Ratkin is a senior mineral deposits geologist for the Russian Southeast. While participating in the associated project for the paper in this volume, he was a senior scientist and laboratory chief in the Far East Geological Institute, Russian Academy of Sciences, Vladivostok. He is currently a consulting geologist in European Russia.

\section{Sergey M. Rodionov}

Russian Academy of Sciences, Khabarovsk, Russia

Sergey M. Rodionov is a senior mineral deposits and regional geologist for the Russian Southeast. He is also the associate director of the Institute of Tectonics and Geophysics, Russian Academy of Sciences, Khabarovsk.

\section{Klaus J. Schulz}

\section{U.S. Geological Survey, Reston, Va., U.S.A.}

Dr. Klaus J. Schulz is a research geologist with the U.S. Geological Survey in the Eastern Mineral Resources Team, Reston, Va. He currently directs USGS efforts to evaluate the feasibility of conducting quantitative global assessments of undiscovered nonfuel mineral resources. He has previously directed and (or) participated in several regional and detailed-scale mineral resource assessments, including the USGS-Costa Rican National Mineral Resource Assessment and the U.S. National Mineral Resource Assessment for Undiscovered Deposits of Gold, Silver, Copper, Lead, and Zinc. He has also organized and co-directed several workshops, the most recent being the IUGS/UNESCO (International Union of Geological Sciences/United Nations Educational, Scientific and Cultural Organization) Deposit-Modeling Workshop on Base- and Precious-Metal Deposits in the Arabian Shield, November 12-19, 1999, in Jiddah, Saudi Arabia. Dr. Schulz's research has focused on the metallogeny of Precambrian terranes and on volcanic-hosted and magmatic sulfide mineral deposits. He is the current USGS member of the IUGS/UNESCO Deposit Modeling Program steering committee. He served as the chief of the USGS Branch of Eastern Mineral Resources from 1989 to 1996 . Dr. Schulz holds a B.S. degree in geology from the University of Wisconsin, an M.S. degree in petrology from the University of Minnesota, and a Ph.D. in igneous petrology/geochemistry from the University of Minnesota.

\section{Deborah J. Shields}

\section{U.S. Forest Service, Ft. Collins, Colo., U.S.A.}

Dr. Deborah Shields is principal mineral economist for the U.S. Department of Agriculture (USDA), Forest Service, Research and Development Division. She directs the agency's energy and mineral economics and mineral policy research programs, providing technical and scientific input to the Forest Service Strategic Plan, the Resource Planning Act Assessment, and the National Forest planning process. In addition, she leads the agency's effort to include nonrenewable resources in sustainable forest management, working with stakeholders in other government agencies, Tribal governments, industry, academia, and nongovernmental organizations to develop indicators of sustainability for energy and mineral resources. She has organized and will be co-director of an advanced research workshop (ARW) entitled "Sustainable Mineral Resource Management in Karst Areas." The ARW is sponsored by the NATO (North Atlantic Treaty Organisation) Scientific Affairs Division and by UNESCO (United Nations Educational, Scientific and Cultural Organization), UNEP (United Nations Environment Programme), the USDA Forest Service, and the Geological Survey of Slovenia. Deborah also provides technical support on sustainability issues to the U.S. delegation to the meetings of the Mining Ministers of the Americas. Finally, she is program manager for human dimensions research for the Front Range Ecosystem Management Project.

Prior to working for the Forest Service, Dr. Shields worked for the U.S. Department of the Interior, Bureau of Mines, specializing in international mineral supply and trade analysis and forecasting. She has published in the areas of sustainability policy and theory, utility theory and welfare economics, decision theory and decision-support systems, and network modeling. She holds a B.S in wildlife management from Colorado State University, an M.S. in mineral economics from the Colorado School of Mines, and a Ph.D. in rangeland ecosystem science from Colorado State University.

\section{Vladimir I. Shpikerman \\ All-Russian Geological Research Institute (VSEGEI), St. Petersburg, Russia}

Vladimir I. Shpikerman is a senior mineral deposits and regional geologist for the Russian Northeast. While participating in the associated project for the paper in this volume, he was a senior scientist and laboratory chief in the Northeast Integrated Scientific Research Institute, Russian Academy of Sciences, Magadan, Russia. He is currently a senior mineral deposits geologist in the All-Russian Geological Research Institute (VSEGEI) in St. Petersburg, Russia.

\section{W. David Sinclair Geological Survey of Canada, Ottawa, Canada}

Dave Sinclair is a graduate of the University of Toronto (B.S., 1966) and the University of Wisconsin (M.S., 1970; Ph.D., 1973). From 1973 to 1977 , he was employed by the Department of Indian Affairs and Northern Development in Whitehorse, Yukon Territory, as a district geologist and was acting resident geologist in 1976-77. In 1977, he joined the Geological Survey of Canada in Ottawa, where he has specialized 
in the geology of granite-related mineral deposits. He currently manages the World Minerals Geoscience Database Project.

\section{Donald A. Singer}

\section{U.S. Geological Survey, Menlo Park, Calif., U.S.A.}

Donald Singer is primarily interested in the application of quantitative methods to mineral resource assessments and exploration. He has written more than 200 papers on resource assessments, deposit models, quantitative methods, and exploration strategies. Recent work has been on developing and testing methods such as neural networks to integrate geoscience information for resource assessments and exploration. The Society of Economic Geologists awarded him its Silver Medal in 1999. He has been a geologist with the U.S. Geological Survey in Menlo Park, Calif., since 1973. Prior to this, he was a system analyst with Kennecott Copper. Don holds a Ph.D. in mineralogy and petrology from The Pennsylvania State University.

\section{Milica Veselinovic-Williams Council for Geoscience, Pretoria, South Africa}

Mrs. Milica Veselinovic-Williams studied at Belgrade University, Yugoslavia, and obtained her B.S. (Hons.) in geology in 1985. Subsequently, she worked as an exploration geologist for the Geoinstitut, Belgrade. In 1992, she obtained her M.S. in exploration geology from Rhodes University, South Africa. She joined the Council for Geoscience (formerly the Geological Survey of South Africa) in 1994 and became the main author of the "1:5 000000 International Digital Metallogenic Map of Africa" and its database. Under her supervision, the first edition of sheets 5 and 6 (south of the Equator) was published in digital GIS format on a CD-ROM in June 1999. Milica is also extensively involved in the design and development of a number of GIS database models for the production of metallogenic maps.

\section{Gotthard Walser}

World Bank, Washington, D.C., U.S.A.

Dr. Walser is a senior mining specialist at the Mining Department of the World Bank, Washington, D.C. Through advising services or technical assistance loans, the focus of his activity is to assist governments to develop their mining sector and promote investments leading to sustainable development through policy, legal, and institutional reforms, as well as capacity building, environmental protection, and improved community participation. He is particularly interested in the reform of public mining institutions and strengthening of governance; in the development of geoscientific, environmental, and mining information systems; and in environmental and social issues related to mining. He currently leads or participates in projects in Algeria, Argentina, Burkina Faso, Ecuador, Madagascar, Mauritania, and Mozambique.

Prior to joining the World Bank in 1994, Dr. Walser worked with the Swedish Geological Survey, and later with its International Division, for more than 15 years, gaining broad professional and management experience. Responsibilities during this period included the planning and management of regional mapping and mineral resource assessment programs, as well as ore exploration, mine evaluation, and development projects; this work occurred through assignments both in Sweden and overseas, including many African and, particularly after 1982, Latin American countries. Dr. Walser holds a B.S., M.S. and Ph.D. in earth sciences from the University of Geneva in Switzerland.

\section{Friedrich-Wilhelm Wellmer Bundesanstalt für Geowissenschaften und Rohstoffe, Hannover, Germany}

Professor Wellmer (Dr.-Ing., Dr. h.c.) became president of the Bundesanstalt für Geowissenschaften und Rohstoffe (Federal Institute for Geosciences and Natural Resources and the Lower Saxony Geological Survey) in 1996. He studied mining and geology at the Technical Universities of Berlin and Clausthal. He worked for the German mining company Metallgesellschaft AG and its Canadian and Australian subsidiaries in Europe, North and South America, Australia, Oceania, and the Far East. Before joining the Federal Institute for Geosciences and Natural Resources, the Federal German Geological Survey BGR in Hannover, he was director of exploration at the Metallgesellschaft of Australia Pty. Ltd. in Melbourne. Professor Wellmer also teaches raw materials policy and economic geology at the Technical University of Berlin. He was awarded an honorary doctorate of the Technical University Mining Academy of Freiberg in 1999 and of the Technical University of Clausthal in 2003. 

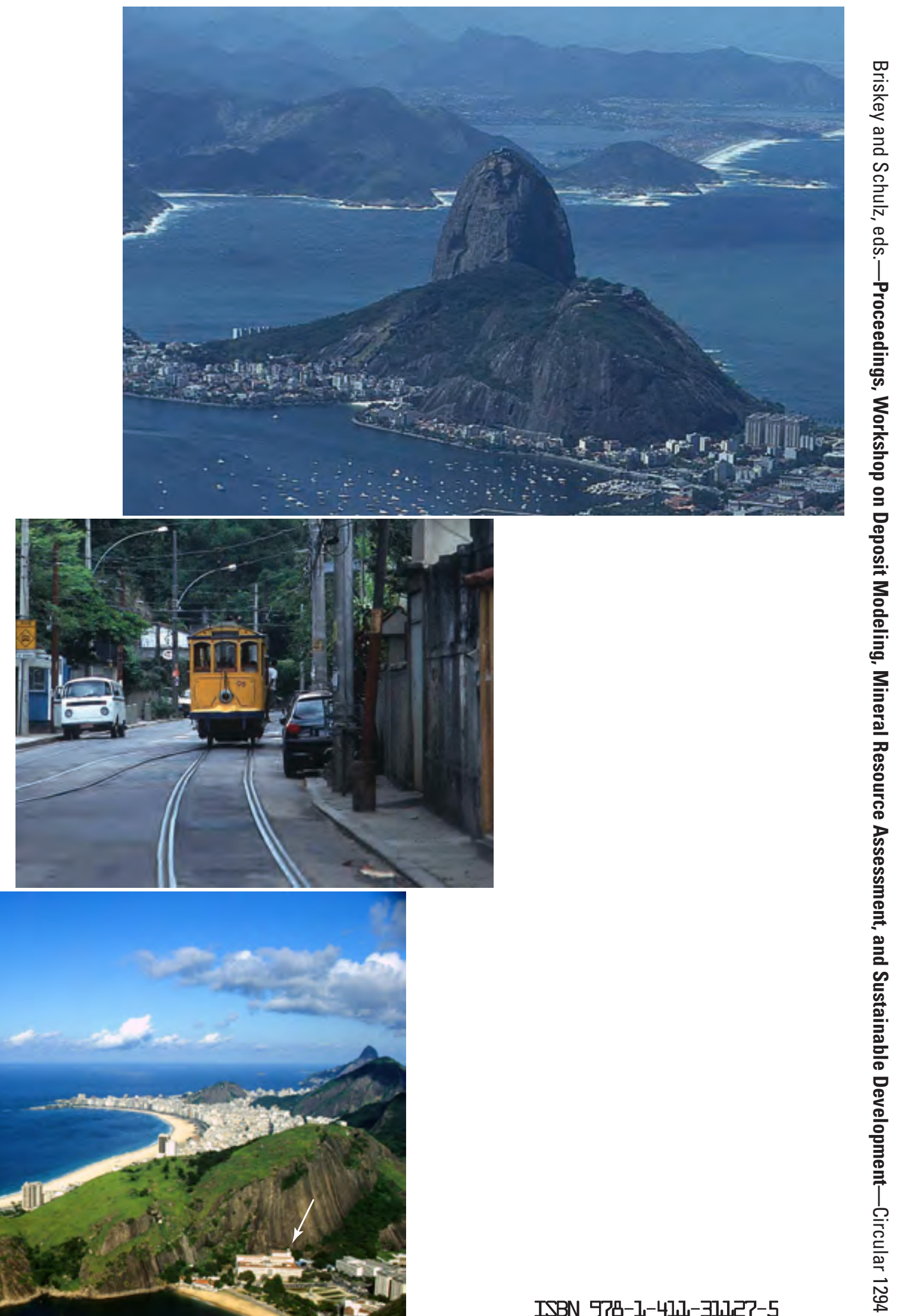